Florida International University FIU Digital Commons

FIU Electronic Theses and Dissertations

University Graduate School

$1-11-2018$

\title{
Hybrid Electrochemical Capacitors: Materials, Optimization, and Miniaturization
}

Richa Agrawal

Department of Mechanical and Materials Engineering, Florida International University, ragra005@fiu.edu

DOI: 10.25148 /etd.FIDC006581

Follow this and additional works at: https://digitalcommons.fiu.edu/etd

Part of the Materials Chemistry Commons, Materials Science and Engineering Commons, Nanoscience and Nanotechnology Commons, and the Physical Chemistry Commons

\section{Recommended Citation}

Agrawal, Richa, "Hybrid Electrochemical Capacitors: Materials, Optimization, and Miniaturization" (2018). FIU Electronic Theses and Dissertations. 3680.

https://digitalcommons.fiu.edu/etd/3680

This work is brought to you for free and open access by the University Graduate School at FIU Digital Commons. It has been accepted for inclusion in FIU Electronic Theses and Dissertations by an authorized administrator of FIU Digital Commons. For more information, please contact dcc@fiu.edu. 


\section{FLORIDA INTERNATIONAL UNIVERSITY}

Miami, Florida

\section{HYBRID ELECTROCHEMICAL CAPACITORS: MATERIALS, OPTIMIZATION, AND MINIATURIZATION}

A dissertation submitted in partial fulfillment of the requirement for the degree of

DOCTOR OF PHILOSOPHY

in

MATERIALS SCIENCE AND ENGINEERING

by

Richa Agrawal

2018 
To: Dean John L. Volakis

College of Engineering and Computing

This dissertation entitled Hybrid Electrochemical Capacitors: Materials, Optimization, and Miniaturization, written by Richa Agrawal, having been approved in respect to style and intellectual content, is referred to you for judgment.

We have read this dissertation and recommend that it be approved.

Norman D. H. Munroe

Nezih Pala

Bilal El-Zahab

Irene Calizo

Chunlei Wang, Major Professor

Date of Defense: January 11, 2018

The dissertation of Richa Agrawal is approved.

Dean John L. Volakis

College of Engineering and Computing

Andrés G. Gil

Vice President for Research and Economic Development and Dean of the University Graduate School

Florida International University 2018 
C Copyright 2018 by Richa Agrawal All rights reserved. 


\section{DEDICATION}

This work is dedicated to the greatest teacher and educator of all, life - for the plethora of crests and troughs it leads you through and for the dreams, aspirations, and the ceaseless

hope that it brings. 


\section{ACKNOWLEDGMENTS}

First and foremost, I would like to express my sincerest gratitude toward dissertation advisor Dr. Chunlei Wang for her guidance, vision and support throughout my doctoral program. I also appreciate her efforts on reviewing and critiquing my research and writing, which helped me in improving the quality of my work.

I would like to extend my gratitude to the members of my dissertation committee - Dr. Norman Munroe, Dr. Bilal El-Zahab, Dr. Irene Calizo, and Dr. Nezih Pala for their willingness to serve on my committee and for their invaluable encouragement and support. I am also thankful to Dr. Arvind Agarwal, Dr. Shekhar Bhansali, Dr. Surendra Saxena, Dr. Cesar Levy, Dr. Lidia Kos, and Dr. Anthony McGoron for their help and support during the course of my PhD.

I am very thankful to the University Graduate School (UGS) at Florida International University for supporting me through Presidential Fellowship (PF), Dissertation Evidence Acquisition (DEA), and Dissertation Year Fellowship (DYF) awards. I am also thankful to the Department of Mechanical and Materials Engineering (MME) at FIU for providing me with teaching assistantship (TA) and the National Science Foundation (NSF) to support my $\mathrm{PhD}$ program.

This work would not have been possible without the technical facilities provided at Advanced Materials Engineering Research Institute (AMERI) at FIU. I am very grateful to Shravana Katakam, Alexander Franco, Patrick Roman, Steward Schwarz, and Neal Ricks for their patience and help with my experimentation.

I am thankful to the members of my research group - Majid Beidaghi, Varun Penmatsa, Chunhui Chen, Yong Hao, Yin Song, Michael Franc Villegas, Ebenezer 
Adelowo, Amin Rabiei Baboukani, Shahrzad Forouzanfar, Iman Khakpour, and Omena Okpowe for their company and help during my $\mathrm{PhD}$. I would also like to thank the wonderful friends that I have made at FIU - Debrupa Lahiri, Ali Henriques, and Pranjal Nautiyal.

This dissertation would not come to fruition without the endless support from my family - I am very lucky to have my Ma and Papa, Rama Agrawal and Bhoo Prakash Agrawal, who never stopped believing in me. They have always given me selflessly throughout their life without ever asking for anything in return. I would like to thank my younger brother, Harsshit, for always being there for me and for being an awesome sibling, a fantastic friend and a great confidant. I am also thankful for my extended family, especially my Tauji, Piyush Chand Agrawal, for the pillar of wisdom that he is. I would also like to thank my in-laws, especially my father-in-law, Hernando Nieto. Lastly, I would like to thank the love of my life, my husband, and my best friend, Andy. He has been with me through thick and thin and has always comforted me in periods of selfdoubt and uncertainty. He has always motivated me to be courageous and to be the best version of me, and I could not thank him enough for that. 


\title{
ABSTRACT OF THE DISSERTATION
}

\section{HYBRID ELECTROCHEMICAL CAPACITORS: MATERIALS, OPTIMIZATION, AND MINIATURIZATION}

\author{
by
}

Richa Agrawal

Florida International University, 2018

Miami, Florida

\section{Professor Chunlei Wang, Major Professor}

With the ever-advancing technology, there is an incessant need for reliable electrochemical energy storage (EES) components that can provide desired energy and power. At the forefront of EES systems are electrochemical capacitors (ECs), also known as supercapacitors that typically have higher power and superior cycle longevity but lower energy densities than their battery counterparts. One of the routes to achieve higher energy density for ECs is using the hybrid EC configuration, which typically utilizes a redox electrode coupled with a counter double-layer type electrode.

In this dissertation, both scale-up (coin-cell type) as well as scale-down (on-chip miniaturized) hybrid ECs were designed, constructed and evaluated. The first part of the dissertation comprised material identification, syntheses, and electrochemical analyses. Lithium titanate-anatase titanium oxide $\left(\mathrm{Li}_{4} \mathrm{Ti}_{5} \mathrm{O}_{12}-\mathrm{TiO}_{2}\right)$ composites were synthesized via electrostatic spray deposition (ESD) and characterized in both half-cell and full-cell assembly against lithium and nanostructured carbon based counter electrodes, respectively. The second redox type material studied for hybrid electrochemical capacitors was ESD derived manganese oxide $\left(\mathrm{MnO}_{\mathrm{x}}\right)$. The $\mathrm{MnO}_{\mathrm{x}}$ electrodes exhibited a 
high gravimetric capacitance of $225 \mathrm{~F} \mathrm{~g}^{-1}$ in aqueous media. Further improvement in the rate handling of the $\mathrm{MnO}_{\mathrm{x}}$ electrodes was achieved by using CNT additives. The $\mathrm{MnO}_{\mathrm{x}}-$ CNT composites were tested in full-cell assembly against activated carbon counter electrodes and tested for different anode and cathode mass ratios in order to achieve the best energy-power tradeoff, which was the second major goal of the dissertation. The optimized hybrid capacitor was able to deliver a high specific energy density of $30.3 \mathrm{Wh}$ $\mathrm{kg}^{-1}$ and a maximal power density of $4 \mathrm{~kW} \mathrm{~kg}^{-1}$. The last part of the dissertation focused on a scale-down miniaturized hybrid microsupercapacitor; an interdigitated electrode design was adopted in order to shorten the ion-transport pathway, and $\mathrm{MnO}_{\mathrm{x}}$ and reduced graphene oxide (rGO) were chosen as the redox and double layer components, respectively. The hybrid microsupercapacitor was able to deliver a high stack energy density of $1.02 \mathrm{mWh} \mathrm{cm}^{-3}$ and a maximal stack power density of $3.44 \mathrm{~W} \mathrm{~cm}^{-3}$, both of which are comparable with thin-film batteries and commercial supercapacitor in terms of volumetric energy and power densities. 


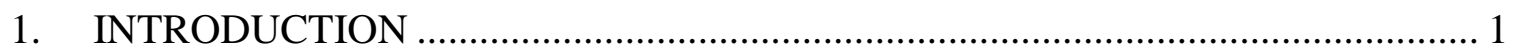

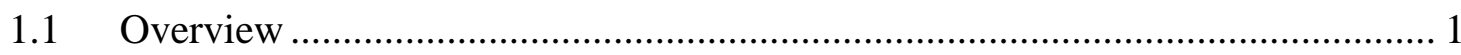

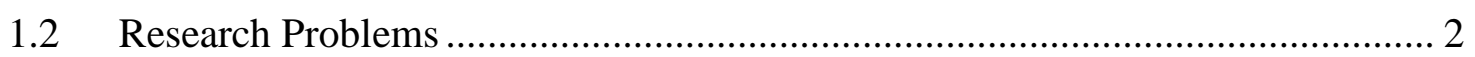

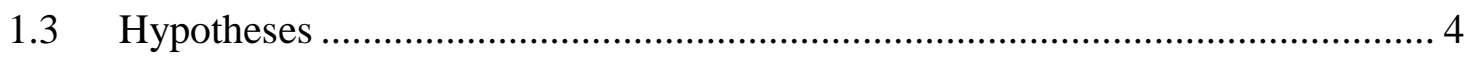

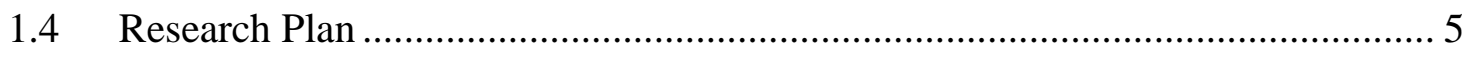

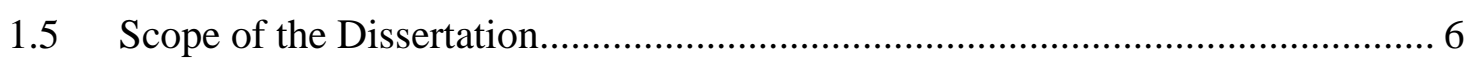

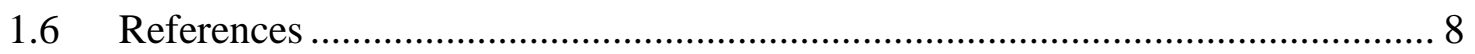

2. BACKGROUND AND LITERATURE REVIEW ……………........................ 9

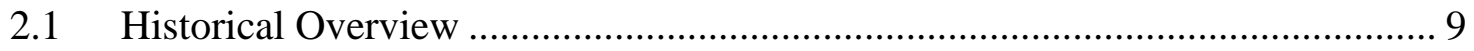

2.2 Commercial Market and Research Trends in Supercapacitors ............................ 9

2.3 Fundamentals of Electrochemical Capacitors ................................................... 11

2.4 Classification of Electrochemical Capacitors ................................................ 12

2.4.1 Electrochemical Double layer Capacitors (EDLCs) .................................... 13

2.4.2 Pseudocapacitors .............................................................................. 14

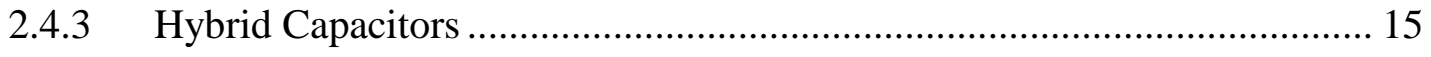

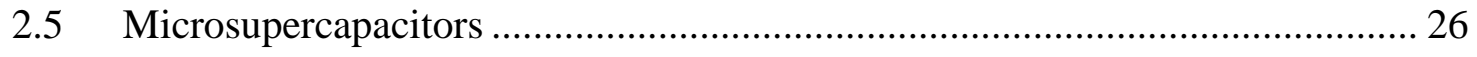

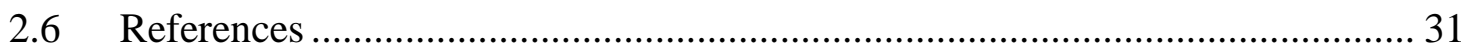

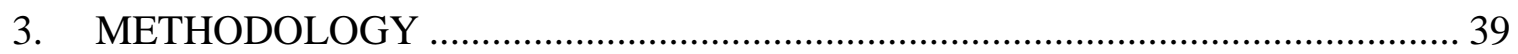

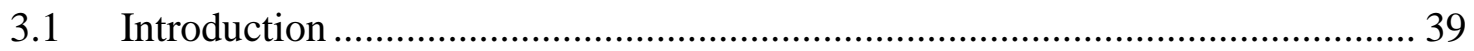

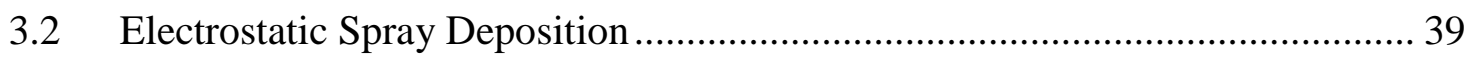

3.3 Carbon Microelectromechanical Systems (C-MEMS) …………………….... 41

3.4 Gold microelectrode fabrication.................................................................. 42

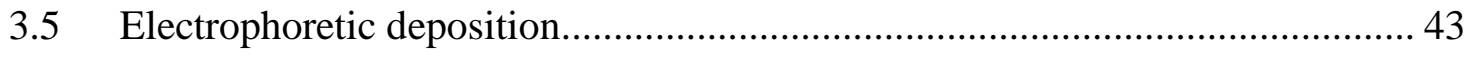

3.6 Electrochemical deposition of manganese oxide .............................................. 45

3.7 Material Characterization ............................................................................ 46

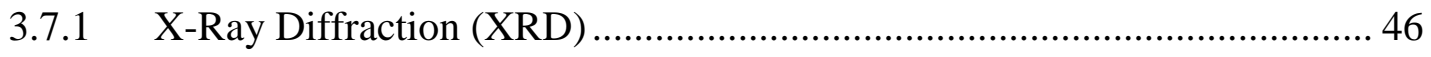

3.7.2 Scanning Electron Microscopy (SEM) ……….......................................... 47

3.7.3 Transmission Electron Microscopy (TEM) ............................................... 47

3.7.4 Fourier Transform Infrared (FT-IR) Spectroscopy ..................................... 47 
3.8 Electrode Preparation and Cell Assembly.................................................... 47

3.8.1 Electrodes Prepared via Casting …………………................................ 47

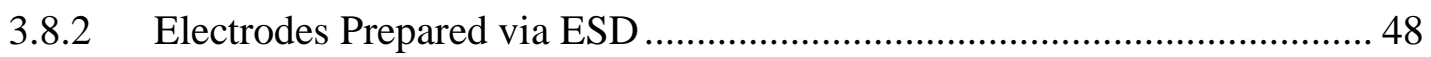

3.8.3 Electrochemical Cell Assembly ............................................................... 48

3.9 Electrochemical Characterization ............................................................... 48

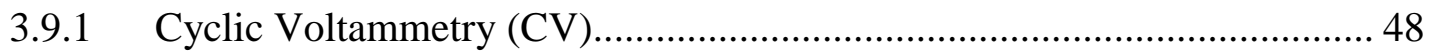

3.9.2 Galvanostatic Charge-discharge (GCD) ................................................ 49

3.9.3 Electrochemical Impedance Spectroscopy (EIS) ........................................ 49

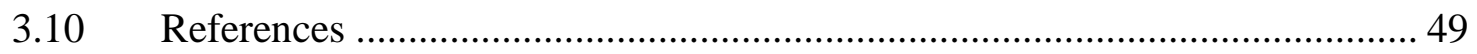

4. A HIGH ENERGY 3V LITHIUM-ION CAPACITOR SYNTHESIZED VIA ELECTROSTATIC SPRAY DEPOSITION ………………................................... 52

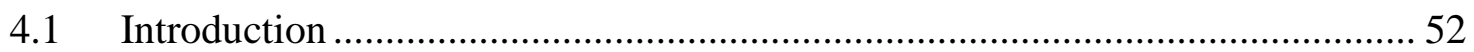

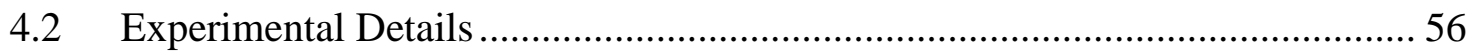

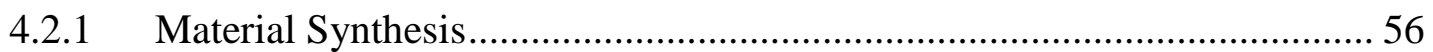

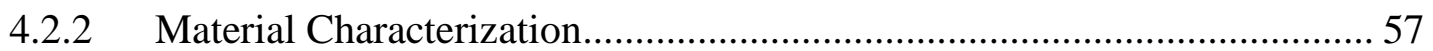

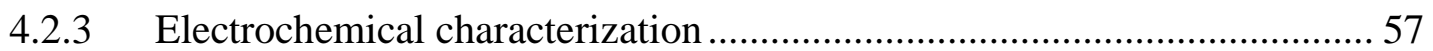

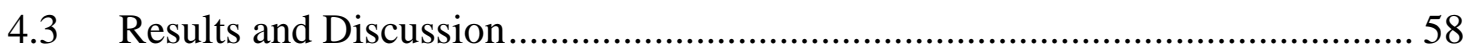

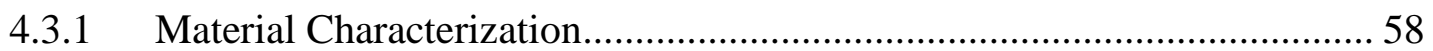

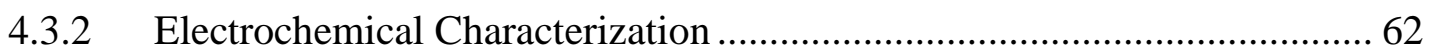

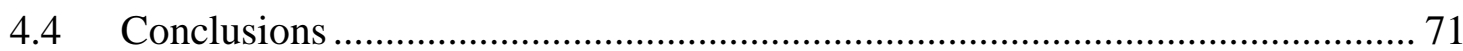

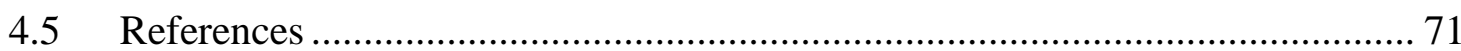

5. ELECTROSTATIC SPRAY DEPOSITION BASED MANGANESE OXIDE FILMS: FROM PSEUDOCAPACITIVE CHARGE STORAGE MATERIALS TO THREE-DIMENSIONAL MICROELECTRODE INTEGRANDS................................. 75

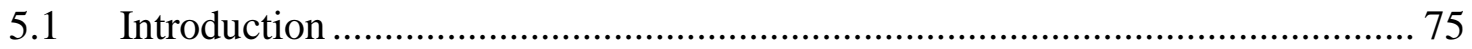

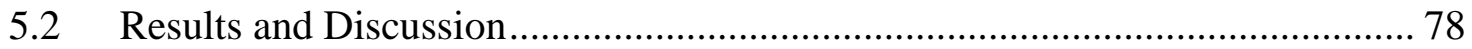

5.2.1 Crystallographic, Spectroscopic and Microstructural Studies on the As-

Prepared and Cycled $\mathrm{MnO}_{\mathrm{x}}$ Films .................................................................. 78

5.2.2 Electrochemical Characterization of the $\mathrm{MnO}_{\mathrm{x}}$ Films .............................. 82

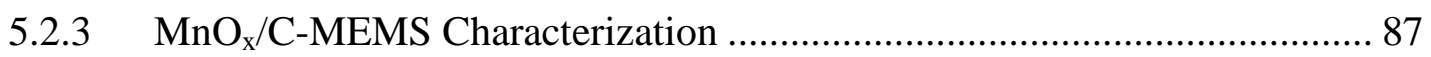

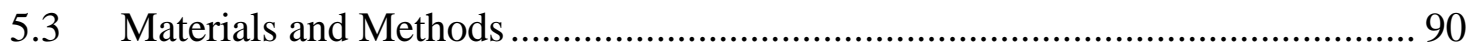

5.3.1 Manganese Oxide Electrode Synthesis ...................................................... 90

5.3.2 Structural and Material Characterization …………...................................... 90 


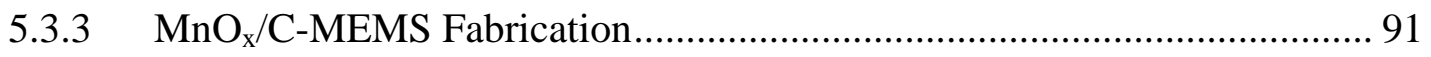

5.3.4 Electrochemical Characterization .......................................................... 92

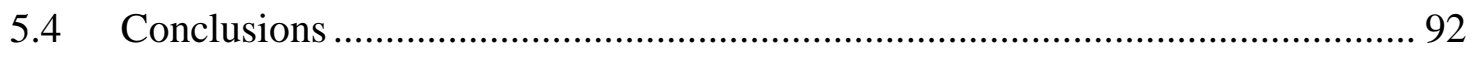

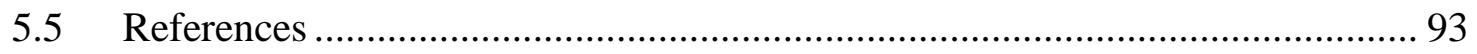

6. EXPANDING THE POTENTIAL WINDOW OF AQUEOUS ASYMMETRIC ELECTROCHEMICAL CAPACITORS WITH ELECTROSTATICALLY SPRAYED MANGANESE OXIDE COMPOSITE FILMS..................................................... 98

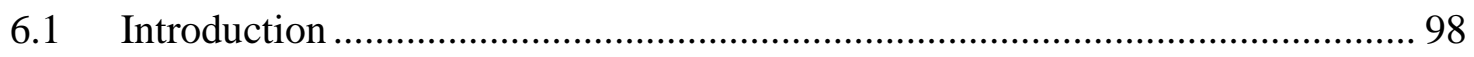

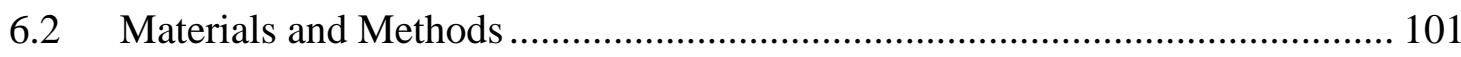

6.2.1 ESD based manganese oxide electrode synthesis ..................................... 101

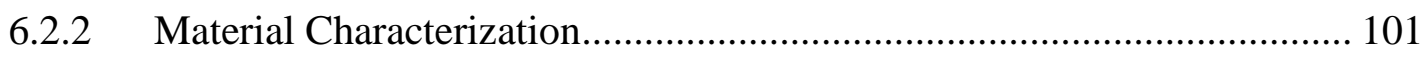

6.2.3 Electrochemical Characterization .......................................................... 102

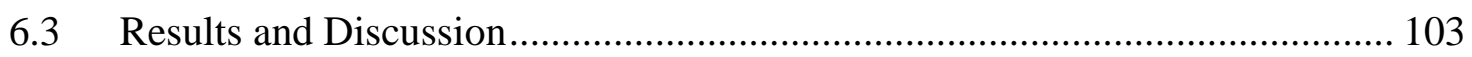

6.3.1 Crystallographic, spectroscopic and microstructural studies .................... 103

6.3.2 Comparative electrochemical studies on the pristine $\mathrm{MnO}_{\mathrm{x}}$ and

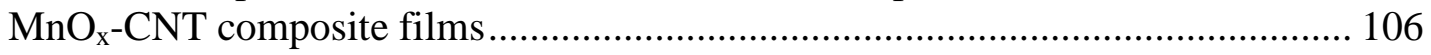

6.3.3 $\mathrm{MnO}_{\mathrm{x}}$-CNT 9-1 electrode before and after electrochemical cycling ........ 111

6.3.4 Electrochemical characterization of the $\mathrm{AC}$ anode................................... 111

6.3.5 Electrochemical characterization of the asymmetric and symmetric

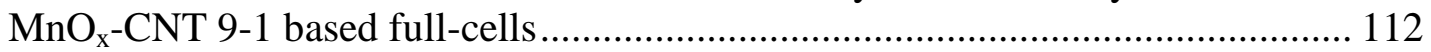

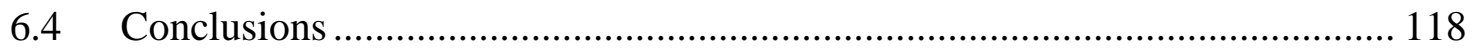

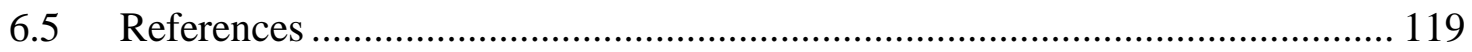

7. ON-CHIP ASYMMETRIC MICROSUPERCAPACITORS COMBINING REDUCED GRAPHENE OXIDE AND MANGANESE OXIDE FOR HIGH

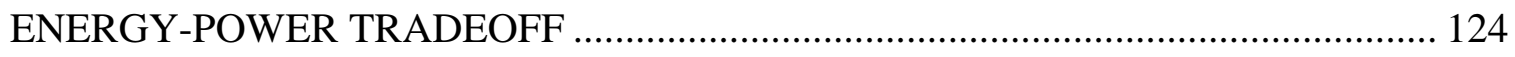

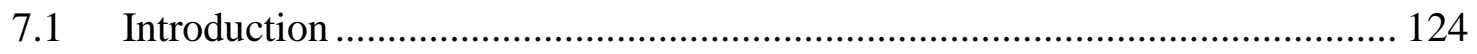

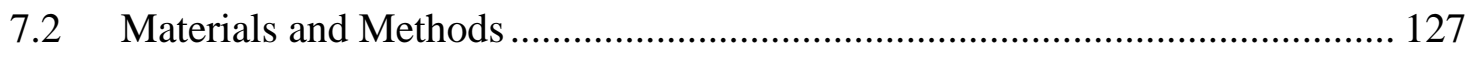

7.2.1 Fabrication of the interdigital gold micro-current collectors ..................... 127

7.2.2 Active Material Integration ................................................................. 129

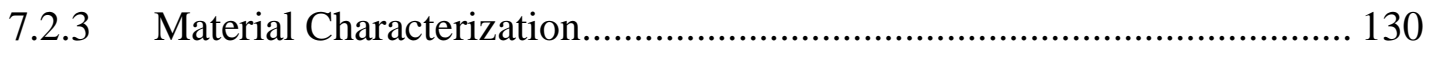

7.2.4 Electrochemical Characterization ............................................................ 131

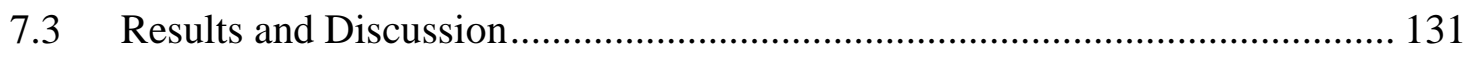

7.3.1 Spectroscopic, crystallographic and microstructural characterization performed on the manganese oxide and $\mathrm{rGO}$ microelectrodes 
7.3.2 Electrochemical Characterization of the symmetric $\mathrm{rGO} / / \mathrm{rGO}$,

$\mathrm{MnO}_{\mathrm{x}} / / \mathrm{MnO}_{\mathrm{x}}$, and asymmetric $\mathrm{rGO}-\mathrm{MnO}_{\mathrm{x}}$ microsupercapacitors ......................... 135

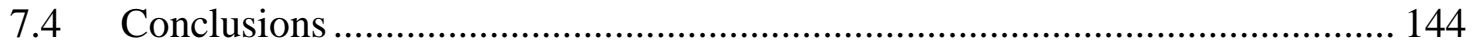

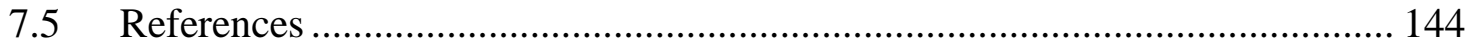

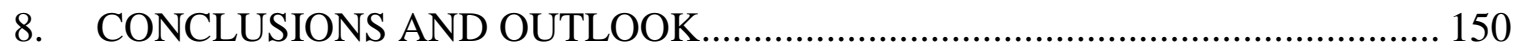

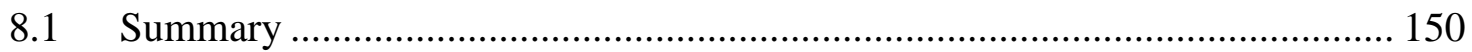

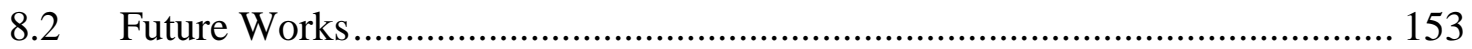

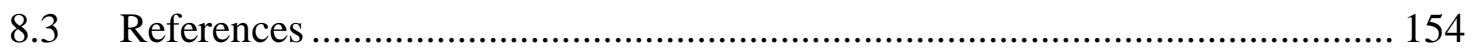

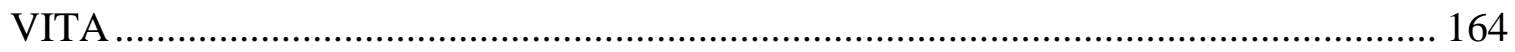




\section{LIST OF TABLES}

TABLE

PAGE

Table 2.1: Summary of pseudocapacitive/double layer composites reported in the literature

Table 2.2: Summary of some of the reported pseudocapacitive/double layer asymmetric supercapacitors

Table 2.3: Summary of the lithium-ion capacitor based studies reported in the literature

Table 4.1: Comparison of the ESD based Li-HEC with other hybrid electrochemical capacitors.

Table 5.1: Solution and charge-transfer resistances computed from equivalent circuit at different cycles.

Table 6.1: $\mathrm{R}_{\mathrm{s}}$ and $\mathrm{R}_{\mathrm{ct}}$ values of the pristine $\mathrm{MnO}_{\mathrm{x}}, \mathrm{MnO}_{\mathrm{x}}-\mathrm{CNT}$ 9-1 and $\mathrm{MnO}_{\mathrm{x}}-\mathrm{CNT}$ 8-2 electrodes

Table 6S 1: Electrochemical characteristics of the symmetric AC//AC system, symmetric $\mathrm{MnO}_{\mathrm{x}}-\mathrm{CNT}$ 9-1// $\mathrm{MnO}_{\mathrm{x}}-\mathrm{CNT}$ 9-1 system, and the optimized asymmetric $\mathrm{MnO}_{\mathrm{x}}-\mathrm{CNT}$ 9-1//AC system 


\section{LIST OF FIGURES}

FIGURE

PAGE

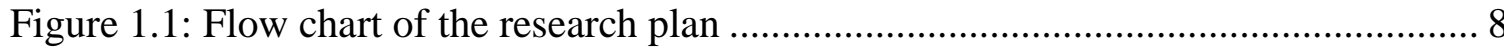

Figure 2.1: Number of publications resulting from supercapacitor research in the past decade (Source: Web of Science) .................................................................. 10

Figure 2.2: Ragone plot for different energy storage devices................................. 11

Figure 2.3: Classification of Electrochemical Capacitors......................................... 13

Figure 2.4: Construction of an asymmetric capacitor; the assembly is contained in an

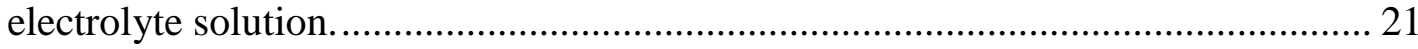

Figure 3.1: Schematic illustration of the ESD process (left); digital photograph of ESD lab setup.

Figure 3.2: Schematic illustration of the C-MEMS process (Adapted from [14]); b) SEM micrograph of carbon micro-pillar arrays; c) Photograph of a device containing micro-pillars on carbon current collectors and contact pads..... 42

Figure 3.3: Schematic illustration of the gold microelectrode fabrication. 43

Figure 3.4: a) Schematic illustration of the EPD setup used to deposit rGO films for this dissertation; b) top view of the EPD based rGO films.

Figure 3.5: a) Schematic illustration of the electrochemical deposition setup used to deposit $\mathrm{MnO}_{\mathrm{x}}$ films; b) microstructure of the $\mathrm{MnO}_{\mathrm{x}}$ nanoparticles

Figure 4.1: (a) The XRD pattern of the as-deposited and calcined anode powders, (b) The FTIR pattern of the GO and ESD based rGO.

Figure 4.2: Morphology of the as-deposited (a) and calcined (b) ATO-LTO films, (c) typical TEM micrograph of the calcined ATO-LTO powder, the inset shows the SAED pattern, (d) Top view of the rGO-CNT cathode

Figure 4.3: (a) Cyclic voltammograms of the rGO-CNT composite electrode for different scan rates between a potential of 2.0-4.0V (vs. $\left.\mathrm{Li} / \mathrm{Li}^{+}\right),($b) discharge capacity of the rGO-CNT composite for the first $~ 90$ cycles at a current density of $0.1 \mathrm{Ag}^{-1}$, (c) typical charge-discharge curves of the rGO-CNT electrode at different current densities, (d) rate capability of the rGO-CNT composites.

Figure 4.4: (a) Cyclic voltammograms of the ATO-LTO composite electrode at a scan rate of $0.2 \mathrm{mVs}^{-1}$ for the first five cycles, (b) cyclic voltammograms of the ATOLTO composite at different scan rates ranging from $0.2 \mathrm{mVs}^{-1}$ to $5 \mathrm{mVs}^{-1}$; the inset 
shows the dependence of the anodic peak current on the square root of the scan rate, (c) typical charge-discharge curves of the ATO-LTO composite electrode for the first two cycles at a current density of $0.1 \mathrm{Ag}^{-1}$, (d) rate capability of the ATOLTO composite anodes.

Figure 4.5: (a) Cyclic voltammograms of the Li-HEC at different scan rates ranging from 2-20 $\mathrm{mVs}^{-1}$, (b) typical charge-discharge curves of the Li-HEC cells at different current densities, (c) rate capability, and (d) cyclability of the Li-HEC full cells.

Figure 4.6: Ragone Plot of the ESD-based Li-HEC full cells based on discharge characteristics.

Figure 5.1: (a) XRD pattern of the as-deposited $\mathrm{MnO}_{x}$ powders; (b) FTIR pattern of the as-deposited $\mathrm{MnO}_{x}$ films; (c) SEM microstructure of the as-deposited $\mathrm{MnO}_{x}$ films; (d) HRTEM micrograph of the as-deposited $\mathrm{MnO}_{x}$ powders; the inset depicts the SAED pattern.

Figure 5.2: (a) XRD pattern of the cycled $\mathrm{MnO}_{\mathrm{x}}$ powders; (b) FTIR pattern of the cycled $\mathrm{MnO}_{x}$ films; (c) microstructure of the cycled $\mathrm{MnO}_{x}$ films showing layered platelet-like morphology; (d) HRTEM of the cycled $\mathrm{MnO}_{x}$ powders; the inset shows the SAED pattern, (b) represents birnessite phases, whereas (d) represents hausmannite phase.

Figure 5.3: (a) CV curves of the $\mathrm{MnO}_{x}$ films at different cycles scanned at a sweep rate of $5 \mathrm{mV} \cdot \mathrm{s}^{-1}$; (b) typical GCD curves of the $\mathrm{MnO}_{x}$ films at a constant chargedischarge current rate of $0.5 \mathrm{Ag}^{-1}$ for different cycles; (c) Nyquist plots of the $\mathrm{MnO}_{x}$ films at different cycles; the inset depicts the equivalent circuit used for system analyses; (d) cycling behavior of the $\mathrm{MnO}_{x}$ films; (e) galvanostatic charge-discharge profiles of the $\mathrm{MnO}_{x}$ films at different current rates; (f) $\mathrm{CV}$ curves at different sweep rates $\left(2-100 \mathrm{mV} \cdot \mathrm{s}^{-1}\right)$.

Figure 5.4: (a) Schematic representation of $\mathrm{MnO}_{x}$-ME fabrication process (detailed description in Section 3.3); (b) SEM micrograph of a typical $\mathrm{MnO}_{x}$-encrusted carbon micro-pillar; the inset shows $\mathrm{MnO}_{x}$-encrusted micro-pillar arrays; (c) zoomed-in view of the microstructure of the electrostatic spray deposition (ESD)generated $\mathrm{MnO}_{x}$ films, (d) cyclability of the $\mathrm{MnO}_{x}$-ME electrodes; the inset depicts typical charge-discharge curves of the $\mathrm{MnO}_{x}-\mathrm{ME}$ at different current rates $\left(0.05-0.5 \mathrm{~mA} \cdot \mathrm{cm}^{-2}\right)$; (e) geometric and stack capacitances of the $\mathrm{MnO}_{x}$-MEs at different rates; (f) Ragone chart of the $\mathrm{MnO}_{x}$-MEs.

Figure 6.1: a) X-ray diffraction patterns of the as-prepared $\mathrm{MnO}_{\mathrm{x}}, \mathrm{MnO}_{\mathrm{x}}-\mathrm{CNT}$ 9-1, $\mathrm{MnO}_{\mathrm{x}}$-CNT 8-2 composites and CNTs; b) FTIR spectra of the pristine $\mathrm{MnO}_{\mathrm{x}}$ films, $\mathrm{MnO}_{\mathrm{x}}-\mathrm{CNT}$ 9-1, and $\mathrm{MnO}_{\mathrm{x}}-\mathrm{CNT}$ 8-2 films, and the CNTs. 
Figure 6.2: Top-view of the a) pristine $\mathrm{MnO}_{\mathrm{x}}$; b) $\mathrm{MnO}_{\mathrm{x}}-\mathrm{CNT}$ 9-1; c) $\mathrm{MnO}_{\mathrm{x}}-\mathrm{CNT}$ 8-2,

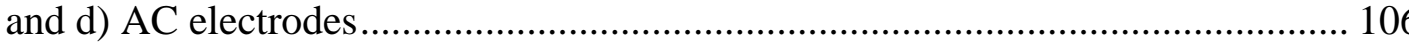

Figure 6.3: a) Nyquist curves of the pristine $\mathrm{MnO}_{\mathrm{x}}$ electrodes and the $\mathrm{MnO}_{\mathrm{x}}-\mathrm{CNT}$ composite electrodes; b) Cycling performance of the pristine $\mathrm{MnO}_{\mathrm{x}}$ electrodes and the $\mathrm{MnO}_{\mathrm{x}}-\mathrm{CNT}$ composites electrodes; c) cyclic voltammetry (CV) curves of the $\mathrm{MnO}_{\mathrm{x}}-\mathrm{CNT}$ electrodes at different scan rates; d) scan rate dependence of the pristine $\mathrm{MnO}_{\mathrm{x}}, \mathrm{MnO}_{\mathrm{x}}-\mathrm{CNT}$ 9-1, and $\mathrm{MnO}_{\mathrm{x}}-\mathrm{CNT}$ 8-2 electrodes; e) galvanostatic charge-discharge (GCD) curves of the $\mathrm{MnO}_{\mathrm{x}}$-CNT 9-1 electrode at different current rates; and f) rate capability of the pristine $\mathrm{MnO}_{\mathrm{x}}, \mathrm{MnO}_{\mathrm{x}}-\mathrm{CNT} 9-1$, and $\mathrm{MnO}_{\mathrm{x}}$-CNT 8-2 electrodes.

Figure 6.4: a) CV curves of the $\mathrm{AC}$ electrode and the $\mathrm{MnO}_{\mathrm{x}}-\mathrm{CNT}$ 9-1 electrode at a scan rate of $10 \mathrm{mVs}^{-1}$; b) typical Nyquist plots of the $\mathrm{AC} / / \mathrm{AC}$ and $\mathrm{MnO}_{\mathrm{x}}-\mathrm{CNT} 9-$ $1 / / \mathrm{MnO}_{\mathrm{x}}-\mathrm{CNT}$ 9-1 symmetric systems as well as the asymmetric capacitor $\mathrm{MnO}_{\mathrm{x}^{-}}$ CNT 9-1//AC (mass ratio of 1:2.6); c) CV and d) GCD curves of the asymmetric $\mathrm{MnO}_{\mathrm{x}}$-CNT 9-1//AC system (MR 1:2.6); e) cyclability of the symmetric $\mathrm{AC} / / \mathrm{AC}$, symmetric $\mathrm{MnO}_{\mathrm{x}}-\mathrm{CNT}$ 9-1// $\mathrm{MnO}_{\mathrm{x}}-\mathrm{CNT}$ 9-1 and $\mathrm{MnO}_{\mathrm{x}}-\mathrm{CNT}$ 9-1//AC system (MR 1:2.6); f) Ragone chart depicting the energy-power characteristics of the $\mathrm{MnO}_{\mathrm{x}}-\mathrm{CNT}$ 9-1//AC system (MR 1:2.6) with works reported in the literature.

Figure 6.5: A radar chart depicting the electrochemical performance of the symmetric $\mathrm{MnO}_{\mathrm{x}}-\mathrm{CNT}$ 9-1// $\mathrm{MnO}_{\mathrm{x}}-\mathrm{CNT}$ 9-1 capacitor, the symmetric AC//AC capacitor and the asymmetric $\mathrm{MnO}_{\mathrm{x}}-\mathrm{CNT} 9-1 / / \mathrm{AC}$ capacitor evaluated for mass ratio (MR) 1:2.6; the characteristics have been normalized by the values exhibited by the asymmetric capacitor and the red numbers next to axes labels depict the true values corresponding to the asymmetric capacitor.

Figure 7.1: Schematic illustration of the asymmetric $\mathrm{rGO} / / \mathrm{MnO}_{\mathrm{x}}$ microsupercapacitor construction

Figure 7.2: The FTIR spectra of the starting graphene oxide powders and the EPD reduced graphene oxide films

Figure 7.3: a) FTIR spectrum and b) the X-ray diffraction (XRD) pattern of the electrochemically deposited $\mathrm{MnO}_{\mathrm{x}}$ films.

Figure 7.4: a) SEM micrograph of the interdigitated $\mathrm{rGO}$ and $\mathrm{MnO}_{\mathrm{x}}$ microelectrodes; b) cross sectional view and c) top view of the rGO coated microelectrodes; d-f) cross sectional view of the $\mathrm{MnO}_{\mathrm{x}}$ microelectrodes deposited at 0.6, 0.9 and $1.2 \mathrm{Ccm}^{-2}$, respectively; g-i) top-view of the $\mathrm{MnO}_{\mathrm{x}}$ microelectrodes deposited at $0.6,0.9$ and $1.2 \mathrm{Ccm}^{-2}$, respectively. 
Figure 7.5: Typical CV curves (scanned at 1-20V s${ }^{-1}$ ); b) GCD curves at different current densities; c) EIS spectra (between 100000-0.01Hz) and d) cycle life of the symmetric rGO- rGO microsupercapacitor

Figure 7.6: a) Typical CV curves (scanned at 1-20Vs ${ }^{-1}$ ); b) GCD curves at different current densities; c) EIS spectra (between 100000-0.01Hz) and d) cycle life of the symmetric $\mathrm{MnO}_{\mathrm{x}} / / \mathrm{MnO}_{\mathrm{x}}$ microsupercapacitor

Figure 7.7: a) Typical CV curves (scanned at 5-20Vs ${ }^{-1}$ ); b) GCD curves at different current densities; c) EIS spectra (between 100000-0.01Hz) and d) cycle life of the asymmetric $\mathrm{rGO} / / \mathrm{MnO}_{\mathrm{x}}-0.9 \mathrm{C}$ microsupercapacitor

Figure 7.8: Rate capability of the $\mathrm{MnO}_{\mathrm{x}} / / \mathrm{MnO}_{\mathrm{x}}, \mathrm{rGO} / / \mathrm{rGO}, \mathrm{rGO} / / \mathrm{MnO}_{\mathrm{x}}-0.6 \mathrm{C}$, $\mathrm{rGO} / / \mathrm{MnO}_{\mathrm{x}}-0.9 \mathrm{C}$, and $\mathrm{rGO} / / \mathrm{MnO}_{\mathrm{x}}-1.2 \mathrm{C} \mathrm{MSCs}$ in terms of a) areal and b) stack capacitances.

Figure 7.9: Ragone plot depicting the volumetric energy and power densities exhibited by the asymmetric $\mathrm{rGO} / / \mathrm{MnO}_{\mathrm{x}}-0.9 \mathrm{C}$ MSC in comparison with thin film lithium ion battery, commercial supercapacitors and electrolytic capacitors along with carbon onion based microsupercapacitors (Reproduced with permission from reference 44) and other data points taken from the literature [32, 46, 47, 48].

Figure 6S 1: a) cyclic voltammetry (CV) and the b) galvanostatic charge-discharge (GCD) curves of the $\mathrm{MnO}_{\mathrm{x}}$ electrode; a) CV and the d) GCD curves of the $\mathrm{MnO}_{\mathrm{x}^{-}}$ CNT 8-2 electrode.

Figure 6S 2: a) Nyquist plots of the $\mathrm{MnO}_{\mathrm{x}}-\mathrm{CNT}$ 9-1 electrode before and after cycling; the inset depicts the equivalent circuit analyses; b) $\mathrm{MnO}_{\mathrm{x}}-\mathrm{CNT}$ microstructure after cycling; some cracks are visible after cycling; c) zoomed-in version of the microstructure; CNTs are conspicuous; d) long-term cycling of the $\mathrm{MnO}_{\mathrm{x}}-\mathrm{CNT}$ 9-1 electrode.

Figure 6S 3: a) Nyquist plot of the freshly prepared AC electrode; the inset depicts the equivalent circuit used for cell analyses; b) cycling of the AC anode; c) GCD plots of the AC anode at different current rates; d) rate capability of the AC anode.

Figure 6S 4: GCD curves of the a) symmetric AC//AC capacitor; b) symmetric $\mathrm{MnO}_{\mathrm{x}^{-}}$ CNT 9-1// $\mathrm{MnO}_{\mathrm{x}}-\mathrm{CNT}$ 9-1 capacitor; c) asymmetric capacitor MR 1:2; d) asymmetric capacitor MR 1:2.4; e) asymmetric capacitor MR 1:3; f) asymmetric capacitor MR 1:4.

Figure 6S 5: a) Rate capability and b) Ragone chart of the different EC systems. 159

Figure 7S 1: Microstructure of the single layer graphene oxide (SLGO) 161 
Figure 7S 2: Typical cyclic voltammograms at different scan rates of a) the asymmetric $\mathrm{rGO} / / \mathrm{MnO}_{\mathrm{x}}-0.6 \mathrm{C} \mathrm{MSC}$ and $\mathrm{b}$ ) the asymmetric $\mathrm{rGO} / / \mathrm{MnO}_{\mathrm{x}}-1.2 \mathrm{C}$ MSC; typical GCD curves of c) the asymmetric $\mathrm{rGO} / / \mathrm{MnO}_{\mathrm{x}}-0.6 \mathrm{C} \mathrm{MSC}$ and d) the asymmetric $\mathrm{rGO} / / \mathrm{MnO}_{\mathrm{x}}-1.2 \mathrm{C} \mathrm{MSC}$; cycle life of e) the asymmetric $\mathrm{rGO} / / \mathrm{MnO}_{\mathrm{x}}-0.6 \mathrm{C} \mathrm{MSC}$ and $\mathrm{f}$ ) the asymmetric $\mathrm{rGO} / / \mathrm{MnO}_{\mathrm{x}}-1.2 \mathrm{C} \mathrm{MSC}$.

Figure 7S 3: Ragone chart of the different MSC systems. 163 


\section{INTRODUCTION}

\subsection{Overview}

With the ever-changing technology, reliable energy storage has become rather a prerequisite. Given the myriad of applications ranging from microelectronics to electric vehicles to large-scale stationary applications, the required electrochemical energy storage system becomes very device-specific. With the recent boom in the development of miniaturized electronic systems such as wireless sensors, implantable devices, smart cards etc., the demand for miniaturized power sources is at an all-time high. For such electronic devices, the power requirement typically ranges from several hundred $\mu \mathrm{W}$ to several hundred $\mathrm{mW}$, while energy requirement ranges from several hundred $\mu \mathrm{Wh}$ to several hundred $\mathrm{mWh}$ [1]. For instance, implantable devices such as pacemaker and cardiac defibrillator typically require $30-100 \mu \mathrm{W}$. Sensor nodes typically consume a power of 1-20 $\mu \mathrm{W}$ depending upon the complexity of the sensing requirement and speed of transmission. Micro energy systems such as microbatteries, micro fuel-cells along with micro energy harvesters are considered to be the next generation energy and power sources for such systems. However, quite akin to their larger counterparts, microbatteries and micro fuel cells suffer from low power density and limited cycle life and energy harvesters on the other hand require an energy storage component in tandem to store their excess energy [2]. Electrochemical capacitors, also known as supercapacitors or ultracapacitors can provide both transient and high powers and long cycle lives but with limited energy. One of the solutions to providing peak power and high energy at the same time is connecting the batteries and supercapacitors externally [3]. Nevertheless it is desirable for the next generation micro-power device to be a single standalone device for 
a simultaneous supply of high power and high energy. In general, energy and power densities are based on larger cells. However, these values are rather diminished in microbatteries and microsupercapacitors because of the weight of the packaging, hardware, limited area, etc. All these factors demand the development of a novel on-chip micro-power, which combines both the advantages of microbatteries and microsupercapacitors. Creating such devices however, requires thorough understanding of the mechanisms of combining two disparate charge storage mechanisms harmoniously into one optimal system.

\subsection{Research Problems}

The ultimate goal of this dissertation is to design, fabricate and assess high power and high energy hybrid/asymmetric electrochemical capacitors in both coin cell (scaleup) and miniaturized (scale-down) forms. However, the intrinsic disparity in the charge storage mechanisms as well as the rate handling characteristics of double layer and redox materials makes hybridization a challenging process. The research problems encountered in this dissertation and their possible solutions are discussed as follows:

1. What are the factors that must be addressed to obtain the optimized power and energy densities along with high cycle life in the hybrid system?

a. The cell capacity $(A h)$ is limited by the double layer component: In order to optimize the cell performance, the redox/faradaic component can be operated at a certain depth of discharge, where the capacities of the two components are similar. However, such an operation is undesirable for long cycling. Another method is choosing an appropriate mass ratio of the redox and double layer electrode, which 
can ensure that similar charges are held by the two electrodes. However, a very massive double layer electrode can compromise with the rate capability of the system and therefore the best electrode mass ratio for optimal energy-power tradeoff should be investigated.

b. Large power disparity in the double-layer and faradaic components: Given the low RC time constant of double layer capacitors, they charge and discharge in very short periods of time. Redox materials on the other hand typically possess lower power than their double layer counterparts, which can be attributed to sluggish ion diffusion processes, as a result of which the redox/faradaic component becomes the dictating factor of the resulting cell power. However, the power mismatch can be addressed by carefully designing the redox electrode, for instance - i) nanostructuring the material can ensure shorter ion transport pathways and improve the electrode kinetics; ii) engineering the thickness of the electrode can also address the relative inferior kinetics of the redox electrode - typically thin films exhibit superior kinetics and low resistance; iii) adding optimal amounts of conducting agent additives - typically metal oxides exhibit low electronic conductivity, which can be offset by using conducting agents such as carbon black (CB) or even nanostructured graphitic carbons like carbon nanotube (CNT), which can provide for lower percolation thresholds than the conventional $\mathrm{CB}$. Therefore the power mismatch between the double layer and redox electrode can be addressed by nanostructuring and optimizing the electrode thicknesses and also by optimizing nanostructured carbon additive content. 
c. Cycle life is typically limited by the redox component: Typically the double layer electrode exhibits superior cycle character to the redox electrode. However, the cycle life of the cell also depends on the current at which the cell is cycled along with the cell voltage. Therefore, choosing optimal current and voltage can enhance the cyclelife of the hybrid/asymmetric device.

2. How to ensure optimal energy-power tradeoff for the asymmetric microsupercapacitor? Unlike the scale-up systems, miniaturized supercapacitors have much lower effective material mass loadings due to their much smaller footprints. As a result of the diminutive electrode material loading on the microsupercapacitor platforms, gravimetric performance metrics are therefore inappropriate. More reliable assessment criteria for asymmetric microsupercapacitors include geometric and volumetric normalization, which makes optimizing the active material thickness an effective route to ensure maximal energy-power tradeoff. Furthermore, from an architectural standpoint, the "in-plane interdigitated design" can offer a multitude of advantages. For instance, having alternating digits of anode and cathode materials in close proximity can shorten the ion-transport pathways and effectively improve the rate capability of the on-chip micro-system.

\subsection{Hypotheses}

As discussed in the previous section, the inherent capacity and rate mismatch between the double layer and redox electrodes can be addressed using several different routes in order to ensure maximal energy-power tradeoff. For "scale-up" systems, the most appropriate evaluation criterion is gravimetric. In general, electrode materials that 
rely on redox charge storage mechanisms such as manganese oxides $\left(\mathrm{MnO}_{\mathrm{x}}\right)$, lithium insertion electrodes $\left(\mathrm{Li}_{4} \mathrm{Ti}_{5} \mathrm{O}_{12}\right.$, anatase $\left.\mathrm{TiO}_{2}\right)$ exhibit higher capacity than double-layer materials (activated carbons, graphene, CNT). The capacity mismatch between the two types of electrodes can be addressed by adjusting the electrode mass ratio to ensure charge equivalence in the electrodes. In order to address the intrinsic kinetics mismatch between the redox and the double layer electrode, the redox electrode can be complemented with nanostructured graphitic carbons, which have lower percolation thresholds than the conventionally used carbon black; optimal carbon content in the hybrid electrode can ensure effective dispersion of the nanostructured carbon and better rate handling of the redox material. For the "scale-down" or miniature systems, on the other hand, gravimetric metrics are inappropriate given the smaller device footprints. A more balanced system in terms of energy and power can be achieved by optimizing active material thicknesses. It is also hypothesized, that the interdigitated asymmetric design can enhance the rate capability of the device since it offers the feasibility of having alternating fingers of anode and cathode materials in close proximity, which can shorten the ion-transport pathways.

\subsection{Research Plan}

The research plan adopted for this dissertation is presented in Figure 1.1; the specific goals that were worked toward are as follows:

1. Material identification and synthesis: In order to design and evaluate full cell hybrid systems, it is imperative to identify the electrode material. To attain this goal, the faradaic electrode materials $\left(\mathrm{MnO}_{x}, \mathrm{Li}_{4} \mathrm{Ti}_{5} \mathrm{O}_{12}\right.$-anatase $\left.\mathrm{TiO}_{2}\right)$ were synthesized via 
electrostatic spray deposition (ESD) and were characterized from both materials and electrochemical aspects.

2. Empirical electrochemical performance optimization of the asymmetric/hybrid electrochemical capacitor: The electrodes synthesized in the previous objective served as the framework for constructing and evaluating the asymmetric full-cell system. The relatively inferior kinetics of the redox electrode was addressed using optimal nanostructured carbon additive. The full-cell asymmetric system was optimized for maximal energy-power tradeoff using different electrode mass ratios.

3. Microelectrode platform development and active materials integration: Microelectrodes based on carbon microelectromechanical systems (C-MEMS) and 2D interdigitated gold electrodes were developed and characterized. The active materials were integrated using ESD, electrophoretic deposition (EPD) and electrochemical deposition.

4. Electrochemical performance optimization of the asymmetric/hybrid microsupercapacitor: The hybrid microsupercapacitor was optimized using different electrode thicknesses and alternating interdigitated fingers of the anode and cathode materials.

\subsection{Scope of the Dissertation}

Chapter 2 provides the background of the dissertation along with relevant literature review. Supercapacitors have been discussed from both charge-storage and configuration perspectives. Both scale-up and miniaturized supercapacitors have been discussed. Chapter 3 provides detailed methodology of the experimental techniques adopted for this dissertation, which include photolithography techniques and active 
material integration methods including electrostatic spray deposition (ESD) and electrodeposition. Chapter 4 investigates a scale-up hybrid capacitor (lithium-ion capacitor) design utilizing a lithium insertion host viz. anatase $\mathrm{TiO}_{2}-\mathrm{Li}_{4} \mathrm{Ti}_{5} \mathrm{O}_{12}$ (ATOLTO) composite film in a lithium-containing electrolyte. To couple the ATO-LTO anode, an ESD based rGO-CNT cathode was used. The ESD based lithium-ion capacitor was able to demonstrate a high cell voltage of $3 \mathrm{~V}$ in addition to superior gravimetric energy density as well as capacity. Chapter 5 discusses electrostatic spray deposition (ESD) derived manganese oxide $\left(\mathrm{MnO}_{\mathrm{x}}\right)$ electrodes and their investigation as pseudocapacitive charge storage material as well as microelectrode-integrands. Chapter 6 provides an indepth study of ESD based manganese oxide and carbon nanotube $\left(\mathrm{MnO}_{\mathrm{x}}-\mathrm{CNT}\right)$ composites for scale-up asymmetric supercapacitor design and evaluation. The chapter elucidates that the utilization of a pseudocapacitive component and a double layer component within the same cell significantly stretches the cell voltage of aqueous electrolytes, and results in superior energy and power characteristics. Chapter 6 also discusses the empirical conditions for optimized energy-power trade-off for the asymmetric system. Chapter 7 expands on the concept of asymmetric capacitor configuration from scale-up to scale-down miniaturized system. From the electrochemical characterization performed on the interdigital systems, the asymmetric microsupercapacitor comprising $\mathrm{MnO}_{\mathrm{x}}$ cathode and reduced graphene oxide (rGO) anode demonstrates superior electrochemical characteristics than the symmetric $\mathrm{rGO} / / \mathrm{rGO}$ and $\mathrm{MnO}_{\mathrm{x}} / / \mathrm{MnO}_{\mathrm{x}}$ microsupercapacitor configurations. Chapter 8 provides with a summary and future works in the direction of this dissertation. 


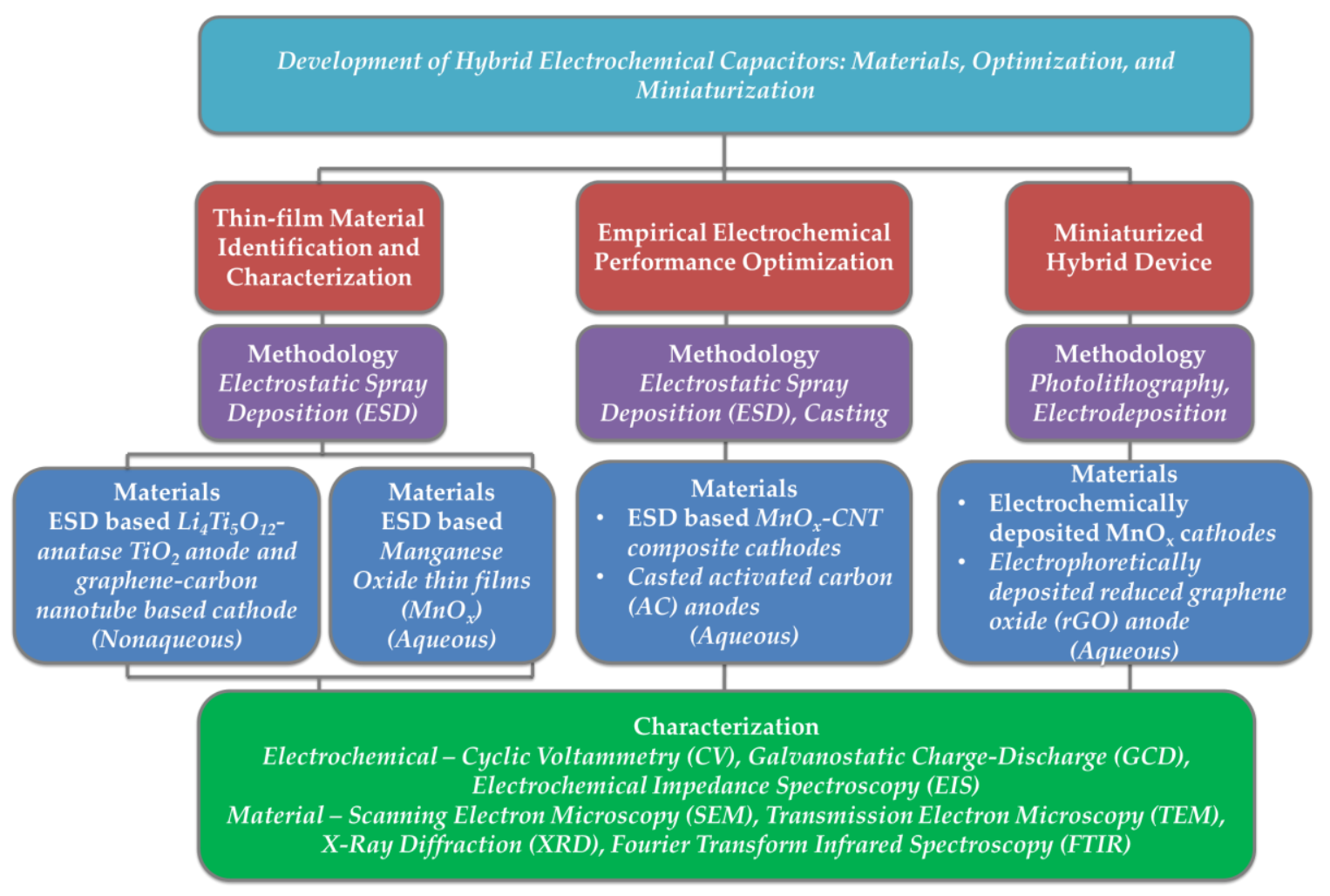

Figure 1.1: Flow chart of the research plan

\subsection{References}

1. Agrawal, R., Adelowo, E., Baboukani, A.R., Villegas, M.F., Henriques, A. and Wang, C., 2017. Electrostatic Spray Deposition-Based Manganese Oxide FilmsFrom Pseudocapacitive Charge Storage Materials to Three-Dimensional Microelectrode Integrands. Nanomaterials, 7(8), p.198.

2. Beidaghi, M. and Gogotsi, Y., 2014. Capacitive energy storage in micro-scale devices: recent advances in design and fabrication of micro-supercapacitors. Energy \& Environmental Science, 7(3), pp.867-884.

3. Cericola, D. and Kötz, R., 2012. Hybridization of rechargeable batteries and electrochemical capacitors: Principles and limits. Electrochimica Acta, 72, pp.1-17. 


\section{BACKGROUND AND LITERATURE REVIEW}

\subsection{Historical Overview}

The discovery of the electrochemical double layer capacitors (EDLCs) dates back to 1957 when Becker patented a "Low voltage electrolytic capacitor" with porous carbon electrodes [1]. The double layer phenomenon however was not properly understood at that time. In 1966, researchers at Standard Oil of Ohio (SOHIO) patented "electrical energy storage apparatus" while working on fuel cell designs [2]. SOHIO did not commercialize their invention and licensed their technology to Nippon Electric Company (NEC), who marketed the results as "supercapacitors" in 1978 [3]. Around the same time, Panasonic marketed its "Goldcaps" brand, which became a successful energy source for memory backup applications [3]. The earlier applications of electrochemical capacitors primarily comprised low current applications such as powering SRAM chips for data backup. In late 1970s, Brian Evans Conway conducted extensive work on ruthenium oxide based electrochemical capacitors. The charge storage mechanism in his capacitors was a combination of Helmholtz double-layer and "pseudocapacitive", which is essentially faradaic activity at the electrode-electrolyte interface. Due to the increased amounts of possible applications, the entire field of electrochemical capacitors flourished in the 1990s and a lot of research and development efforts have been invested in supercapacitors since then.

\subsection{Commercial Market and Research Trends in Supercapacitors}

In a recent press release by Transparency Market Research [4], the global market for supercapacitors stood at US $\$ 1.21$ billion in 2014 and is anticipated to rise at a compound 
annual growth rate (CAGR) of $22.3 \%$ from 2015 to 2023, as a result of which the market is projected to surge to US $\$ 7.37$ billion by 2023 [4]. The market for hybrid capacitor itself is predicted to rise at a CAGR of $23.5 \%$ during 2015-2023 and is projected to lead the market in the upcoming years [4]. The primarily impetus for the fast supercapacitor market growth is the demand for advanced energy storage systems in the electronics industry. In the automotive industry, on the other hand, the rapid charge and discharge from the supercapacitors can extend battery lifespans [4].

Some of the key players of the global supercapacitor market are Advanced Capacitor Technologies, Axion Power International, Cap XX, EEStor Corporation, ELTON, FastCAP Systems, Maxwell Techonologies, Nesscap Energy, and others. Apart from the thriving industry, supercapacitor research is widely popular in research laboratories and universities. Figure 2.1 elucidates the number of publications on supercapacitor research in the past decade.

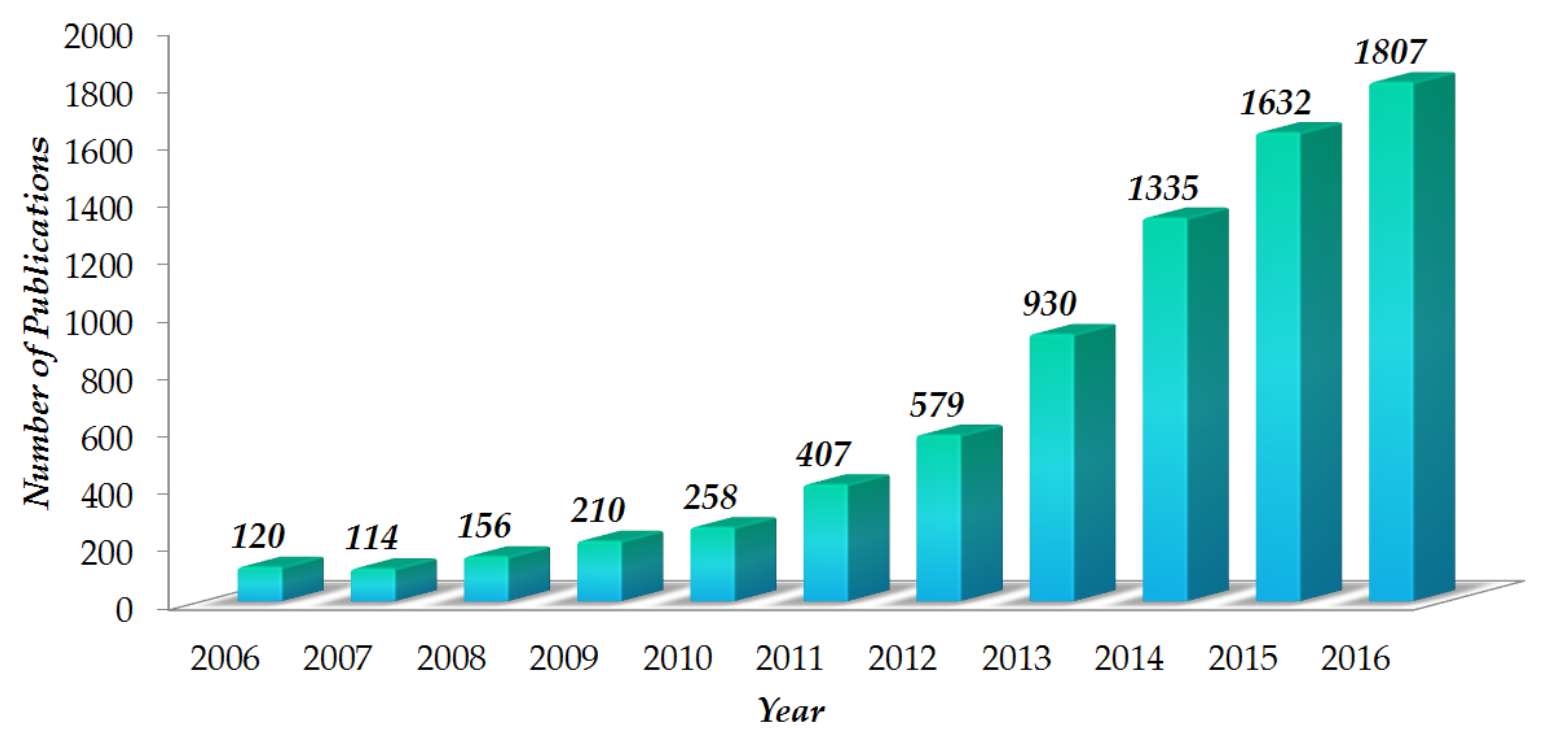

Figure 2.1: Number of publications resulting from supercapacitor research in the past decade (Source: Web of Science) 


\subsection{Fundamentals of Electrochemical Capacitors}

Electrochemical capacitors (ECs), often called as "ultracapacitors" or "supercapacitors", are a class of energy storage devices that bridge the gap between conventional electrolytic capacitors and batteries. These capacitors are characterized by moderate specific energy $\left(\sim 5 \mathrm{Whkg}^{-1}\right)$, high specific power $\left(\sim 10 \mathrm{kWkg}^{-1}\right)$, and superior cycle lives than their battery counterparts. Figure 2.2 depicts the special positioning of electrochemical capacitors in the specific power-specific energy plot also known as "Ragone plot"; it can be seen that electrochemical capacitors bridge the gap between conventional capacitors and batteries, with intermediate time constants.

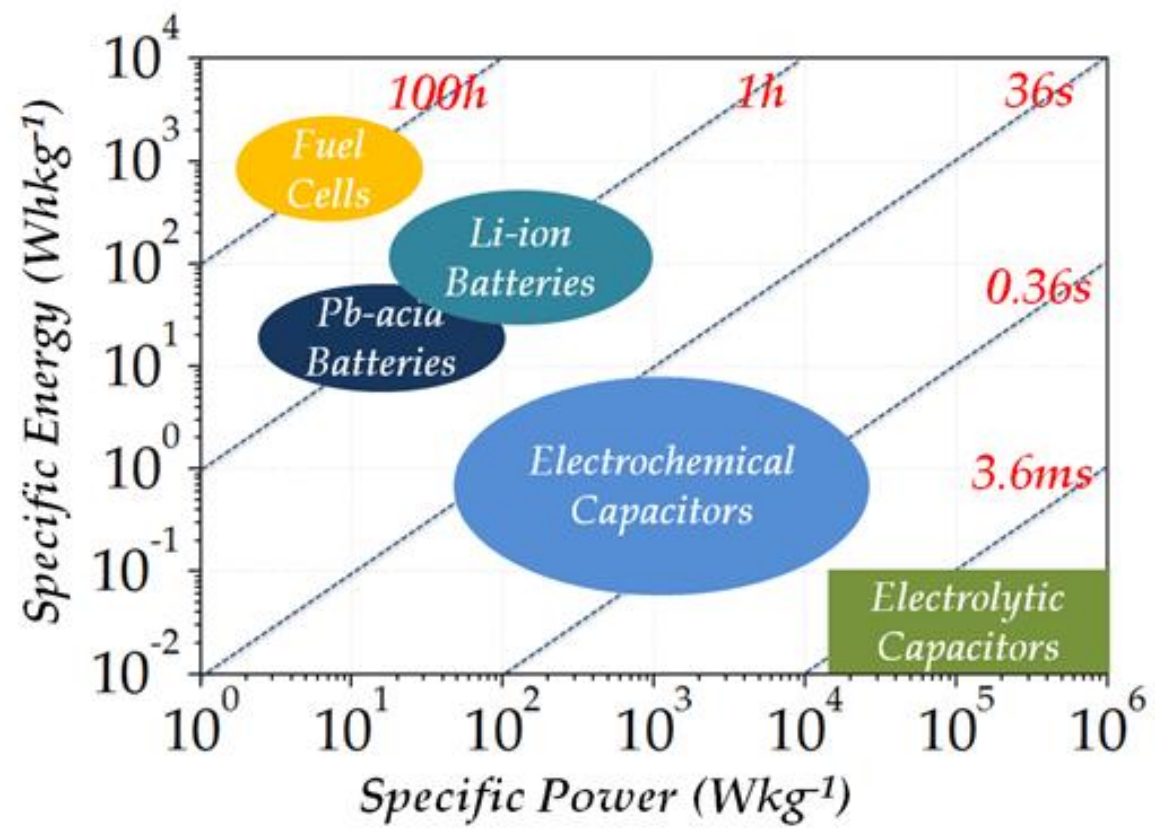

Figure 2.2: Ragone plot for different energy storage devices.

The primary electrochemical characteristics of any energy storage device are its energy density and power density, both of which can be expressed per unit mass (per kilogram), per unit area or per unit volume. The energy of an electrochemical capacitor is given as: 


$$
E=\frac{1}{2} C V^{2}
$$

where $\mathrm{C}$ is the capacitance and $\mathrm{V}$ is the cell voltage. As evident, the energy is related as power-squared and therefore, stretching the cell potential can significantly enhance the energy of the system. Power, on the other hand is the measure of the rate of energy delivery, i.e. energy per unit time. However, the maximum power delivered by a capacitor is limited by the internal resistance of the system, also known as equivalent series resistance (ESR). The maximal power of a system can be computed using equation (2.2).

$$
P_{\text {max }}=\frac{V^{2}}{4 E S R}
$$

As evident from the equation, power is an inverse function of the resistance of the system - lower the resistance, higher is the power delivered by the system. The ESR can be measured as the voltage drop introduced in the discharging part of the charge-discharge curves of the system, and hence decreases the maximum voltage of a capacitor during discharge and therefore limits the maximum power of the system. However, this is the maximum power and in general, the peak power in an actual system is lower than $\mathrm{P}_{\max }$.

\subsection{Classification of Electrochemical Capacitors}

ECs store energy in the form of charge at the electrode/electrolyte interface of materials with high surface area. Depending on the charge storage mechanism ECs are subdivided into (i) Electrochemical Double Layer Capacitors (EDLCs) and (ii) pseudocapacitors. A third category, the so-called "hybrid electrochemical capacitors" essentially combine both EDLCs and pseudocapacitors. 


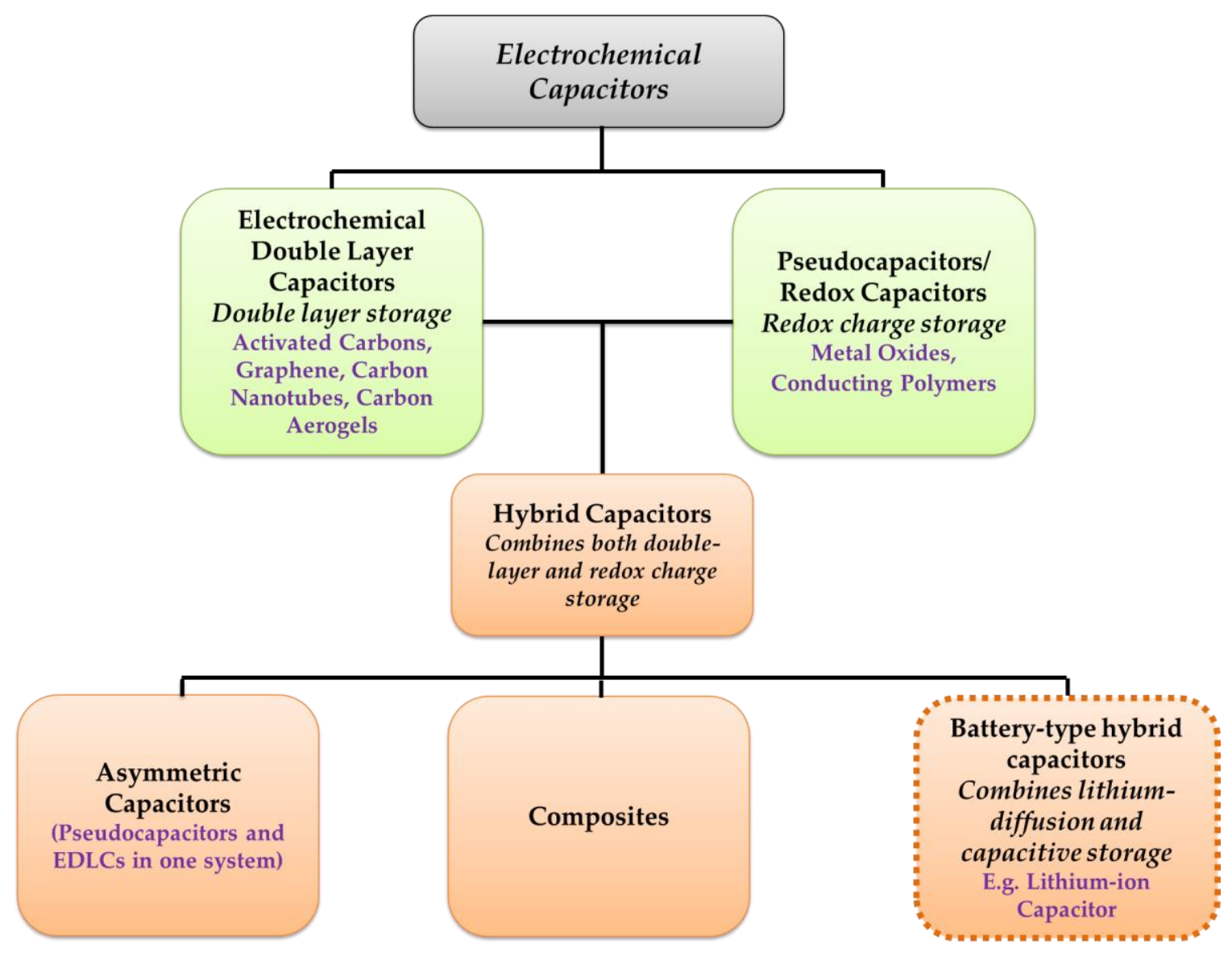

Figure 2.3: Classification of Electrochemical Capacitors

\subsubsection{Electrochemical Double layer Capacitors (EDLCs)}

EDLCs, quite analogous to electrolytic capacitors store energy in an electrostatic manner; charges are stored at the electrode/electrolyte interface and the capacitance is governed by the thickness of the Helmholtz double layer and hence the name. When an external potential is applied, charges accumulate at the electrode surface and the charge buildup leads to diffusion of opposite charges across the separator generating a "double layer" on each electrode. The thickness of the double layer can be computed from equation $(2.3)[5,6]$ : 


$$
\kappa^{-1}=\left(\frac{\varepsilon_{r} \varepsilon_{0} k_{B} T}{F^{2} \sum N_{i} Z_{i}^{2}}\right)^{1 / 2}
$$

where $\kappa^{-1}$ is the double layer thickness, $\varepsilon_{r}$ is the dielectric constant of the electrolyte, $\varepsilon_{0}$ is the electrical permittivity of free space, $k_{B}$ is the Boltzmann constant, $\mathrm{F}$ is the Faraday constant, $N_{i}$ is the ion concentration and $Z_{i}$ is the ionic charge. Typically EDLCs have capacitances larger than one or two orders of magnitude higher than electrolytic capacitors given the fact that the electrodes used for EDLCs are porous and possess very large surface areas. Furthermore, EDLCs also exhibit high cycling abilities, usually of the order of $10^{5}-10^{6}$ cycles. EDLC materials include carbon based materials including activated carbon (AC), carbon aerogels, carbon nanotubes (CNTs), onion like carbons (OLCs), carbon nanowires (CNWs), carbon nanorods, carbon nanofibers (CNFs), and graphene [7].

\subsubsection{Pseudocapacitors}

In contrast to conventional capacitors and EDLCs, pseudocapacitors store charge in a Faradaic manner, or in other words, the capacitance in this kind of capacitors arises from the transfer of charge between the electrode and electrolyte. This charge transfer is highly reversible and fast and as a result of which the charging and discharging curves of these devices look like those of a typical capacitor. The latter is referred to as "pseudo" owing to the reversible Faradaic-type charging and discharging. Owing to a Faradaic mechanism of charge storage, these capacitors in general exhibit higher specific energies and capacitances than their EDLC counterparts [8,9]. The most widely used pseudocapacitive materials include metal oxides (mostly ruthenium oxide, manganese 
oxide, and nickel hydroxide), conducting polymers including polyaniline (PANI), polypyrrole (PPY), polythiophene (PTH) and their derivatives [7].

\subsubsection{Hybrid Capacitors}

As their name suggests, hybrid capacitors comprise mechanisms from both double-layer and redox-based charge storage. Hybrid capacitors can be further classified based on material design and device configuration; the former comprises composite electrodes, whereas the latter encompasses "asymmetric" type electrochemical capacitors. Composites in general can be explained as material hybrids, containing a harmonious amalgamation of redox and double layer materials within one electrode. Asymmetric systems are essentially devices that contain one largely redox type and the other largely double layer type electrode. It should be noted that asymmetric capacitors can contain pristine redox and double layer counter electrodes and vice versa, as well as material composites as electrodes.

\subsubsection{Composite electrodes}

As mentioned previously, pseudocapacitive materials exhibit rather high capacitance but since these devices depend primarily on redox processes, they have lower cycle lives than double layer capacitors. Composite hybrid electrodes can therefore benefit from higher capacitances of pseudocapacitors and long cycle lives of double layer capacitors. Among the conducting polymers, PANI, PPY, PTH and their derivatives are widely investigated. Upon oxidation, the electrolyte ions are transferred to the polymer chain, whereas upon reduction, the ions detach from the chain and get released into the electrolyte; the process is shown in Equation (2.4). The ion transfer typically takes place 
through the bulk of the electrodes and as a result of which the resultant specific capacitance is high.

$$
\left[P P Y^{+} X^{-}\right]+e^{-} \leftrightarrow[P P Y]+X^{-}(2.4)
$$

However, the ion insertion/extraction is accompanied with volumetric changes in the electrodes, which results in degradation from shrinking, swelling, etc. leading to a loss in conductivity and mechanical stability. Conducting polymers can therefore benefit from the carbon based materials which are known for their mechanical strength and resilience. These dl carbons can act as buffers and alleviate mechanical stresses resulting from volumetric changes and therefore improve the electrode longevity. Furthermore, the addition of $\mathrm{d}$ based materials can enhance the conductivity and rate capability of the system.

Transition metal oxides (TMOs) such as $\mathrm{RuO}_{2}, \mathrm{NiO}_{\mathrm{x}}$, manganese oxides $\left(\mathrm{MnO}_{\mathrm{x}}\right)$, on the other hand, undergo fast reversible redox reactions at their surfaces, which lend their pseudocapacitive characteristics. Typically, TMOs exhibit larger capacitances than their double layer counterparts. However, they suffer from poor electrical conductivity and low cycle lives. Optimal TMO/double layer composites can therefore benefit from the large capacitance of the metal oxides, the superior electrical conductivity and cycling performance of the carbons. Furthermore, especially for nanostructured carbons such as carbon nanotubes and graphene, TMOs can act as "spacers" and suppress their agglomeration, which can help fully exploit their high surface areas and capacitances. Table 2.1 lists specifications of some of the pseudocapacitive/double layer composite electrodes reported in the literature. 
Table 2.1: Summary of pseudocapacitive/double layer composites reported in the literature

\begin{tabular}{|c|c|c|c|c|c|}
\hline Composite & Morphology & Electrolyte & Performance & $\begin{array}{l}\text { Capacitance } \\
\text { retention }\end{array}$ & Ref \\
\hline Graphene/PANI nanorods & $\begin{array}{l}\text { Fibrous } \\
\text { morphology with } \\
\text { appropriate pore } \\
\text { size distribution }\end{array}$ & $1 \mathrm{M} \mathrm{HClO}_{4}$ & $\begin{array}{l}878.57 \mathrm{Fg}^{-1} \text { at } 1 \\
\mathrm{Ag}^{-1}\end{array}$ & $\begin{array}{l}\text { Low } \\
\text { capacitance } \\
\text { fading after } 1000 \\
\text { cycles }\end{array}$ & 10 \\
\hline Graphene/PANI paper & Layered structure & $1 \mathrm{M} \mathrm{H}_{2} \mathrm{SO}_{4}$ & $233 \mathrm{Fg}^{-1}$ & N/A & 11 \\
\hline Graphene/PANI & $\begin{array}{l}\text { Uniform } \\
\text { morphology with no } \\
\text { indication of PANI } \\
\text { and graphene } \\
\text { agglomeration }\end{array}$ & $1 \mathrm{M} \mathrm{H}_{2} \mathrm{SO}_{4}$ & $640 \mathrm{Fg}^{-1}$ & $\begin{array}{l}90 \% \text { after } 1000 \\
\text { charge/discharge } \\
\text { cycles }\end{array}$ & 12 \\
\hline $\begin{array}{l}\text { Graphene } \\
\text { Nanosheets/PANI }\end{array}$ & $\begin{array}{l}\text { Nano fibrillar } \\
\text { morphology }\end{array}$ & $1 \mathrm{M} \mathrm{H}_{2} \mathrm{SO}_{4}$ & $\begin{array}{l}1130 \mathrm{Fg}^{-1} \text { at } 5 \\
\mathrm{mVs}^{-1}\end{array}$ & $\begin{array}{l}87 \% \text { after } 1000 \\
\text { cycles }\end{array}$ & 13 \\
\hline $\begin{array}{l}\text { Graphene Oxide } \\
\text { (GO)/PANI }\end{array}$ & $\begin{array}{l}\text { Hierarchical } \\
\text { Structure }\end{array}$ & $1 \mathrm{M} \mathrm{H}_{2} \mathrm{SO}_{4}$ & $\begin{array}{l}555 \mathrm{Fg}^{-1} \text { at a } \\
\text { discharge current } \\
\text { density of } 0.2 \mathrm{Ag}^{-1}\end{array}$ & $\begin{array}{l}92 \% \text { after } 2000 \\
\text { cycles }\end{array}$ & 14 \\
\hline $\begin{array}{l}\text { Graphene } \\
\text { Oxide(GO)/PANI/CO } 2\end{array}$ & $\begin{array}{l}\text { PANI nanoparticles } \\
\text { uniformly coated on } \\
\text { GO sheets }\end{array}$ & $\begin{array}{l}1 \mathrm{M} \mathrm{H}_{2} \mathrm{SO}_{4} \\
\text { solution. }\end{array}$ & ${ }_{1}^{425 \mathrm{Fg}^{-1}}$ at $0.2 \mathrm{Ag}^{-}$ & $\begin{array}{l}83 \% \text { after } 500 \\
\text { cycles }\end{array}$ & 15 \\
\hline $\begin{array}{l}\text { Reduced Graphene } \\
\text { Oxide/PANI }\end{array}$ & $\begin{array}{l}\text { Fibrillar } \\
\text { morphology }\end{array}$ & $\begin{array}{l}1 \mathrm{M} \\
\text { aqueous } \\
\mathrm{H}_{2} \mathrm{SO}_{4} \\
\text { solution }\end{array}$ & $250 \mathrm{Fg}^{-1}$ & N/A & 16 \\
\hline $\begin{array}{l}\text { Graphene } \\
\text { Nanosheets/PPy }\end{array}$ & $\begin{array}{l}\text { PPy } \\
\text { homogeneously } \\
\text { surrounded by GNS }\end{array}$ & $1 \mathrm{M} \mathrm{H}_{2} \mathrm{SO}_{4}$ & ${ }_{1}^{482 \mathrm{Fg}^{-1}}$ at $0.5 \mathrm{Ag}^{-}$ & $\begin{array}{l}95 \% \text { after } 1000 \\
\text { cycles }\end{array}$ & 17 \\
\hline $\begin{array}{l}\text { Graphene } \\
\text { Nanosheets/PPy }\end{array}$ & $\begin{array}{l}\text { Dispersed network - } \\
\text { polypyrrole } \\
\text { nanowire } \\
\text { attached to basal } \\
\text { planes of GNS }\end{array}$ & $1 \mathrm{M} \mathrm{NaCl}$ & $\begin{array}{l}165 \mathrm{Fg}^{-1} \text { at } \\
1 \mathrm{Ag}^{-1}\end{array}$ & $\begin{array}{l}92 \% \text { after } 1000 \\
\text { cycles }\end{array}$ & 18 \\
\hline $\begin{array}{l}\text { Graphene Oxide/PPy } \\
\text { nanowires }\end{array}$ & $\begin{array}{l}\text { PPy nanowires } \\
\text { attached } \\
\text { to the surface of GO } \\
\text { nanosheets }\end{array}$ & $\begin{array}{l}1 \mathrm{M} \mathrm{KCl} \\
\text { aqueous } \\
\text { solution }\end{array}$ & $633 \mathrm{Fg}^{-1}$ at $1 \mathrm{Ag}^{-1}$ & $\begin{array}{l}94 \% \text { after } 1000 \\
\text { cycles }\end{array}$ & 19 \\
\hline $\begin{array}{l}\text { Reduced Graphene } \\
\text { Oxide/PPy }\end{array}$ & $\begin{array}{l}\text { PPy located on } \\
\text { both sides of the } \\
\text { GO sheets }\end{array}$ & $1 \mathrm{M} \mathrm{H}_{2} \mathrm{SO}_{4}$ & $\begin{array}{l}376 \mathrm{Fg}^{-1} \text { at a scan } \\
\text { rate of } 25 \mathrm{mVs}^{-1}\end{array}$ & $\begin{array}{l}84 \% \text { after } 1000 \\
\text { cycles }\end{array}$ & 20 \\
\hline
\end{tabular}




\begin{tabular}{|c|c|c|c|c|c|}
\hline $\begin{array}{l}\text { Reduced Graphene Oxide } \\
\text { (rGO)/PPy }\end{array}$ & $\begin{array}{l}\text { GO/PPy composite } \\
\text { was uniformly } \\
\text { electropolymerized } \\
\text { onto the surface of } \\
\text { gold electrode }\end{array}$ & $1 \mathrm{M} \mathrm{H}_{2} \mathrm{SO}_{4}$ & $424 \mathrm{Fg}^{-1}$ at $1 \mathrm{Ag}^{-1}$ & N/A & 21 \\
\hline $\begin{array}{l}\mathrm{MnO}_{2} / \mathrm{Graphene} / \text { Nickel } \\
\text { foam }(\mathrm{NF})\end{array}$ & $\begin{array}{l}\text { Nanoneedle like } \\
\mathrm{MnO}_{2} \text { uniformly } \\
\text { grew on porous } \\
\text { G/NF sheets }\end{array}$ & $\begin{array}{l}0.5 \mathrm{M} \\
\mathrm{Na}_{2} \mathrm{SO}_{4}\end{array}$ & $\begin{array}{l}476 \mathrm{Fg}^{-1} \text { at } 1 \mathrm{Ag}^{-1} \\
216 \mathrm{Fg}^{-1} \text { at } 10 \mathrm{Ag}^{-1}\end{array}$ & N/A & 22 \\
\hline Graphene/MWNTs/MnO ${ }_{2}$ & $\begin{array}{l}\text { Nanowires on } \\
\text { graphene/MWNT } \\
\text { foam }\end{array}$ & $2 \mathrm{M} \mathrm{Li}_{2} \mathrm{SO}_{4}$ & $\begin{array}{l}1108.9 \mathrm{Fg}^{-1} \text { at } 1.89 \\
\mathrm{Ag}^{-1}\end{array}$ & $\begin{array}{l}97.94 \% \text { after } \\
13000 \text { cycles }\end{array}$ & 23 \\
\hline $\begin{array}{l}\text { Reduced Graphene } \\
\text { Oxide } / \mathrm{MnO}_{2}\end{array}$ & $\begin{array}{l}\text { Flower-like } \\
\text { nanoparticles }\end{array}$ & $\begin{array}{l}1 \mathrm{M} \\
\mathrm{Na}_{2} \mathrm{SO}_{4}\end{array}$ & $450 \mathrm{Fg}^{-1}$ at $2 \mathrm{mVs}^{-1}$ & $\begin{array}{l}90 \% \text { after } 10000 \\
\text { cycles }\end{array}$ & 24 \\
\hline $\mathrm{N}$-doped graphene/ $\mathrm{MnO}_{2}$ & $\begin{array}{l}\text { Sheet like } \\
\text { morphology }\end{array}$ & $\begin{array}{l}1 \mathrm{M} \\
\mathrm{Na}_{2} \mathrm{SO}_{4}\end{array}$ & $\begin{array}{l}257.1 \mathrm{Fg}^{-1}, 224.4 \\
\mathrm{Fg}^{-1}, 205.6 \mathrm{Fg}^{-1} \\
\text { and } 192.5 \mathrm{Fg}^{-1} \text { at } \\
\text { densities of } 0.2 \text {, } \\
0.5,1 \text { and } 2 \mathrm{Ag}^{-1} \text {, } \\
\text { respectively. }\end{array}$ & $\begin{array}{l}94.2 \% \text { after } \\
2000 \text { cycles }\end{array}$ & 25 \\
\hline Graphene/ $/ \mathrm{Mn}_{3} \mathrm{O}_{4}$ & Nanoparticles & $\begin{array}{l}1 \mathrm{M} \\
\mathrm{Na}_{2} \mathrm{SO}_{4} \\
6 \mathrm{M} \mathrm{KOH}\end{array}$ & $\begin{array}{l}175 \mathrm{Fg}^{-1} \text { and } 256 \\
\mathrm{Fg}^{-1} \text { for } 1 \mathrm{M} \\
\mathrm{Na}_{2} \mathrm{SO}_{4} \text { and } 6 \mathrm{M} \\
\mathrm{KOH} \text { respectively }\end{array}$ & N/A & 26 \\
\hline $\mathrm{RuO}_{2} /$ Graphene & $\begin{array}{l}5-10 \mathrm{~nm} \mathrm{RuO}_{2} \mathrm{NPs} \\
\text { well anchored to the } \\
\text { graphene backbone }\end{array}$ & $1 \mathrm{M} \mathrm{H}_{2} \mathrm{SO}_{4}$ & $\begin{array}{l}570 \mathrm{Fg}^{-1} \text { for } 38.3 \\
\mathrm{wt} \% \text { of } \mathrm{Ru} \text { at } \\
1 \mathrm{mVs}^{-1}\end{array}$ & $\begin{array}{l}97.9 \% \text { after } \\
1000 \text { cycles }\end{array}$ & 27 \\
\hline $\begin{array}{l}\mathrm{Fe}_{3} \mathrm{O}_{4} / \text { reduced Graphene } \\
\text { Oxide }\end{array}$ & Nanoparticles & $1 \mathrm{M} \mathrm{KOH}$ & $\begin{array}{l}220.1 \mathrm{Fg}^{-1} \text { at } 0.5 \\
\mathrm{Ag}^{-1}\end{array}$ & $\begin{array}{l}\text { Capacitance } \\
\text { increases from } \\
180.6 \mathrm{Fg}^{-1} \text { to } \\
220.1 \mathrm{Fg}^{-1} \\
\text { during first } 800 \\
\text { cycles and } \\
\text { remains stable } \\
\text { until } 3000 \text { cycles }\end{array}$ & 28 \\
\hline $\begin{array}{l}\text { Reduced Graphene } \\
\text { Oxide/Co(OH })_{2}\end{array}$ & Nanoparticles & $2 \mathrm{M} \mathrm{KOH}$ & $\begin{array}{l}476 \mathrm{Fg}^{-1} \text { at } 1 \mathrm{Ag}^{-1} \\
300 \mathrm{Fg}^{-1} \text { at } 10 \mathrm{Ag}^{-1}\end{array}$ & $\begin{array}{l}90 \% \text { after } 1000 \\
\text { cycles }\end{array}$ & 29 \\
\hline Graphene $/ \mathrm{Co}_{3} \mathrm{O}_{4}$ & $\begin{array}{l}\text { Multi-layered } \\
\text { morphology with } \\
\text { uniform distribution } \\
\text { of } \mathrm{Co}_{3} \mathrm{O}_{4}\end{array}$ & $6 \mathrm{M} \mathrm{KOH}$ & $331 \mathrm{Fg}^{-1}$ at $5 \mathrm{Ag}^{-1}$ & $\begin{array}{l}122 \% \text { after } 5000 \\
\text { cycles }\end{array}$ & 30 \\
\hline Graphene/ZnO & Particles & $1 \mathrm{M} \mathrm{KOH}$ & $\begin{array}{l}\text { Highest } \\
\text { capacitance of } 62.2 \\
\mathrm{Fg}^{-1}\end{array}$ & $\begin{array}{l}\text { Only } 5.1 \% \text { drop } \\
\text { after } 200 \text { cycles }\end{array}$ & 31 \\
\hline
\end{tabular}


Key: PPy - polypyrrole; $\mathrm{Fe}_{3} \mathrm{O}_{4}$ - iron oxide; $\mathrm{rGO}$ - reduced graphene oxide, $\mathrm{ZnO}$ - zinc oxide, $\mathrm{KOH}$ potassium hydroxide; PANI - polyaniline; $\mathrm{RuO}_{2}$ - ruthenium oxide

\subsubsection{Asymmetric-type Hybrid Capacitors}

In a broader sense, asymmetric-type hybrid capacitors comprise two electrodes with different charge-storage mechanisms. The rationale for using the asymmetric capacitor design is essentially utilizing the larger charge storage capability of the redoxbased electrode and the faster kinetics and cycle longevity of the double layer electrode from one cohesive system. Figure 2.4 illustrates the schematic illustration of the construction of an asymmetric capacitor; the components are packaged and contained in an electrolyte solution. According to equation (2.1), the energy of a supercapacitor is directly proportional to the cell capacitance and has direct quadratic dependence on the cell voltage. The total capacitance of cell $\left(\mathrm{C}_{\text {cell }}\right)$ containing electrodes with individual capacitances $\mathrm{C}_{1}$ and $\mathrm{C}_{2}$ can be computed using equation (2.5):

$$
\frac{1}{C_{\text {cell }}}=\frac{1}{C_{1}}+\frac{1}{C_{2}}
$$

Since two dissimilar electrodes are used in an asymmetric capacitor, these electrodes possess different capacitances. In general the redox electrode has a much larger capacitance than its double layer counterpart and therefore the overall capacitance exhibited by the device is $\mathrm{C}_{\text {cell }} \sim \mathrm{C}_{\text {redox }}$, which in principle, is the capacitance of the redox electrode. Hence, the capacitance of a capacitor in an asymmetric configuration is twice of that in symmetric, if the same electrode were utilized. As a result of this higher capacitance, energy density of an asymmetric cell is much higher. However, it should be noted that equation (2.4) is a theoretical approximation that only considers the electrodes 
of the system, and therefore the empirical values may differ owing to other cell components including contributions from electrolyte, separator, current collectors, and so on. The optimal material choice for designing an asymmetric system stems from the following key considerations:

i. Matching the capacity of the active materials: Since the redox electrode typically has a much higher specific capacitance than the double layer electrode, there is a mismatch in the charge held by the individual electrodes, if the identical masses were used for both the electrodes. To compensate for the capacity mismatch at a given current rate, the active material mass on the electrodes can be adjusted in order to ensure that the charge held by the individual electrodes is balanced.

ii. Maximizing the operational voltage of the cell: Both the electrodes should be chosen such that their potentials are either at high or low end of the operating voltage. Since energy increases as potential squared, the wider the voltage window, more is the enhancement in the energy.

Furthermore the two electrodes can be engineered in terms of porosity, microstructure, mass, thickness, etc. in order to exploit the full potential of each of the component. When optimized, such a system can provide with the benefits from both the redox-based and capacitive system. Two types of asymmetric capacitor systems have been widely investigated including pseudocapacitive/double layer systems, and lithiumbased battery-type hybrid capacitors. Generally, the former are based in aqueous media whereas the latter are contained in nonaqueous lithium-containing electrolytes. 


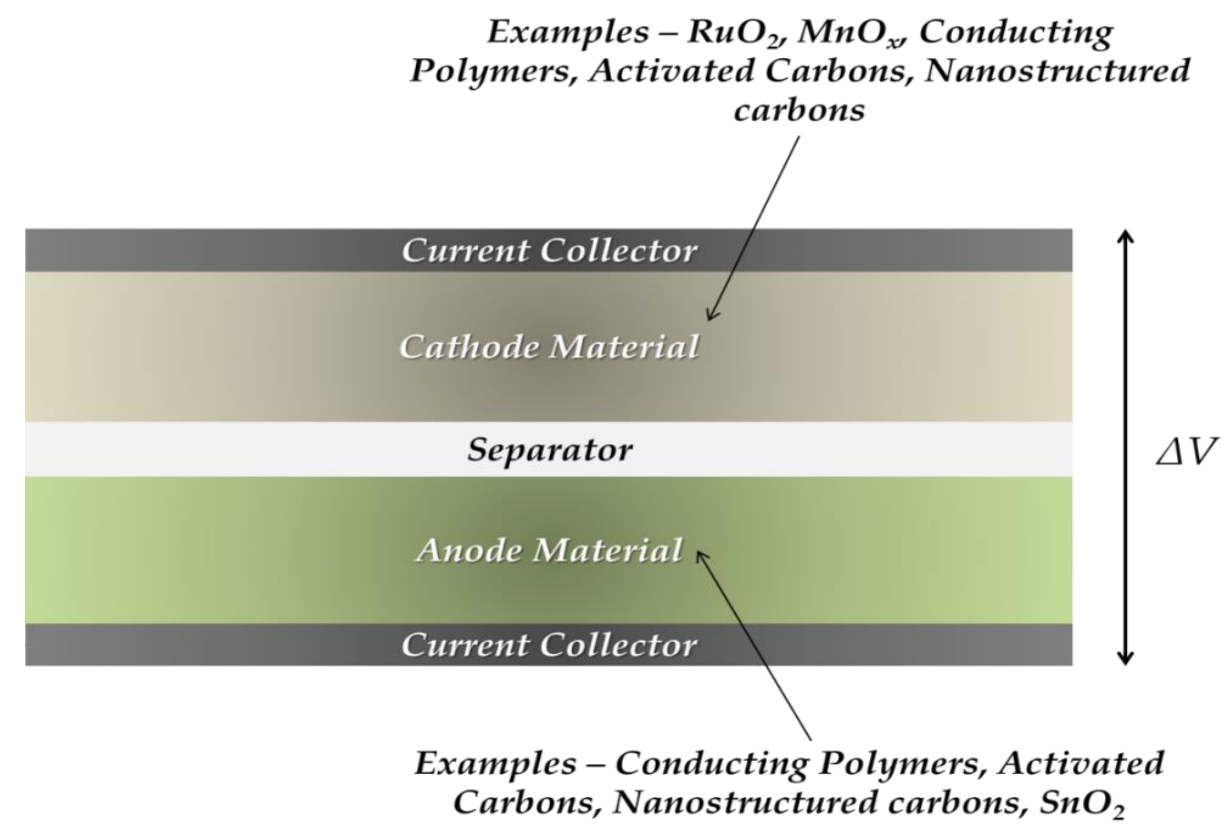

Figure 2.4: Construction of an asymmetric capacitor; the assembly is contained in an electrolyte solution.

\subsection{Pseudocapacitive/double layer (dl) based asymmetric capacitors}

The asymmetric design blends the characteristics of both electrochemical capacitors and batteries by utilizing the high capacity of the pseudocapacitive electrodes and the fast charge-discharge response arising from the double layer mechanism from the carbon based electrodes. Typically a high surface area carbon based electrode is utilized as the negative electrode, whereas a battery-type or pseudocapacitive electrode is used as the positive electrode. Furthermore, asymmetric electrochemical capacitors with double layer and pseudocapacitive electrodes offer the advantage of stretching the voltage of full electrochemical cells even in water based media. The high overpotentials for $\mathrm{H}_{2}$ and $\mathrm{O}_{2}$ evolution at the carbon-based electrode and the pseudocapacitive electrode, respectively effectively extend the potential window of aqueous electrolytes beyond the 
thermodynamic limit $(\sim 1.2 \mathrm{~V})$, resulting in significantly higher energy densities than the capacitors in symmetric systems. The use of aqueous electrolytes is desirable owing to their high ionic conductivity, and the feasibility to fabricate devices without the need for contained atmospheres like argon- or nitrogen-filled glove boxes [32]. Chapter 5 of the dissertation elucidates one such asymmetric capacitor constructed with manganese oxidecarbon nanotube $\left(\mathrm{MnO}_{\mathrm{x}}-\mathrm{CNT}\right)$ composite electrodes along with activated carbon $(\mathrm{AC})$ counter electrodes. Table 2.2 provides a summary of the some of the asymmetric systems based on pseudocapacitive and double layer electrodes in the literature.

Table 2.2: Summary of some of the reported pseudocapacitive/double layer asymmetric supercapacitors

\begin{tabular}{|c|c|c|c|c|c|c|}
\hline Positive Electrode & $\begin{array}{l}\text { Negative } \\
\text { Electrode }\end{array}$ & Electrolyte & $\begin{array}{l}\text { Current } \\
\text { density/scan } \\
\text { rate }\end{array}$ & $\begin{array}{l}\text { Specific Capacitance } \\
\text { /Performance }\end{array}$ & $\begin{array}{l}\text { Capacitance } \\
\text { Retention }\end{array}$ & Ref \\
\hline $\begin{array}{l}\mathrm{MnO}_{2} \\
\text { nanowire/Graphene }\end{array}$ & Graphene & $\begin{array}{l}1 \mathrm{M} \\
\mathrm{Na}_{2} \mathrm{SO}_{4}\end{array}$ & $0.5 \mathrm{Ag}^{-1}$ & 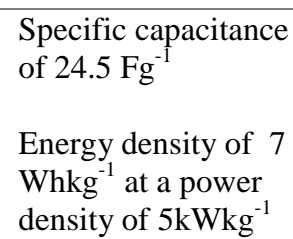 & $\begin{array}{l}79 \% \text { after } \\
1000 \text { cycles }\end{array}$ & 33 \\
\hline $\begin{array}{l}\mathrm{MnO}_{2} \text {-coated } \\
\text { Graphene }\end{array}$ & Graphene & $1 \mathrm{M} \mathrm{KCl}$ & $4 \mathrm{~mA}$ & $\begin{array}{l}\text { Specific capacitance } \\
\text { of } 328 \mathrm{Fg}^{-1} \\
\text { Energy density of } \\
11.4 \mathrm{Whkg}^{-1} \\
\text { Power density of } \\
25.8 \mathrm{kWkg}^{-1}\end{array}$ & $\begin{array}{l}99 \% \text { after } \\
1300 \text { cycles }\end{array}$ & 34 \\
\hline $\mathrm{MnO}_{2}$ nanotubes & $\begin{array}{l}\text { Activated } \\
\text { Graphene }\end{array}$ & $\begin{array}{l}1 \mathrm{M} \\
\mathrm{Na}_{2} \mathrm{SO}_{4}\end{array}$ & $0.25 \mathrm{Ag}^{-1}$ & $\begin{array}{l}\text { Specific capacitance } \\
\text { of } 365 \mathrm{Fg}^{-1} \\
\text { Energy density of } \\
22.5 \mathrm{Whkg}^{-1} \\
\text { Power density of } \\
146.2 \mathrm{kWkg}^{-1}\end{array}$ & $\begin{array}{l}90.4 \% \text { after } \\
3000 \text { cycles }\end{array}$ & 35 \\
\hline $\begin{array}{l}\text { Reduced Graphene } \\
\text { Oxide/ } \mathrm{MnO}_{2}\end{array}$ & RGO & $\begin{array}{l}1 \mathrm{M} \\
\mathrm{Na}_{2} \mathrm{SO}_{4}\end{array}$ & $10 \mathrm{mAg}^{-1}$ & $\begin{array}{l}\text { Specific capacitance } \\
\text { of } 113 \mathrm{mFcm}^{-2} \\
\text { Energy density of } \\
11.5 \mu \mathrm{Whcm}^{-2}\end{array}$ & $\begin{array}{l}93 \% \text { after } \\
3600 \text { cycles }\end{array}$ & 36 \\
\hline
\end{tabular}




\begin{tabular}{|c|c|c|c|c|c|c|}
\hline & & & & $\begin{array}{l}\text { Power density of } 3.8 \\
\mathrm{mWcm}^{-2}\end{array}$ & & \\
\hline PANI & Graphene & $1 \mathrm{M} \mathrm{HCl}$ & & $\begin{array}{l}\text { Energy density of } \\
4.86 \mathrm{Whkg}^{-1} \\
\text { Power density of } \\
8.75 \mathrm{kWkg}^{-1}\end{array}$ & & 37 \\
\hline $\begin{array}{l}\text { Graphene } / \mathrm{MnO}_{2-} \\
\text { textile }\end{array}$ & $\begin{array}{l}\text { SWNTs- } \\
\text { textiles }\end{array}$ & $\begin{array}{l}0.5 \mathrm{M} \\
\mathrm{Na}_{2} \mathrm{SO}_{4}\end{array}$ & & $\begin{array}{l}\text { Energy density of } \\
12.5 \mathrm{Whkg}^{-1} \\
\text { Power density of } 110 \\
\mathrm{kWkg}^{-1}\end{array}$ & $\begin{array}{l}95 \% \text { after } \\
5000 \text { cycles }\end{array}$ & 38 \\
\hline Graphene/ $\mathrm{MnO}_{2}$ & $\begin{array}{l}\text { Activated } \\
\text { carbon } \\
\text { nanofibers } \\
(\mathrm{ACN})\end{array}$ & $\begin{array}{l}1 \mathrm{M} \\
\mathrm{Na}_{2} \mathrm{SO}_{4}\end{array}$ & $200 \mathrm{mV} / \mathrm{s}$ & $\begin{array}{l}\text { Specific capacitance } \\
\text { of } 113.5 \mathrm{Fg}^{-1} \\
\text { Energy density of } \\
51.1 \mathrm{Whkg}^{-1} \\
\text { Power density of } 198 \\
\mathrm{kWkg}^{-1}\end{array}$ & $\begin{array}{l}97.3 \% \text { after } \\
1000 \text { cycles }\end{array}$ & 39 \\
\hline $\begin{array}{l}\text { Vertically aligned } \\
\mathrm{MnO}_{2} \text { nanoplates }\end{array}$ & $\begin{array}{l}\text { graphene } \\
\text { hydrogel }\end{array}$ & $\begin{array}{l}1 \mathrm{M} \\
\mathrm{Na}_{2} \mathrm{SO}_{4}\end{array}$ & $1 \mathrm{~A}$ & $\begin{array}{l}\text { Specific capacitance } \\
\text { of } 41.7 \mathrm{Fg}^{-1} \\
\text { Energy density of } \\
23.2 \mathrm{Whkg}^{-1} \\
\text { Power density of } 1 \\
\mathrm{kWkg}^{-1}\end{array}$ & $\begin{array}{l}83.4 \% \text { after } \\
5000 \text { cycles }\end{array}$ & 40 \\
\hline $\mathrm{Ni}(\mathrm{OH})_{2} / \mathrm{CNTs}$ & $\begin{array}{l}\text { Iron } \\
\text { nanosheets } \\
\text { on } \\
\text { graphene } \\
\text { sheets }\end{array}$ & $6 \mathrm{M} \mathrm{KOH}$ & & $\begin{array}{l}\text { Energy density of } \\
140 \mathrm{Wh} / \mathrm{kg}\end{array}$ & $\begin{array}{l}78 \% \text { after } \\
2000 \text { cycles }\end{array}$ & 41 \\
\hline $\begin{array}{l}\mathrm{MnO}_{2} / \text { graphene } \\
\text { oxide composite }\end{array}$ & $\begin{array}{l}\text { Graphene } \\
\text { oxide } \\
\text { (GO) }\end{array}$ & $1 \mathrm{M} \mathrm{HCl}$ & $0.5 \mathrm{~A} / \mathrm{g}$ & $\begin{array}{l}\text { Specific capacitance } \\
\text { of } 280 \mathrm{~F} / \mathrm{g} \\
\text { Energy density of } \\
35 \mathrm{Wh} / \mathrm{kg} \\
\text { Power density of } 7.5 \\
\mathrm{~kW} / \mathrm{kg}\end{array}$ & $\begin{array}{l}70 \% \text { after } \\
1000 \text { cycles }\end{array}$ & 42 \\
\hline (2D) $\mathrm{MnO}_{2}$ & GNS & $\begin{array}{l}\mathrm{Ca}\left(\mathrm{NO}_{3}\right)_{2-}^{-} \\
\mathrm{SiO}_{2} \\
\text { composite } \\
\text { gel }\end{array}$ & $0.1 \mathrm{~A} / \mathrm{g}$ & $\begin{array}{l}\text { Specific capacitance } \\
\text { of } 774 \mathrm{~F} / \mathrm{g} \\
\text { Energy density of } \\
97.2 \mathrm{Wh} / \mathrm{kg}\end{array}$ & $\begin{array}{l}97 \% \text { after } \\
10000 \\
\text { cycles }\end{array}$ & 43 \\
\hline
\end{tabular}

\subsection{Battery-type lithium-ion based asymmetric capacitors}

Lithium-ion batteries (LIBs) are known for their outstanding energy densities (150$200 \mathrm{Whkg}^{-1}$ ) and thus if an LIB electrode were coupled with an EC electrode, the resulting device can benefit from the high energy density of LIB and the high power 
density of the supercapacitor. For such a hybrid capacitor, a capacitive cathode and a lithium-intercalating anode are typically used along with a lithium-ion electrolyte. For brevity, such capacitors will be referred to as "lithium-ion capacitors" from henceforth. Charge is stored by reversible adsorption/desorption of anions at the surface of the capacitive cathode while at the anode, charge is stored via a reversible insertion/extraction mechanism of the lithium ions. The combined effects provide with an opportunity to enhance both the energy and power densities, while still maintaining superior cycle lives as compared to rechargeable batteries. The concept of such a hybrid supercapacitor was pioneered by Amatucci et al. [44] based on activated carbon (AC) and $\mathrm{Li}_{4} \mathrm{Ti}_{5} \mathrm{O}_{12}$ as the supercapacitor electrode and the Li-intercalating electrode, respectively. Although theoretically enticing, such a device poses several design challenges that must be addressed in order to fully exploit the benefits from both the battery and capacitor electrodes. For instance, lithium-ion intercalation is a Faradaic process which is far more sluggish than the non-Faradaic adsorption and desorption of ions; this mismatch in kinetics leads to a mismatch in power characteristics of the positive and negative electrodes, which must be addressed in order to realize the best of both electrodes. Several methods can be adopted in order to address the kinetics mismatch of the two electrodes - for instance adding conducting carbons in optimal ratios to metal oxides can improve their electronic conductivity and help balance the kinetics mismatch of the two electrodes. Furthermore, the "nano"-sizing the electrode materials provide the benefit of improved kinetics, given the concomitant shortening of ion and electron paths that comes with nano-structuring [45]. As noted by Cericola [46], a combination of both the double layer and redox based materials within one electrode, which they referred to as the 
"internal parallel system" offers the advantage of realizing both the charge-storage mechanisms from each of the electrodes and offset the shortcomings that arise from having only pristine electrodes. The combination of a redox based material and a double layer material within one electrode allows for intrinsic potential matching as the materials used have to be stable for the same voltage window [46]. Furthermore, the internal parallel system mitigates the capacity mismatch arising from the disparate charge storage mechanism of the redox and double layer materials, and therefore helps in higher material utilization rate. Table 2.3 provides a summary of some of the lithium-ion capacitors reported in the literature.

\section{Table 2.3: Summary of the lithium-ion capacitor based studies reported in the literature}

\begin{tabular}{|c|c|c|c|c|c|}
\hline Cathode & Anode & Electrolyte & $\begin{array}{l}\text { Voltage } \\
\text { window }\end{array}$ & Electrochemical Performance & Ref. \\
\hline $\begin{array}{l}\text { Activated } \\
\text { graphene }\end{array}$ & Graphite & $\begin{array}{l}1 \mathrm{M} \mathrm{LiPF}_{6} \text { in } \\
\text { EC/DEC } 1: 1 \\
\text { (volume) }\end{array}$ & $2-4 \mathrm{~V}$ & $\begin{array}{l}\text { Specific Capacitance of } 266 \mathrm{Fg}^{-1} \text { at } \\
\text { a current density of } 0.5 \mathrm{Ag}^{-1} \\
\text { Energy density of } 147.8 \mathrm{Whkg}^{-1}\end{array}$ & 47 \\
\hline $\begin{array}{l}\text { Trigol-Reduced } \\
\text { Graphene Oxide }\end{array}$ & LTO & $\begin{array}{l}1 \mathrm{M} \mathrm{LiPF}_{6} \text { in } \\
\text { EC/DEC } 1: 1 \\
\text { (volume) }\end{array}$ & $1-3 \mathrm{~V}$ & $\begin{array}{l}\text { Maximal energy density of } 45 \\
\mathrm{Whkg}^{-1}\end{array}$ & 48 \\
\hline Activated carbon & $\mathrm{TiO}_{2} / \mathrm{rGO}$ & $\begin{array}{l}1 \mathrm{M} \mathrm{LiPF}_{6} \text { in } \\
\text { EC/DEC } 1: 1 \\
\text { (volume) }\end{array}$ & $1-3 \mathrm{~V}$ & $\begin{array}{l}\text { Energy density of } 42 \mathrm{Whkg}^{-1} \text { at a } \\
\text { power density of } 0.8 \mathrm{kWkg}^{-1}\end{array}$ & 49 \\
\hline $\begin{array}{l}\mathrm{MnO}_{2} \text { nanorodes } \\
\text { on } \mathrm{rGO}\end{array}$ & $\begin{array}{l}\mathrm{V}_{2} \mathrm{O}_{5} \text { nanowire } \\
\text { on } \mathrm{rGO}\end{array}$ & $\begin{array}{l}1 \mathrm{M} \text { LiTFSI in } \\
\text { dry acetonitrile }\end{array}$ & $0-2 \mathrm{~V}$ & $\begin{array}{l}36.9 \mathrm{Fg}^{-1} \\
\text { Energy density of } 15 \mathrm{Whkg}^{-1} \text { at a } \\
\text { power density of } 0.4365 \mathrm{kWkg}^{-1}\end{array}$ & 50 \\
\hline $\begin{array}{l}\text { Spectracarb fiber } \\
\text { cloth }\end{array}$ & $\begin{array}{l}\mathrm{V}_{2} \mathrm{O}_{5} \text { nanowire } \\
\text { graphene } \\
\text { composite }\end{array}$ & $\begin{array}{l}1 \mathrm{M} \text { LiTFSI in } \\
\text { dry acetonitrile }\end{array}$ & $0-2 \mathrm{~V}$ & $\begin{array}{l}80 \mathrm{Fg}^{-1} \\
\text { Energy density of } 38.8 \mathrm{Whkg}^{-1} \text { at a } \\
\text { power density of } 0.455 \mathrm{kWkg}^{-1}\end{array}$ & 51 \\
\hline $\begin{array}{l}\text { Functionalized } \\
\text { graphene }\end{array}$ & $\begin{array}{l}\text { Modified } \\
\text { graphite }\end{array}$ & $\begin{array}{l}1 \mathrm{M} \mathrm{LiPF}_{6} \text { with } 3 \\
\text { wt } \% \text { VC in } \\
\text { EC/DEC } 1: 1\end{array}$ & $2-4 \mathrm{~V}$ & $\begin{array}{l}\text { Energy density of } 61 \mathrm{Whkg}^{-1} \text { at a } \\
\text { power density of } 1.452 \mathrm{kWkg}^{-1}\end{array}$ & 52 \\
\hline
\end{tabular}




\begin{tabular}{|c|c|c|c|c|c|}
\hline & & (volume) & & & \\
\hline $\mathrm{AC}$ & $\begin{array}{l}\text { Graphene } \\
\text { sheets wrapped } \\
\text { nano- } \mathrm{Li}_{4} \mathrm{Ti}_{5} \mathrm{O}_{12}\end{array}$ & $\begin{array}{l}1 \mathrm{M} \mathrm{LiPF}_{6} / \mathrm{EC} / \\
\text { DMC } \\
\text { (nonaqueous) }\end{array}$ & $\begin{array}{l}1.5-3.0 \\
V\end{array}$ & $\begin{array}{l}29.2 \mathrm{Wh} \mathrm{kg}^{-1} \\
\text { at a power density of } 58.4 \mathrm{~W} \mathrm{~kg}^{-1} \\
1782.7 \mathrm{~W} \mathrm{~kg}^{-1} \\
\text { the specific energy retains } 13.4 \\
\mathrm{Whkg}^{-1}\end{array}$ & 53 \\
\hline $\mathrm{AC}$ & $\begin{array}{l}\text { Carbon coated } \\
\mathrm{Li}_{4} \mathrm{Ti}_{5} \mathrm{O}_{12}\end{array}$ & $\begin{array}{l}1 \mathrm{M} \mathrm{LiPF}_{6} \text { in } \\
\text { propylene } \\
\text { carbonate } \\
\text { (nonaqueous) }\end{array}$ & $\begin{array}{l}1.5- \\
2.5 \mathrm{~V}\end{array}$ & $\begin{array}{l}\sim 30 \mathrm{mAhg}^{-1} \text { at } 0.17 \mathrm{Ag}^{-1} \\
16 \mathrm{Whkg}^{-1} \text { at } 1010 \mathrm{Wkg}^{-1}\end{array}$ & 54 \\
\hline $\mathrm{AC}$ & $\begin{array}{l}\text { Carbon } \\
\text { modified } \\
\mathrm{Li}_{4} \mathrm{Ti}_{5} \mathrm{O}_{12}\end{array}$ & $\begin{array}{l}\text { 1-M LiPF6 in } \\
\text { EC/DMC (1:3 in } \\
\text { volume) }\end{array}$ & $\begin{array}{l}1.5- \\
3.0 \mathrm{~V}\end{array}$ & $\begin{array}{l}{ }_{1}^{83 \mathrm{Fg}^{-1}} \text { at a current rate of } 60 \mathrm{mAg}^{-} \\
16 \mathrm{Whkg}^{-1} \text { at } 440 \mathrm{Wkg}^{-1}\end{array}$ & 55 \\
\hline $\begin{array}{l}\text { Reduced } \\
\text { graphene oxide- } \\
\text { carbon nanotube } \\
\text { composite (rGO- } \\
\text { CNT) }\end{array}$ & $\begin{array}{l}\text { Anatase } \mathrm{TiO}_{2^{-}} \\
\mathrm{Li}_{4} \mathrm{Ti}_{5} \mathrm{O}_{12}\end{array}$ & $\begin{array}{l}1 \mathrm{M} \mathrm{LiPF}_{6} / \mathrm{EC} / \\
\text { DMC } \\
\text { (nonaqueous) }\end{array}$ & $0.05-3 \mathrm{~V}$ & $\begin{array}{l}\sim 32 \mathrm{mAhg}^{-1} \text { at } 0.1 \mathrm{Ag}^{-1} \\
33.35 \mathrm{Whkg}^{-1} \text { at } 83.55 \mathrm{Wkg}^{-1} \\
26.2 \mathrm{Whkg}^{-1} \text { at } 327.5 \mathrm{Wkg}^{-1} \\
15.09 \mathrm{Whkg}^{-1} \text { at } 1207.4 \mathrm{Wkg}^{-1}\end{array}$ & 56 \\
\hline
\end{tabular}

\subsection{Microsupercapacitors}

Miniaturized supercapacitors, also known as microsupercapacitors (MSCs) have gained much attention in recent years. These devices find application in implantable biomedical devices, environmental sensors, microelectromechanical systems (MEMS) and also in some small personal electronics which require the power in microwatts [57]. Quite akin to their macro counterparts, microsupercapacitors can be connected in series or parallel in order to meet the voltage, current and capacity requirements depending upon the given application. In general, for micro-supercapacitors, the total footprint area of the device is in the millimeter or centimeter range. Microsupercapacitors consist of either thin film electrodes with a thickness of less than $10 \mu \mathrm{m}$ or arrays of microelectrodes with micron-scale sizes which can either be $2 \mathrm{D}$ or 3D. For supercapacitors in the "macro" regime, the electrochemical performance is usually 
reported as specific capacitance, energy and power densities, all in gravimetric terms, i.e. per unit mass. Since any physical quantity in gravimetric terms is a direct measure of mass and the mass of the electrode materials is almost negligible for a microsupercapacitor, gravimetric parameters are rendered almost inappropriate for reporting the performance of a microsupercapacitor [58]. And hence, the key to report the performance of a microsupercapacitor accurately is the footprint area and energy and power in terms of areal density [59].

The first generation of micro-supercapacitors followed the planar 2D architecture of conventional supercapacitors, consisting of two electrodes and a separator soaked in an electrolyte. And to date for cost-effective mass production, the 2D design is preferred over other designs. However, owing to the small footprint area of microsupercapacitors, the areal energy density is quite low for the $2 \mathrm{D}$ design. One of the approaches to increase the area of the electrodes is the construction of a platform with electrodes arranged in an "interdigited" fashion. Such a design offers several advantages over the conventional 2D design [60-63], for instance, having the electrodes in the same plane is not only is easy to fabricate, but also helps in achieving smaller distances between the electrodes, thereby improving electron transport and kinetics.

Graphene is a popular candidate for MSC applications given its high specific surface area, excellent mechanical strength and electrical conductivity. However, a critical consideration for using graphene based materials is the restacking of individual graphene sheets during the electrode processing, which hinders the facile accessibility of electrolyte ions to the electrode. In the conventional 2D design, the complete active surface of the graphene sheets is not always accessed. However, it was demonstrated by 
Yoo et al [64], that having graphene electrodes side by side in an in-plane design increases the accessibility of the ions to the entire surface of graphene sheets by creating diffusion channels between the electrodes. The proposed micro-supercapacitor was based on a planar architecture of opposing graphene thin films. The structure comprised graphene flakes connecting along the flake edges, which provided sufficient porosity to maximize the coverage of the electrode surface. The effect of graphene edges resulted in specific capacitances of $80 \mu \mathrm{Fcm}^{-2}$ for the few-layer graphene electrode, while much higher specific capacitances $\left(0.394 \mathrm{mFcm}^{-2}\right)$ were achieved for multilayer $\mathrm{rGO}$ electrodes. It was concluded therefore that the planar geometry provided superior charge mobility and effective utilization of the electrochemical surface area by minimizing the diffusion barriers of electrolyte ions. To further increase the electrolyte ion accessibility to the graphene sheets and prevent restacking, CNTs can also be used as spacers. Beidaghi et al. [65], fabricated $\mathrm{rGO} / \mathrm{CNT}$ composite based microsupercapacitors by combining photolithography lift-off methods with electrostatic spray deposition. The reduction of GO and the fabrication of electrodes were both achieved by deposition of a solution of $\mathrm{GO}$ or $\mathrm{GO} / \mathrm{CNT}$ on a heated substrate. The electrochemical results indicated high accessibility of the electrolyte ions to the electrodes and faster ionic transport for a layered structure of $\mathrm{CNT} / \mathrm{rGO}$. The microsupercapacitor with the electrode composition of $90 \% \mathrm{rGO}$ and $10 \% \mathrm{CNT}$ exhibited a capacitance of $6.1 \mathrm{mFcm}^{-2}$ at a scan rate of 0.01 $\mathrm{Vs}^{-1}$. Even at a very high scan rate of $50 \mathrm{Vs}^{-1}$, the $\mathrm{rGO} / \mathrm{CNT}$ micro-supercapacitor showed a specific capacitance of $2.8 \mathrm{mFcm}^{-2}$. Another example of graphene based interdigited microsupercapacitors is the carpet-based microsupercapacitors based on graphene/CNTs/Ni electrodes reported by Lin et al [66]. The microsupercapacitor showed 
an impedance phase angle of -81.58 at a frequency of $120 \mathrm{~Hz}$, similar to that of commercial aluminum electrolytic capacitors. The microsupercapacitor also delivered an energy density of $2.42 \mathrm{mWhcm}^{-3}$ in ionic liquid and a maximum power density of 115 $\mathrm{Wcm}^{-3}$ in aqueous electrolyte at a scan rate of $400 \mathrm{Vs}^{-1}$. The excellent performance of this micro-supercapacitor was attributed to the seamless $\mathrm{CNT} /$ graphene junctions at the interface of the differing carbon allotropic forms. Another important factor that affects the performance of micro-supercapacitors is the thickness of the electrode. Generally, as the thickness of the electrode increases, the increased mass loading of the electrode material increases the electrode resistance which results in decreased gravimetric capacitance. Although thin electrodes show less areal capacitance due to the small mass loading, their very high rate capability and frequency response outweigh the relatively lower specific capacitance. Liu et al [67] demonstrated a microsupercapacitor based on very thin films of graphene quantum dots (GQD) .The device was fabricated by electrophoretic deposition of $365 \mathrm{~nm}$ thick films of GQD on patterned $\mathrm{Au}$ microelectrodes. The device showed capacitive behavior even at high CV scans rates and very small $\mathrm{RC}$ time constants of $103.6 \mu$ s in aqueous and $53.8 \mu$ s in ionic electrolytes. The remarkable performance was attributed to the small thickness of electrodes along with the device architecture and good electrical conductivity of GQDs along with the presence of abundant edge defects. However, this high rate performance came at the cost of specific capacitance and energy density, as device capacitance was $534.7 \mu \mathrm{Fcm}^{-2}$ in aqueous electrolyte, which is quite low as compared to other prototypes reported in the literature. 
Another consideration is for designing MSCs is the limited footprint area to construct the device. This shortcoming can be addressed by using three-dimensional architectures. The carbon microelectromechanical systems (C-MEMS) technique, also known as carbon-MEMS is a microfabrication procedure that essentially involves the pyrolysis of a patterned photoresist into carbon structures [68-71]. C-MEMS offers the feasibility of creating 3D micro-pillars, which offsets the limitation of the small footprint area required for miniaturized systems. The idea of using 3D C-MEMS-based microstructures as current collectors for the integration of other capacitive materials was first demonstrated by Chen et al. [72], where they grew carbon nanotubes (CNTs) on the surface of the CMEMS structures using spray deposition. The CNT/C-MEMS structures were reported to exhibit specific capacitance as high as 20 times that of the bare C-MEMS structures. Beidaghi et al [73] reported electrochemically activated 3D C-MEMS structures for MSC applications; the electrochemically activated C-MEMS capacitors exhibited a high geometric specific capacitance of $75 \mathrm{mFcm}^{-2}$. The superior electrochemical performance as opposed to the non-activated C-MEMS samples was ascribed to i) the introduction of oxygen-containing functional groups from the activation process, which not only enhances the wettability of the electrode surface but also adds additional pseudocapacitance; ii) the increase in the surface area by the electrochemical treatment, since the treatment oxidizes the carbon surface and opens up closed pores; finally another possible reason for the performance enhancement could be; iii) the irreversible intercalation of electrolyte ions during the polarization process; ions are intercalated into the carbon structures during the first polarization cycle and provide larger capacitance for the successive cycles [73]. Other reports documenting the use of C-MEMS based 
platforms for MSC applications include manganese oxide $\left(\mathrm{MnO}_{\mathrm{x}}\right)$ integrated carbon micro-pillars [74], and polypyrrole (PPy) integrated C-MEMS structures [75]. In a symmetric two electrode setup, the $\mathrm{MnO}_{\mathrm{x}}$ integrated C-MEMS micro-electrodes exhibited a cell capacitance of $0.55 \mathrm{Fcm}^{-2}$ at $0.05 \mathrm{mAcm}^{-2}$. Furthermore, the $\mathrm{MnO}_{\mathrm{x}} / \mathrm{C}$ MEMS electrodes exhibited a maximal stack power density of $28.3 \mathrm{mWcm}^{-3}$ and a maximal stack energy density of $0.51 \mathrm{mWhcm}^{-3}$. The PPy integrated C-MEMS microsupercapacitors, on the other hand, exhibited a specific capacitance of 162.07 $\pm 12.40 \mathrm{mF} \mathrm{cm}^{-2}$ at $20 \mathrm{mV} \mathrm{s}^{-1}$, in addition to a power density of $1.62 \pm 0.12 \mathrm{~mW} \mathrm{~cm}^{-2}$ computed for the same scan rate.

\subsection{References}

1. Becker, H.I., Gen Electric, 1957. Low voltage electrolytic capacitor. U.S. Patent $2,800,616$.

2. Rightmire, R.A., Standard Oil Co, 1966. Electrical energy storage apparatus. U.S. Patent 3,288,641.

3. Schindall, J., 2007. The charge of the ultracapacitors. IEEE Spectrum, 44(11), pp.4246.

4. https://www.transparencymarketresearch.com/supercapacitor-market.html

5. Amatucci, G.G., Badway, F., Du Pasquier, A. and Zheng, T., 2001. An asymmetric hybrid nonaqueous energy storage cell. Journal of the Electrochemical Society, 148(8), pp.A930-A939.

6. James, S.R., 1988. Introduction to the principles of ceramic processing. Editorial Willy Interscience, USA.

7. Agrawal, R., Chen, C., Hao, Y., Song, Y. and Wang, C., 2015. Graphene for supercapacitors. Graphene-Based Energy Devices.

8. Conway BE (1999) Electrochemical Supercapacitors: Scientific Fundamentals and Technological Applications. Kluwer Academic/Plenum Publishes, New York. 
9. Beguin F, Frackowiak E (eds) (2013) Supercapacitors: Materials, Systems, and Applications. Wiley-VCH Verlag GmbH \& Co. KGaA

10. Hu, L., Tu, J., Jiao, S., Hou, J., Zhu, H. and Fray, D.J., 2012. In situ electrochemical polymerization of a nanorod-PANI-Graphene composite in a reverse micelle electrolyte and its application in a supercapacitor. Physical Chemistry Chemical Physics, 14(45), pp.15652-15656.

11. Wang, D.W., Li, F., Zhao, J., Ren, W., Chen, Z.G., Tan, J., Wu, Z.S., Gentle, I., Lu, G.Q. and Cheng, H.M., 2009. Fabrication of graphene/polyaniline composite paper via in situ anodic electropolymerization for high-performance flexible electrode. ACS nano, 3(7), pp.1745-1752.

12. Feng, X.M., Li, R.M., Ma, Y.W., Chen, R.F., Shi, N.E., Fan, Q.L. and Huang, W., 2011. One-step electrochemical synthesis of graphene/polyaniline composite film and its applications. Advanced Functional Materials, 21(15), pp.2989-2996.

13. Li, J., Xie, H., Li, Y., Liu, J. and Li, Z., 2011. Electrochemical properties of graphene nanosheets/polyaniline nanofibers composites as electrode for supercapacitors. Journal of Power Sources, 196(24), pp.10775-10781.

14. Xu, J., Wang, K., Zu, S.Z., Han, B.H. and Wei, Z., 2010. Hierarchical nanocomposites of polyaniline nanowire arrays on graphene oxide sheets with synergistic effect for energy storage. ACS nano, 4(9), pp.5019-5026.

15. Xu, G., Wang, N., Wei, J., Lv, L., Zhang, J., Chen, Z. and Xu, Q., 2012. Preparation of graphene oxide/polyaniline nanocomposite with assistance of supercritical carbon dioxide for supercapacitor electrodes. Industrial \& Engineering Chemistry Research, 51(44), pp.14390-14398.

16. Kumar NA, Choi HJ, Shin YR, et al (2012) Polyaniline-Grafted Reduced Graphene Oxide for Efficient Electrochemical Supercapacitors. ACS Nano 6(2):1715-1723. doi: $10.1021 / \mathrm{nn} 204688 \mathrm{c}$

17. Zhang DC, Zhang X, Chen Y, et al (2011) Enhanced capacitance and rate capability of graphene/polypyrrole composite as electrode material for supercapacitors. J Power Sources 196:5990-5996. doi:10.1016/j.jpowsour.2011.02.090

18. Biswas S, Drzal LT (2010) Multilayered Nanoarchitecture of Graphene Nanosheets and Polypyrrole Nanowires for High Performance Supercapacitor Electrodes. Chem Mater 22:5667-5671. doi:10.1021/cm101132g

19. Li J, Xie HQ (2012) Synthesis of graphene oxide/polypyrrole nanowire composites for supercapacitors. Mater Lett 78:106-109. doi:10.1016/j.matlet.2012.03.013 
20. Pham HD, Pham VH, Oh ES, et al (2012) Synthesis of polypyrrole-reduced graphene oxide composites by in-situ photopolymerization and its application as a supercapacitor electrode. Korean J Chem Eng 29(1):125-129. doi:10.1007/s11814011-0145-y

21. Chang HH, Chang CK, Tsai YC, Liao CS (2012) Electrochemically synthesized graphene/polypyrrole composites and their use in supercapacitor. Carbon 50:2331 2336. doi:10.1016/j.carbon.2012.01.056

22. Zhao YQ, Zhao DD, Tang PY et al (2012) MnO2/graphene/nickel foam composite as high performance supercapacitor electrode via a facile electrochemical deposition strategy. Materials Letters 76: 127-130

23. Wang W, Guo S, Bozhilov KN et al (2013) Intertwined Nanocarbon and Manganese Oxide Hybrid Foam for High-Energy Supercapacitors. Small, 9: 3714-3721. doi: $10.1002 / \mathrm{smll} .201300326$

24. Ge J, Yao HB, Hu W et al (2013) Facile dip coating processed graphene/MnO2 nanostructured sponges as high performance supercapacitor electrodes. Nano Energy 2: 505-513

25. Yang S, Song X, Zhang P et al (2013) Facile Synthesis of Nitrogen-Doped Graphene-Ultrathin MnO2 Sheet Composites and Their Electrochemical Performances. ACS Appl. Mater. Interfaces 5: 3317-3322

26. Wang B, Park J, Wang C et al (2010) Mn3O4 nanoparticles embedded into graphene nanosheets: Preparation, characterization, and electrochemical properties for supercapacitors. Electrochimica Acta 55: 6812-6817

27. Wu ZS, Wang DW, Ren W et al (2010), Anchoring Hydrous $\mathrm{RuO}_{2}$ on Graphene Sheets for High-Performance Electrochemical Capacitors. Adv. Funct. Mater., 20: 3595-3602. doi: 10.1002/adfm.201001054

28. Wang Q, Jiao L, Du Hongmei D et al (2014) Fe3O4 nanoparticles grown on graphene as advanced electrode materials for supercapacitors. J Power Sources 245: 101-106. DOI: 10.1016/j.jpowsour.2013.06.035

29. Li Z, Wang J, Niu L et al (2014) Rapid synthesis of graphene/cobalt hydroxide composite with enhanced electrochemical performance for supercapacitors. $J$ of Power Sources 245: 224-231. DOI: 10.1016/j.jpowsour.2013.06.121 
30. Li Q, Hu X, Yang Q et al (2014) Electrocapacitive performance of graphene/Co3O4 hybrid material prepared by a nanosheet assembly route. Electrochimica Acta 119: 184-191. DOI: 10.1016/j.electacta.2013.12.066

31. Wang J, Gao Z, Li Z et al (2011) Green synthesis of graphene nanosheets/ZnO composites and electrochemical properties. Journal of Solid State Chemistry 184: $1421-1427$

32. Long, J.W., Bélanger, D., Brousse, T., Sugimoto, W., Sassin, M.B. and Crosnier, O., 2011. Asymmetric electrochemical capacitors-Stretching the limits of aqueous electrolytes. MRS Bulletin, 36(7), pp.513-522.

33. Wu ZS, Ren W, Wang DW et al (2010) High-Energy $\mathrm{MnO}_{2}$ Nanowire/Graphene and Graphene Asymmetric Electrochemical Capacitors. ACS Nano 4(10): 5835-5842. doi:10.1021/nn101754k

34. Cheng Q, Tang J, Jun Ma et al (2011) Graphene and nanostructured $\mathrm{MnO}_{2}$ composite $\begin{array}{llllll}\text { electrodes for supercapacitors. } & \text { Carbon 49: } 2917 & -2925 .\end{array}$ doi:10.1016/j.carbon.2011.02.068

35. Huang M, Zhang Y, Li F et al (2014) Self-Assembly of Mesoporous Nanotubes Assembled from Interwoven Ultrathin Birnessite-type $\mathrm{MnO}_{2}$ Nanosheets for Asymmetric Supercapacitors. SCIENTIFIC REPORTS 4: 3878. doi: $10.1038 /$ srep03878

36. Sumboja A , Foo CY, Wang X et al (2013) Large Areal Mass, Flexible and FreeStanding Reduced Graphene Oxide/Manganese Dioxide Paper for Asymmetric Supercapacitor Device. Adv. Mater. 25: 2809-2815. doi:10.1002/adma.201205064

37. Hung PJ, Chang KH, Lee YF et al (2010) Ideal asymmetric supercapacitors consisting of polyaniline nanofibers and graphene nanosheets with proper complementary potential windows. Electrochimica Acta 55: 6015-6021. doi:10.1016/j.electacta.2010.05.058

38. Yu G, Hu L, Vosgueritchian $\mathrm{M}$ et al (2011) Solution-Processed Graphene/ $\mathrm{MnO}_{2}$ Nanostructured Textiles for High-Performance Electrochemical Capacitors. Nano Lett. 11: 2905-2911. doi:10.1021/nl2013828

39. Fan Z, Yan J, Wei $T$ et al (2011) Asymmetric Supercapacitors Based on Graphene/ $\mathrm{MnO}_{2}$ and Activated Carbon Nanofiber Electrodes with High Power and Energy Density. Adv. Funct. Mater. 21: 2366-2375. doi:10.1002/adfm.201100058

40. Gao H, Xiao F, Ching CB et al (2012) High-Performance Asymmetric Supercapacitor Based on Graphene Hydrogel and Nanostructured $\mathrm{MnO}_{2}$. ACS Appl. Mater Interfaces 4: 2801-2810. doi:10.1021/am300455d 
41. Long C, Wei T, Yan J et al (2013) Supercapacitors Based on Graphene-Supported Iron Nanosheets as Negative Electrode Materials. ACS Nano 7(12): 11325-11332. doi:10.1021/nn405192s

42. Jafta CJ, Nkosi F, Roux LL et al (2013) Manganese oxide/graphene oxide composites for high-energy aqueous asymmetric electrochemical capacitors. Electrochimica Acta 110: 228-233. doi:10.1016/j.electacta.2013.06.096

43. Shi S, Xu C, Yang C et al (2013) Flexible asymmetric supercapacitors based on ultrathin two-dimensional nanosheets with outstanding electrochemical performance and aesthetic property. SCIENTIFIC REPORTS 3: 2598 doi:10.1038/srep02598

44. Amatucci, G.G., Badway, F., Du Pasquier, A. and Zheng, T., 2001. An asymmetric hybrid nonaqueous energy storage cell. Journal of the Electrochemical Society, 148(8), pp.A930-A939.

45. Cericola, D. and Kötz, R., 2012. Hybridization of rechargeable batteries and electrochemical capacitors: Principles and limits. Electrochimica Acta, 72, pp.1-17.

46. Simon, P., Gogotsi, Y. and Dunn, B., 2014. Where do batteries end and supercapacitors begin?Science, 343(6176), pp.1210-1211.

47. Stoller MD, Murali S, Quarles N et al (2012) Activated graphene as a cathode material for Li-ion hybrid supercapacitors. Phys Chem Chem Phys 14: 3388-3391. doi:10.1039/c2cp00017b

48. Aravindan V, Mhamane D, Ling WC et al (2013) Nonaqueous Lithium-Ion Capacitors with High Energy Densities using Trigol-Reduced Graphene Oxide Nanosheets as Cathode-Active Material. ChemSusChem 6: 2240 - 2244. doi:10.1002/cssc.201300465

49. Kim H , Cho MY, Kim MH et al (2013) A Novel High-Energy Hybrid Supercapacitor with an Anatase $\mathrm{TiO}_{2}$-Reduced Graphene Oxide Anode and an Activated Carbon Cathode. Adv Energy Mater 3: 1500-1506. doi:10.1002/aenm.201300467

50. Perera SD, Rudolph M, Mariano RG et al (2013) Manganese oxide nanorodgraphene/vanadium oxide nanowire-graphene binder-freepaper electrodes for metaloxide hybrid supercapacitors. Nano Energy 2: 966-975. doi:10.1016/j.nanoen.2013.03.018

51. Perera SD, Liyanage AD, Nijem $\mathrm{N}$ et al. (2013) Vanadium oxide nanowire e Graphene binder free nanocomposites paper electrodes for supercapacitors: A facile 
green approach. Journal of Power Sources 230: 130-137. doi:10.1016/j.jpowsour.2012.11.118

52. Lee JH, Shin WH, Lim SY et al (2013) Modified graphite and graphene electrodes for high-performance lithium ion hybrid capacitors. Mater Renew Sustain Energy 2: 22. doi:10.1007/s40243-014-0022-9

53. Yuan, T., Li, W.T., Zhang, W., He, Y.S., Zhang, C., Liao, X.Z. and Ma, Z.F., 2014. One-pot spray-dried graphene sheets-encapsulated nano-Li4Ti5O12 microspheres for a hybrid batcap system. Industrial \& Engineering Chemistry Research, 53(27), pp.10849-10857.

54. Jung, H.G., Venugopal, N., Scrosati, B. and Sun, Y.K., 2013. A high energy and power density hybrid supercapacitor based on an advanced carbon-coated Li $4 \mathrm{Ti} 5 \mathrm{O}$ 12 electrode. Journal of Power Sources, 221, pp.266-271.

55. Ni, J., Yang, L., Wang, H. and Gao, L., 2012. A high-performance hybrid supercapacitor with Li4Ti5O12-C nano-composite prepared by in situ and ex situ carbon modification. Journal of Solid State Electrochemistry, 16(8), pp.2791-2796.

56. Agrawal, R., Chen, C., Dages, S. and Wang, C., 2017. A High Energy 3V LithiumIon Capacitor Synthesized via Electrostatic Spray Deposition. Adv. Mater. Lett, 8, pp.783-790.

57. Beidaghi, M.; Gogotsi, Y. Capacitive energy storage in micro-scale devices: Recent advances in design and fabrication of micro-supercapacitors. Energy Environ. Sci. 2014, 7, 867-884, doi:10.1039/C3EE43526A

58. Gogotsi Y and Simon P (2011) True performance metrics in electrochemical energy storage. Science 334:917-918. doi: 10.1126/science.1213003

59. Arthur TS, Bates DJ, Dunn B (2011) Three-dimensional electrodes and battery architectures. MRS Bull 36:523-531. doi: 10.1557/mrs.2011.156

60. Sun W and Chen XY (2009) Fabrication and tests of a novel three dimensional microsupercapacitor. Microelectron Eng 86: 1307-1310. doi: 10.1016/j.mee.2008.12.010.

61. Sun W, Zheng RL, Chen XY (2010) Symmetric redox supercapacitor based on microfabrication with three-dimensional polypyrrole electrodes. J Power Sources 195:7120-7125. doi: 10.1016/j.jpowsour.2010.05.012

62. Sung JH, Kim S, Lee KH (2004) Fabrication of all-solid-state electrochemical microcapacitors. J Power Sources 133:312-319. doi: 10.1016/j.jpowsour.2004.02.003. 
63. Chmiola J, Largeot C, Taberna PL et al. Monolithic Carbide-derived carbon films for micro-supercapacitors (2010) Science 328:480-483. doi: 10.1126/science.1184126.

64. Yoo JJ, Balakrishnan K, Huang JS et al. (2011) Ultrathin planar graphene supercapacitors. Nano Lett 11:1423-1427. doi: 10.1021/n1200225j.

65. Beidaghi M and Wang CL (2012) Micro-supercapacitors based on interdigital electrodes of reduced graphene oxide and carbon nanotube composites with ultrahigh power handling performance. Adv Funct Mater 22:4501-4510. doi: 10.1002/adfm.201201292.

66. Lin J, Zhang C, Yan Z et al. (2013) 3-dimensional graphene carbon nanotube carpetbased microsupercapacitors with high electrochemical performance. Nano Lett 13:7278. doi: 10.1021/nl3034976.

67. Liu WW, Feng YQ, Yan XB et al. (2013) Superior micro-supercapacitors based on graphene quantum dots. Adv Func Mater 23:4111-4122. doi: 10.1002/adfm.201203771.

68. Wang, C., Taherabadi, L., Jia, G., Madou, M., Yeh, Y. and Dunn, B., 2004. C-MEMS for the manufacture of 3D microbatteries. Electrochemical and Solid-State Letters, 7(11), pp.A435-A438.

69. Wang, C., Jia, G., Taherabadi, L.H. and Madou, M.J., 2005. A novel method for the fabrication of high-aspect ratio C-MEMS structures. Journal of microelectromechanical systems, 14(2), pp.348-358.

70. Song, Y., Agrawal, R., Hao, Y., Chen, C. and Wang, C., 2014. C-MEMS based microsupercapacitors and microsensors. ECS Transactions, 61(7), pp.55-64.

71. Agrawal, R., Beidaghi, M., Chen, W. and Wang, C., 2015, May. Carbon microelectromechanical systems (C-MEMS) based microsupercapacitors. In Proceedings of SPIE. Society of Photo-optical Instrumentation Engineers

72. Chen, W.; Beidaghi, M.; Penmatsa, V.; Bechtold, K.; Kumari, L.; Li, W.Z.; Wang, C. Integration of Carbon Nanotubes to C-MEMS for On-chip supercapacitors. IEEE Trans. Nanotechnol. 2010, 9, 734-740, doi:10.1109/TNANO.2010.2049500.

73. Beidaghi, M.; Chen, W.; Wang, C. Electrochemically activated carbon microelectrode arrays for electrochemical micro-capacitors. J. Power Sources 2011, 196, 2403-2409, doi:10.1016/j.jpowsour.2010.09.050.

74. Agrawal, R., Adelowo, E., Baboukani, A.R., Villegas, M.F., Henriques, A. and Wang, C., 2017. Electrostatic Spray Deposition-Based Manganese Oxide Films- 
From Pseudocapacitive Charge Storage Materials to Three-Dimensional Microelectrode Integrands. Nanomaterials, 7(8), p.198.

75. Beidaghi, M.; Wang, C. Micro-supercapacitors based on three dimensional interdigital polypyrrole/C-MEMS electrodes. Electrochim. Acta 2011, 56, 95089514, doi:10.1016/j.electacta.2011.08.054. 


\section{METHODOLOGY}

\subsection{Introduction}

This section provides the details of the methodology adopted for this thesis - for both the scale-up capacitors as well as the miniaturized versions. For the scale-up systems designed and evaluated in this dissertation, two techniques were used to design the electrodes - i) electrostatic spray deposition (ESD) and ii) slurry casting. The former method provides the benefit of creating thin-films of different materials without the use of a binder, whereas the latter typically requires a binder and is pertinent for creating bulk electrodes with more massive active material loading. For the miniaturized systems, two designs were explored - i) three-dimensional carbon micro-pillar arrays patterned on carbon current collector; and ii) interdigitated gold micro-current collectors. The 3D carbon micro-pillar arrays were created using carbon microelectromechanical systems (C-MEMS), whereas the interdigitated gold current collectors were created using traditional photolithography and lift-off methods. In order to incorporate the active material onto the carbon micro-platforms, ESD was used, whereas electrophoretic and electrochemical deposition methods were used to selectively deposit active material films onto the interdigitated current collectors.

\subsection{Electrostatic Spray Deposition}

Electrostatic Spray Deposition, abbreviated as ESD, was first developed by Schoonman and coworkers at Delft University of Technology [1]. ESD is a low energy electrohydrodynamic spraying technique in which a precursor solution disintegrates into an aerosol spray upon the application of a high voltage between a metal nozzle and a substrate [2-5]. The desired precursor solution is fed through a syringe pump via a nozzle 
connected to a high potential source, whereas the substrate is grounded [2] (Schematic shown in Figure 3.1). The aerosol formed by the charged droplets is attracted to the heated substrate leading to simultaneous solvent evaporation and chemical reactions, leaving behind a thin film $[4,5]$. The advantages of ESD over other thin film production methods include the feasibility of operation in ambient atmosphere at desired temperatures without the need of vacuum, which makes it both cost-effective and facile in terms of operation [3]. Both polycrystalline phases as well as composite materials can be synthesized via ESD by adjusting parameters such as the applied potential, substrate temperature, substrate-nozzle distance, nozzle geometry, precursor solution flow rate and composition [4-6]. One of the very attractive features of ESD is the ability to tailor the morphology of the film by fine tuning the deposition parameters. A host of morphologies have been reported using ESD including dense, fractal, reticular, sponge-like, and porous $[4,5]$. The feasibility of creating high-surface area porous and homogeneous synthetic films makes ESD especially suitable for energy-storage applications. Several works have documented the use of ESD based films for energy storage systems including lithium-ion batteries, electrochemical capacitors, and miniaturized electrochemical energy storage systems [4, 5, 7-9]. 


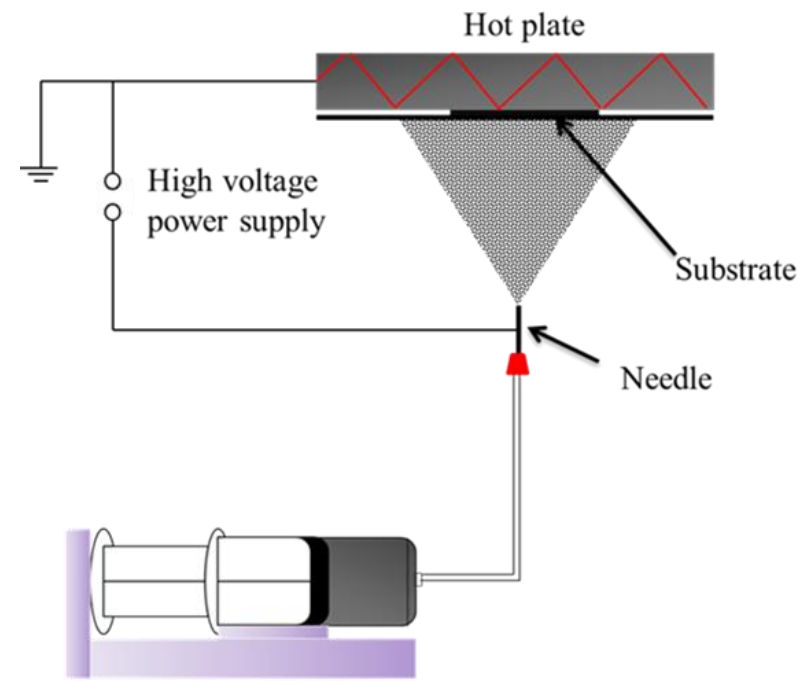

Syringe pump

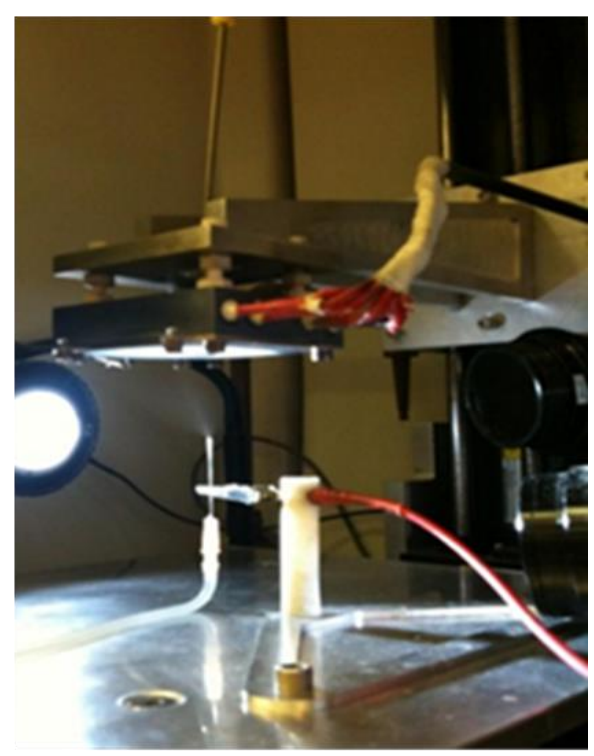

Figure 3.1: Schematic illustration of the ESD process (left); digital photograph of ESD lab setup.

\subsection{Carbon Microelectromechanical Systems (C-MEMS)}

Carbon microelectromechanical systems, also referred to as carbon-MEMS or CMEMS is a term used for a set of fabrication methods used to convert a patterned photosensitive polymers to glassy carbonaceous using pyrolysis [9-14]. The typical CMEMS fabrication process has been illustrated in Figure 3.2a. For the studies carried out for this dissertation, the C-MEMS-based 3D micro-pillars were prepared by a two-step photolithography process followed by a pyrolysis step. Detailed experimental procedure can be found in Chapter 5. Figures 3.2b and 3.2c illustrate typical SEM image of the CMEMS based micro-pillar arrays and a digital image of the micro-device, respectively. 
a)

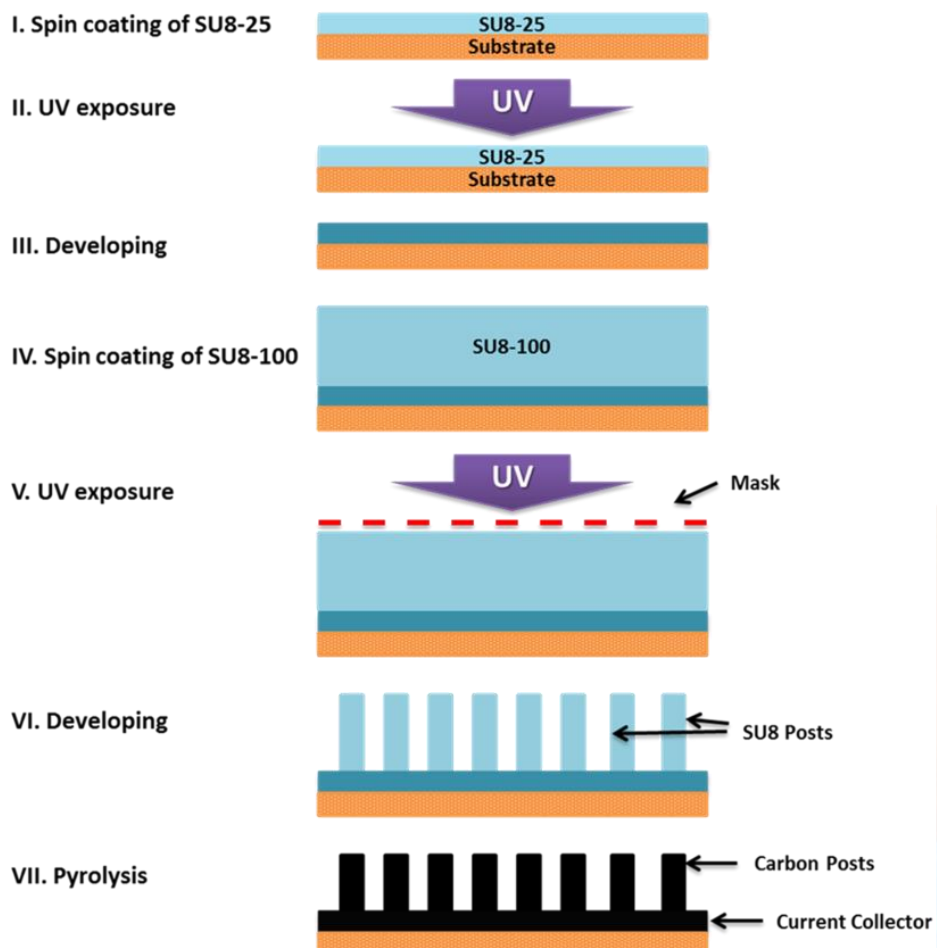

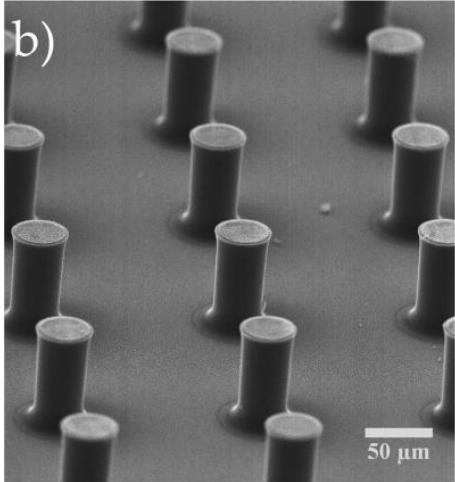

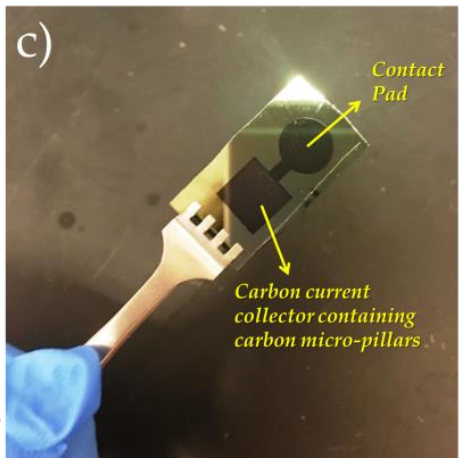

Figure 3.2: Schematic illustration of the C-MEMS process (Adapted from [14]); b) SEM micrograph of carbon micro-pillar arrays; c) Photograph of a device containing micropillars on carbon current collectors and contact pads.

\subsection{Gold microelectrode fabrication}

For this dissertation, in order to construct the interdigital gold micro-current collectors, traditional photolithography and lift-off methods were used. A schematic illustration has been shown in Figure 3.4. First, AZ 5214 was spun-coated on a 4" $\mathrm{Si} / \mathrm{SiO}_{2}$ (100) wafer at a speed of $5000 \mathrm{rpm}$ for 30 seconds. After the spin coating process, a soft bake was carried out for 1 minute at a temperature of $110^{\circ} \mathrm{C}$ on a leveled hot plate. After the bake process, ultraviolet exposure was carried out using an OAI mask aligner with a $\mathrm{UV}$ dose of $230 \mathrm{mJcm}^{-2}$. Following the expose step, developing was carried out using AZ 300 MIF for $\sim 45$ seconds. After the developing a descum step was carried out using an 
$\mathrm{O}_{2}$ plasma at a flow rate of $60 \mathrm{sccm}$ and a pressure of $400 \mathrm{mTorr}$ for 30 seconds using an reactive ion etching (RIE). Following the patterning of the photoresist, metallization process with $\mathrm{Ti} / \mathrm{Au}(20 / 300 \mathrm{~nm})$ was carried out using e-beam evaporation using a CHA evaporator. After the metallization process, lift-off was carried out using acetone and mechanical agitation followed by isopropyl alcohol rinsing and $\mathrm{N}_{2}$ drying. Finally, a 30s $\mathrm{O}_{2}$ plasma treatment at 400 mTorr was carried out in order to functionalize the gold electrodes for better active material adhesion.

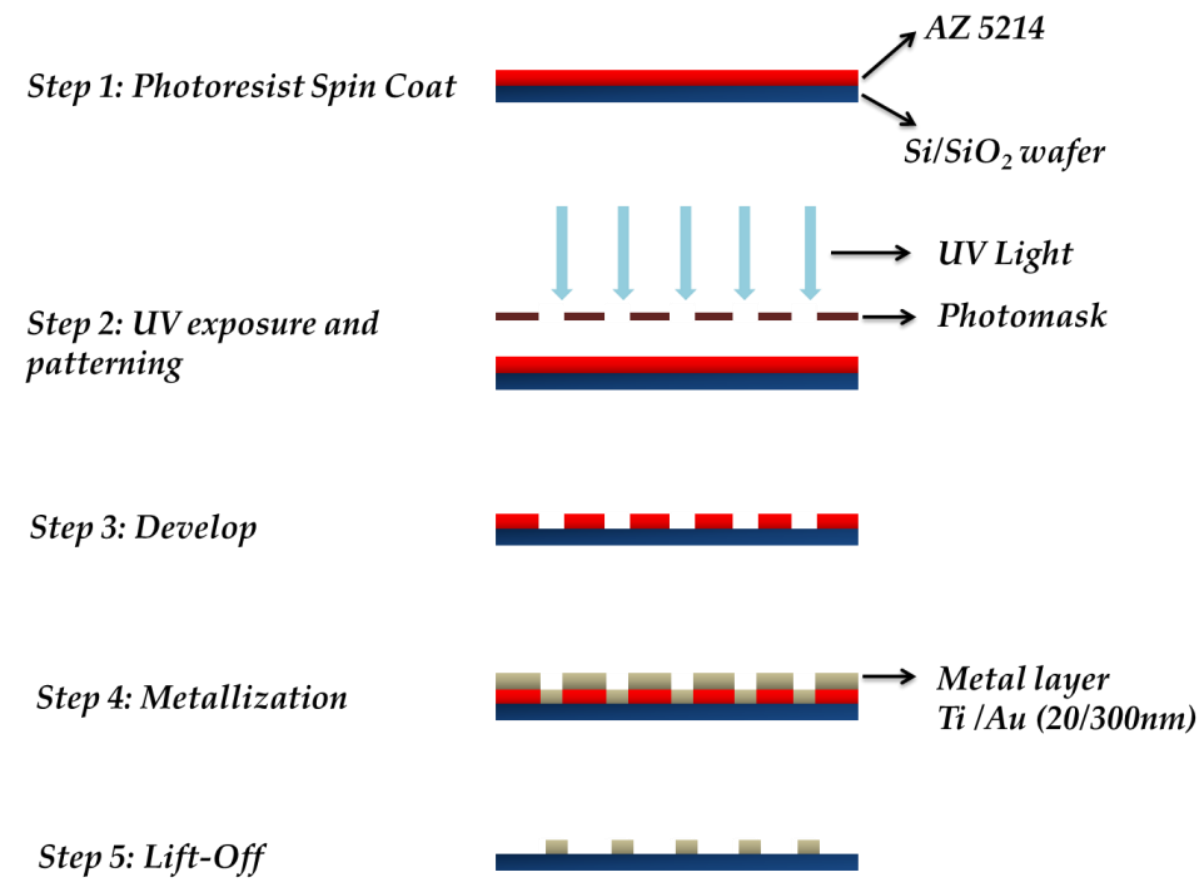

Figure 3.3: Schematic illustration of the gold microelectrode fabrication.

\subsection{Electrophoretic deposition}

In order to incorporate reduced graphene oxide (rGO) onto gold microelectrodes, electrophoretic deposition (EPD) was used for this dissertation. EPD is an attractive thinfilm synthesis technique, in which essentially charged particles move under the effect of 
an electric field in liquid media. The ease of tailoring the processing parameters in order to adjust the chemical and morphological conditions of the deposit is what makes EPD so versatile. EPD has been widely used in order to synthesize graphene-related materials. In its simplest form, the EPD process requires the application of an electric potential between two electrodes in a particle-suspension. The eventual collection of the particles moving under the influence of an electric field, results in the formation of a deposit. The advantages of EPD include cost effectiveness, simplicity, uniformity of the deposit, controllable deposition, predictability of deposition kinetics, and the possibility of sequential and co-deposition of different particles [15]. However, the limitations of EPD include i) the need for a stable suspension with sufficient particle surface charge; ii) the need for using electrically conducting substrates; iii) the possibility of side reactions; and iv) limited film thicknesses. Figure 3.6a illustrates a schematic description of the EPD process utilized for the purpose of this dissertation. The working electrode was the bare interdigitated gold micro-current collector whereas the counter was a platinum foil and the two electrodes were connected to dc power supply. The suspension comprised graphene oxide (GO) powder in a solution containing $\mathrm{C}_{2} \mathrm{H}_{5} \mathrm{OH}$ and deionized water $(90: 10 \mathrm{v}: \mathrm{v})$. Figure $3.6 \mathrm{~b}$ shows the microstructure of the EPD based rGO film. Further characterization details on the films are explained in Chapter 7. 

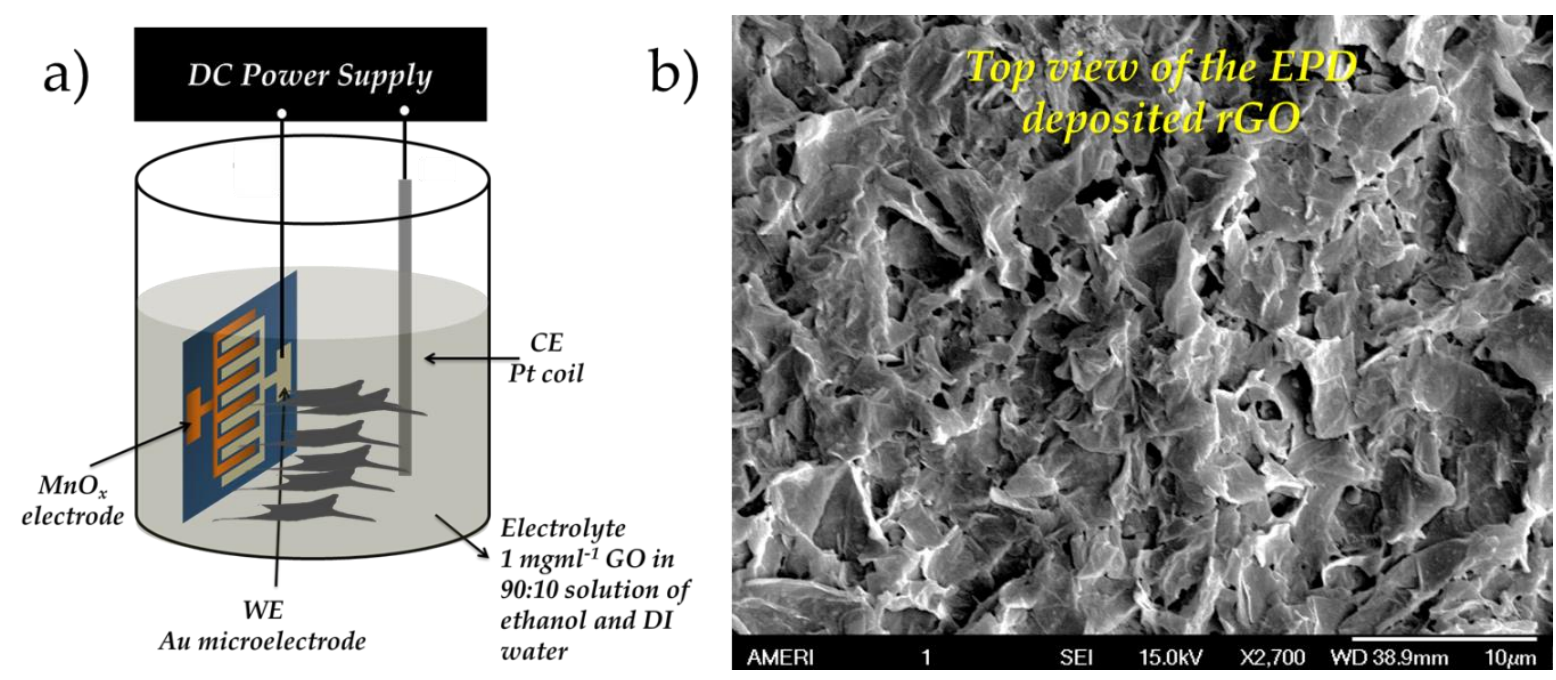

Figure 3.4: a) Schematic illustration of the EPD setup used to deposit rGO films for this dissertation; b) top view of the EPD based rGO films

\subsection{Electrochemical deposition of manganese oxide}

Electrochemical deposition is a popular technique to deposit thin films of metal oxides without the use of binders. The relative simplicity, the low energy consumption, and the ability to control morphology by fine tuning the deposition parameters make electrodeposition very appealing to synthesize binder-free thin films. Different modes of electrodeposition include: i) potentiodynamic (cyclic voltammetry $(C V)$ ); ii) potentiostatic (chronoamperometry $(C A)$ ) and iii) galvanostatic (chronopotentiometry $(C P))$ [16]. For the purpose of this dissertation, anodic chronopotentiometry was applied. Figure 3.7a and Figure $3.7 \mathrm{~b}$ illustrate the schematic setup used for the synthesis of the manganese oxide $\left(\mathrm{MnO}_{\mathrm{x}}\right)$ films, and the resultant microstructure, respectively. The microstructure comprised manganese oxide nanorods; detailed material investigation is presented in Chapter 7. 
a)

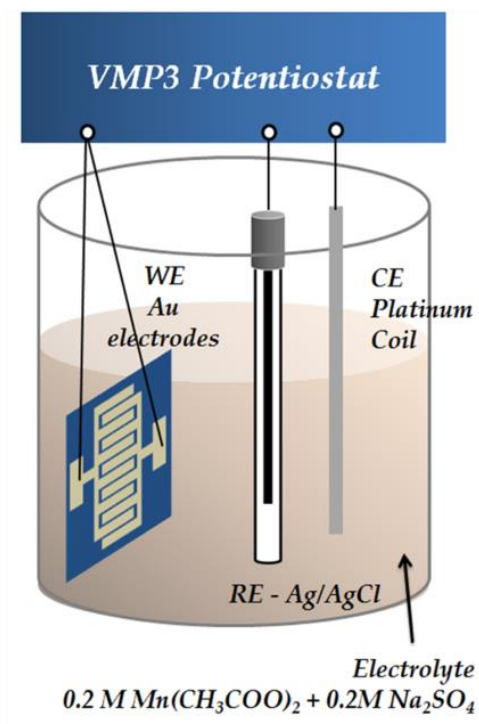

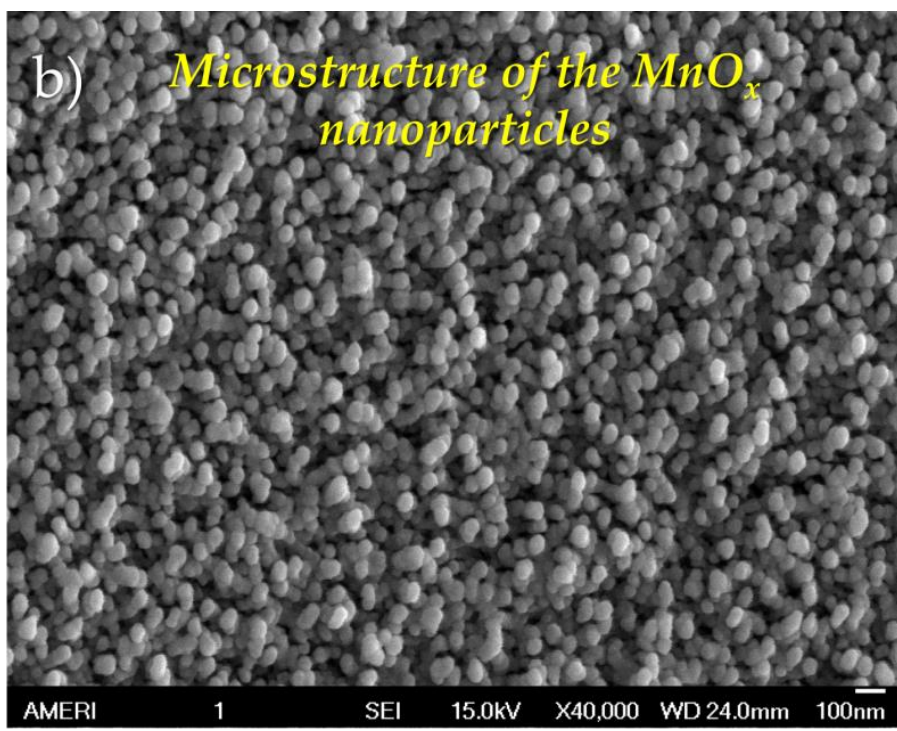

Figure 3.5: a) Schematic illustration of the electrochemical deposition setup used to deposit $\mathrm{MnO}_{\mathrm{x}}$ films; b) microstructure of the $\mathrm{MnO}_{\mathrm{x}}$ nanoparticles

\subsection{Material Characterization}

The techniques used for characterization of the materials used in this dissertation are described in this section:

\subsubsection{X-Ray Diffraction (XRD)}

XRD is an analytical technique that can provide information about the crystallinity and crystallographic orientations $(\boldsymbol{h k l})$ of a material. Bragg's law $(n \lambda=2 d \sin \theta)$ describes the relationship between interplanar spacing $\mathrm{d}$, scattering angle $\theta$ and wavelength $\lambda$. All the XRD measurements of the materials used in this dissertation were recorded using a Siemens D-5000 diffractometer with $\mathrm{Cu}$ Ka radiation $(\lambda=0.154056 \mathrm{~nm})$. The patterns were identified using the "Joint Committee on Powder Diffraction Standards - International Center for Diffraction Data (JCPDS-ICDD)" database. 


\subsubsection{Scanning Electron Microscopy (SEM)}

In order to investigate the microstructure of the materials synthesized, a field emission-scanning electron microscope (JEOL 6335FE-SEM, Peabody, MA, USA) was used; the accelerating voltages for imaging were generally kept between $10-20 \mathrm{kV}$ for typical working distances between 15-39 mm.

\subsubsection{Transmission Electron Microscopy (TEM)}

The TEM images were taken by using a Philips CM-200 FEG TEM operating at 200 $\mathrm{kV}$. Selected area electron diffraction (SAED) analyses were performed in order to study the sample crystallinity.

\subsubsection{Fourier Transform Infrared (FT-IR) Spectroscopy}

Spectroscopic studies on the samples were carried out using a JASCO FTIR-4100 equipped with an attenuated total reflectance (ATR) accessory between wavenumbers of 4000 and $500 \mathrm{~cm}^{-1}$ at room temperature.

\subsection{Electrode Preparation and Cell Assembly}

\subsubsection{Electrodes Prepared via Casting}

Casting is a general process that has been widely used in both laboratory and industrial scales. For this dissertation, first a slurry comprising the active material, binder (PVDF) and conducting additive (Super $\mathrm{P} \mathrm{Li}^{\circledR}$ ) was prepared in the ratio of 80:10:10 (in that order) in NMP solvent and thereafter casted onto stainless steel substrates. The electrodes were dried thoroughly $\left(80^{\circ} \mathrm{C}\right.$ for $\left.24 \mathrm{~h}\right)$ before being used for final cell assembly. 


\subsubsection{Electrodes Prepared via ESD}

Most of the electrodes deposited by ESD were used directly as working electrodes without the use of any additional binders or conducting agents in either half or full cell assembly (Please refer to Chapters 4, 5 and 6 for more experimental details).

\subsubsection{Electrochemical Cell Assembly}

The electrochemical test cells for this dissertation were tested in both coin-cell and beaker setups. For coin cell assembly, CR-2032 type coin cells were utilized; the ESD based or the casted electrode was used as the working electrode against the respective counter electrode (lithium, activated carbon, nanostructured carbon); Celgard 2400 microporous polypropylene film was used as the separator. Two electrolytes were used: 1 $\mathrm{M} \mathrm{LiPF}_{6}$ dissolved in carbonate solvents (nonaqueous) and $1 \mathrm{M} \mathrm{Na}_{2} \mathrm{SO}_{4}$ (aqueous). A nickel foam spacer was used for coin-cell assembly to ensure good electrical contact.

\subsection{Electrochemical Characterization}

\subsubsection{Cyclic Voltammetry (CV)}

Cyclic voltammetry is a type potentiodynamic electrochemical technique which is used to investigate the reversibility of different electrochemical reactions. In a typical CV experiment, the working electrode potential is ramped linearly vs. time at a certain scan rate $\left(\mathrm{mV} \mathrm{s}^{-1}\right)$. The data are plotted as current vs. voltage. For this dissertation, the CV tests were performed using a Bio-logic versatile multichannel potentiostat (VMP3, Bio logic). Detailed experimental details can be found in the respective research chapter. 


\subsubsection{Galvanostatic Charge-discharge (GCD)}

GCD characterization is crucial to study the electrochemical reactions, cycling stability and rate capability of an electrochemical cell. Potential vs. time (or capacity) plot is used to review the electrochemical reactions during constant current charge/discharge by examining the plateau position (vs. potential). In order to study the rate response of a cell, GCD cycling is carried out at different currents. All the electrochemical cells were galvanostatically cycled at room temperature using BiologicVMP3 Potentiostat and NEWARE BTS-610 Battery Test System.

\subsubsection{Electrochemical Impedance Spectroscopy (EIS)}

Electrochemical impedance spectroscopy (EIS) is a perturbative characterization of the dynamics of an electrochemical reaction, which records the response of an electrochemical cell to an applied potential or current. For this dissertation, EIS studies were performed using a Bio-logic versatile multichannel potentiostat (VMP3, Bio logic). Typically an AC oscillation of $10 \mathrm{mV}$ amplitude was applied over the frequencies from $100 \mathrm{kHz}$ to $10 \mathrm{mHz}$; the data were fitted using Z-fit function in EC-Lab (V10.40) software using relevant Randles circuits.

\subsection{References}

1. Chen, C.H., Kelder, E.M. and Schoonman, J., 1996. Unique porous LiCoO 2 thin layers prepared by electrostatic spray deposition. Journal of materials science, 31(20), pp.5437-5442.

2. Jaworek, A., Sobczyk, A., Krupa, A., Lackowski, M. and Czech, T., 2009. Electrostatic deposition of nanothin films on metal substrate. Bulletin of the Polish Academy of Sciences: Technical Sciences, 57(1), pp.63-70.

3. Jaworek, A.T.S.A. and Sobczyk, A.T., 2008. Electrospraying route to nanotechnology: an overview. Journal of electrostatics, 66(3), pp.197-219. 
4. Chen, C., Agrawal, R., Kim, T.K., Li, X., Chen, W., Yu, Y., Beidaghi, M., Penmatsa, V. and Wang, C., 2014. Nanostructured Electrodes via Electrostatic Spray Deposition for Energy Storage System. ECS Transactions, 61(27), pp.155-163.

5. Li, X. and Wang, C., 2013. Engineering nanostructured anodes via electrostatic spray deposition for high performance lithium ion battery application. Journal of Materials Chemistry A, 1(2), pp.165-182.

6. Sokolov, S., Paul, B., Ortel, E., Fischer, A. and Kraehnert, R., 2011. Templateassisted electrostatic spray deposition as a new route to mesoporous, macroporous, and hierarchically porous oxide films. Langmuir, 27(5), pp.1972-1977.

7. Agrawal, R., Chen, C., Dages, S. and Wang, C., 2017. A High Energy 3V LithiumIon Capacitor Synthesized via Electrostatic Spray Deposition. Adv. Mater. Lett, 8, pp.783-790.

8. Dhanabalan, A., Li, X., Agrawal, R., Chen, C. and Wang, C., 2013. Fabrication and Characterization of $\mathrm{SnO} 2 /$ Graphene composites as high capacity anodes for Li-ion Batteries. Nanomaterials, 3(4), pp.606-614.

9. Agrawal, R., Adelowo, E., Baboukani, A.R., Villegas, M.F., Henriques, A. and Wang, C., 2017. Electrostatic Spray Deposition-Based Manganese Oxide FilmsFrom Pseudocapacitive Charge Storage Materials to Three-Dimensional Microelectrode Integrands. Nanomaterials, 7(8), p.198.

10. Wang, C., Taherabadi, L., Jia, G., Madou, M., Yeh, Y. and Dunn, B., 2004. C-MEMS for the manufacture of 3D microbatteries. Electrochemical and Solid-State Letters, 7(11), pp.A435-A438.

11. Wang, C., Jia, G., Taherabadi, L.H. and Madou, M.J., 2005. A novel method for the fabrication of high-aspect ratio C-MEMS structures. Journal of microelectromechanical systems, 14(2), pp.348-358.

12. Song, Y., Agrawal, R., Hao, Y., Chen, C. and Wang, C., 2014. C-MEMS based microsupercapacitors and microsensors. ECS Transactions, 61(7), pp.55-64.

13. Agrawal, R., Beidaghi, M., Chen, W. and Wang, C., 2015, May. Carbon microelectromechanical systems (C-MEMS) based microsupercapacitors. In Proceedings of SPIE. Society of Photo-optical Instrumentation Engineers.

14. Agrawal, R. and Wang, C., C-MEMS based on-chip microsupercapacitors: In Carbon: The next silicon? Book 2-- Applications (eds. Marc Madou, Victor H. Perez- 
Gonzalez, and Bidhan Pramanick), pp 123-137, Momentum Press (2016); Print ISBN: 9781606508831

15. Diba, M., Fam, D.W., Boccaccini, A.R. and Shaffer, M.S., 2016. Electrophoretic deposition of graphene-related materials: A review of the fundamentals. Progress in Materials Science, 82, pp.83-117.

16. Majid, S.R., 2016. Effects of Electrodeposition Mode and Deposition Cycle on the Electrochemical Performance of $\mathrm{MnO}_{2}-\mathrm{NiO}$ Composite Electrodes for High-EnergyDensity Supercapacitors. PloS one, 11(5), p.e0154566. 


\section{A HIGH ENERGY 3V LITHIUM-ION CAPACITOR SYNTHESIZED VIA ELECTROSTATIC SPRAY DEPOSITION}

\subsection{Introduction}

In order to keep up with the demands of the ever evolving technology and the automotive industry, developing high performing energy storage devices is extremely crucial. At the heart of electrochemical energy storage devices are electrochemical capacitors, which essentially bridge the gap between electrolytic capacitors and secondary batteries with high gravimetric power densities $\left(\sim 10 \mathrm{kWkg}^{-1}\right)$ and moderate energy densities $\left(<10 \mathrm{Whkg}^{-1}\right)$. However, in order to expand the applicability of ECs, one of the critical factors that requires immediate attention is their relatively low energy density. In the wake of addressing this shortcoming of ECs, the concept of lithium ion battery (LIB) and EC hybridization has gained significant scientific attention in recent years. In practice, battery and capacitor hybridization can be achieved at both external and internal levels. As noted by Cericola et al [1], external hybridization involves hardwiring of the two devices in either serial or parallel arrangement, whereas internal hybridization in essence is hybridization within the device itself. Similar to the external setup, internal hybridization can be carried out in both serial and parallel arrangements. The internal serial configuration comprises a pristine redox battery-type electrode along with a counter double layer capacitive cathode; whereas the internal parallel arrangement consists of bi-material electrodes, in which both redox and double layer materials coexist within one electrode. One of the first reports on nonaqueous internal hybrids was documented by Amatucci et al in 2001 [2], where they used $\mathrm{Li}_{4} \mathrm{Ti}_{5} \mathrm{O}_{12}$ as the negative lithium intercalating electrode and activated carbon as the double layer electrode; the 
reported device was able to deliver a gravimetric energy density of $25 \mathrm{Whkg}^{-1}$. Since then many other systems with lithium-intercalating materials including graphite [3, 4], $\mathrm{Li}_{4} \mathrm{Ti}_{5} \mathrm{O}_{12}[5,6], \mathrm{LiFePO}_{4}$ [7], $\mathrm{LiMn}_{2} \mathrm{O}_{4}$ [8], $\mathrm{TiO}_{2}$ [9-11], and double layer materials including activated carbon $[2,5,6]$, and graphene $[8,12]$ have been investigated.

Graphene, the one-atom thick sheet of $\mathrm{sp}^{2}$ hybridized carbon atoms is considered ideal for double layer capacitive charge storage owing to its high theoretical specific surface area $\left(\sim 2600 \mathrm{~m}^{2} / \mathrm{g}\right)$, exceptional electronic conductivity and superior mechanical strength [13]. However, one of the major shortcomings of graphene is sheet aggregation and restacking, which significantly reduces the effective accessible surface area for the electrolyte ions, which ultimately deteriorates the cell performance. One of the strategies to minimize the graphene sheet restacking is the addition of "nanospacers" such as CNT $[14,15]$. Incorporating CNT into the graphene matrix not only allows for a larger accessible surface area but also enhances the electrical conductivity. Furthermore, the addition of CNT nanofillers has shown improvement in the mechanical robustness of different composites [16]. From our previous studies [14], microsupercapacitors fabricated with reduced graphene oxide-carbon nanotube (rGO-CNT) composites with a gravimetric composition of $90 \%$ rGO and 10\% CNT exhibited exceptional power handling with a RC time constant of only $4.8 \mathrm{~ms}$. The further addition of CNT enhanced the power handling but exhibited a negative impact on the specific capacitance of the device [14]. Therefore rGO-CNT composite electrodes with the same composition were chosen for the lithium hybrid electrochemical capacitor (Li-HEC) fabrication for this study. To couple the rGO-CNT electrode, an anatase $\mathrm{TiO}_{2}-\mathrm{Li}_{4} \mathrm{Ti}_{5} \mathrm{O}_{12}$ (ATO-LTO) anode was chosen. $\mathrm{TiO}_{2}$ (TO) with a maximum theoretical capacity of $335 \mathrm{mAhg}^{-1}$ (for $\mathrm{x}=1$ for 
$\mathrm{Li}_{\mathrm{x}} \mathrm{TiO}_{2}$ ) [17], is a competitive alternative to graphite-based anodes, which exhibit a theoretical capacity of $372 \mathrm{mAhg}^{-1}$. One of the disadvantages of graphite is the low lithium intercalation potential $\left(\sim 0.1 \mathrm{~V} v s \mathrm{Li} / \mathrm{Li}^{+}\right)$. Such low operating potentials are very close to lithium plating and can promote dendritic lithium growth, which can result in catastrophic cell short-circuiting. Both TO and LTO intercalate lithium at much higher potentials $\sim 1.4-1.8 \mathrm{~V}$ [17] and $\sim 1.55 \mathrm{~V}$ vs. $\mathrm{Li} / \mathrm{Li}^{+}$[18], respectively, which are much higher than graphite operating potential. Among the three most sought after TO polymorphs including anatase, bronze and rutile, anatase is considered an ideal host for lithium-ion storage given the highly distorted edge-sharing $\mathrm{TiO}_{2}$ octahedra arrangement, which facilitates lithium insertion and extraction $[19,20]$. Furthermore the very low volumetric strain ( 4\%) in ATO lattice during cycling is ideal for cycle longevity [20]. Furthermore, titania has superior electrical conductivity and lithium diffusivity than LTO $[21,22]$ and faster lithium insertion/extraction can help realize higher rate batteries than LTO alone. In other reports, TO-LTO composites have shown enhancement in lithium diffusion, improved charge-transfer kinetics along with better electronic conductivity [23].

The electrodes used for the Li-HEC construction for this study were created via electrostatic spray deposition (ESD) technique. The ESD process is a low energy electrohydrodynamic spraying technique in which a precursor solution disintegrates into an aerosol spray upon the application of a high voltage between a metal nozzle and a substrate [24-27]. The desired precursor solution is fed through a syringe pump via a nozzle connected to a high potential source, whereas the substrate is grounded [24]. The aerosol formed by the charged droplets is attracted to the heated substrate leading to 
simultaneous solvent evaporation and chemical reactions, leaving behind a thin film [26, 27]. The advantages of ESD over other thin film production methods include the feasibility of operation in ambient atmosphere at desired temperatures without the need of vacuum, which makes it both cost-effective and facile in terms of operation [25]. Both polycrystalline phases as well as composite materials can be synthesized via ESD by adjusting parameters such as the applied potential, substrate temperature, substrate-nozzle distance, nozzle geometry, precursor solution flow rate and composition [26-28]. One of the very attractive features of ESD is the ability to tailor the morphology of the film by fine tuning the deposition parameters. A host of morphologies have been reported using ESD including dense, fractal, reticular, sponge-like, and porous [26, 27]. The feasibility of creating high-surface area porous and homogeneous synthetic films makes ESD especially suitable for energy-storage applications. Several works have documented the use of ESD based films for energy storage systems including both lithium-ion batteries and electrochemical capacitors [26, 27, 29-30]. The ESD based rGO-CNT and the ATOLTO electrodes, synthesized in this work were able to deliver discharge capacities of $\sim 63$ $\mathrm{mAhg}^{-1}$ and $95 \mathrm{mAhg}^{-1}$, respectively at a current density of $0.1 \mathrm{Ag}^{-1}$ with good reversibility. The Li-HEC cells constructed with the rGO-CNT and ATO-LTO electrodes were stable for a cell potential of $0.05-3.0 \mathrm{~V}$ and were able to deliver a high discharge capacity of $\sim 32 \mathrm{mAhg}^{-1}$ at a current rate of $0.1 \mathrm{Ag}^{-1}$ with excellent rate characteristics and reversibility. Furthermore, the hybrid electrochemical cells were able to deliver a maximum gravimetric energy density of $33.35 \mathrm{Whkg}^{-1}$ and a maximum power density of 1207.4 $\mathrm{Wkg}^{-1}$, with specific energy ranging between 33.35-15.09 $\mathrm{Whkg}^{-1}$ at power densities of $83.55-1207.4 \mathrm{Wkg}^{-1}$. All the cell parameters were normalized with the total 
anode and cathode active material masses. Additionally, the Li-HEC cells were able to retain a capacity of $\sim 77 \%$ after 100 cycles. Therefore, the use of a simple and costeffective process such as ESD was demonstrated in order to construct high energy LiHECs with good power handling capability.

\subsection{Experimental Details}

\subsubsection{Material Synthesis}

\subsubsection{Cathode Preparation}

For the rGO-CNT cathode, the raw materials were single layer graphene oxide (GO) and carboxyl-functionalized multi-walled carbon nanotubes (MWCNT-COOH). Both the materials were procured from Cheap Tubes Inc. (USA). GO and CNT were first

dissolved in 1, 2-propanediol (Sigma Aldrich) in a concentration of $1 \mathrm{mgml}^{-1}$ and were then ultrasonicated for thorough dispersion for $1 \mathrm{~h}$. After sonication, the suspension was used immediately for ESD on stainless steel substrates preheated at $250^{\circ} \mathrm{C}$. The $\mathrm{GO}$ and CNT were used in a gravimetric mass ratio of 9:1, which was selected based on the optimum composition based on our previous works [14]. The flow rate was kept between 4-6 $\mathrm{mlhr}^{-1}$ at a potential of 5-7 $\mathrm{kV}$ and the deposition was carried out for 4 hours. The electrodes were then directly used for material and electrochemical characterization without adding any binders or conducting additives.

\subsubsection{Anode Preparation}

The ATO-LTO anodes were prepared using lithium acetate (Sigma Aldrich) and titanium butoxide (Sigma Aldrich) in a molar ratio of 4:5, respectively in ethyl alcohol and butyl carbitol (4:1 v:v). The solution was directly used as the precursor and deposited 
on a preheated nickel foam substrate using ESD. The substrate was preheated at $250^{\circ} \mathrm{C}$ and the precursor solution flow rate was kept between 1-2 $\mathrm{mlhr}^{-1}$. The potential was kept between $5-7 \mathrm{kV}$ and the distance between the needle and the substrate was approximately $3 \mathrm{~cm}$. The deposition was carried out for $2 \mathrm{~h}$. Post ESD deposition, the substrates with ESD films were calcined in an argon atmosphere in a Lindberg alumina tube furnace at a temperature of $750^{\circ} \mathrm{C}$ for $2 \mathrm{~h}$. After the calcination process, the films were allowed to cool down to room temperature and thereafter were directly used for electrochemical characterization without any further treatment or addition of binders or conducting additives.

\subsubsection{Material Characterization}

The crystallinity of the as-deposited and calcined anode powders was studied using a Siemens 5000D X-ray Diffractometer with $\mathrm{Cu} \mathrm{K} \alpha$ radiation. Further crystallographic studies on the anode powders calcined at $750^{\circ} \mathrm{C}$ were carried out using a Philips CM-200 200KeV Transmission Electron Microscope (TEM). The morphology of the as-deposited and calcined anode films and the rGO-CNT cathode films was characterized using a JEOL SEM 6330F Field Emission Scanning Electron Microscope (FE-SEM) in the secondary electron imaging (SEI) mode. To characterize GO functionalization and reduction, Fourier transform-infrared spectroscopy (FT-IR) was carried out using a JASCO FT-IR 4100 spectrometer.

\subsubsection{Electrochemical characterization}

The electrochemical characterization was carried out in CR-2032 type coin cells.

In order to characterize the electrode performance versus $\mathrm{Li} / \mathrm{Li}^{+}$, the $\mathrm{rGO}-\mathrm{CNT}$ and the 
ATO-LTO electrodes were first assembled in half-cells as working electrodes with a lithium foil serving both as the counter and reference electrode. 1.0M lithium hexafluorophosphate $\left(\mathrm{LiPF}_{6}\right)$ in ethylene carbon $(\mathrm{EC})$ : diethyl carbonate $(\mathrm{DEC})$ in a volume ratio of $1: 1$ was used as the electrolyte, and a Celgard 2400 polypropylene (Charlotte, NC, USA) film was used as the separator. The cells were assembled in an argon-filled glove box (VAC Nexus I, Hawthorne, CA, USA) with $\mathrm{O}_{2}$ level $<1 \mathrm{ppm}$. Cyclic voltammetry (CV) studies on both rGO-CNT and ATO-LTO electrodes were carried out using a Bio-logic versatile multichannel potentiostat (VMP3) whereas galvanostatic charge-discharge cycling, rate performance and cycle life testing were carried out using a NEWARE BTS-610 Battery Test System (Shenzhen, China). The full hybrid cells comprising the rGO-CNT cathode and ATO-LTO anode were assembled after prelithiating the ATO-LTO anode for 5 cycles and after obtaining the activation of the rGO-CNT electrode for $\sim 100$ cycles. For the full cell systems the electrolyte was 1.0M lithium hexafluorophosphate $\left(\mathrm{LiPF}_{6}\right)$ in ethylene carbon (EC): diethyl carbonate (DEC) in a volume ratio of 1:1, with a Celgard 2400 propylene film separator. Similar to the half-cell assembly, the full cell assembly was carried out in CR-2032 type coin cells.

\subsection{Results and Discussion}

\subsubsection{Material Characterization}

The XRD patterns of the as-deposited and anode powders calcined at $750^{\circ} \mathrm{C}$ are shown in Figure 4.1a. As evident, the as-deposited powder exhibits no discernable peaks whereas the diffraction data from the calcined powder validates the presence of both LTO and anatase $\mathrm{TiO}_{2}$ phase. The peaks at $18.3^{\circ}, 35.5^{\circ}, 43.2^{\circ}, 57.2^{\circ}$ and $62.8^{\circ}$ correspond to (111), (311), (400), (333) and (440) planes from LTO (JCPDS card number 00-049-0207) 
whereas the peak at $53.8^{\circ}$ corresponds to (105) plane from anatase $\mathrm{TiO}_{2}$ (JCPDS card number 00-021-1272). The FTIR pattern of the GO powder and the ESD based rGO film is depicted in Figure 4.1b. The broad absorption peak centered around $3378 \mathrm{~cm}^{-1}$ in the GO powder, which signals the presence of hydroxyl groups [14, 31] and water is substantially reduced in the rGO pattern. The other significant peaks present in the GO powder are signaled at $1727 \mathrm{~cm}^{-1}, 1624 \mathrm{~cm}^{-1}, 1373 \mathrm{~cm}^{-1}, 1226 \mathrm{~cm}^{-1}$, and $1083 \mathrm{~cm}^{-1}$ are attributed to $\mathrm{C}=\mathrm{O}$ stretching [31], aromatic $\mathrm{C}=\mathrm{C}$ stretching [32], carboxyl [33], epoxide C-O-C or phenolic C-O-H stretching vibrations [33], C-O stretching in epoxy or alkoxy groups [33], respectively. It is worth noting that the peak intensity from the groups that signal the presence of oxygen and water are substantially mitigated in the rGO spectrum. Figure $4.2 \mathrm{a}$ and $4.2 \mathrm{~b}$ display the SEM images of the as deposited ESD and calcined ATO-LTO films, respectively. Prior to the thermal treatment, the film particles are mostly flaky, whereas upon the calcination, the particles become more circular with no appreciable change in size. The TEM micrograph of the ATO-LTO powder is shown in Figure $4.2 \mathrm{c}$ and the SAED pattern is shown as the inset. The TEM studies confirmed the presence of both anatase $\mathrm{TiO}_{2}$ and LTO. The anatase- $\mathrm{TiO}_{2}$ phase with a d-spacing of 3.50 $\AA$, $2.23 \AA, 1.86 \AA, 1.54 \AA$, and $1.19 \AA$ had (hkl) orientations of (101), (112), (200), (213), and (008), respectively, whereas the LTO with d-spacings of $1.25 \AA$, $1.19 \AA$, and $1.09 \AA$ and (hkl) orientation of (622), (444), and (731), respectively. The top view of the rGO-CNT electrode is shown in Figure 4.2d. As evident, the electrode morphology was porous and loose; porous morphology is ideal for double-layer charge storage mechanism and allows for high rate capability realization. 

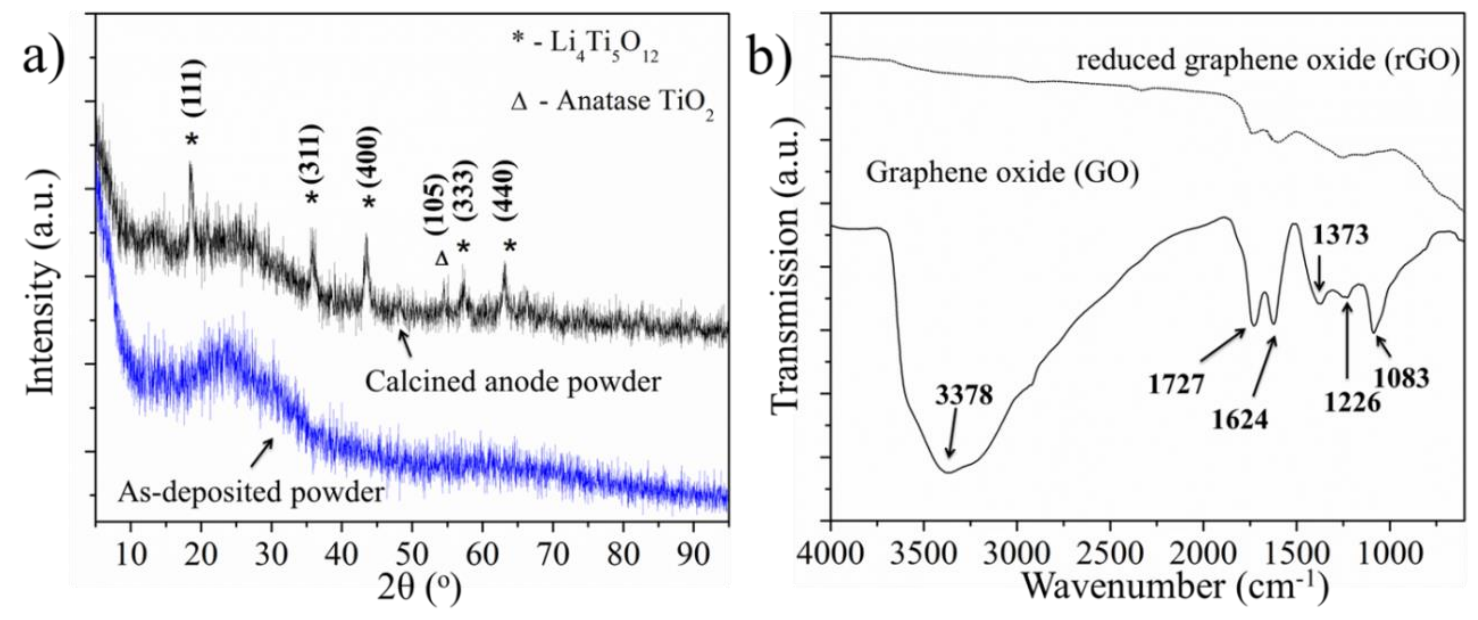

Figure 4.1: (a) The XRD pattern of the as-deposited and calcined anode powders, (b) The FTIR pattern of the GO and ESD based rGO. 

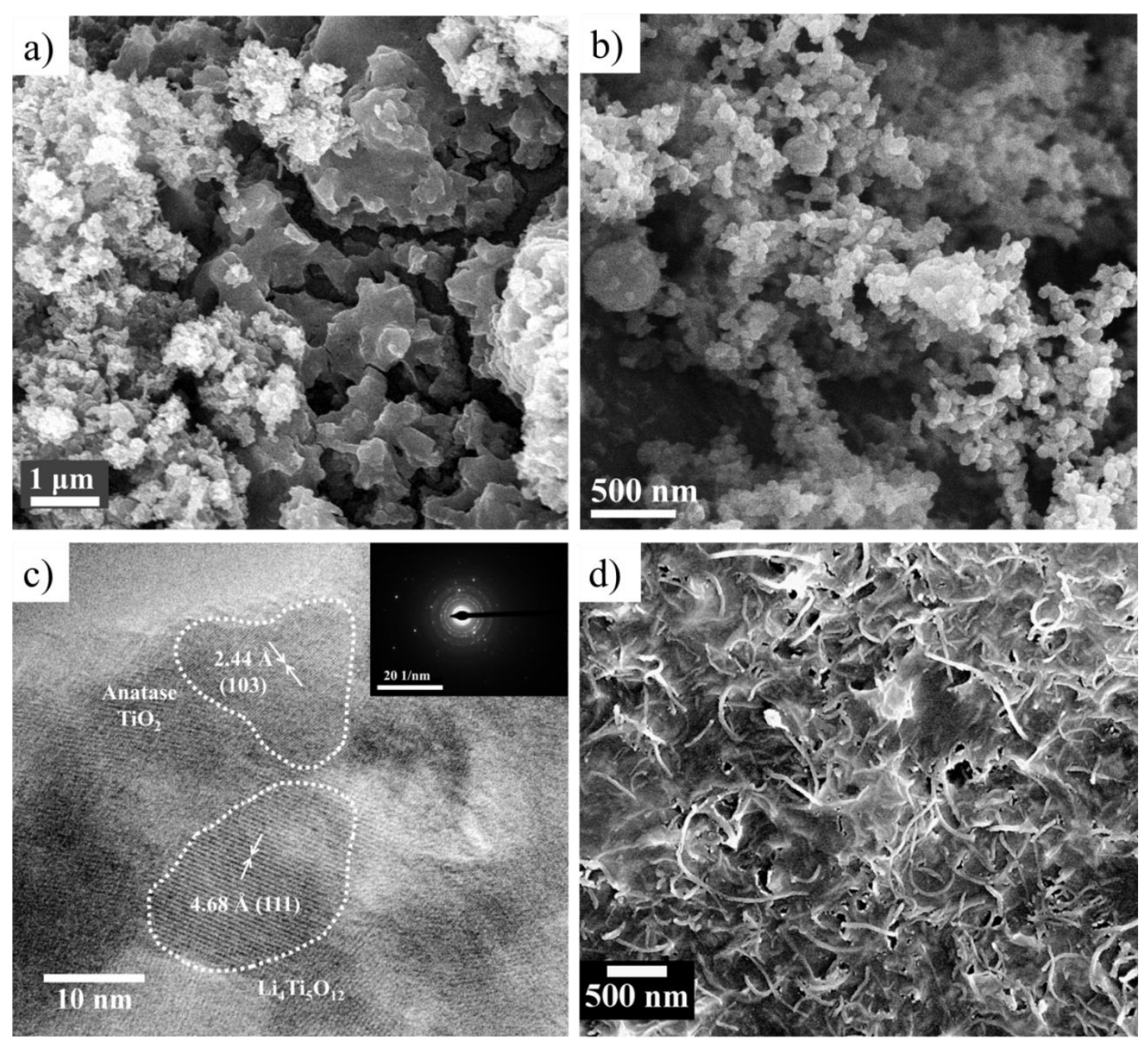

Figure 4.2: Morphology of the as-deposited (a) and calcined (b) ATO-LTO films, (c) typical TEM micrograph of the calcined ATO-LTO powder, the inset shows the SAED pattern, (d) Top view of the rGO-CNT cathode 
a)

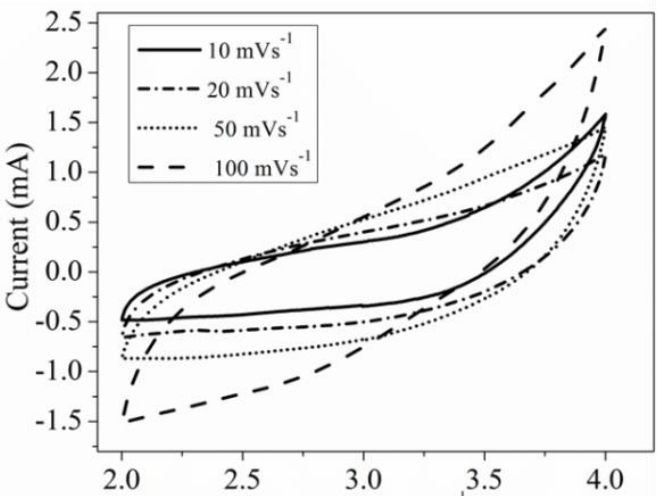

c)

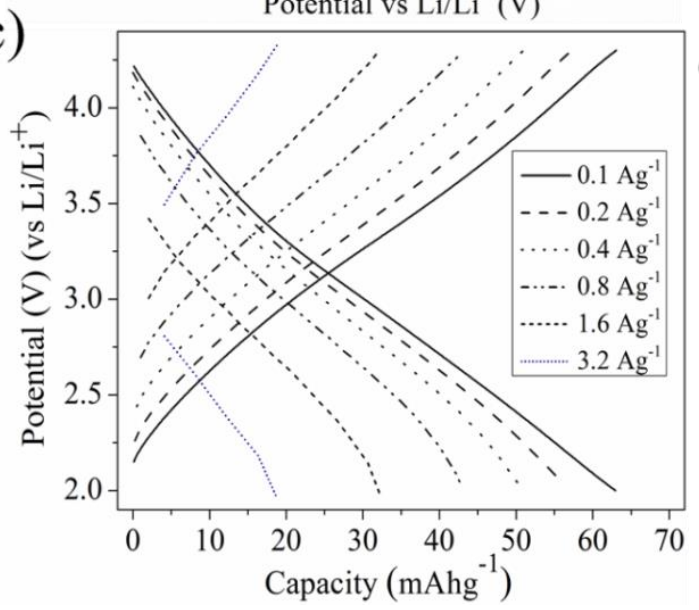

b)

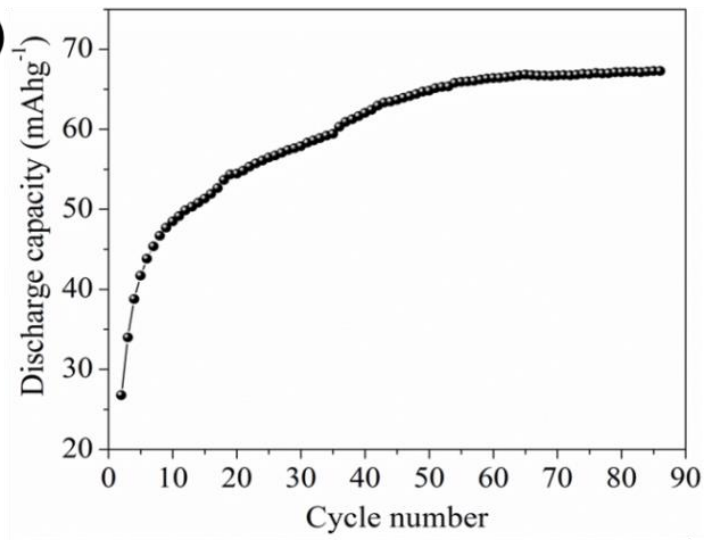

d)

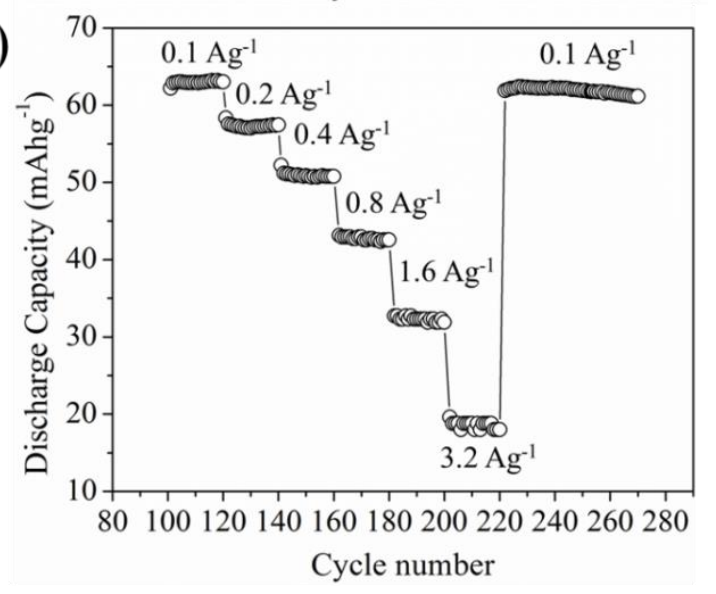

Figure 4.3: (a) Cyclic voltammograms of the rGO-CNT composite electrode for different scan rates between a potential of $2.0-4.0 \mathrm{~V}\left(\mathrm{vs} . \mathrm{Li} / \mathrm{Li}^{+}\right)$, (b) discharge capacity of the rGOCNT composite for the first $\sim 90$ cycles at a current density of $0.1 \mathrm{Ag}^{-1}$, (c) typical chargedischarge curves of the rGO-CNT electrode at different current densities, (d) rate capability of the rGO-CNT composites.

\subsubsection{Electrochemical Characterization}

\subsubsection{1 rGO-CNT half-cell}

The cyclic voltammograms at different scan rates of the rGO-CNT composite electrode are shown in Figure 4.3a. The shape of the curves is typical of a double layer capacitor with no discernable redox peaks. A very interesting phenomenon was observed in Figure 4.3b; the discharge capacity of the rGO-CNT cathode steadily increased until around the first 60 cycles and then stabilized. The capacity enhancement could be a result 
of electrochemical activation of the active material and has been reported for graphene based devices in other reports [14, 34]. Figure 4.3c shows the galvanostatic chargedischarge curves of the rGO-CNT composite after the electrochemical activation. The curves are mostly triangular in shape as expected for surface charge storage mechanism. The iR drops however were quite significant at higher current densities, which could be a result of the relatively high resistivity of the composite resulting from the remnant oxygen-containing groups present in the rGO. Figure $4.3 \mathrm{~d}$ shows the rate capability of the rGO-CNT composite. The capacity is stable as noted for a step size of 20 cycles for each current rate and almost all of the capacity is recovered when the cell was cycled from 3.2 $\mathrm{Ag}^{-1}$ to $0.1 \mathrm{Ag}^{-1}$. Discharge capacities of ca. $63 \mathrm{mAhg}^{-1}, 55 \mathrm{mAhg}^{-1}, 50 \mathrm{mAhg}^{-1}, 43$ $\mathrm{mAhg}^{-1}, 32 \mathrm{mAhg}^{-1}$, and $18 \mathrm{mAhg}^{-1}$ are noted for current rates of $0.1 \mathrm{Ag}^{-1}, 0.2 \mathrm{Ag}^{-1}, 0.4$ $\mathrm{Ag}^{-1}, 0.8 \mathrm{Ag}^{-1}, 1.6 \mathrm{Ag}^{-1}$, and $3.2 \mathrm{Ag}^{-1}$ respectively. The discharge capacities are reported from the last cycle of the respective current rate. 

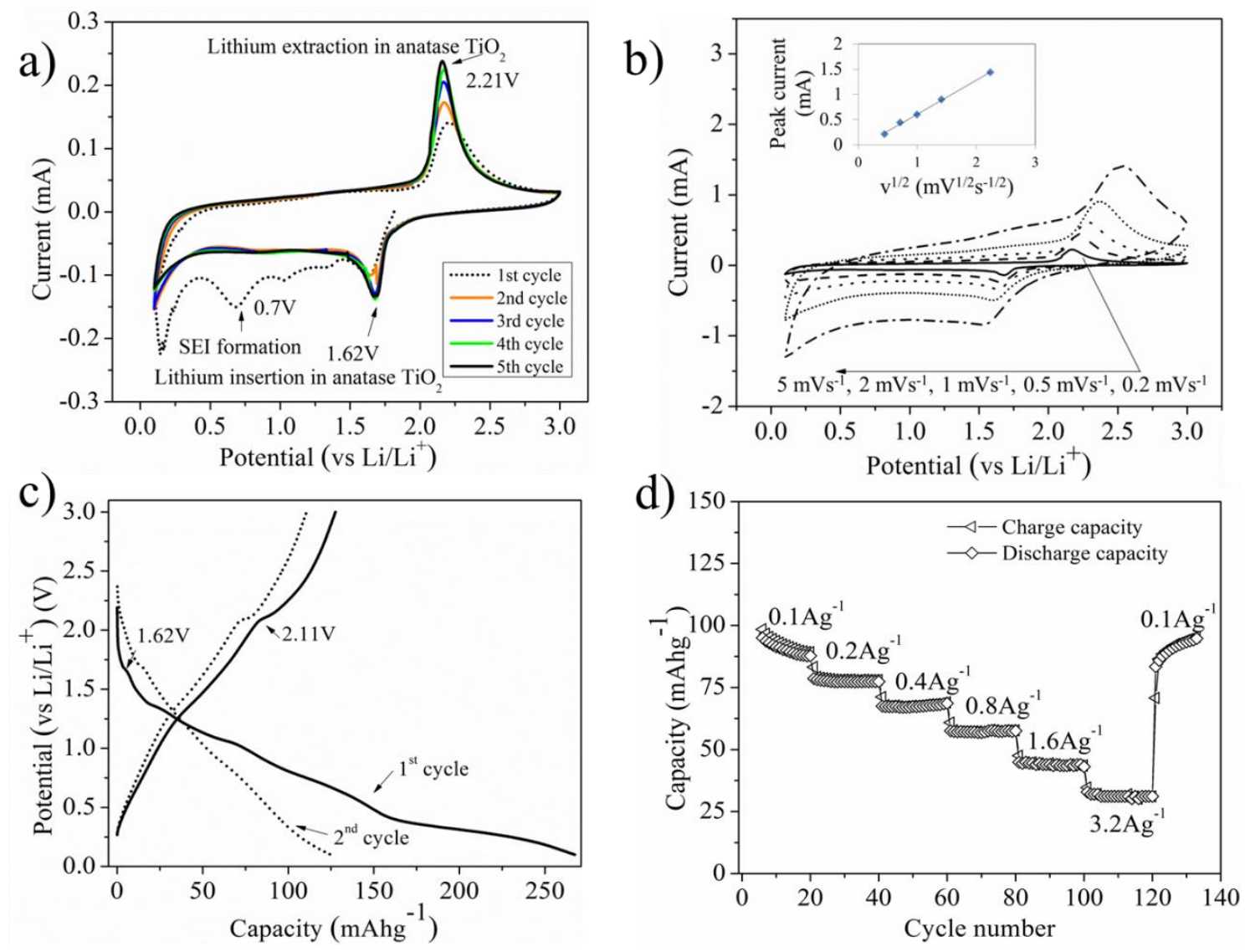

Figure 4.4: (a) Cyclic voltammograms of the ATO-LTO composite electrode at a scan rate of $0.2 \mathrm{mVs}^{-1}$ for the first five cycles, (b) cyclic voltammograms of the ATO-LTO composite at different scan rates ranging from $0.2 \mathrm{mVs}^{-1}$ to $5 \mathrm{mVs}^{-1}$; the inset shows the dependence of the anodic peak current on the square root of the scan rate, (c) typical charge-discharge curves of the ATO-LTO composite electrode for the first two cycles at a current density of $0.1 \mathrm{Ag}^{-1}$, (d) rate capability of the ATO-LTO composite anodes.

\subsubsection{ATO-LTO half cell}

The CV curves of the ATO-LTO composite electrodes for the first five cycles at a scan rate of $0.2 \mathrm{mVs}^{-1}$ are shown in Figure 4.4a. In the first cycle, in the cathodic branch of the scan, two peaks were observed at $1.62 \mathrm{~V}$ vs. $\mathrm{Li} / \mathrm{Li}^{+}$and $0.7 \mathrm{~V}$ vs. $\mathrm{Li} / \mathrm{Li}^{+}$, whereas in the anodic branch one major peak at $2.21 \mathrm{~V}$ vs. $\mathrm{Li} / \mathrm{Li}^{+}$was observed. The peak at $0.7 \mathrm{~V}$ disappeared in the subsequent cycles and is ascribed to the possible solid electrolyte 
interphase (SEI) formation. The redox peak pair appearing at $1.62 \mathrm{~V}$ and $2.21 \mathrm{~V}$ is attributed to the lithium insertion and extraction in ATO. The CV of the ATO-LTO composite at different scan rates is shown in Figure 4.4b. As evident the peaks shifted upon the application of a higher scan rate. The inset depicts the relationship between the square root of the scan rate and the respective anodic peak current and a linear correlation between the two parameters is established. This indicates the predominance of redox based reactions for the anode based on the Randles-Sevcik equation [35]. It should be noted that no discernable activity of LTO is detected in the CV curves, which indicates that ATO is the primarily active electrochemical phase in the composite. The possible reason for no noticeable LTO electrochemical activity could be the competitive crystal growth during the calcination process, which could have resulted in trace LTO amounts. Similar phenomenon, where one of the phases is predominantly electrochemically active in the composite, has been reported in other works $[36,37]$. Figure $4.4 \mathrm{c}$ shows the charge discharge curves of the first and second cycles of the ATO-LTO composite at a current density of $0.1 \mathrm{Ag}^{-1}$. Two humps centered at $1.62 \mathrm{~V}$ and $2.21 \mathrm{~V}$ are observed which are consistent with the CV ATO insertion/extraction redox pair. It should be noted that the first discharge capacity of the composite is $\sim 267 \mathrm{mAhg}^{-1}$ whereas the first charge capacity is $\sim 127 \mathrm{mAhg}^{-1}$ which results in a coulombic efficiency of $\sim 47 \%$ resulting in an irreversible capacity loss of $140 \mathrm{mAhg}^{-1}$, which possibly is a result of the SEI formation. In the second cycle however, the discharge capacity is $\sim 124 \mathrm{mAhg}^{-1}$ and the charge capacity is $110.5 \mathrm{mAhg}^{-1}$ which results in a much improved coulombic efficiency of $\sim 89 \%$. Figure $4.4 \mathrm{~d}$ shows the rate capability of the ATO-LTO composite anode at different rates for a cycle step of 20 cycles. Discharge capacities of ca. $88 \mathrm{mAhg}^{-1}, 77$ 
$\mathrm{mAhg}^{-1}, 68 \mathrm{mAhg}^{-1}, 57 \mathrm{mAhg}^{-1}, 44 \mathrm{mAhg}^{-1}$, and $31 \mathrm{mAhg}^{-1}$, were noted at the last cycle for current rates of $0.1 \mathrm{Ag}^{-1}, 0.2 \mathrm{Ag}^{-1}, 0.4 \mathrm{Ag}^{-1}, 0.8 \mathrm{Ag}^{-1}$, and $1.6 \mathrm{Ag}^{-1}$, respectively. Furthermore, the composite exhibited good reversibility since all of the capacity was restored after the cell was cycled back from a high current rate of $3.2 \mathrm{Ag}^{-1}$ to a low current rate of $0.1 \mathrm{Ag}^{-1}$.

\subsubsection{Li-HEC cell}

The Li-HEC cell performance is depicted in Figure 4.5. The cells were constructed after prelithiating the anode to a potential of $0.05 \mathrm{~V} v \mathrm{vi} / \mathrm{Li}^{+}$at a very low current rate of $0.05 \mathrm{Ag}^{-1}$. As noted by Zheng [38], organic electrolytes have relatively lower salt concentration as opposed to aqueous electrolytes and therefore the energy of the hybrid device can be limited by the electrolyte when a lithium intercalating anode is used. As the cell charges, the lithium ions are consumed at the negative electrode whereas the anions are adsorbed at the cathode. If the electrolyte were depleted of ions, the device cannot be charged further and as a solution, they proposed the utilization of a prelithiated anode, which could compensate for the electrolyte ion depletion [39]. The rGO-CNT electrodes, on the other hand were used for Li-HEC construction after full electrochemical activation, i.e. after $\sim 100$ cycles. As was noted in Figure $4.3 \mathrm{~b}$, the discharge capacity of the rGO-CNT electrode increased steadily for the first $\sim 60$ cycles and then stabilized. Allowing the rGO-CNT electrode to activate before Li-HEC assembly ensured higher capacity utilization from the cathode. As noted in Figure 4.5a, the shape of the CV curves of the Li-HECs is typical of capacitive behavior with a slight deviation, which could be a result of the composite charge storage characteristics arising 
from the predominantly redox-diffusion controlled lithium storage in the anode as opposed to the surface-dominated double layer charge adsorption in the cathode. The galvanostatic charge-discharge curves of the Li-HEC, displayed as Figure 4.5b, are mostly triangular for a cell potential between a cell potential of $0.01-3.0 \mathrm{~V}$ also indicative of capacitive behavior. The rate capability of the Li-HEC cell is shown in Figure 4.5c the full cell was able to deliver discharge capacities of $32.29 \mathrm{mAhg}^{-1}, 27.70 \mathrm{mAhg}^{-1}$, $22.82 \mathrm{mAhg}^{-1}, 17.45 \mathrm{mAhg}^{-1}$, and $12.27 \mathrm{mAhg}^{-1}$ for current rates of $72.5 \mathrm{mAg}^{-1}, 145$ $\mathrm{mAg}^{-1}, 290 \mathrm{mAg}^{-1}, 580 \mathrm{mAg}^{-1}$, and $1160 \mathrm{mAg}^{-1}$, respectively. Moreover, the cell performance was very stable for a cycle step of 10 for the given current rate and all of the cell capacity is recovered after cycling from a high current rate of $1160 \mathrm{mAg}^{-1}$ to 72.5 $\mathrm{mAg}^{-1}$, which is indicative of good rate capability and reversibility of the full cell. Figure 4.5d shows the capacitive retention of the Li-HEC full after 100 cycles; the cell was able to retain $\sim 77 \%$ of the initial capacitance. The Figure 4.6 shows the Ragone chart of the Li-HEC cell based on discharge characteristics. The hybrid capacitor was able to deliver a maximum energy density of $33.35 \mathrm{Whkg}^{-1}$ and a maximum power density of 1207.4 $\mathrm{Wkg}^{-1}$. All the cell parameters were normalized with the total anode and cathode active material masses. The range for the energy density was between $33.35-15.09 \mathrm{Whkg}^{-1}$ at power densities of 83.55-1207.4 $\mathrm{Wkg}^{-1}$. The energy-power characteristics of the Li-HEC cells are superior to aqueous hybrid systems including $\mathrm{RuO}_{2}-\mathrm{TiO}_{2} / / \mathrm{AC}$ [40], $\mathrm{LiTi}_{2}\left(\mathrm{PO}_{4}\right)_{3} / / \mathrm{AC}$ [41] configurations, as well as comparable or even better than nonaqueous hybrid systems comprising modified LTO [42-44]. Table 4.1 summarizes the electrochemical performance of this work along with some of the other hybrid capacitors reported in other reports. The superior energy-power characteristics are attributed to the 
utilization of an organic electrolyte, which allows for a wider stable electrochemical potential window $(0.05-3 \mathrm{~V})$ and the porous morphology of the ESD generated rGO-CNT cathode, which is ideal for high power handling applications. It should be noted that this work combined a pristine lithium-intercalation based anode with a double layer counter cathode, categorically a "serial" system. Enhancement in energy-power characteristics is expected with the utilization of a "parallel" system. The combination of a redox based material and a double layer material within one electrode allows for intrinsic potential matching as the materials used have to be stable for the same voltage window [1]. Furthermore, the internal parallel system mitigates the capacity mismatch arising from the disparate charge storage mechanism of the redox and double layer materials, and therefore helps in higher material utilization rate. In addition, improving the ionic and electronic conductivity of the electrodes is expected to further improve the Li-HEC performance. This work is still in nascent phase and as mentioned, much enhancement is expected with the use of an ESD based parallel system, which is a subject of future works. 

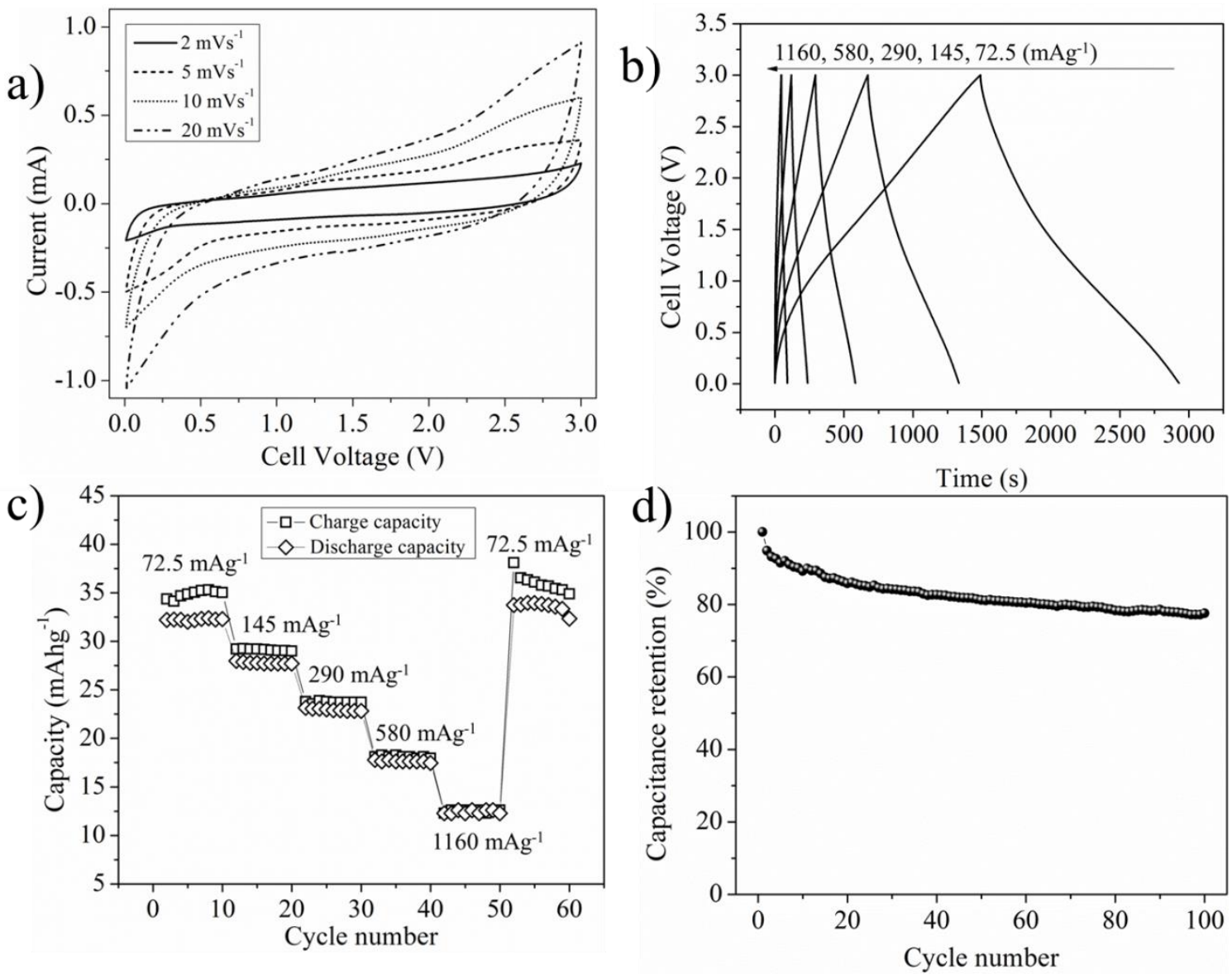

Figure 4.5: (a) Cyclic voltammograms of the Li-HEC at different scan rates ranging from 2-20 $\mathrm{mVs}^{-1}$, (b) typical charge-discharge curves of the Li-HEC cells at different current densities, (c) rate capability, and (d) cyclability of the Li-HEC full cells.

Table 4.1: Comparison of the ESD based Li-HEC with other hybrid electrochemical capacitors.

\begin{tabular}{|c|c|c|c|c|c|c|c|}
\hline $\begin{array}{l}\text { Positive } \\
\text { electrode }\end{array}$ & $\begin{array}{l}\text { Negative } \\
\text { electrode }\end{array}$ & Electrolyte & $\begin{array}{l}\text { Cell } \\
\text { Voltage } \\
\text { (V) }\end{array}$ & $\begin{array}{l}\text { Capacitance } \\
\left(\mathrm{Fg}^{-1}\right)\end{array}$ & $\begin{array}{l}\text { Capacity } \\
\left(\mathrm{mAhg}^{-1}\right)\end{array}$ & $\begin{array}{l}\text { Energy-power } \\
\text { characteristics }\end{array}$ & Ref. \\
\hline $\mathrm{RuO}_{2} / \mathrm{TiO}_{2}$ & $\mathrm{AC}$ & $\begin{array}{l}1 \mathrm{M} \mathrm{KOH} \\
\text { (aqueous) }\end{array}$ & $0-1.4 \mathrm{~V}$ & $\begin{array}{l}46 \mathrm{Fg}^{-1} \text { at } \\
130 \mathrm{mAcm}^{-2}\end{array}$ & - & $\begin{array}{l}12.5 \mathrm{Whkg}^{-1} \text { at } \\
\text { a power density } \\
\text { of } 150 \mathrm{Wkg}^{-1} \\
5.7 \mathrm{Wkg}^{-1} \text { at a } \\
\text { power density } \\
\text { of } 1207 \mathrm{Wkg}^{-1}\end{array}$ & 40 \\
\hline $\mathrm{AC}$ & $\begin{array}{l}\text { Carbon- } \\
\text { coated } \\
\mathrm{LiTi}_{2}\left(\mathrm{PO}_{4}\right)_{3}\end{array}$ & $\begin{array}{l}1 \mathrm{M} \mathrm{Li}_{2} \mathrm{SO}_{4} \\
\text { (aqueous) }\end{array}$ & $\begin{array}{l}0.3 \text { to } \\
1.5 \mathrm{~V}\end{array}$ & - & $\begin{array}{l}30 \\
\mathrm{mAhg}^{-1} \\
\text { at } 2 \\
\mathrm{mAcm}^{-2}\end{array}$ & $\begin{array}{l}24 \mathrm{Wh} \mathrm{kg}^{-1} \text { at a } \\
\text { power density } \\
\text { of about } \\
200 \mathrm{~W} \mathrm{~kg}^{-1}\end{array}$ & 41 \\
\hline
\end{tabular}




\begin{tabular}{|c|c|c|c|c|c|c|c|}
\hline & & & & & & $\begin{array}{l}15 \mathrm{Wh} \mathrm{kg}^{-1} \text { at a } \\
\text { power density } \\
\text { of } 1000 \mathrm{~W} \mathrm{~kg}^{-1}\end{array}$ & \\
\hline $\mathrm{AC}$ & $\begin{array}{l}\text { Graphene } \\
\text { sheets } \\
\text { wrapped } \\
\text { nano- } \\
\mathrm{Li}_{4} \mathrm{Ti}_{5} \mathrm{O}_{12}\end{array}$ & $\begin{array}{l}1 \mathrm{M} \\
\mathrm{LiPF}_{6} / \mathrm{EC} / \\
\mathrm{DMC} \\
\text { (nonaqueous) }\end{array}$ & $\begin{array}{l}1.5-3.0 \\
V\end{array}$ & & & $\begin{array}{l}29.2 \mathrm{Wh} \mathrm{kg}^{-1} \\
\text { at a power } \\
\text { density of } 58.4 \\
\mathrm{~W} \mathrm{~kg}^{-1} \\
1782.7 \mathrm{~W} \mathrm{~kg}^{-1} \\
\text {, the specific } \\
\text { energy retains } \\
13.4 \mathrm{Wh} \\
\mathrm{kg}^{-1}\end{array}$ & 42 \\
\hline $\mathrm{AC}$ & $\begin{array}{l}\text { Carbon } \\
\text { coated } \\
\mathrm{Li}_{4} \mathrm{Ti}_{5} \mathrm{O}_{12}\end{array}$ & $\begin{array}{l}1 \mathrm{M} \mathrm{LiPF}_{6} \text { in } \\
\text { propylene } \\
\text { carbonate } \\
\text { (nonaqueous) }\end{array}$ & $\begin{array}{l}1.5- \\
2.5 \mathrm{~V}\end{array}$ & & $\begin{array}{l}\sim 30 \\
\mathrm{mAhg}^{-1} \\
\text { at } 0.17 \\
\mathrm{Ag}^{-1}\end{array}$ & $\begin{array}{l}16 \mathrm{Whkg}^{-1} \text { at } \\
1010 \mathrm{Wkg}^{-1}\end{array}$ & 43 \\
\hline $\mathrm{AC}$ & $\begin{array}{l}\text { Carbon } \\
\text { modified } \\
\mathrm{Li}_{4} \mathrm{Ti}_{5} \mathrm{O}_{12}\end{array}$ & $\begin{array}{l}\text { 1-M LiPF6 in } \\
\text { EC/DMC } \\
\text { (1:3 in } \\
\text { volume) }\end{array}$ & $\begin{array}{l}1.5- \\
3.0 \mathrm{~V}\end{array}$ & $\begin{array}{l}83 \mathrm{Fg}^{-1} \text { at a } \\
\text { current rate } \\
\text { of } 60 \mathrm{mAg}^{-1}\end{array}$ & & $\begin{array}{l}16 \mathrm{Whkg}^{-1} \text { at } \\
440 \mathrm{Wkg}^{-1}\end{array}$ & 44 \\
\hline $\begin{array}{l}\text { Reduced } \\
\text { graphene } \\
\text { oxide- } \\
\text { carbon } \\
\text { nanotube } \\
\text { composite } \\
\text { (rGO- } \\
\text { CNT) }\end{array}$ & $\begin{array}{l}\text { Anatase } \\
\mathrm{TiO}_{2^{-}} \\
\mathrm{Li}_{4} \mathrm{Ti}_{5} \mathrm{O}_{12}\end{array}$ & $\begin{array}{l}1 \mathrm{M} \\
\mathrm{LiPF}_{6} / \mathrm{EC} / \\
\mathrm{DMC} \\
\text { (nonaqueous) }\end{array}$ & $0.05-3 \mathrm{~V}$ & - & $\begin{array}{l}\sim 32 \\
\mathrm{mAhg}^{-1} \\
\text { at } 0.1 \mathrm{Ag}^{-}\end{array}$ & $\begin{array}{l}33.35 \mathrm{Whkg}^{-1} \text { at } \\
83.55 \mathrm{Wkg}^{-1} \\
26.2 \mathrm{Whkg}^{-1} \text { at } \\
327.5 \mathrm{Wkg}^{-1} \\
15.09 \mathrm{Whkg}^{-1} \text { at } \\
1207.4 \mathrm{Wkg}^{-1}\end{array}$ & $\begin{array}{l}\text { This } \\
\text { work }\end{array}$ \\
\hline
\end{tabular}

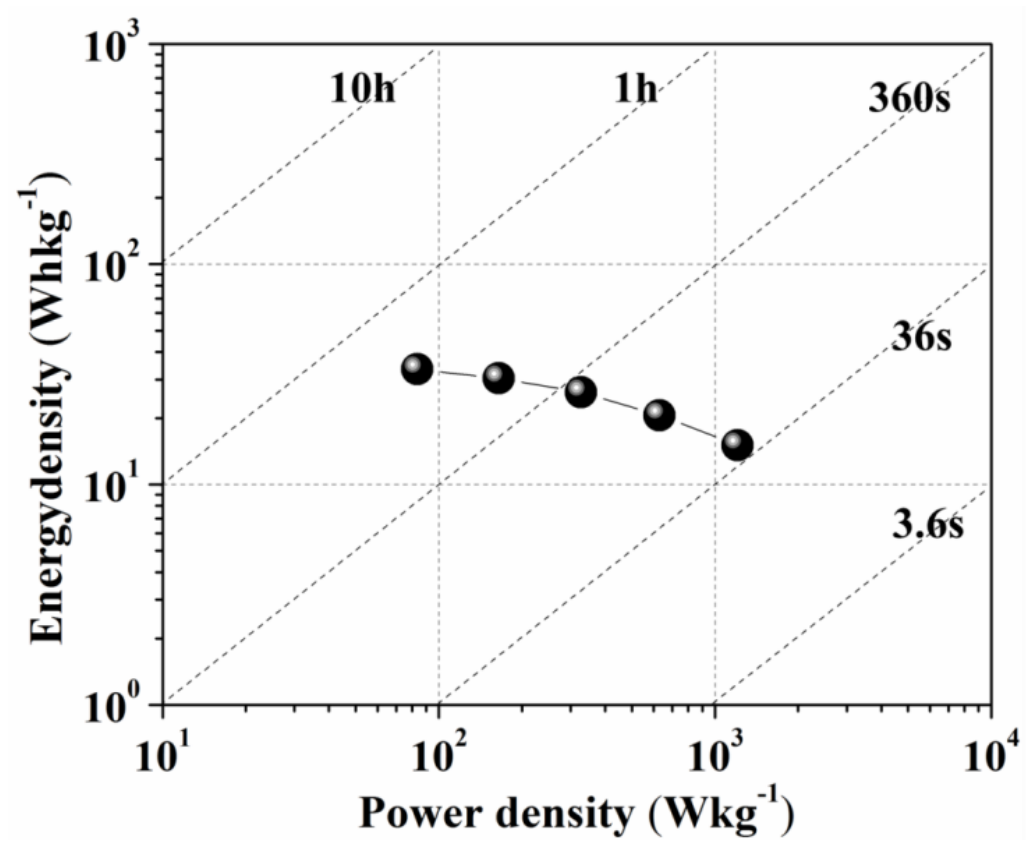

Figure 4.6: Ragone Plot of the ESD-based Li-HEC full cells based on discharge characteristics. 


\subsection{Conclusions}

A novel 3V Li-HEC utilizing ESD based rGO-CNT composite cathode and an anatase $\mathrm{TiO}_{2}-\mathrm{Li}_{4} \mathrm{Ti}_{5} \mathrm{O}_{12}$ anode was constructed and analyzed. The cathode and anode were first analyzed as working electrodes against a lithium counter electrode and were able to deliver discharge capacities of ca. $63 \mathrm{mAhg}^{-1}$ and $95 \mathrm{mAhg}^{-1}$ with good reversibility and cycling. The full Li-HEC cells were able to deliver a maximum energy density of $33.35 \mathrm{Whkg}^{-1}$ and a maximum power density of $1207.4 \mathrm{Wkg}^{-1}$, with specific energy ranging between $33.35-15.09 \mathrm{Whkg}^{-1}$ at power densities of $83.55-1207.4 \mathrm{Wkg}^{-1}$, where all the cell parameters were normalized with the total anode and cathode masses. Furthermore, the Li-HEC cells were able to retain $\sim 77 \%$ of capacitance retention after 100 cycles. The superior energy-power cell characteristics are attributed to the porous electrode structure and the utilization of organic electrolyte which allows for a wider electrochemical potential window. The feasibility of using ESD for construction of a high performance hybrid capacitor was thus demonstrated in this report. Further enhancement in energy and power is expected with the use of ESD based internal parallel systems which can address voltage matching and mitigate double layer and redox charge storage mismatch, which are subjects of future works.

\subsection{References}

1. Cericola, D.; Kotz, R; Electrochim. Acta, 2012, 72, 1-17.

2. Amatucci, G. G.; Badway, F.; Pasquier, A. D.; Zheng, T; J. Electrochem. Soc., 2001, 148, A930-A939.

3. Sivakkumar, S. R.; Milev, A. S.; Pandolfo, A. G.; Electrochim. Acta, 2011, 56, 97009706. 
4. Sivakkumar, S. R.; Nerkar, J. Y.; Pandolfo, A. G.; Electrochim. Acta, 2010, 55, 33303335.

5. Agrawal, R.; Hao, Y.; Song, Y.; Chen, C.; Wang, C.; Proc. SPIE 9493, Energy Harvesting and Storage: Materials, Devices, and Applications VI, 94930B, 2015

6. Naoi, K; Naoi, W; Aoyagi, S.; Miyamoto, J.; Kamino, T.; Acc. Chem. Res., 2013, 46 (5), 1075-1083.

7. Ping, L.; Zheng, J.; Shi, Z.; Qi, J.; Wang C. Y.; Chin. Sci. Bull., 2013, 58, 689.

8. Li, J.; Zhang, X; Peng, R.; Huang, Y.; Guo, L.; Qi, Y. C.; RSC Adv., 2016,6, 5486654873.

9. Byeon, A.; Boota, M.; Beidaghi, M.; Aken, K. V.; Lee, J. W.; Gogotsi, Y.; Electrochem. Commun., 2015, 60, 199-203.

10. Brousse, T.; Marchand, R.; Taberna, P. L.; Simon, P.; J. Power Sources, 2006, 158, 571-577.

11. Hsieh, C. L.; Tsai, D. S.; Chiang, W. W.; Liu, Y. H.; Electrochim. Acta, 2016, 209, 332-340.

12. Tu, F. Y.; Liu; S. Q.; Wu, T. H.; Jin, G. H.; Pan, C. Y.; Powder Technology, 2014, 253, 580-583.

13. Agrawal, R.; Chen, C.; Hao, Y.; Song, Y.; Wang, C. "Graphene for Supercapacitors", In Graphene-Based Energy Devices; Yusoff, A. R. B. M. (Ed.); Wiley-VCH: Weinheim, 2015, pp 171-214.

14. Beidaghi, M.; Wang, C.; Adv. Funct. Mater., 2012, 22, 4501-4510.

15. Jung, N.; Kwon, S.; Lee, D.; Yoon, D. M.; Park, Y. M.; Benayad, A.; Choi, J. Y.; Park, J. S.; Adv. Mater., 2013, 25, 6854-6858.

16. Agrawal, R., Nieto, A., Chen, H., Mora, M., Agarwal, A., ACS Appl. Mater. Interfaces, 2013, 5, 12052-12057.

17. Froschl, T.; Hormann, U.; Kubiak, P.; Kucerova, G.; Pfanzelt, M.; Weiss, C. K.; Behm, R. J.; Huesing, N.; Kaiser, U.; Landfester, K.; Wohlfahrt-Mehrens, M.; Chem Soc Rev, 2012, 41, 5313-5360.

18. Yi, T. F.; Yang, S. Y.; Xie, Y.; J. Mater. Chem. A; 2015, 3, 5750-5777.

19. Chen, J. S.; Lou, X. W.; Electrochem. Commun., 2009, 11, 2332-2335.

20. Deng, D.; Kim, M. G.; Lee, Y. L.; Cho, J.; Energy Environ. Sci., 2009, 2, 818-837. 
21. Gao, L.; Li, S.; Huang, D.; Shen, Y.; Wang, M.; J. Mater. Chem. A; 2015, 3, 10107.

22. Wang, J.; Zhao, H.; Yang, Q.; Wang, C., Lv, P.; Xia, Q.; J. Power Sources, 2013, $222,196$.

23. Yi, T.; Fang, Z.; Xie, Y.; Zhu, Y.; Yang, S.; ACS Appl. Mater. Interfaces, 2014, 6 (22), 20205-20213.

24. Jaworek, A.; Sobczyk, A.T.; Krupa, A.; Lackowski, M.; Czech. T.; Bull. Pol. Acad. Sci., Tech. Sci, 2009, 57, 63.

25. Jaworek, A.; Sobczyk, A.T.; J Electrostat, 2008, 66, 197.

26. Chen, C.; Agrawal, R.; Kim, T. K.; Li, X.; Chen, W.; Yu, Y.; Beidaghi, M.; Penmatsa, V.; Wang, C.; ECS Trans., 2014, 61, 155-163.

27. Li, X.; Wang, C.; Mater. Chem. A, 2013, 1, 165.

28. Sokolov, S.; Paul, B.; Ortel, E.; Fischer, A.; Kraehnert, R.; Langmuir, 2011, 27, 1972.

29. Dhanabalan, A.; Li, X.; Agrawal, R.; Chen, C.; Wang, C.; Nanomaterials, 2013, 3(4), 606-

30. Beidaghi, M.; Wang, Z.; Gu, L.; Wang, C.; J Solid State Electrochem, 2012, 16, 3341.

31. Rattana, T.; Chaiyakun, S.; Witit-anun, N.; Nuntawong, N.; Chindaudom, P.; Oaew, S.; Kedkeaw, C.; Limsuwan, P.; Procedia Engineering, 2012, 32, 759 - 764.

32. González, M. G.; Cabanelas, J. C.; Baselga, J. Applications of FTIR on Epoxy Resins - Identification, Monitoring the Curing Process, Phase Separation and Water Uptake, In Infrared Spectroscopy - Materials Science, Engineering and Technology; Theophanides, T. (Ed.); InTech

33. Sim, L. C.; Leong, K. H.; Ibrahim, S.; Saravanan, P.; J. Mater. Chem. A, 2014, 2, 5315-5322.

34. Kim, H.; Park, K. Y.; Hong, J.; Kang, K.; Sci. Rep., 2014, 4, Article number: 5278.

35. Batchelor-McAuley, C.; Compton, R. G.; J. Electroanal. Chem., 2012, 669, 73-81,

36. Sun, J.; Teng, D.; Liu, Y.; Chi, C.; Yu, Y.; Lan, J. H.; Yang, X.; RSC Adv., 2014,4, 48632-48638.

37. Gao, L.; Huang, D.; Shen, Y.; Wang, M.; J. Mater. Chem. A; 2015, 3, 23570.

38. Zheng, J. P.; J. Electrochem. Soc., 2003, 150, A484-A492: 
39. Zheng, J. P.; J. Electrochem. Soc., 2009, 156, A500-A505.

40. Wang, Y. G., Wang, Z.; Xia, Y.; Electrochim. Acta, 2005, 50, 5641-5646.

41. Luo, J. Y.; Xia, Y.; J. Power Sources, 2009, 186, 224-227.

42. Yuan, T.; Li, W. T.; Zhang, W.; He, Y. S.; Zhang, C.; Liao, X. Z.; Ma, Z. F.; Ind. Eng. Chem. Res., 2014, 53, 10849-10857.

43. Jung, H. G.; Venugopal, N.; Scrosati, B.; Sun, Y. K.; J. Power Sources, 2013, 221, 266.

44. Ni, J.; Yang, L.; Wang, H.; Gao, L.; J Solid State Electrochem, 2012, 16, 2791. 


\section{ELECTROSTATIC SPRAY DEPOSITION BASED MANGANESE OXIDE FILMS: FROM PSEUDOCAPACITIVE CHARGE STORAGE MATERIALS TO THREE-DIMENSIONAL MICROELECTRODE INTEGRANDS}

\subsection{Introduction}

The technological advancement toward small-scale and portable devices has resulted in an increased demand for micro-power systems. For instance, the recent boom in the development of implantable medical devices, wireless sensors, smart cards, microelectromechanical systems (MEMS) and personal electronics has resulted in the need for reliable miniaturized energy storage devices. At present, the majority of the micro-devices rely on batteries to provide the required energy and power. Despite the commercial availability of thin-film or "microbatteries", their relatively poor powerhandling ability and limited lifetime hinder their applicability to systems that require high current spikes [1,2]. As an alternative to batteries, energy harvesters hold significant promise for sustainable environments; however, the currently existing energy harvester systems require an energy storage device in tandem [1]. Electrochemical capacitors or supercapacitors, on the other hand, are electrochemical energy storage systems that possess higher power densities than batteries along with superior lifetime. Conventional supercapacitors, however, are too bulky for small-scale applications and their fabrication methods are not compatible with the currently existing Integrated Circuit (IC) technology. Therefore, of immediate need is downsizing supercapacitors with compatible microelectronic fabrication techniques, so that they can be placed directly on the chip. Such devices, also referred to as micro-supercapacitors (MSCs), generally possess negligible active material masses and, therefore, their performance metrics are typically 
normalized by the area of the system. The typical areal energy and power densities delivered by MSCs range from $\mu \mathrm{Wh}-\mathrm{mWh} \cdot \mathrm{cm}^{-2}$ and $\mu \mathrm{W}-\mathrm{mW} \cdot \mathrm{cm}^{-2}[1,3-5]$. Volumetric/stack normalization is also popular for reporting MSC performance, since it provides insight into intrinsic material properties, as well as device architecture.

In the past decade, carbon microelectromechanical systems (C-MEMS) technique has emerged as a potential technique to successfully fabricate carbon-based current collectors and electrodes for on-chip energy storage and bio-sensing applications [6-13]. The C-MEMS process is a microfabrication technique that essentially involves the pyrolysis of a patterned photoresist into carbon structures. C-MEMS offers the feasibility of creating 3D micro-pillars, which offsets the limitation of the small footprint area required for miniaturized systems. The idea of using 3D C-MEMS-based microstructures as current collectors for the integration of other capacitive materials was first demonstrated by Chen et al. [11], where they grew carbon nanotubes (CNTs) on the surface of the C-MEMS structures. The CNT/C-MEMS structures were reported to exhibit specific capacitance as high as 20 times that of the bare C-MEMS structures. Other reports have documented the use of C-MEMS-based MSCs including electrochemically activated C-MEMS [12], and polypyrrole (PPY) decorated C-MEMS structures [13]. Apart from CNT and PPY, manganese oxides offer great promise as active materials, owing to their high theoretical specific capacitance, environmental benignity, large abundance, and low cost [14-17]. Of all polymorphs, birnessite $\mathrm{MnO}_{2}$, in particular, is very well suited for energy storage applications, given the simultaneous utilization of the double-layer capacitance as well as the $\mathrm{Mn}^{3+} / \mathrm{Mn}^{4+}$ redox couple [17]. Its layered structure exhibits edge-sharing $\mathrm{MnO}_{6}$ octahedra in the sheets, and the facile 
in-and-out cation motion from the interlayer region allows for partial electrolyte ion intercalation into the lamellar region [17]. One of the recently proposed synthetic routes to obtaining birnessite $\mathrm{MnO}_{2}$ (layered) is the electrochemical phase transition from hausmannite $\mathrm{Mn}_{3} \mathrm{O}_{4}$ (spinel) [18-20]. The synergy between the hausmannite and birnessite phases has been documented to yield superior current response as opposed to the pristine $\mathrm{MnO}_{2}$ or $\mathrm{Mn}_{3} \mathrm{O}_{4}$ phases [21,22]. Furthermore, as noted by Kim et al. [23], the spontaneous transition of layered to spinel manganese oxides is one of the critical factors that compromises with their structural stability, and therefore, the opposite transition from spinel to layered phases could be advantageous for enhancing the cycle life of layered birnessite materials.

In this work, porous manganese oxide films were synthesized via electrostatic spray deposition (ESD) and evaluated as pseudocapacitive materials and as active materials for C-MEMS integration. ESD is an electrohydrodynamic spraying technique, which essentially involves the disintegration of a precursor solution into an aerosol spray upon the application of a high voltage between the feeding source and a grounded preheated substrate. The ability to tailor the film morphology by fine-tuning deposition parameters, without the need for vacuum, is what makes ESD an attractive and cost-effective thinfilm synthesis method [24-29]. The ESD-derived manganese oxide films were able to deliver specific capacitances as high as $225 \mathrm{~F} \cdot \mathrm{g}^{-1}$ from $72 \mathrm{~F} \cdot \mathrm{g}^{-1}$ upon electrochemical cycling in neutral aqueous media. The enhancement in capacitance was ascribed to a partial phase transformation from hausmannite $\mathrm{Mn}_{3} \mathrm{O}_{4}$ (spinel) to birnessite $\mathrm{MnO}_{2}$ (layered). In addition to the enhancement in charge storage capacity, a concomitant improvement in kinetics and resistivity was observed upon cycling. Given the 
coexistence of the two phases, the films are referred to as $\mathrm{MnO}_{x}$ henceforth. Several reports have documented the use of ESD-based manganese oxide films but their direct applicability to microsystems has not been explored [30,31]. Given the potent advantages of thin films for microsystems, the ESD-based $\mathrm{MnO}_{x}$ were integrated onto the C-MEMSgenerated 3D carbon micro-pillars and evaluated as MSC systems. In a two-electrode configuration, the $\mathrm{MnO}_{x} / \mathrm{C}$-MEMS microelectrodes (MEs) were able to deliver specific capacitance as high as $0.055 \mathrm{~F} \cdot \mathrm{cm}^{-2}$, much higher than other microsystems [32-34]; the maximal volumetric energy and power densities delivered by the $\mathrm{MnO}_{x} / \mathrm{MEs}$ were 0.51 $\mathrm{mWh} \cdot \mathrm{cm}^{-3}\left(1.84 \mathrm{~J} \cdot \mathrm{cm}^{-3}\right)$ and $28 \mathrm{~mW} \cdot \mathrm{cm}^{-3}\left(28.3 \mathrm{~mJ} \cdot \mathrm{s}^{-1} \cdot \mathrm{cm}^{-3}\right)$, respectively. The excellent areal capacitance and the relatively high stack energy density of the $\mathrm{MnO}_{x}$-MEs are attributed to the pseudocapacitive $\mathrm{MnO}_{x}$ as well as the three-dimensional architectural framework provided by the micro-pillars.

\subsection{Results and Discussion}

\subsubsection{Crystallographic, Spectroscopic and Microstructural Studies on the As- Prepared and Cycled $\mathrm{MnO}_{\mathrm{x}}$ Films}

The XRD pattern of the as-deposited manganese oxide powders is depicted in Figure 5.1a. The as-deposited powder was confirmed to be hausmannite- $\mathrm{Mn}_{3} \mathrm{O}_{4}$ (Joint Committee on Powder Diffraction Standards (JCPDS) Card Number: 00-24-0734). The peaks at $18.0^{\circ}, 28.9^{\circ}, 32.4^{\circ}, 36.2^{\circ}, 38.3^{\circ}, 44.5^{\circ}, 50.9^{\circ}, 53.6^{\circ}, 58.5^{\circ}, 60.1^{\circ}, 64.8^{\circ}$ and $74.3^{\circ}$ are attributed to the (hkl) planes (101), (112), (103), (211), (004), (220), (105), (321), (215), (400) and (413), respectively. The XRD pattern of the cycled $\mathrm{MnO}_{x}$ (after 1000 cycles), depicted in Figure 5.2a, on the other hand, did not exhibit any sharp peaks indicating the phase to be mostly amorphous. The broad peak centered at $18.64^{\circ}$ is indexed 
as (002) plane of the birnessite $\mathrm{MnO}_{2}$ phase, whereas the two faint peaks located at $36.7^{\circ}$ and $65.7^{\circ}$ are identified as (006) and (119) planes, respectively (JCPDS Card Number: 00018-0802) [35]. The Fourier Transform Infrared (FTIR) spectrum of the as-synthesized $\mathrm{MnO}_{x}$ films between frequencies of $500-4000 \mathrm{~cm}^{-1}$ is depicted in Figure 5.1b. In the highfrequency region, the broad peak centered at $3345 \mathrm{~cm}^{-1}$ is assigned to $-\mathrm{OH}$ stretching vibrations [36], whereas the peak located at around $1624 \mathrm{~cm}^{-1}$ is attributed to $-\mathrm{OH}$ bending vibrations [36]. In the lower frequency region, the absorption peaks located at $529 \mathrm{~cm}^{-1}$ and $602 \mathrm{~cm}^{-1}$ are ascribed to Mn-O stretching modes in the octahedral and tetrahedral sites, respectively [20,36-38]. The FTIR spectrum of the cycled $\mathrm{MnO}_{x}$ (after 1000 cycles) film is shown in Figure 5.2b. It should be noted that while the majority of the peaks signaling -OH bending and stretching are still visible, the peak at $602 \mathrm{~cm}^{-1}$ which signals the presence of the tetrahedral stretch of Mn-O disappears, indicating a loss of order in the crystal structure as compared to the as-synthesized $\mathrm{MnO}_{x}$ films. However, the peak at $525 \mathrm{~cm}^{-1}$ is still present indicating that the cycled films comprise predominantly Mn-O groups from the octahedral layers, which is also indicative of birnessite phase. The microstructure of the asdeposited manganese oxide sample is shown in Figure 5.1c; the microstructure was mostly porous with reticular network-like morphology. The microstructure of the electrochemically cycled manganese oxide (after 1000 cycles) is shown in Figure 5.2c. As evident, there is a dramatic change in the morphology as compared to the as-deposited films; as opposed to the previous reticular structure, the post-cycling structure is predominantly "layered" platelet-like, which is reminiscent of birnessitic- $\mathrm{MnO}_{2}[19,20]$. Figure 5.1d shows the High Resolution Transmission Electron Microscope (HRTEM) micrograph of the sample; the particles were nano-sized with different planar orientations. 
The lattice fringes with d-spacings of $4.78 \AA$ and $2.47 \AA$ were indexed as (hkl) orientations of (101) and (211) of hausmannite- $\mathrm{Mn}_{3} \mathrm{O}_{4}$. The Selected Area Electron Diffraction (SAED) pattern is shown as the inset of Figure 5.1d. The d-spacings of $2.41 \AA, 2.03 \AA, 1.83 \AA, 1.54$ $\AA, 1.27 \AA, 1.10 \AA$ and $1.03 \AA$ corresponded to (hkl) orientations of (211), (220), (204), (224), (413), (512) and (327) of hausmannite- $\mathrm{Mn}_{3} \mathrm{O}_{4}$. The HRTEM of the cycled $\mathrm{MnO}_{x}$ powders is shown in Figure 5.2d and the detailed SAED analysis is shown as the inset. The d-spacings of $2.29 \AA$ and $1.50 \AA$, correspond to (hkl) planes of (006) and (119) of the birnessite phase, respectively, whereas the d-spacings of $2.01 \AA, 1.82 \AA$ and $1.13 \AA$ correspond to (220), (204) and (512) planes of the hausmannite phase. 

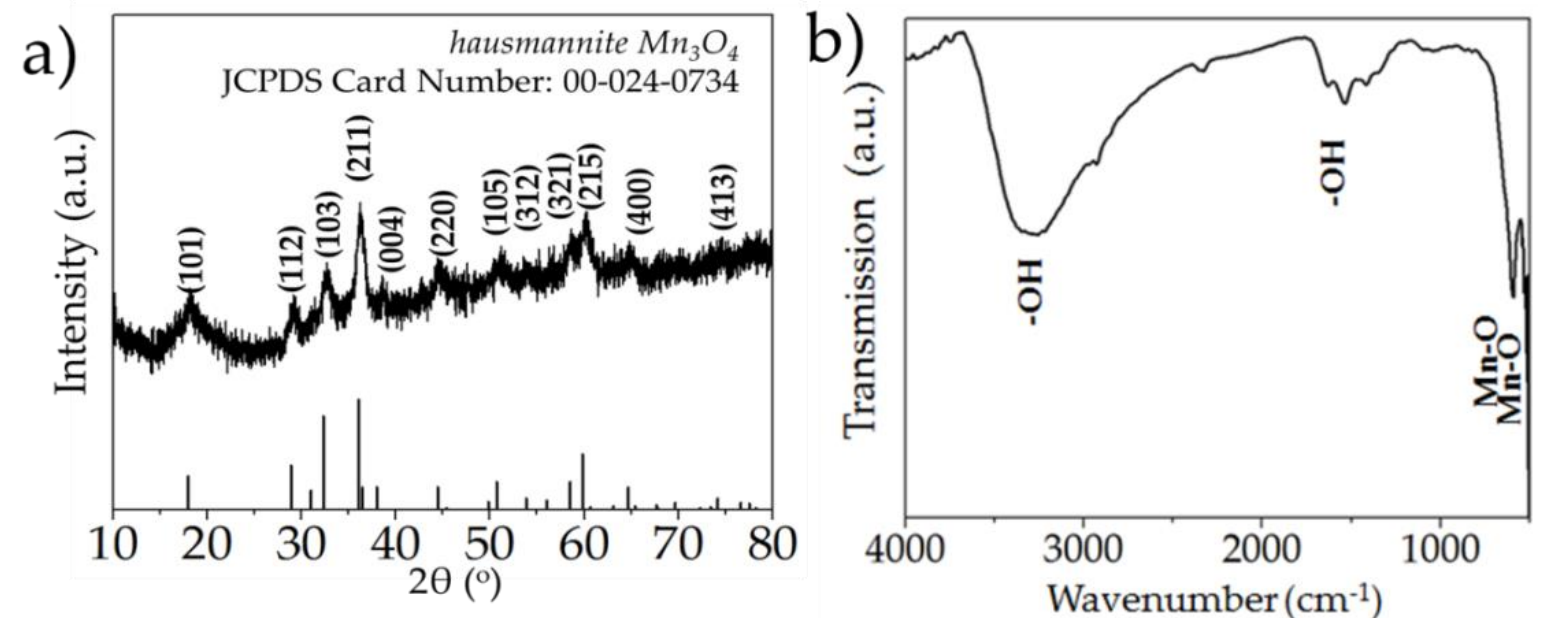

c)
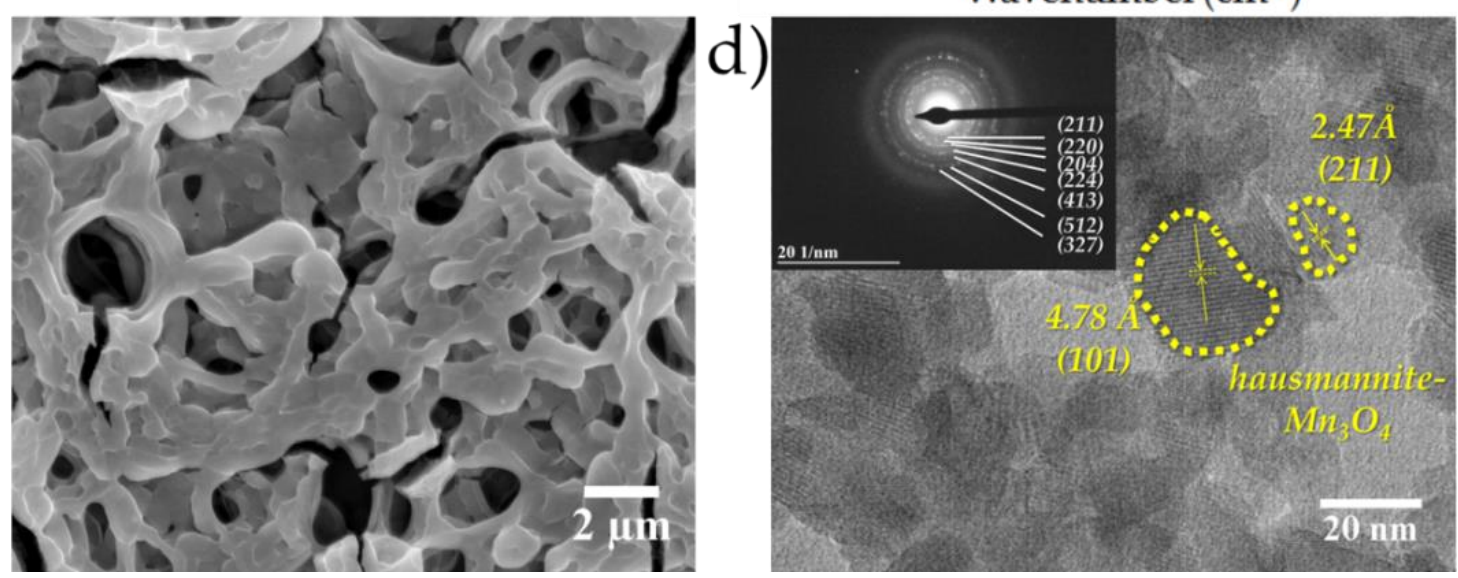

Figure 5.1: (a) XRD pattern of the as-deposited $\mathrm{MnO}_{x}$ powders; (b) FTIR pattern of the as-deposited $\mathrm{MnO}_{x}$ films; (c) $\mathrm{SEM}$ microstructure of the as-deposited $\mathrm{MnO}_{x}$ films; (d) HRTEM micrograph of the as-deposited $\mathrm{MnO}_{x}$ powders; the inset depicts the SAED pattern. 
a)

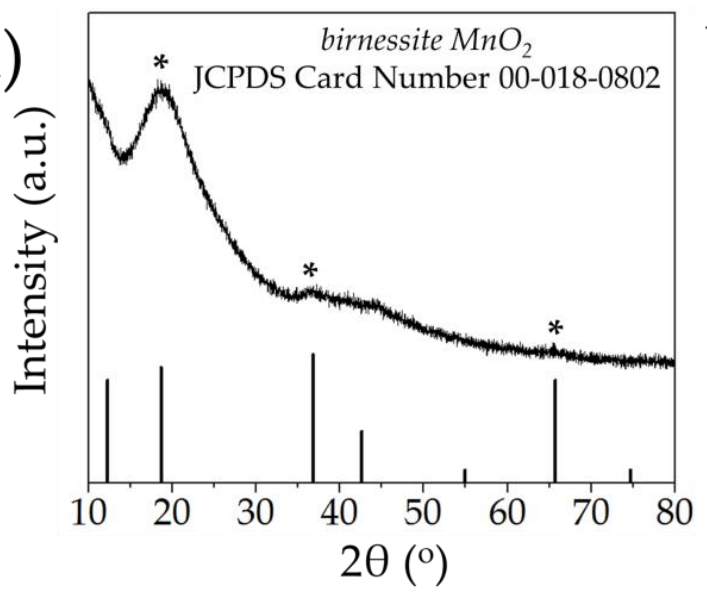

c)

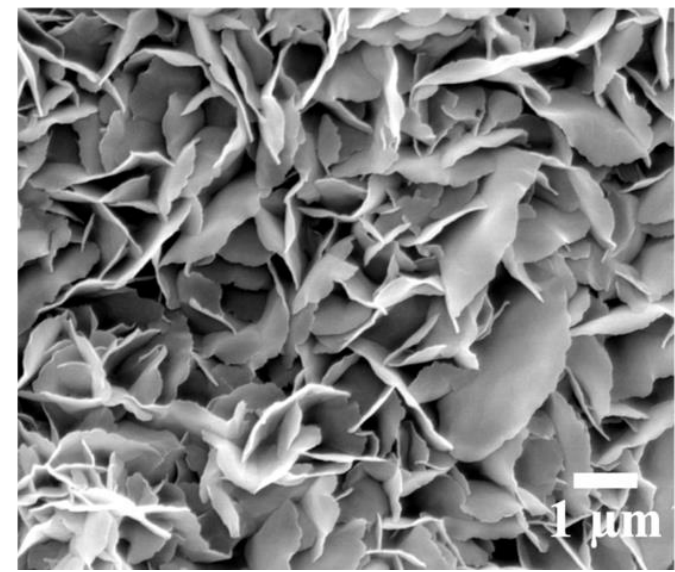

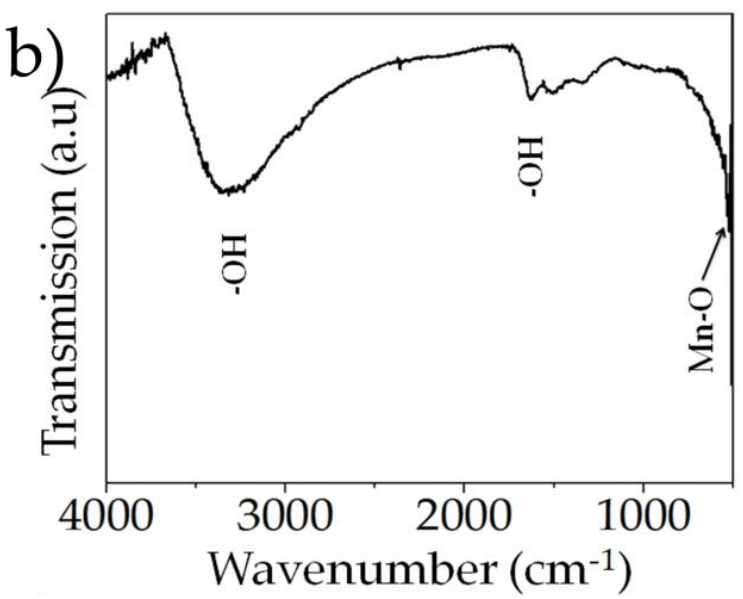

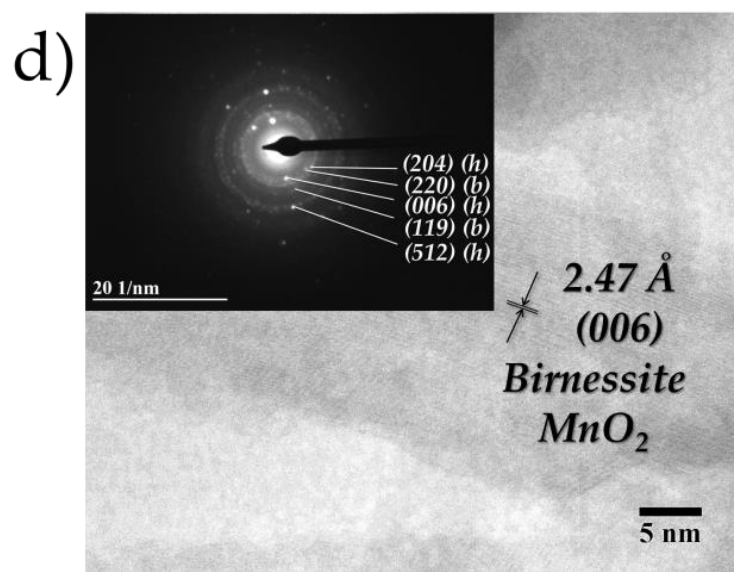

Figure 5.2: (a) XRD pattern of the cycled $\mathrm{MnO}_{\mathrm{x}}$ powders; (b) FTIR pattern of the cycled $\mathrm{MnO}_{x}$ films; (c) microstructure of the cycled $\mathrm{MnO}_{x}$ films showing layered platelet-like morphology; (d) HRTEM of the cycled $\mathrm{MnO}_{x}$ powders; the inset shows the SAED pattern, (b) represents birnessite phases, whereas (d) represents hausmannite phase.

\subsubsection{Electrochemical Characterization of the $\mathrm{MnO}_{\mathrm{x}}$ Films}

The cyclic voltammograms (CV) of the as-synthesized manganese oxide films between potentials of $-0.1 \mathrm{~V}$ and $0.9 \mathrm{~V}\left(\mathrm{vs} . \mathrm{Ag} / \mathrm{AgCl}\right.$ ) at a sweep rate of $5 \mathrm{mV} \cdot \mathrm{s}^{-1}$ are shown in Figure 5.3a. As evident for the 2nd cycle, the CV has no discernible redox peaks. Upon cycling, however, there is a gradual origin and increase in the intensity of anodic and cathodic currents around $0.63 \mathrm{~V}$ and $0.34 \mathrm{~V}$, which is attributed to the oxidation and reduction between the $\mathrm{Mn}^{3+} / \mathrm{Mn}^{4+}$ redox couple, as per the Pourbaix 
diagram $[21,30,39]$. It is worth noting that the area under the CV curve increases substantially upon cycling, which implies that there is enhancement in capacitance upon electrochemical cycling. The gravimetric specific capacitances $\left(C_{s}\right)$ at the 2 nd, 10th, 20th, 50th, 100th, 200th and the 500th cycles were approximated as 56, 102, 129, 156, 162, 163 and $160 \mathrm{~F} \cdot \mathrm{g}^{-1}$, respectively, using Equation (1), where $C_{s}$ is the specific capacitance, $\mathrm{m}$ is the mass of the electrode, $s$ is the scan rate, $\Delta V$ is the voltage window, $I$ is the current, and $V$ is the voltage.

$$
C_{s}=\frac{1}{2 m s \Delta V} \int I d V
$$

Figure 5.3b depicts the galvanostatic charge-discharge (GCD) curves of the $\mathrm{MnO}_{x}$ films at a current density of $0.5 \mathrm{Ag}^{-1}$. As evident, there is a significant enhancement in capacitance from the 2nd cycle accompanied with a marked decrease in the voltage drop in the subsequent cycles. At the 2nd, 10th, 20th, 50th, 100th, 200th and 500th cycles, the specific capacitance was approximated as 72, 139, 172, 197, 214, 225, 223 and $215 \mathrm{~F} \cdot \mathrm{g}^{-1}$, respectively. In order to investigate the resistivity changes upon subsequent cycling in the sample, Electrochemical Impedance Spectroscopy (EIS) studies were carried between frequencies of 100,000 Hz and $0.01 \mathrm{~Hz}$. A typical Nyquist curve comprised a depressed semicircle in the high-frequency region followed by a relatively linear slope in the lower frequencies. The diameter of the semicircular region is associated with the chargetransfer resistance of the system at the electrode-electrolyte interface, and equivalent circuit analyses were done in order to verify the effect of cycling on the resistance of the system. The equivalent circuit for the Nyquist plots has been depicted as the inset of Figure 5.3c. $R_{s}, R_{c t}, W, C_{d l}$ and $C_{p}$ stand for solution resistance, charge-transfer resistance, 
Warburg impedance, double-layer capacitance, and pseudocapacitance, respectively [40]. The values of $R_{c t}$ and $R_{s}$ at different cycles have been tabulated in Table 5.1.

\section{Table 5.1: Solution and charge-transfer resistances computed from equivalent circuit at different cycles.}

\begin{tabular}{ccccccc}
\hline & $\begin{array}{c}\text { Before } \\
\text { Cycling }\end{array}$ & $\begin{array}{c}\text { After 100 } \\
\text { Cycles }\end{array}$ & $\begin{array}{c}\text { After 200 } \\
\text { Cycles }\end{array}$ & $\begin{array}{c}\text { After 300 } \\
\text { Cycles }\end{array}$ & $\begin{array}{c}\text { After 400 } \\
\text { Cycles }\end{array}$ & $\begin{array}{c}\text { After 500 } \\
\text { Cycles }\end{array}$ \\
\hline $\mathrm{R}_{\mathrm{s}}(\Omega)$ & 3.56 & 4.51 & 4.51 & 9.54 & 4.44 & 5.11 \\
\hline $\mathrm{R}_{\mathrm{ct}}(\Omega)$ & 198.91 & 81.63 & 55.31 & 62.95 & 67.84 & 72 \\
\hline
\end{tabular}

As evident, the charge-transfer resistance decreases rapidly for the first 200 cycles, which can be ascribed to the transformation of the relatively insulating $\mathrm{Mn}_{3} \mathrm{O}_{4}$ to the more conducting birnessite $\mathrm{MnO}_{2}$, and is consistent with previous reports [19]. The slight increase in the resistance after the 200th cycle can be attributed to the resistance changes in the predominantly active birnessite phase upon cycling. The long-term cycling of the $\mathrm{MnO}_{x}$ films has been shown in Figure 5.3d. The specific capacitance of the electrode steadily increases from ca. $72 \mathrm{~F} \cdot \mathrm{g}^{-1}$ at the second cycle to a maximal capacitance of 225 $\mathrm{F} \cdot \mathrm{g}^{-1}$ at the 200th cycle. It should be noted that even the starting capacitance of the $\mathrm{MnO}_{x}$ electrodes was superior to the previously ESD-synthesized $\beta-\mathrm{MnO}_{2}$ films, which yielded a low gravimetric capacitance of $13 \mathrm{~F} \cdot \mathrm{g}^{-1}$ [41]. At the 1000th cycle, the capacitance dropped to $199 \mathrm{~F} \cdot \mathrm{g}^{-1}$, resulting in a capacitive drop of approximately $11.6 \%$ when compared with the maximal capacitance reached by the system. The GCD curves at different current densities are shown in Figure 5.3e. The electrodes were able to deliver 
capacitances of $233,221,196,167,131$ and $88 \mathrm{~F}^{-} \mathrm{g}^{-1}$ at current densities of $0.1,0.2,0.4$, $0.8,1.6$ and $3.2 \mathrm{Ag}^{-1}$, respectively. The effect of scan rate on the capacitance of the $\mathrm{MnO}_{x}$ films is shown in Figure 5.3f. The capacitances were estimated to be ca. 164, 136, 110, 77,47 and $30 \mathrm{~F} \cdot \mathrm{g}^{-1}$ at scan rates of $2,5,10,20,50$ and $100 \mathrm{mV} \cdot \mathrm{s}^{-1}$, respectively. As evident, the capacitance of the $\mathrm{MnO}_{x}$ electrodes decreases with increasing scan rate in addition to the clear deviation from the relatively rectangular capacitive shape. This is expected since the rapid electrolyte ion flux at higher scan rates limits the diffusioncontrolled charge storage processes at the $\mathrm{MnO}_{x}$ electrode surface, resulting in lower utilization of active charge storage sites, thereby limiting the charge storage [42]. 

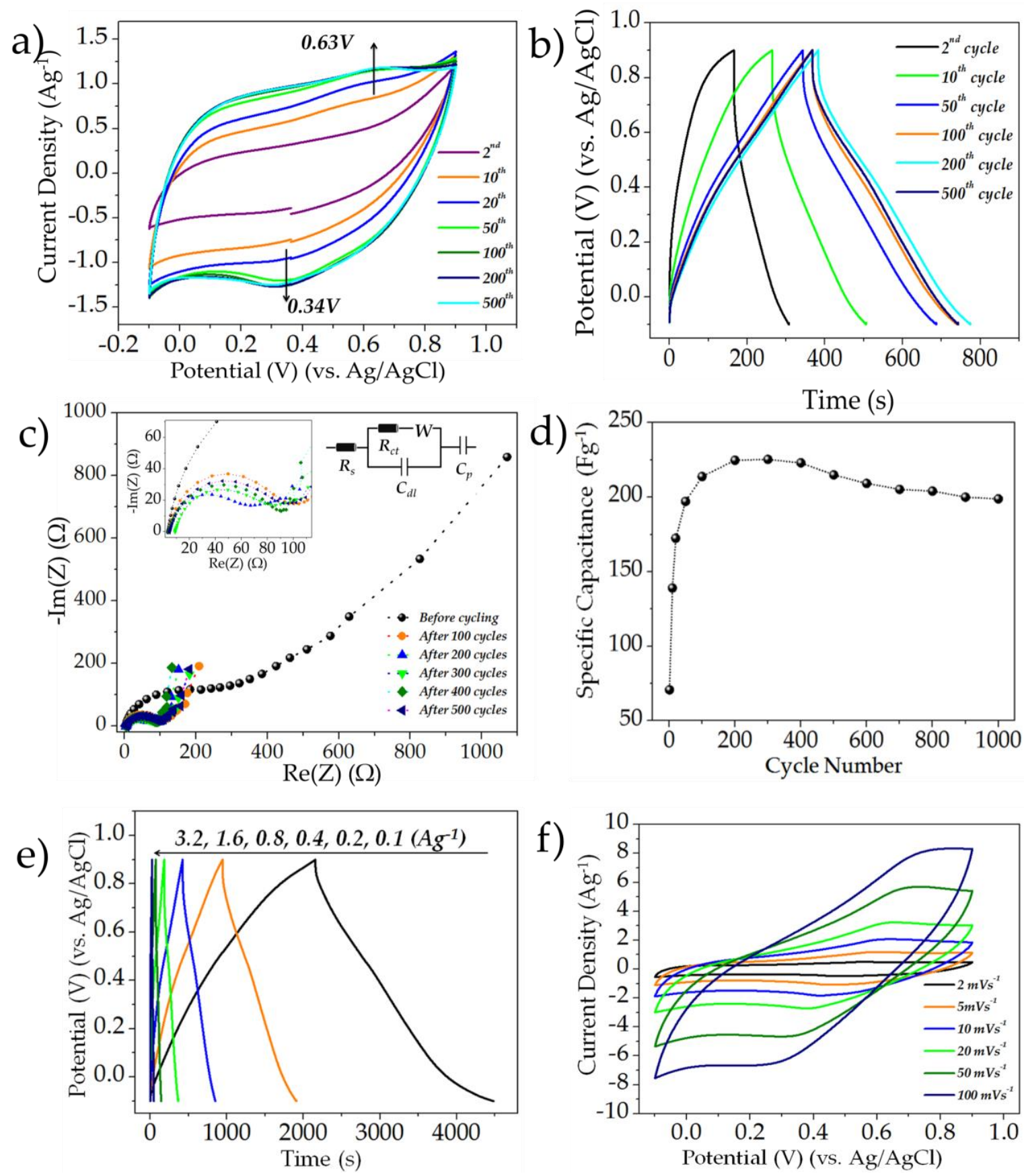

Figure 5.3: (a) $\mathrm{CV}$ curves of the $\mathrm{MnO}_{x}$ films at different cycles scanned at a sweep rate of $5 \mathrm{mV} \cdot \mathrm{s}^{-1}$; (b) typical GCD curves of the $\mathrm{MnO}_{x}$ films at a constant charge-discharge current rate of $0.5 \mathrm{Ag}^{-1}$ for different cycles; (c) Nyquist plots of the $\mathrm{MnO}_{x}$ films at different cycles; the inset depicts the equivalent circuit used for system analyses; (d) cycling behavior of the $\mathrm{MnO}_{x}$ films; (e) galvanostatic charge-discharge profiles of the $\mathrm{MnO}_{x}$ films at different current rates; (f) CV curves at different sweep rates (2-100 $\left.\mathrm{mV} \cdot \mathrm{s}^{-1}\right)$. 


\subsection{3 $\mathrm{MnO}_{\mathrm{x}} / \mathrm{C}$-MEMS Characterization}

Figure 5.4a shows the typical fabrication process of the $\mathrm{MnO}_{x}$-MEs and the detailed explanation is given in Section 3.3. The typical $\mathrm{MnO}_{x}-\mathrm{ME}$ architecture is shown in Figure 5.4b. A typical micro-pillar had an average height of $\sim 75 \mu \mathrm{m}$ and a width of $\sim 35 \mu \mathrm{m}$ (adjusted for tilt angle). Figure 5.4c shows the magnified view of the side of the manganese oxide-encrusted micro-pillars; as evident, the films were reticular with very porous and consistent network-like morphology, analogous to the ones synthesized previously. The thickness of the manganese oxide film was approximately $0.6-0.8 \mu \mathrm{m}$. For stack energy and power density calculations, the energy and power were normalized with the volume of the electrodes, for which the height of the posts was multiplied with the footprint of the device $\left(1 \mathrm{~cm}^{2}\right)$, equating to a volume of $v=1 \mathrm{~cm}^{2} \times 0.0075 \mathrm{~cm}=$ $0.0075 \mathrm{~cm}^{3}$. In order to evaluate the electrochemical performance of the $\mathrm{MnO}_{x}$-MEs, two identical $\mathrm{MnO}_{x}$-MEs were used in a two-electrode symmetric cell setup and the cell was analyzed between a voltage window of 0 and $0.7 \mathrm{~V}$ in $1 \mathrm{M} \mathrm{Na}_{2} \mathrm{SO}_{4}$. For the symmetrical cell system, one of the $\mathrm{MnO}_{x}$-MEs functioned as the working electrode, whereas the other served as the counter electrode. The typical cycling behavior of the $\mathrm{MnO}_{x}$-MEs is shown in Figure 4 d. As evident, the cell capacitance increased from $\approx 14.7 \mathrm{mF} \cdot \mathrm{cm}^{-2}$ to $\approx 19.8$ $\mathrm{mF} \cdot \mathrm{cm}^{-2}$ from the 2 nd to the 500th cycle, respectively. The enhancement in capacitance can be attributed to the electrochemical activation of the $\mathrm{MnO}_{x}$ films upon cycling. GCD curves at different current densities are shown as the inset; the predominantly triangular shape of the charge-discharge curves indicates the capacitive nature of the microelectrodes. Figure 4e shows rate-handling capability of the system, the system was able to deliver geometric capacitances (normalized by footprint area) as high as 55 
$\mathrm{mF} \cdot \mathrm{cm}^{-2}$ at a current rate of $0.05 \mathrm{~mA} \cdot \mathrm{cm}^{-2}$, while still maintaining a capacitance of 22.5 $\mathrm{mF} \cdot \mathrm{cm}^{-2}$ at a current density of $0.5 \mathrm{~mA} \cdot \mathrm{cm}^{-2}$. The maximal stack capacitance (normalized by volume) achieved was $7.44 \mathrm{~F} \cdot \mathrm{cm}^{-3}$, resulting in a maximal stack energy density of $0.51 \mathrm{mWh} \cdot \mathrm{cm}^{-3}\left(1.84 \mathrm{~J} \cdot \mathrm{cm}^{-3}\right)$, whereas the maximal power density achievable was approximated as $28.3 \mathrm{~mW} \cdot \mathrm{cm}^{-3}\left(28.3 \mathrm{~mJ} \cdot \mathrm{s}^{-1} \cdot \mathrm{cm}^{-3}\right)$, as shown in the Ragone chart in Figure 4f. The range of energy density achievable by the system was $0.21-0.51$ $\mathrm{mWh} \cdot \mathrm{cm}^{-3}$, for a power density range of $28.3-1.1 \mathrm{~mW} \cdot \mathrm{cm}^{-3}$. It should be noted that the areal capacitance delivered by the $\mathrm{MnO}_{x}$-MEs was fairly high as compared to other microsystems reported in the literature [32-34], which is ascribed to the threedimensional carbon micro-pillar framework which provides for a much larger surface area for active material integration. Despite the excellent areal capacitance and the relatively high energy density of the $\mathrm{MnO}_{x}$-MEs, their low power density needs to be addressed. Enhancement in the power handling is expected with the use of hybrid $\mathrm{MnO}_{x}$ structures containing a combination of pseudocapacitive $\mathrm{MnO}_{x}$ and conducting doublelayer nanostructured carbons, as well as constructing on-chip inter-digitated systems. Designing inter-digitated designs with anode and cathode on the same chip reduces iontransport resistance [1], as a result of which, the kinetics of the system can be enhanced. Devising such hybrid structures/inter-digitated systems to further enhance the power of $\mathrm{MnO}_{x}$-MEs is a subject of future works. 

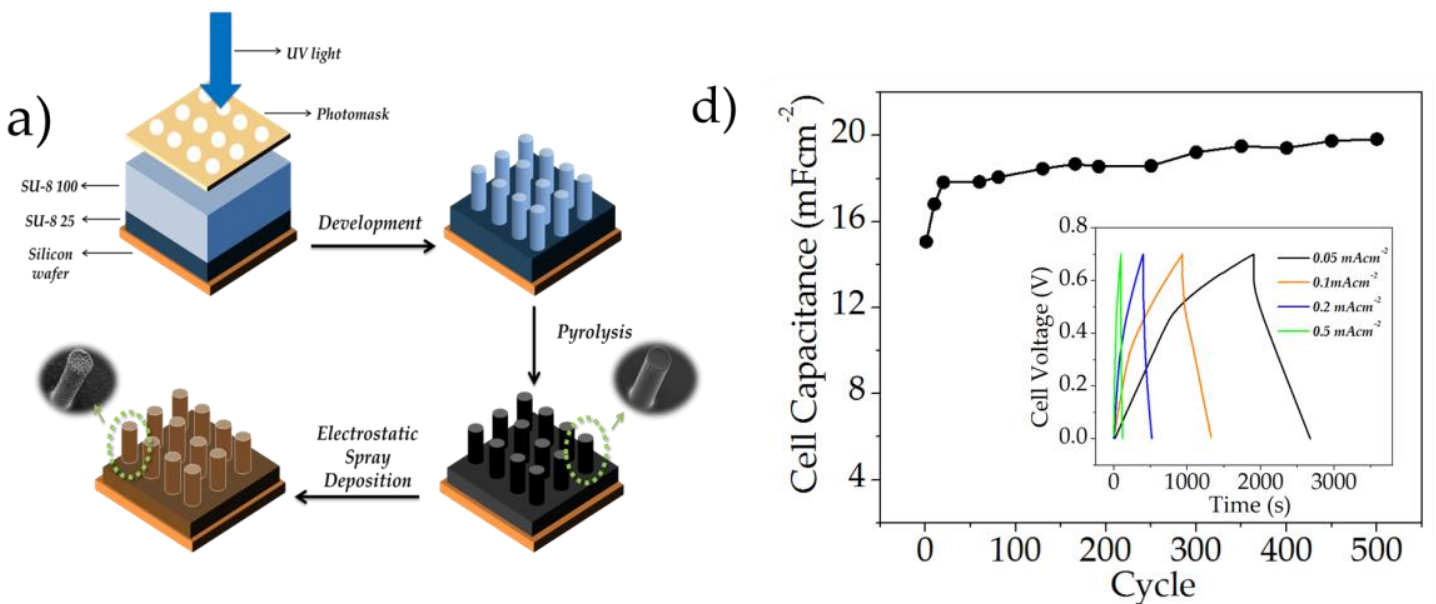

b)
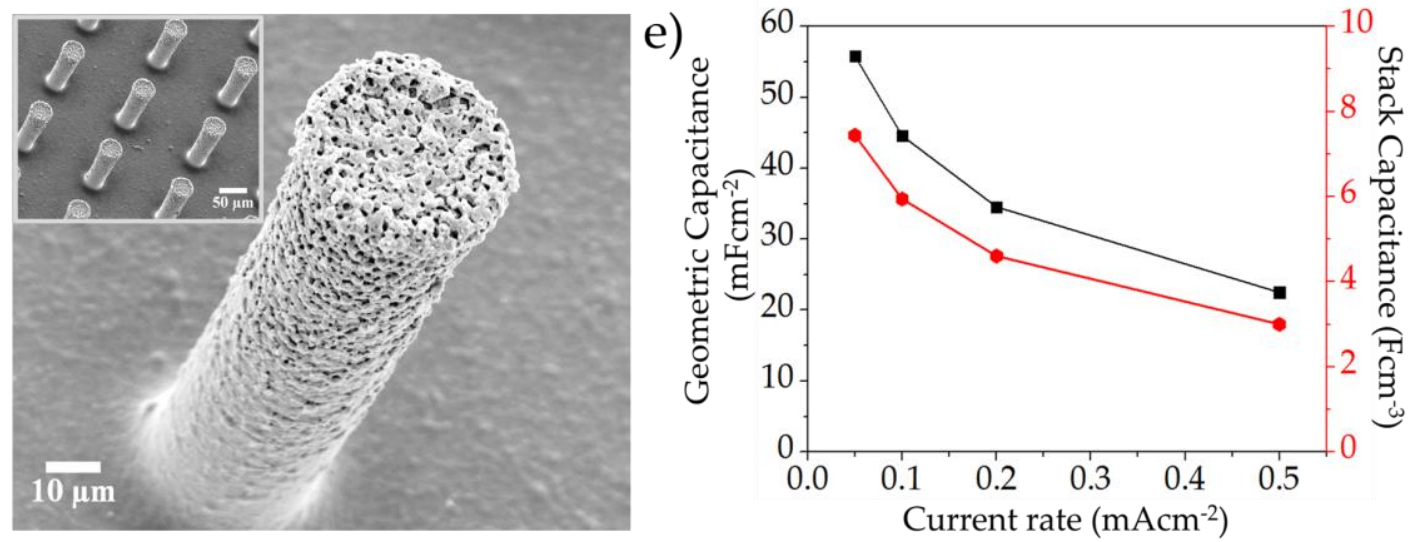

c)
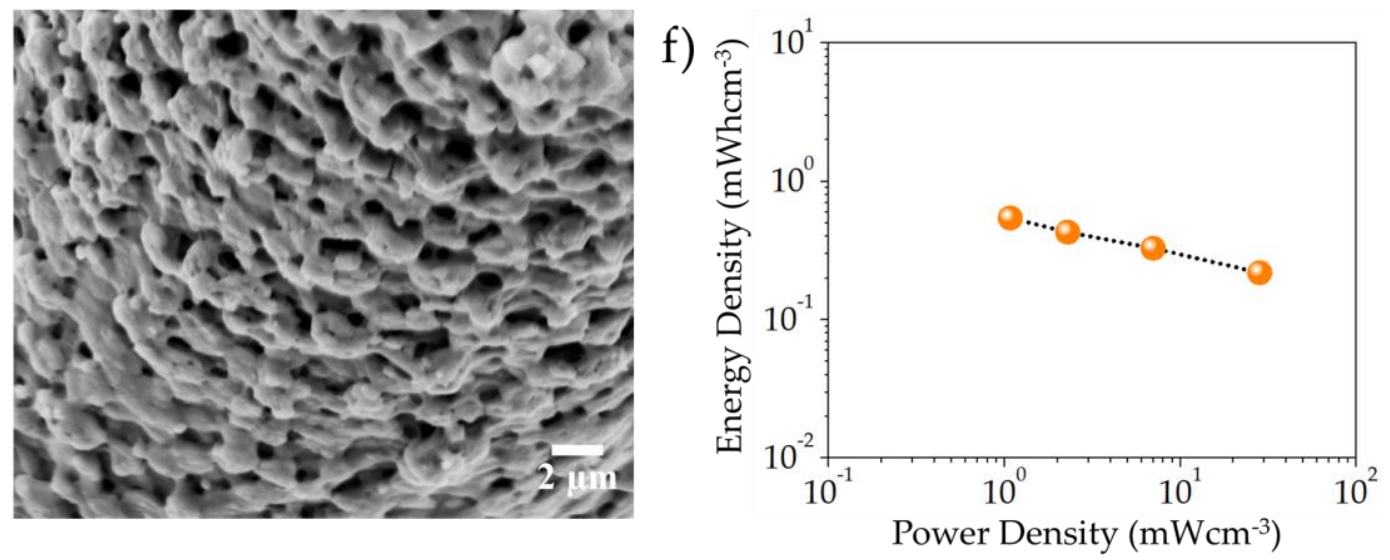

Figure 5.4: (a) Schematic representation of $\mathrm{MnO}_{x}$-ME fabrication process (detailed description in Section 3.3); (b) SEM micrograph of a typical $\mathrm{MnO}_{x}$-encrusted carbon micro-pillar; the inset shows $\mathrm{MnO}_{x}$-encrusted micro-pillar arrays; (c) zoomed-in view of the microstructure of the electrostatic spray deposition (ESD)-generated $\mathrm{MnO}_{x}$ films, (d) cyclability of the $\mathrm{MnO}_{x}$-ME electrodes; the inset depicts typical charge-discharge curves of the $\mathrm{MnO}_{x}$-ME at different current rates $\left(0.05-0.5 \mathrm{~mA} \cdot \mathrm{cm}^{-2}\right)$; (e) geometric and stack capacitances of the $\mathrm{MnO}_{x}$-MEs at different rates; (f) Ragone chart of the $\mathrm{MnO}_{x}$-MEs. 


\subsection{Materials and Methods}

\subsubsection{Manganese Oxide Electrode Synthesis}

Manganese (II) acetate tetrahydrate $\left(\mathrm{Mn}\left(\mathrm{CH}_{3} \mathrm{COO}\right)_{2} \cdot 4 \mathrm{H}_{2} \mathrm{O}\right.$, Alfa Aesar, Ward Hill, MA, USA) was first dissolved in 1,2-propanediol (Sigma Aldrich, St. Louis, MO, USA) in the ratio $2.4 \mathrm{mg} \cdot \mathrm{mL}^{-1}$ with constant stirring for $30 \mathrm{~min}$ and directly used as the precursor solution in order to deposit the $\mathrm{MnO}_{x}$ films. For the ESD setup, the feeding rate was kept at $3 \mathrm{~mL} \cdot \mathrm{h}^{-1}$ and the voltage between the needle and substrate was kept between 6 and $8 \mathrm{kV}$. The distance between the needle and the substrate was approximately $4 \mathrm{~cm}$ and the deposition was carried out at $300{ }^{\circ} \mathrm{C}$ on stainless steel substrates. The typical gravimetric mass yield was $1 \pm 0.05 \mathrm{mg}$ per sample.

\subsubsection{Structural and Material Characterization}

Spectroscopic studies were carried out using FTIR spectroscopy in order to study the effect of cycling on the surface chemistry of the $\mathrm{MnO}_{x}$ films using a JASCO FTIR 4100 equipped with an Attenuated Total Reflectance (ATR) accessory. For crystallinity studies, the powders were scratched off from the stainless steel substrates before and after cycling. The crystallinity of the as-deposited and cycled manganese oxide films was studied using a Siemens 5000D X-ray Diffractometer with $\mathrm{Cu} \mathrm{K} \alpha$ radiation (Siemens, Munich, Germany). Further crystallographic studies on the as-deposited and cycled powders were carried out using a Philips CM-200 $200 \mathrm{KeV}$ Transmission Electron Microscope (TEM) (FEI Philips, Hillsborough, OR, USA). The morphology of the asdeposited and cycled films, as well as the $\mathrm{MnO}_{x} / \mathrm{C}$-MEMS microelectrodes, was studied using a scanning electron microscope (JEOL SEM 6330F, Peabody, MA, USA) in the secondary electron imaging (SEI) mode. 


\subsection{3 $\mathrm{MnO}_{\mathrm{x}} / \mathrm{C}-\mathrm{MEMS}$ Fabrication}

The experimental setup and details of the C-MEMS process used in this work have been reported previously [3-6]. A schematic illustration of $\mathrm{MnO}_{x}-\mathrm{ME}$ fabrication is shown in Figure 5.4a. In brief, the C-MEMS-based 3D micro-pillars were prepared by a two-step photolithography process followed by a pyrolysis step. In the first photolithography step, a two-dimensional square (10 mm side) pattern was created using NANO $^{\mathrm{TM}}$ SU-8 25 (Microchem, Westborough, MA, USA), as the current collector. The photoresist film was spun-coated onto a silicon oxide wafer (4”, (llll 0 l $)$-oriented, n-type) at $500 \mathrm{rpm}$ for $12 \mathrm{~s}$ and at $3000 \mathrm{rpm}$ for $30 \mathrm{~s}$ by using a Headway Research photoresist spinner, followed by soft baking at $65^{\circ} \mathrm{C}$ for $3 \mathrm{~min}$ and hard baking at $95{ }^{\circ} \mathrm{C}$ for $7 \mathrm{~min}$ on a leveled hotplate. The baked photoresist was thereafter patterned with a UV exposure dose of $300 \mathrm{~mJ} \mathrm{~cm}^{-2}$ using an OAI (800) Mask Aligner. After the exposure process, a post-expose bake was conducted at $65^{\circ} \mathrm{C}$ for $1 \mathrm{~min}$ and $95^{\circ} \mathrm{C}$ for $5 \mathrm{~min}$ on a hotplate. The second photolithography step comprised building the cylindrical micro-pillar arrays using NANO ${ }^{\mathrm{TM}}$ SU-8 100 (Microchem, Westborough, MA, USA) on the patterned current collector. SU-8 100 was spun-coated at $500 \mathrm{rpm}$ for $12 \mathrm{~s}$ and at $1500 \mathrm{rpm}$ for $30 \mathrm{~s}$ using a Headway Research photoresist spinner. The spun-coated photoresist was then soft baked at $65^{\circ} \mathrm{C}$ for $10 \mathrm{~min}$ on a leveled hot plate and hard baked at $95^{\circ} \mathrm{C}$ for $45 \mathrm{~min}$ in an oven. The exposure was done using a UV exposure dose of $700 \mathrm{~mJ} \mathrm{~cm}^{-2}$ using an OAI (800) Mask Aligner, following which a post-expose bake was performed at $65{ }^{\circ} \mathrm{C}$ for 3 min and $95{ }^{\circ} \mathrm{C}$ for $10 \mathrm{~min}$ in an oven. Afterward, the sample was developed by $\mathrm{NANO}^{\mathrm{TM}}$ SU-8 developer (Microchem, Westborough, MA, USA) for 15-20 min to wash away any remaining unexposed photoresist, followed by isopropanol rinsing and nitrogen drying. 
Finally, the resultant SU-8 structures were pyrolyzed at $900{ }^{\circ} \mathrm{C}$ for $1 \mathrm{~h}$ in a Lindberg alumina-tube furnace with a continuous flow of argon at a ramp of $5{ }^{\circ} \mathrm{C} / \mathrm{min}$. After the carbonization process, the carbon samples were allowed to cool to room temperature naturally and directly used as substrates for $\mathrm{MnO}_{x}$ integration using ESD as described in Section 4.3.1.

\subsubsection{Electrochemical Characterization}

The electrochemical characterization on the manganese oxide films deposited on stainless steel substrates as well as carbon micro-pillars was carried out using a Bio-logic Versatile Multichannel Potentiostat (VMP3). For half-cell studies, the $\mathrm{MnO}_{x}$ films were used as the working electrode, a platinum wire served as the counter electrode, while an $\mathrm{Ag} / \mathrm{AgCl}$ electrode served as the reference electrode; the $\mathrm{MnO}_{x}$ films were tested between potentials of $-0.1 \mathrm{~V}$ and $0.9 \mathrm{~V}$ (vs. $\mathrm{Ag} / \mathrm{AgCl}$ ). A neutral aqueous electrolyte of $1.0 \mathrm{M}$ $\mathrm{Na}_{2} \mathrm{SO}_{4}$ was used for the cell assembly. For the $\mathrm{MnO}_{x} / \mathrm{C}$-MEMS characterization, two of the manganese oxide-encrusted carbon micro-pillars were used in a symmetric configuration in $1.0 \mathrm{M} \mathrm{Na}_{2} \mathrm{SO}_{4}$ aqueous electrolyte for a cell potential of $0-0.7 \mathrm{~V}$.

\subsection{Conclusions}

In this paper, manganese oxide films were synthesized using electrostatic spray deposition (ESD) and characterized as pseudocapacitive materials for electrochemical capacitor applications in neutral aqueous media. The initial phase synthesized was the relatively insulating hausmannite- $\mathrm{Mn}_{3} \mathrm{O}_{4}$, which partially transformed into the conducting birnessite- $\mathrm{MnO}_{2}$ upon electrochemical cycling, resulting in an enhanced gravimetric

capacitance from $72 \mathrm{~F} \cdot \mathrm{g}^{-1}$ to $225 \mathrm{~F} \cdot \mathrm{g}^{-1}$. Furthermore, $\mathrm{MnO}_{x}-\mathrm{MEs}$ were created by 
combining bottom-up ESD approach and top-down C-MEMS approach. In a twoelectrode setup, the $\mathrm{MnO}_{x}$-MEs were able to deliver geometric specific capacitances as high as $0.055 \mathrm{~F} \cdot \mathrm{cm}^{-2}$, and maximal volumetric energy and power densities of 0.51 $\mathrm{mWh} \cdot \mathrm{cm}^{-3}$ and $28.3 \mathrm{~mW} \cdot \mathrm{cm}^{-3}$, respectively. The excellent areal capacitance and the high stack energy density of the $\mathrm{MnO}_{x}$-MEs are attributed to the pseudocapacitive $\mathrm{MnO}_{x}$ as well as the three-dimensional architectural framework of the micro-pillars. The feasibility of using ESD for high gravimetric thin-film manganese oxide films and high areal capacitance 3D microelectrodes was therefore established.

\subsection{References}

1. Beidaghi, M.; Gogotsi, Y. Capacitive energy storage in micro-scale devices: Recent advances in design and fabrication of micro-supercapacitors. Energy Environ. Sci. 2014, 7, 867-884, doi:10.1039/C3EE43526A

2. Agrawal, R.; Chen, C.; Hao, Y.; Song, Y.; Wang, C. Graphene for Supercapacitors. In Graphene Based Energy Devices; Rashid bin Mohd Yusoff, A., Ed.; Wiley-VCH Verlag GmbH \& Co. KGaA: Weinheim, Germany, 2015; pp. 171-214; doi:10.1002/9783527690312.ch6.

3. Yoo, J.J.; Balakrishnan, K.; Huang, J.; Meunier, V.; Sumpter, B.G.; Srivastava, A.; Conway, M.; Mohana Reddy, A.L.; Yu, J.; Vajtai, R.; et al. Ultrathin planar graphene supercapacitors. Nano Lett. 2011, 11, 1423-1427, doi:10.1021/nl200225j.

4. Huang, P.; Heon, M.; Pech, D.; Brunet, M.; Taberna, P.L.; Gogotsi, Y.; Lofland, S.; Hettinger, J.D.; Simon, P. Micro-supercapacitors from carbide derived carbon (CDC) films on silicon chips. J. Power Sources 2013, 225, 240-244, doi:10.1016/j.jpowsour.2012.10.020.

5. Liu, W.W.; Feng, Y.Q.; Yan, X.B.; Chen, J.T.; Xue, Q.J. Superior MicroSupercapacitors Based on Graphene Quantum Dots. Adv. Funct. Mater. 2013, 23, 4111-4122, doi:10.1002/adfm.201203771.

6. Wang, C.; Taherabadi, L.; Jia, G.; Madou, M.; Yeh, Y.; Dunn, B. C-MEMS for the Manufacture of 3D Microbatteries. Electrochem. Solid State Lett. 2004, 7, A435A438, doi:10.1149/1.179815. 
7. Wang, C.; Jia, G.; Taherabadi, L.H.; Madou, M.J. A Novel Method for the Fabrication of High-Aspect Ratio C-MEMS Structures. J. Microelectromech. Syst. 2005, 14, 348-358, doi:10.1109/JMEMS.2004.839312.

8. Song, Y.; Agrawal, R.; Hao. Y.; Chen, C.; Wang, C. C-MEMS Based Microsupercapacitors and Microsensors. ECS Trans. 2014, 61, 55-64, doi:10.1149/06107.0055ecst.

9. Song, Y.; Chen, C.; Wang, C. Graphene/Enzyme Encrusted Three-Dimensional Carbon Micropillar Arrays for Mediatorless Micro-Biofuel Cells. Nanoscale 2015, 7, 7084-7090, doi:10.1039/C4NR06856D.

10. Agrawal, R.; Beidaghi, M.; Chen, W.; Wang, C. Carbon microelectromechanical systems (C-MEMS) based microsupercapacitors. In Proceedings of the SPIE International Society for Optics and Photonics Sensing Technology + Applications, Baltimore, MD, USA, 20 April 2015; p. 94930C. doi:10.1117/12.2180122.

11. Chen, W.; Beidaghi, M.; Penmatsa, V.; Bechtold, K.; Kumari, L.; Li, W.Z.; Wang, C. Integration of Carbon Nanotubes to C-MEMS for On-chip supercapacitors. IEEE Trans. Nanotechnol. 2010, 9, 734-740, doi:10.1109/TNANO.2010.2049500.

12. Beidaghi, M.; Chen, W.; Wang, C. Electrochemically activated carbon microelectrode arrays for electrochemical micro-capacitors. J. Power Sources 2011, 196, 2403-2409, doi:10.1016/j.jpowsour.2010.09.050.

13. Beidaghi, M.; Wang, C. Micro-supercapacitors based on three dimensional interdigital polypyrrole/C-MEMS electrodes. Electrochim. Acta 2011, 56, 95089514, doi:10.1016/j.electacta.2011.08.054.

14. Wang, J.G.; Kang, F.; Wei, B. Engineering of $\mathrm{MnO}_{2}$-based nanocomposites for highperformance supercapacitors. Prog. Mater Sci. 2015, 74, 51-124, doi:10.1016/j.pmatsci.2015.04.003.

15. Wang, G.; Zhang, L.; Zhang, J. A review of electrode materials for electrochemical supercapacitors. Chem. Soc. Rev. 2012, 41, 797-828, doi:10.1039/C1CS15060J.

16. Gonzalez, A.; Goikolea, E.; Barrena, J.A.; Mysyk, R. Review on supercapacitors: Technologies and materials. Renew. Sustain. Energy Rev. 2016, 58, 1189-1206, doi:10.1016/j.rser.2015.12.249.

17. Wei, W.; Cui, X.; Chen, W.; Ivey, D.G. Manganese oxide-based materials as electrochemical supercapacitor electrodes. Chem. Soc. Rev. 2011, 40, 1697-1721, doi:10.1039/COCS00127A.

18. Komaba, S.; Tsuchikawa, T.; Ogata, A.; Yabuuchi, N.; Nakagawa, D.; Tomita, M. Nano-structured birnessite prepared by electrochemical activation of manganese 
(III)-based oxides for aqueous supercapacitors. Electrochim. Acta 2012, 59, 455463, doi:10.1016/j.electacta.2011.10.098.

19. Dubal, D.P.; Dhawale, D.S.; Salunkhe, R.R.; Lokhande, C.D. A novel chemical synthesis of $\mathrm{Mn}_{3} \mathrm{O}_{4}$ thin film and its stepwise conversion into birnessite $\mathrm{MnO}_{2}$ during super capacitive studies. J. Electroanal. Chem. 2010, 647, 60-65, doi:10.1016/j.jelechem.2010.05.010.

20. Dubal, D.P.; Dhawale, D.S.; Salunkhe, R.R.; Lokhande, C.D. Conversion of chemically prepared interlocked cubelike $\mathrm{Mn}_{3} \mathrm{O}_{4}$ to birnessite $\mathrm{MnO}_{2}$ using electrochemical cycling. J. Electrochem. Soc. 2010, 157, A812-A817, doi:10.1149/1.3428675.

21. Wu, T.H.; Hesp, D.; Dhanak, V.; Collins, C.; Braga, F.; Hardwick, L.J.; Hu, C.C. Charge storage mechanism of activated manganese oxide composites for pseudocapacitors. J. Mater. Chem. A 2015, 3, 12786-12795, doi:10.1039/C5TA03334A.

22. Hu, C.C.; Hung, C.Y.; Chang, K.H.; Yang, Y.L. A hierarchical nanostructure consisting of amorphous $\mathrm{MnO}_{2}, \mathrm{Mn}_{3} \mathrm{O}_{4}$ nanocrystallites, and single-crystalline $\mathrm{MnOOH}$ nanowires for supercapacitors. J. Power Sources 2011, 196, 847-850, doi:10.1016/j.jpowsour.2010.08.001.

23. Kim, S.; Nam, K.W., Lee, S.; Cho, W.; Kim, J.S.; Kim, B.G.; Oshima, Y.; Kim, J.S.; Doo, S.G.; Chang, H.; et al. Direct Observation of an Anomalous Spinel-to-Layered Phase Transition Mediated by Crystal Water Intercalation. Angew. Chem. Int. Ed. 2015, 54, 15094-15099, doi:10.1002/anie.201505487.

24. Jaworek, A.; Sobczyk, A.T.; Krupa, A.; Lackowski, M.; Czech, T. Electrostatic deposition of nanothin films on metal substrate. Bull. Pol. Acad. Sci. Tech. Sci. 2009, 57, 63-70, doi:10.2478/v10175-010-0106-3.

25. Jaworek, A.; Sobczyk, A.T. Electrospraying route to nanotechnology: An overview. J. Electrostat. 2008, 66, 197-219, doi:10.1016/j.elstat.2007.10.001.

26. Chen, C.; Agrawal, R.; Kim, T.K.; Li, X.; Chen, W.; Yu, Y.; Beidaghi, M.; Penmatsa, V.; Wang, C. Nanostructured Electrodes via Electrostatic Spray Deposition for Energy Storage System. ECS Trans. 2014, 61, 155-163, doi:10.1149/06127.0155ecst.

27. Li, X.; Wang, C. Engineering nanostructured anodes via electrostatic spray deposition for high performance lithium ion battery application. J. Mater. Chem. A 2013, 1, 165, doi:10.1039/C2TA00437B. 
28. Dhanabalan, A.; Li, X.; Agrawal, R.; Chen, C.; Wang, C. Fabrication and Characterization of $\mathrm{SnO}_{2} /$ Graphene Composites as High Capacity Anodes for Li-Ion Batteries. Nanomaterials 2013, 3, 606-614, doi:10.3390/nano3040606.

29. Agrawal, R.; Chen, C.; Dages, S.; Wang, C. A High Energy 3V Lithium-Ion Capacitor Synthesized via Electrostatic Spray Deposition. Adv. Mater. Lett. 2017, 8, 783-790, doi:10.5185/amlett.2017.7098.

30. Nam, K.W.; Kim, K.B. Manganese oxide film electrodes prepared by electrostatic spray deposition for electrochemical capacitors. J. Electrochem. Soc. 2006, 153, A81-A88, doi:10.1149/1.2131821.

31. Dai, Y.; Wang, K.; Zhao, J.; Xie, J. Manganese oxide film electrodes prepared by electrostatic spray deposition for electrochemical capacitors from the $\mathrm{KMnO}_{4}$ solution. J. Power Sources 2006, 161, 737-742, doi:10.1016/j.jpowsour.2006.04.098.

32. Pech, D.; Brunet, M.; Dinh, T.M.; Armstrong, K.; Gaudet, J.; Guay, D. Influence of the configuration in planar interdigitated electrochemical micro-capacitors. J. Power Sources 2013, 230, 230-235, doi:10.1016/j.jpowsour.2012.12.039.

33. Thissandier, F.; Gentile, P.; Brousse, T.; Bidan, G.; Sadki, S. Are tomorrow's microsupercapacitors hidden in a forest of silicon nanotrees? J. Power Sources 2014, 269, 740-746, doi:10.1016/j.jpowsour.2014.05.060.

34. In, J.B.; Hsia, B.; Yoo, J.H.; Hyun, S.; Carraro, C.; Maboudian, R.; Grigoropoulos, C.P. Facile fabrication of flexible all solid-state micro-supercapacitor by direct laser writing of porous carbon in polyimide. Carbon 2015, 83, 144-151, doi:10.1016/j.carbon.2014.11.017.

35. Tolstoy, V.P.; Gulina, L.B. Synthesis of Birnessite Structure Layers at the Solutionair Interface and the Formation of Microtubules from Them. Langmuir 2014, 30, 8366-8372, doi:10.1021/la501204k.

36. Chu, H.Y.; Lai, Q.Y.; Wang, L.; Lu, J.F.; Zhao, Y. Preparation of $\mathrm{MnO}_{2} / \mathrm{WMNT}$ composite and $\mathrm{MnO}_{2} / \mathrm{AB}$ composite by redox deposition method and its comparative study as supercapacitive materials. Ionics 2010, 16, 233-238, doi:10.1007/s11581009-0378-5.

37. Julien, C.M.; Massot, M.; Poinsignon, C. Lattice vibrations of manganese oxides: Part I. Periodic structures. Spectrochim. Acta Mol. Biomol. Spectrosc. 2004, 60, 689700, doi:1016/S1386-1425(03)00279-8.

38. Ocana, M. Uniform particles of manganese compounds obtained by forced hydrolysis of manganese (II) acetate. Colloid Polym. Sci. 2000, 278, 443-449, doi:10.1007/s003960050537. 
39. Pourbaix, M. Atlas of Electrochemical Equilibria in Aqueous Solutions; National Association of Corrosion Engineers: Houston, TX, USA, 1974.

40. Dong, R.; Ye, Q.; Kuang, L.; Lu, X.; Zhang, Y.; Zhang, X.; Tan, G.; Wen, Y.; Wang, F. Enhanced supercapacitor performance of $\mathrm{Mn}_{3} \mathrm{O}_{4}$ nanocrystals by doping transition-metal ions. ACS Appl. Mater. Interfaces 2013, 5, 9508-9516, doi:10.1021/am402257y.

41. Chen, W.; Fan, Z.; Gu, L.; Bao, X.; Wang, C. Enhanced capacitance of manganese oxide via confinement inside carbon nanotubes. Chem. Commun. 2010, 46, 39053907, doi:10.1039/C000517G.

42. Wan, C.; Yuan, L.; Shen, H. Effects of electrode mass-loading on the electrochemical properties of porous $\mathrm{MnO}_{2}$ for electrochemical supercapacitor. Int. J. Electrochem. Sci. 2014, 9, 4024-4038. 


\section{EXPANDING THE POTENTIAL WINDOW OF AQUEOUS ASYMMETRIC ELECTROCHEMICAL CAPACITORS WITH ELECTROSTATICALLY SPRAYED MANGANESE OXIDE COMPOSITE FILMS}

\subsection{Introduction}

Electrochemical capacitors (ECs), also known as "supercapacitors" account for an emerging class of electrochemical energy-storage systems (EES). Typically, ECs differ from their electrostatic counterparts by storing charge at the electrode-electrolyte interface (Helmholtz double layer) as opposed to an electric field across a dielectric, and therefore demonstrate specific capacitances at least an order of magnitude higher than that of conventional capacitors [1]. The enhancement in energy however, comes with a decrease in specific power, typically by an order or two of magnitude $\left(\sim 10 \mathrm{kWkg}^{-1}\right)$. Despite, the relatively high energy density $\left(\sim 3-5 \mathrm{Whkg}^{-1}\right)$ of ECs as compared to traditional capacitors, their gravimetric energy density remains much lower than secondary batteries ( 200 $\mathrm{Whkg}^{-1}$ for lithium-ion batteries). Much research has been invested into enhancing the energy density of ECs, since their low time constants and high cycle longevity are attractive features for harnessing and reusing the energy from repetitive motion [1]. One of the alternatives to achieving superior energy densities is the asymmetric design, which combines a positive pseudocapacitive electrode and a negative double layer (dl) electrode within one system. Such a system benefits from the large capacitance of the redox-based electrode and the high rate capability of the dl electrode. Furthermore, the synergy of using the disparate electrodes in one system allows to stretch the potential window of water based electrolytes beyond the thermodynamic limit $(\sim 1.2 \mathrm{~V})$ by utilizing the large overpotentials for hydrogen and oxygen evolution at the negative $\mathrm{dl}$ electrode and the positive pseudocapacitive electrode, respectively $[1,2]$. In a 
symmetric setup in aqueous media, the cell voltage is typically limited to $\sim 1 \mathrm{~V}$ and therefore using the asymmetric design significantly enhances the effective working voltage of the cell. Given the benefits of aqueous electrolytes in terms of costeffectiveness, ease of packaging and safety over nonaqueous electrolytes, it is highly desirable to stretch their electrochemical potential window beyond the thermodynamic limit.

As pseudocapacitive electrode materials, manganese oxides $\left(\mathrm{MnO}_{\mathrm{x}}\right)$ offer significant promise given their high theoretical specific capacitances in aqueous electrolytes, environmental benignity, abundance, and low cost. [3-7]. One of the shortcomings of metal oxide electrodes, however, is their low electronic conductivity. This drawback can however be offset by adding a conducting additive such as carbon nanotubes (CNTs). Given the nanostructured nature of CNTs, they can provide for lower percolation thresholds as compared to the conventionally used carbon black [8]. Furthermore, the addition of CNTs to different composites has shown to improve the mechanical robustness of different composites [9], which can be beneficial for long-term cycling. Based on previous findings, it has been established that only a thin volume of the $\mathrm{MnO}_{\mathrm{x}}$ electrode participates in the charge-storage mechanism under electrochemical capacitor demands [1], which makes synthesizing $\mathrm{MnO}_{\mathrm{x}}$ thin-films an attractive solution for pseudocapacitive needs. Electrostatic Spray Deposition (ESD) is a thin-film synthesis technique, which essentially involves the disintegration of a precursor solution into an aerosol spray upon the application of a high voltage between the feeding source and a grounded preheated substrate [10-13]. The ability to tailor the film morphology by finetuning the deposition parameters, without the need for vacuum or addition of binders is 
what makes ESD an appealing thin-film fabrication method and ESD derived thin-films have been widely reported for energy-storage applications [14-20].

Herein, pristine $\mathrm{MnO}_{\mathrm{x}}$ along with $\mathrm{MnO}_{\mathrm{x}}-\mathrm{CNT}$ composite electrodes with $10 \%$ and $20 \%$ CNT addition were synthesized via ESD and investigated as electrochemical capacitor electrodes. The $10 \%$ CNT composition designated as $\mathrm{MnO}_{\mathrm{x}}-\mathrm{CNT} 9-1$ exhibited superior electrochemical characteristics as opposed to both the pristine $\mathrm{MnO}_{\mathrm{x}}$ electrode as well as the $\mathrm{MnO}_{\mathrm{x}}$-CNT $8-2(20 \% \mathrm{CNT})$ composition. The addition of CNT to the otherwise pristine $\mathrm{MnO}_{\mathrm{x}}$ films resulted in superior charge-transfer characteristics along with higher gravimetric capacitances. In a three-electrode configuration, the $\mathrm{MnO}_{\mathrm{x}}-\mathrm{CNT}$ 9-1 electrode exhibited gravimetric capacitances as high as $281 \mathrm{Fg}^{-1}$ in addition to excellent rate capability and fairly high cycle life ( $\sim 87 \%$ after 1000 cycles). Upon verifying the viability of the $\mathrm{MnO}_{\mathrm{x}}$-CNT 9-1 electrodes as pseudocapacitive charge storage components, they were coupled with commercial activated carbon (AC) based counter electrodes in order to investigate their usage in a practical two-electrode system. Five pertinent mass ratios were evaluated in order to evaluate the optimal balanced cell characteristics. The asymmetric capacitor with $\mathrm{MnO}_{\mathrm{x}}-\mathrm{CNT}$ 9-1//AC with the $\mathrm{AC}$ electrode 2.6 times massive as that of the $\mathrm{MnO}_{\mathrm{x}}-\mathrm{CNT}$ 9-1 electrode, exhibited superior electrochemical characteristics than the other asymmetric systems as well as the symmetric MnOx-CNT 9-1 and symmetric AC systems. The optimized asymmetric capacitor exhibited a maximal energy density of $30.3 \mathrm{Whkg}^{-1}$, which is fairly high for aqueous systems. The excellent electrochemical characteristics of the asymmetric capacitor are ascribed to the i) $2 \mathrm{~V}$ potential window exhibited by the capacitor making full utilization of the overpotentials of $\mathrm{H}_{2}$ and $\mathrm{O}_{2}$ evolution at the negative and positive 
electrodes, respectively; ii) high capacity utilization from the $\mathrm{MnO}_{\mathrm{x}}$-CNT 9-1 electrode, indicating balanced hybrid system.

\subsection{Materials and Methods}

\subsubsection{ESD based manganese oxide electrode synthesis}

Manganese (II) acetate tetrahydrate $\left(\mathrm{Mn}\left(\mathrm{CH}_{3} \mathrm{COO}\right)_{2} \cdot 4 \mathrm{H}_{2} \mathrm{O}\right.$, Alfa Aesar, Ward Hill, MA, USA) was first dissolved in 1,2-propanediol (Sigma Aldrich, St. Louis, MO, USA) in a ratio of $2.4 \mathrm{mgml}^{-1}$ with constant stirring for $30 \mathrm{~min}$ and directly used as the precursor solution to deposit the $\mathrm{MnO}_{x}$ films. For the ESD setup, the feeding rate was kept at $3 \mathrm{mlh}^{-1}$ and the voltage between the needle and substrate was kept between 6 and $8 \mathrm{kV}$. The distance between the needle and the substrate was approximately $4 \mathrm{~cm}$ and the deposition was carried out at $350^{\circ} \mathrm{C}$ on stainless steel substrates. For the $\mathrm{MnO}_{\mathrm{x}}-\mathrm{CNT}$ composites, carboxyl functionalized short multi-walled carbon nanotubes (CNT, Cheap tubes Inc.) were dispersed along with the manganese (II) acetate tetrahydrate in percent mass ratios of $10 \%$ and $20 \%$; the composites are designated as $\mathrm{MnO}_{\mathrm{x}}-\mathrm{CNT} 9-1$ and $\mathrm{MnO}_{\mathrm{x}}-\mathrm{CNT} 8-2$ for the CNT mass ratio of $10 \%$ and $20 \%$, respectively. The composite deposition was carried out on stainless steel substrates preheated at $350^{\circ} \mathrm{C}$ for the identical deposition conditions as that of the pristine $\mathrm{MnO}_{\mathrm{x}}$ films.

\subsubsection{Material Characterization}

In order to investigate the crystallinity of the ESD based pristine $\mathrm{MnO}_{\mathrm{x}}$ and $\mathrm{MnO}_{\mathrm{x}}{ }^{-}$ CNT films, X-ray diffraction (XRD) studies using a Siemens 5000D X-ray diffractometer with $\mathrm{Cu} \mathrm{K} \alpha$ radiation. The morphology of the ESD based $\mathrm{MnO}_{\mathrm{x}}, \mathrm{MnO}_{\mathrm{x}}-\mathrm{CNT}$ 9-1 and $\mathrm{MnO}_{\mathrm{x}}-\mathrm{CNT}$ 8-2 composite electrodes as well as the slurry-casted AC electrode was 
studied using scanning electron microscopy using a JEOL SEM 6330 (JEOL, USA). Spectroscopic studies on the pristine $\mathrm{MnO}_{\mathrm{x}}$ and composite $\mathrm{MnO}_{\mathrm{x}}-\mathrm{CNT}$ films were carried out using Fourier transform infrared spectroscopy (FTIR) using JASCO FTIR-4100 equipped with an ATR-PRO 450S (Attenuated Total Reflectance) accessory.

\subsubsection{Electrochemical Characterization}

The electrochemical characterization on the pristine $\mathrm{MnO}_{\mathrm{x}}, \mathrm{MnO}_{\mathrm{x}}-\mathrm{CNT}$ 9-1, and $\mathrm{MnO}_{\mathrm{x}}-\mathrm{CNT}$ 8-2 electrodes as well as the full-cells was carried out using a Bio-logic Versatile Multichannel Potentiostat (VMP3). For the half-cell studies, the ESD based $\mathrm{MnO}_{x}$ and the $\mathrm{MnO}_{\mathrm{x}}-\mathrm{CNT}$ composite films were used as the working electrode, a platinum coil was used as the counter electrode and an $\mathrm{Ag} / \mathrm{AgCl}$ electrode was used as the reference electrode. Both the pristine and composite $\mathrm{MnO}_{x}$ films were tested between potentials of $-0.1 \mathrm{~V}$ and $0.9 \mathrm{~V}(\mathrm{vs} . \mathrm{Ag} / \mathrm{AgCl}$ ) and a neutral aqueous electrolyte of $1.0 \mathrm{M}$ $\mathrm{Na}_{2} \mathrm{SO}_{4}$ was used for the cell assembly. From comparative electrochemical studies, the $\mathrm{MnO}_{\mathrm{x}}-\mathrm{CNT}$ 9-1 composition demonstrated superior electrochemical characteristics as opposed to both the pristine $\mathrm{MnO}_{\mathrm{x}}$ and the $\mathrm{MnO}_{\mathrm{x}}-\mathrm{CNT}$ 8-2 composite films. For the asymmetric cell characterization, the $\mathrm{MnO}_{\mathrm{x}}-\mathrm{CNT}$ 9-1 films were cycled for 20 chargedischarge cycles, in order to complete the electrochemical activation process and thereafter coupled with a commercial activated carbon (AC, MTI Corp.) based anode in different mass ratios of $1: 2,1: 2.4,1: 2.6,1: 3$, and $1: 4\left(m_{c}: m_{a}\right.$, where $m_{c}$ symbolizes the mass of the $\mathrm{MnO}_{\mathrm{x}}-\mathrm{CNT}$ 9-1 cathode and $\mathrm{m}_{\mathrm{a}}$ symbolizes the mass of the AC anode). The AC electrode was prepared by combining AC, PVDF (polyvinylidene fluoride) and carbon black in a mass ratio of 8:1:1 in N-methyl-2-pyrrolidone (NMP). The resultant 
slurry was casted onto stainless steel substrates and dried for $24 \mathrm{~h}$ at $60^{\circ} \mathrm{C}$ and was used for electrochemical characterization without any further treatment. An aqueous electrolyte of $1 \mathrm{M} \mathrm{Na}_{2} \mathrm{SO}_{4}$ was used for the full cell assembly.

\subsection{Results and Discussion}

\subsubsection{Crystallographic, spectroscopic and microstructural studies}

The X-ray diffraction (XRD) patterns of the as-prepared $\mathrm{MnO}_{\mathrm{x}}, \mathrm{MnO}_{\mathrm{x}}-\mathrm{CNT}$ 9-1, $\mathrm{MnO}_{\mathrm{x}}-\mathrm{CNT}$ 8-2, and CNTs are shown in Figure 6.1a. The ESD derived $\mathrm{MnO}_{\mathrm{x}}$ films were of crystalline nature as confirmed by the presence of fairly sharp characteristic peaks in the XRD spectra; the $\mathrm{MnO}_{\mathrm{x}}$ phase was confirmed to be hausmannite $\mathrm{Mn}_{3} \mathrm{O}_{4}$ but given the tendency of hausmannite $\mathrm{Mn}_{3} \mathrm{O}_{4}$ to electrochemically transform to the amorphous birnessite phase, the manganese oxide based films are referred to as $\mathrm{MnO}_{\mathrm{x}}$. For the pristine $\mathrm{MnO}_{\mathrm{x}}$ powders, the peaks located at $17.9^{\circ}, 28.8^{\circ}, 31.0^{\circ}, 32.4^{\circ}, 36.1^{\circ}, 38.1^{\circ}, 44.5^{\circ}$, $50.9^{\circ}, 53.9^{\circ}, 56.0^{\circ}, 58.4^{\circ}, 60.1^{\circ}, 64.7^{\circ}$, and $74.3^{\circ}$ were attributed (hkl) orientations of (101), (112), (200), (103), (211), (004), (220), (105), (312), (303), (321), (224), (400), and (413) of the hausmannite $\mathrm{Mn}_{3} \mathrm{O}_{4}$ phase (JCPDS card number: 00-024-0734), respectively. As evident, the addition of CNTs to the $\mathrm{MnO}_{\mathrm{x}}$ matrix results in diminished peak intensity, indicating relatively lower degree of crystallinity as compared to the pristine $\mathrm{MnO}_{\mathrm{x}}$ powders. A peak centered at $26.1^{\circ}$ is observed in the $\mathrm{MnO}_{\mathrm{x}}-\mathrm{CNT} 8-2$ pattern, which is ascribed to the (002) plane of graphite [21, 22], as also observed in the parent CNT pattern. However, the characteristic CNT peak was not observed in the $\mathrm{MnO}_{\mathrm{x}}-\mathrm{CNT}$ 9-1 pattern, which could be a result of the low degree of crystallinity of the parent CNTs. To further characterize the ESD derived films, spectroscopic studies using Fourier transform infrared (FTIR) spectroscopy were carried out. The FTIR spectra of the 
pristine $\mathrm{MnO}_{\mathrm{x}}, \mathrm{CNTs}$, as well as the composites are shown in Figure 6.1b. In the CNT spectrum, the peak centered at $3339 \mathrm{~cm}^{-1}$ can be attributed to $-\mathrm{OH}$ groups resulting from water [20] or from -OH from the graphitic framework [23]. The peaks located at 2926 $\mathrm{cm}^{-1}, 1418 \mathrm{~cm}^{-1}, 1020 \mathrm{~cm}^{-1}$, and $848 \mathrm{~cm}^{-1}$ are ascribed to $\mathrm{C}-\mathrm{H}$ groups, $\mathrm{C}-\mathrm{O}$ bonds from carboxylic groups, C-O groups from $-\mathrm{COOH}$ or alkoxy (-O-), and $\mathrm{C}-\mathrm{O}$ groups from epoxy (-C-O-C-) [23], respectively. The largely pronounced $\mathrm{C}-\mathrm{O}$ based groups in the CNT spectrum could be a result of the $\mathrm{COOH}$ functionalization. In the pristine $\mathrm{MnO}_{\mathrm{x}}$ sample, on the other hand, the peaks at $\sim 595 \mathrm{~cm}^{-1}$ and $\sim 510 \mathrm{~cm}^{-1}$ are attributed to the tetrahedral bend and the octahedral distortion vibrations of $\mathrm{Mn}-\mathrm{O}$ [15, 24-27]. It is worth noting that with the addition of CNTs to the $\mathrm{MnO}_{\mathrm{x}}$, the absorption peaks in the low-mid frequency region (700-1700 $\mathrm{cm}^{-1}$ ) start becoming more pronounced, which could be ascribed to the stronger absorption signals resulting from the larger CNT content. 

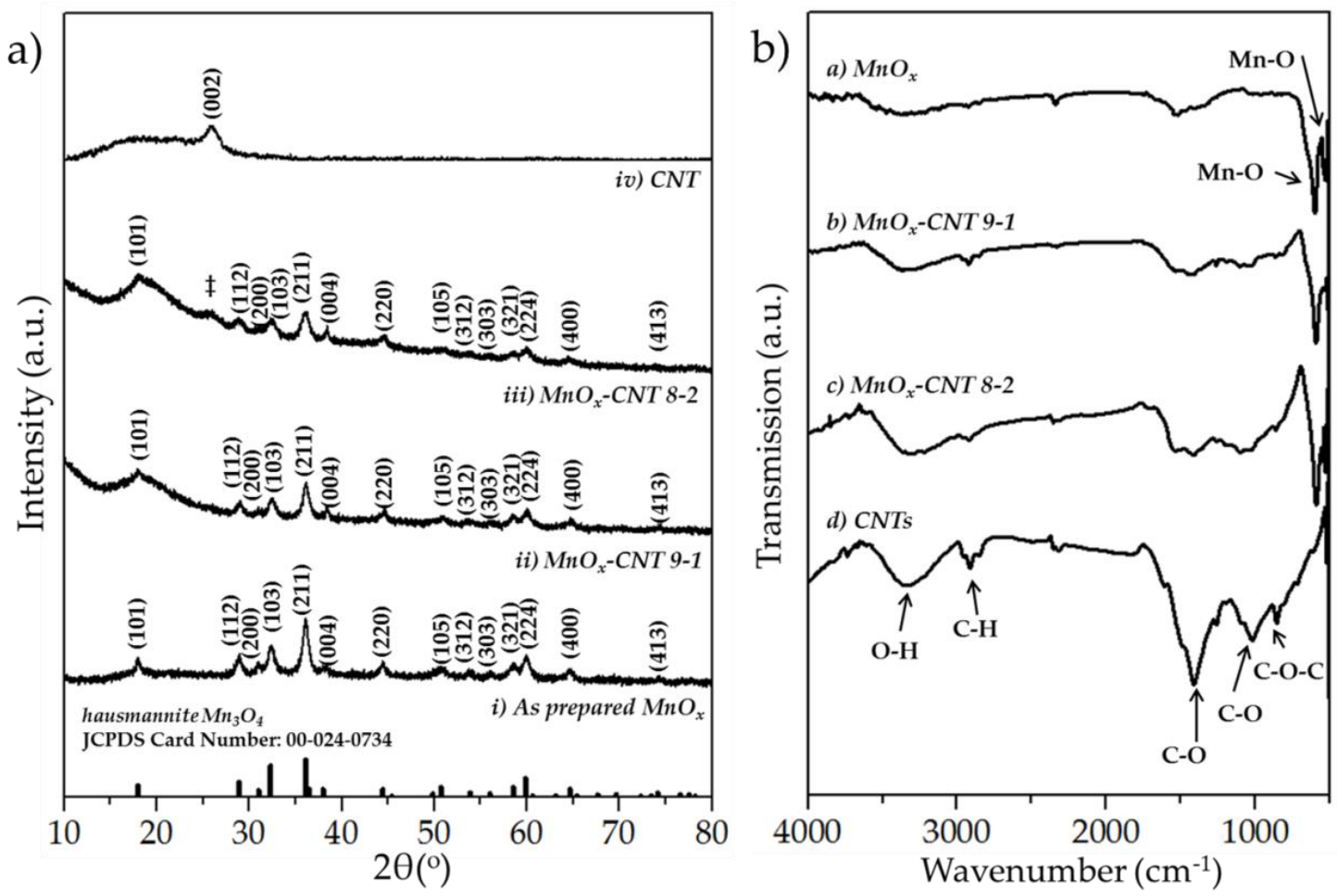

Figure 6.1: a) X-ray diffraction patterns of the as-prepared $\mathrm{MnO}_{\mathrm{x}}, \mathrm{MnO}_{\mathrm{x}}-\mathrm{CNT}$ 9-1, $\mathrm{MnO}_{\mathrm{x}}$-CNT 8-2 composites and CNTs; b) FTIR spectra of the pristine $\mathrm{MnO}_{\mathrm{x}}$ films, $\mathrm{MnO}_{\mathrm{x}}-\mathrm{CNT}$ 9-1, and $\mathrm{MnO}_{\mathrm{x}}-\mathrm{CNT}$ 8-2 films, and the CNTs.

The morphology of the as-deposited $\mathrm{MnO}_{\mathrm{x}}, \mathrm{MnO}_{\mathrm{x}}-\mathrm{CNT}$ 9-1, and $\mathrm{MnO}_{\mathrm{x}}-\mathrm{CNT}$ 8-2 and the $\mathrm{AC}$ electrodes is shown in Figure 6.2. The microstructure of the pristine $\mathrm{MnO}_{\mathrm{x}}$ electrode (Figure 6.2a) comprised a three-dimensional continuous reticular network, which is reminiscent of the previously reported ESD based $\mathrm{MnO}_{\mathrm{x}}$ films [15].The microstructure of the $\mathrm{MnO}_{\mathrm{x}}-\mathrm{CNT}$ 9-1 film is depicted in Figure 6.2b. As evident, the fidelity of the CNTs was not comprised in the composite and the CNTs were wellanchored to the reticular $\mathrm{MnO}_{\mathrm{x}}$ framework. The 3D porous structure is maintained in the $\mathrm{MnO}_{\mathrm{x}}-\mathrm{CNT}$ 9-1 sample, which is expected to be advantageous for electrolyte ion diffusion. Figure 6.2c shows the micrograph of the $\mathrm{MnO}_{\mathrm{x}}-\mathrm{CNT}$ 8-2 electrode; the 3D 
continuous network was maintained with the CNTs well anchored to the skeleton. The presence of CNTs is more conspicuous in the $\mathrm{MnO}_{\mathrm{x}}-\mathrm{CNT}$ 8-2 electrode as compared to the $\mathrm{MnO}_{\mathrm{x}}-\mathrm{CNT}$ 9-1 electrode, which is expected given the larger amount of CNTs present in the composite film. The microstructure of the $\mathrm{AC}$ electrode is shown in Figure $6.2 \mathrm{~d}$; the sample consisted of fairly large bulk sized $(\sim 10 \mu \mathrm{m})$ carbon particles.

a)

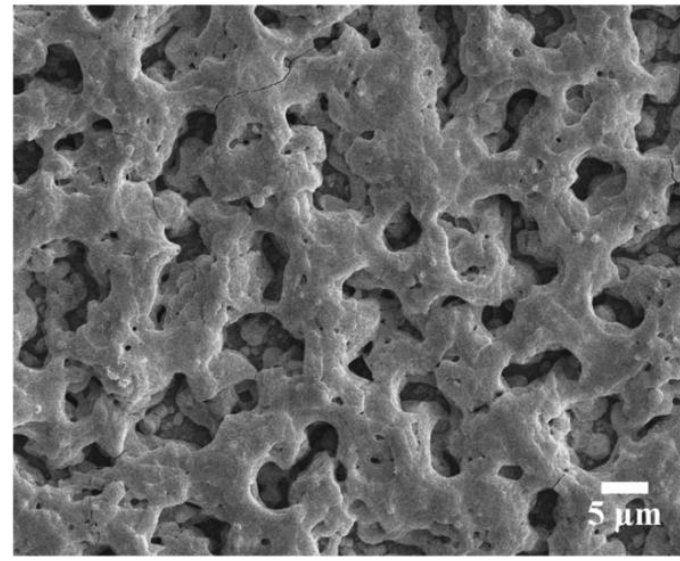

c)

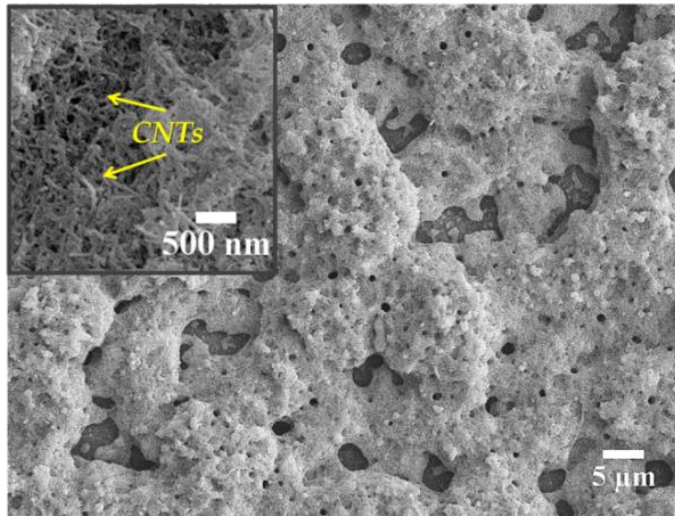

b)

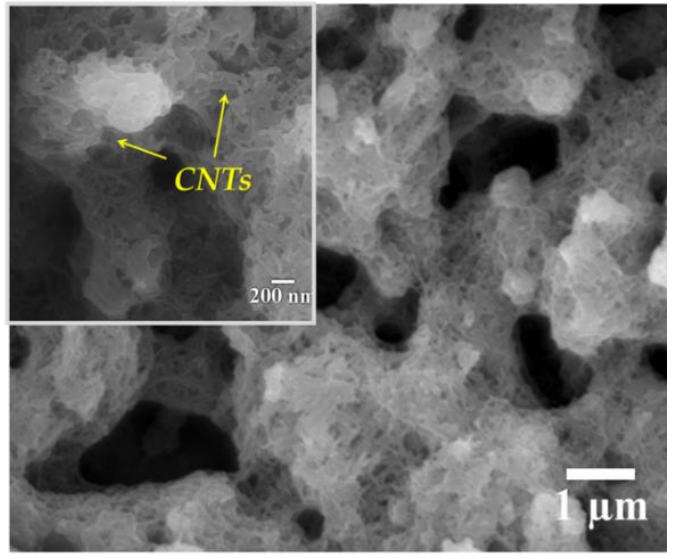

d)

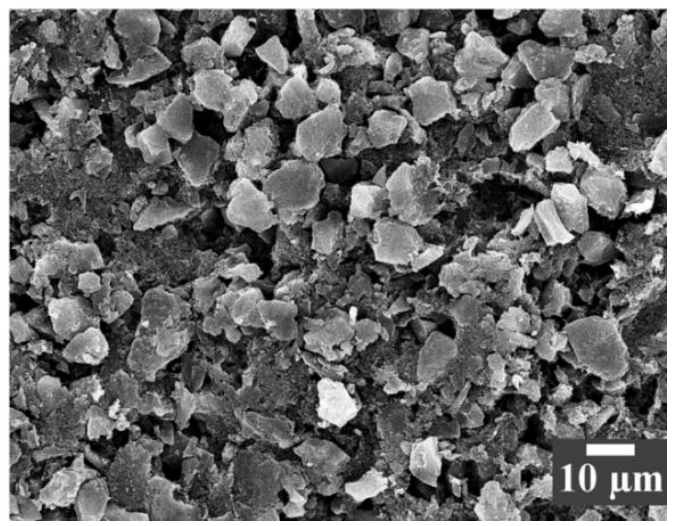

Figure 6.2: Top-view of the a) pristine $\mathrm{MnO}_{\mathrm{x}}$; b) $\mathrm{MnO}_{\mathrm{x}}-\mathrm{CNT}$ 9-1; c) $\mathrm{MnO}_{\mathrm{x}}-\mathrm{CNT} 8-2$, and d) AC electrodes

\subsubsection{Comparative electrochemical studies on the pristine $\mathrm{MnO}_{\mathrm{x}}$ and $\mathrm{MnO}_{\mathrm{x}}-\mathrm{CNT}$ composite films}

The electrochemical impedance spectroscopy (EIS) curves of the as prepared $\mathrm{MnO}_{\mathrm{x}}$,

$\mathrm{MnO}_{\mathrm{x}}-\mathrm{CNT}$ 9-1, and $\mathrm{MnO}_{\mathrm{x}}-\mathrm{CNT}$ 8-2 electrodes are shown in Figure 6.3a. As evident, the 
Nyquist curves (traced between frequencies of $100000 \mathrm{~Hz}$ and $0.01 \mathrm{~Hz}$ ) for all the three compositions comprised a depressed semicircle in the high frequency region followed by a linear slope in the lower frequency regions. The equivalent circuit used for impedance analyses is shown as the inset of Figure 6.3a. $R_{s}, R_{c t}, W, C_{d l}$ and $C_{p}$ stand for solution resistance, charge-transfer resistance, Warburg impedance, double-layer capacitance, and pseudocapacitance, respectively $[15,28]$. As noted, the slope of the linear region gets steeper with the addition of $\mathrm{CNT}$ to the $\mathrm{MnO}_{\mathrm{x}}$. Typically the steeper the linear component of the curve, the better is the sample conductivity. The values of $R_{c t}$ and $R_{S}$ at different cycles have been tabulated in Table 6.1. As expected, both the serial and charge transfer resistances decreased with the addition of CNTs to the $\mathrm{MnO}_{\mathrm{x}}$ matrix. In order to examine the viability of the pristine and composite $\mathrm{MnO}_{\mathrm{x}}$ films for electrochemical cycling and capacitance values, the electrodes were cycled for 100 charge-discharge cycles at a current rate of $0.5 \mathrm{Ag}^{-1}$. As seen in Figure 6.3b, the gravimetric capacitance of the $\mathrm{MnO}_{\mathrm{x}^{-}}$ CNT 8-2 composite was the highest initially but started decaying after $\sim 15$ cycles. The specific capacitance of the pristine $\mathrm{MnO}_{\mathrm{x}}$ electrode kept increasing until the $\sim 60^{\text {th }}$ cycle and then stabilized. The increase in capacitance is ascribed to the electrochemical phase transformation of the hausmannite $\mathrm{Mn}_{3} \mathrm{O}_{4}$ to birnessite $\mathrm{MnO}_{2}$ and is consistent with previous reports $[15,24,29]$. The $\mathrm{MnO}_{\mathrm{x}}-\mathrm{CNT}$ 9-1 electrode on the other hand, demonstrated superior capacitance as compared to both the $\mathrm{MnO}_{\mathrm{x}}-\mathrm{CNT}$ 8-2 composite electrode as well as the pristine $\mathrm{MnO}_{\mathrm{x}}$ electrode.

Cyclic voltammetry $(\mathrm{CV})$ curves of $\mathrm{MnO}_{\mathrm{x}}-\mathrm{CNT}$ 9-1 at different scan rates are shown in Figure 6.3c; the CV curves of the pristine $\mathrm{MnO}_{\mathrm{x}}$ and the $\mathrm{MnO}_{\mathrm{x}}-\mathrm{CNT}$ 8-2 compositions can be found in the supplementary file (Figure 6S1). All the CV curves were traced after 
the electrochemical activation process was completed. The gravimetric specific capacitance of the electrodes were estimated using Equation (6.1), where $C_{s}$ is the specific capacitance, $\mathrm{m}$ is the mass of the electrode, $s$ is the scan rate, $\Delta V$ is the voltage window, $I$ is the current, and $V$ is the potential.

$$
C_{s}=\frac{1}{2 m s \Delta V} \int I d V
$$

The specific capacitance values of the $\mathrm{MnO}_{\mathrm{x}}-\mathrm{CNT}$ 9-1 were calculated as 203, 184, 154, $104,63 \mathrm{Fg}^{-1}$ at scan rates of $5,10,20,50,100 \mathrm{mVs}^{-1}$, respectively. The gravimetric capacitance of the $\mathrm{MnO}_{\mathrm{x}}-\mathrm{CNT}$ 9-1 electrode decreased with increasing scan rates, with a concomitant deviation from the rectangular capacitive shape. This is expected since the rapid electrolyte ion flux at higher scan rates, limits the diffusion-controlled charge storage processes at the electrode surface, resulting in lower utilization of active charge storage sites $[15,30]$. The scan rate dependence of the pristine $\mathrm{MnO}_{\mathrm{x}}$ as well as $\mathrm{MnO}_{\mathrm{x}^{-}}$ CNT 9-1 and $\mathrm{MnO}_{\mathrm{x}}-\mathrm{CNT}$ 8-2 electrodes is depicted in Figure 6.3d. As evident, both the $\mathrm{MnO}_{\mathrm{x}}-\mathrm{CNT}$ 9-1 and MnOx-CNT 8-2 compositions exhibit superior capacitance-scan rate dependence as compared to the pristine $\mathrm{MnO}_{\mathrm{x}}$ electrode, which can be attributed to the enhancement in kinetics from the addition of CNT filler. Figure 6.3e depicts the galvanostatic charge discharge (GCD) curves of the $\mathrm{MnO}_{\mathrm{x}}-\mathrm{CNT}$ 9-1 electrodes, whereas the GCD of the pristine $\mathrm{MnO}_{\mathrm{x}}$ and the $\mathrm{MnO}_{\mathrm{x}}-\mathrm{CNT}$ 8-2 electrodes are depicted in the supplementary file (Figure 6S1). The GCD curves are triangular in shape, which is expected given the predominantly capacitive charge storage in the manganese oxide based electrode. The specific capacitance of the $\mathrm{MnO}_{\mathrm{x}}-\mathrm{CNT}$ 9-1 electrode was estimated as $281,253,221,186,160,122$, and $93 \mathrm{Fg}^{-1}$ at current rate of $0.2,0.4,0.8,1.6,3.2,6.4$, 
and $10 \mathrm{Ag}^{-1}$, respectively. The comparative rate capability of the pristine $\mathrm{MnO}_{\mathrm{x}}, \mathrm{MnO}_{\mathrm{x}^{-}}$ CNT 9-1, as well as the $\mathrm{MnO}_{\mathrm{x}}-\mathrm{CNT}$ 8-2 electrodes is shown in Figure 6.3f. As evident, the rate performance of both the $\mathrm{MnO}_{\mathrm{x}}-\mathrm{CNT}$ 9-1 and the $\mathrm{MnO}_{\mathrm{x}}-\mathrm{CNT}$ 8-2 electrodes was much superior to that of the pristine $\mathrm{MnO}_{\mathrm{x}}$ electrode, which is attributed to the CNT additive and is validated by the more linear component in the Nyquist plots depicted in Figure 6.3a. Given the larger specific capacitance of the $\mathrm{MnO}_{\mathrm{x}}-\mathrm{CNT}$ 9-1 electrode as compared to the $\mathrm{MnO}_{\mathrm{x}}-\mathrm{CNT}$ 8-2 with increasing current rate, the former was identified as the optimal $\mathrm{MnO}_{\mathrm{x}}-\mathrm{CNT}$ composition in terms of electrochemical performance and was used for further characterization and full-cell analyses.

Table 6.1: $\mathrm{R}_{\mathrm{s}}$ and $\mathrm{R}_{\mathrm{ct}}$ values of the pristine $\mathrm{MnO}_{\mathrm{x}}, \mathrm{MnO}_{\mathrm{x}}-\mathrm{CNT}$ 9-1 and $\mathrm{MnO}_{\mathrm{x}}-\mathrm{CNT}$ 8-2 electrodes

\begin{tabular}{ccc}
\hline Electrode & $R_{s}(\Omega)$ & $R_{c t}(\Omega)$ \\
\hline $\mathrm{MnO}_{\mathrm{x}}$ & 9.57 & 681.00 \\
$\mathrm{MnO}_{\mathrm{x}}$-CNT 9-1 & 4.76 & 282.00 \\
$\mathrm{MnO}_{\mathrm{x}}$-CNT 8-2 & 2.31 & 185.70 \\
\hline
\end{tabular}



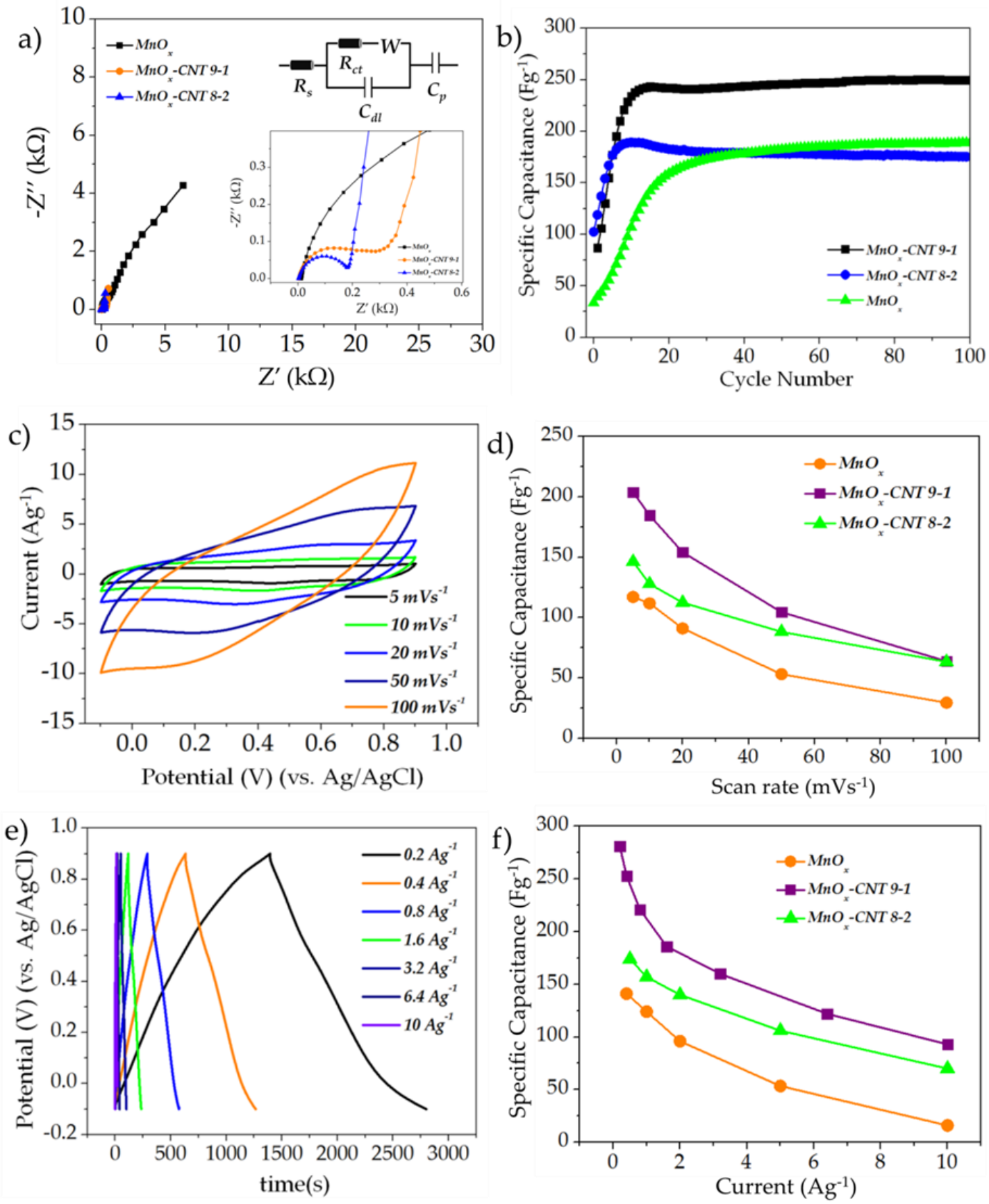

Figure 6.3: a) Nyquist curves of the pristine $\mathrm{MnO}_{\mathrm{x}}$ electrodes and the $\mathrm{MnO}_{\mathrm{x}}-\mathrm{CNT}$ composite electrodes; b) Cycling performance of the pristine $\mathrm{MnO}_{\mathrm{x}}$ electrodes and the $\mathrm{MnO}_{\mathrm{x}}-\mathrm{CNT}$ composites electrodes; c) cyclic voltammetry (CV) curves of the $\mathrm{MnO}_{\mathrm{x}}-\mathrm{CNT}$ electrodes at different scan rates; d) scan rate dependence of the pristine $\mathrm{MnO}_{\mathrm{x}}, \mathrm{MnO}_{\mathrm{x}^{-}}$ CNT 9-1, and $\mathrm{MnO}_{\mathrm{x}}$-CNT 8-2 electrodes; e) galvanostatic charge-discharge (GCD) curves of the $\mathrm{MnO}_{\mathrm{x}}-\mathrm{CNT}$ 9-1 electrode at different current rates; and f) rate capability of the pristine $\mathrm{MnO}_{\mathrm{x}}, \mathrm{MnO}_{\mathrm{x}}-\mathrm{CNT}$ 9-1, and $\mathrm{MnO}_{\mathrm{x}}$-CNT 8-2 electrodes. 


\subsection{3 $\mathrm{MnO}_{\mathrm{x}}-\mathrm{CNT}$ 9-1 electrode before and after electrochemical cycling}

The Nyquist plots of the freshly assembled and cycled $\mathrm{MnO}_{\mathrm{x}}-\mathrm{CNT}$ 9-1(after chargedischarge 1000 cycles) electrode are shown in Figure 6S2a. Both the before and after EIS spectra comprised a depressed semicircular region in the high frequency region followed by a linear slope in the low frequency region, however, the diameter of the semicircular region was largely suppressed in the after curve. The equivalent circuit used for impedance analyses is depicted as the inset and is the same as the one used for previous analyses. The $\mathrm{R}_{\mathrm{ct}}$ component was estimated as $22.6 \Omega$ for the cycled $\mathrm{MnO}_{\mathrm{x}}-\mathrm{CNT} 9-1$ electrode; the decrease in resistance is expected given the electrochemical phase transformation from the relatively insulating hausmannite $\mathrm{Mn}_{3} \mathrm{O}_{4}$ phase to the more conducting birnessite $\mathrm{MnO}_{2}$ phase $[15,29]$. The post electrochemical cycling $\mathrm{MnO}_{\mathrm{x}}-\mathrm{CNT}$ electrode microstructure is depicted in Figure 6S2b. As opposed to the as-synthesized reticular $\mathrm{MnO}_{\mathrm{x}}$ morphology decorated with $\mathrm{CNT}$, the post cycled $\mathrm{MnO}_{\mathrm{x}}-\mathrm{CNT}$ 9-1 electrode was predominantly layered and highly porous, which is reminiscent of birnessite phase $[15,28,29]$. Some cracks were discernible in the cycled films and the CNTs were visible. The long term cyclability of the $\mathrm{MnO}_{\mathrm{x}}-\mathrm{CNT}$ 9-1 electrode is shown as Figure $6 \mathrm{~S} 2 \mathrm{~d} ; 87.4 \%$ of the maximal capacitance was retained after 1000 cycles.

\subsubsection{Electrochemical characterization of the AC anode}

The Nyquist plot of the freshly assembled AC anode is depicted in Figure 6S3a; much alike the composite $\mathrm{MnO}_{\mathrm{x}}-\mathrm{CNT}$ electrodes, a typical Nyquist curve comprised a depressed semicircular region in the high frequency region followed by a steep linear slope in the low frequency region. The inset of Figure 6S3a depicts the equivalent circuit used for the EIS analyses; the same circuit used previously for the $\mathrm{MnO}_{\mathrm{x}}$ based electrodes 
was employed. $R_{s}$ and $R_{c t}$ were estimated as $3.4 \Omega$ and $12.6 \Omega$, respectively. The charge transfer resistance of the $\mathrm{AC}$ electrode was much smaller than the $\mathrm{MnO}_{\mathrm{x}}$ electrode, which is expected given the largely double layer capacitance and superior conductivity of carbon. Figure $6 \mathrm{~S} 3 \mathrm{~b}$ shows the cycling of the $\mathrm{AC}$ anode at a current rate of $0.5 \mathrm{Ag}^{-1}$. The GCD curves of the AC anode at different current rates are shown in Figure 6S3c; the specific capacitance was estimated as $108,94,55$, and $14 \mathrm{Fg}^{-1}$ at current rates of $0.1,0.2$, 0.5 , and $1 \mathrm{Ag}^{-1}$, respectively as shown in the rate capability curve (Figure $6 \mathrm{~S} 3 \mathrm{~d}$ ).

\subsubsection{Electrochemical characterization of the asymmetric and symmetric $\mathrm{MnO}_{\mathrm{x}^{-}}$ CNT 9-1 based full-cells}

Given the large disparity in the specific capacitances exhibited by the $\mathrm{MnO}_{\mathrm{x}}-\mathrm{CNT}$ 9-1 electrode and the commercial AC based anode, it is essential to balance the charges stored by the respective electrodes. As seen in Figure 6.4a, $\mathrm{MnO}_{\mathrm{x}}$-CNT 9-1 electrode encompasses much larger area under the $\mathrm{CV}$ curve as compared to the $\mathrm{AC}$ anode. From equation (1), the specific capacitances of the $\mathrm{AC}$ anode and the $\mathrm{MnO}_{\mathrm{x}}-\mathrm{CNT}$ 9-1 cathode

were estimated as $50 \mathrm{Fg}^{-1}$ and $184 \mathrm{Fg}^{-1}$. Since for the present study an excess of electrolyte was used, the charge balancing was done by $q_{+}=q$, where $\mathrm{q}_{+}$and $\mathrm{q}_{-}$are the charges held by the positive and the negative electrode, respectively. As evident, the anode is the limiting electrode in terms of the charge stored, and it is necessary to adjust the active mass of the electrode accordingly. Depending upon the current rate, the mass of $\mathrm{AC}$ should be in the vicinity of 2-4 times that of the $\mathrm{MnO}_{\mathrm{x}}-\mathrm{CNT} 9-1$ electrode. In order to study the effect of mass ratio on the energy-power trade-off, five pertinent mass ratios (MR) were investigated 1:2, 1:2.4, 1:2.6, 1:3, and 1:4; where the latter value denotes the mass of the AC electrode. Control groups containing symmetric $\mathrm{AC} / / \mathrm{AC}$ and $\mathrm{MnO}_{\mathrm{x}}-\mathrm{CNT}$ 
9-1//MnO ${ }_{\mathrm{x}}-\mathrm{CNT}$ 9-1 systems were also investigated. The GCD plots as well as the rate capability and energy-power characteristics of the different symmetric as well as asymmetric systems are depicted in the supplementary file (Figure 6S4 and 6S5).
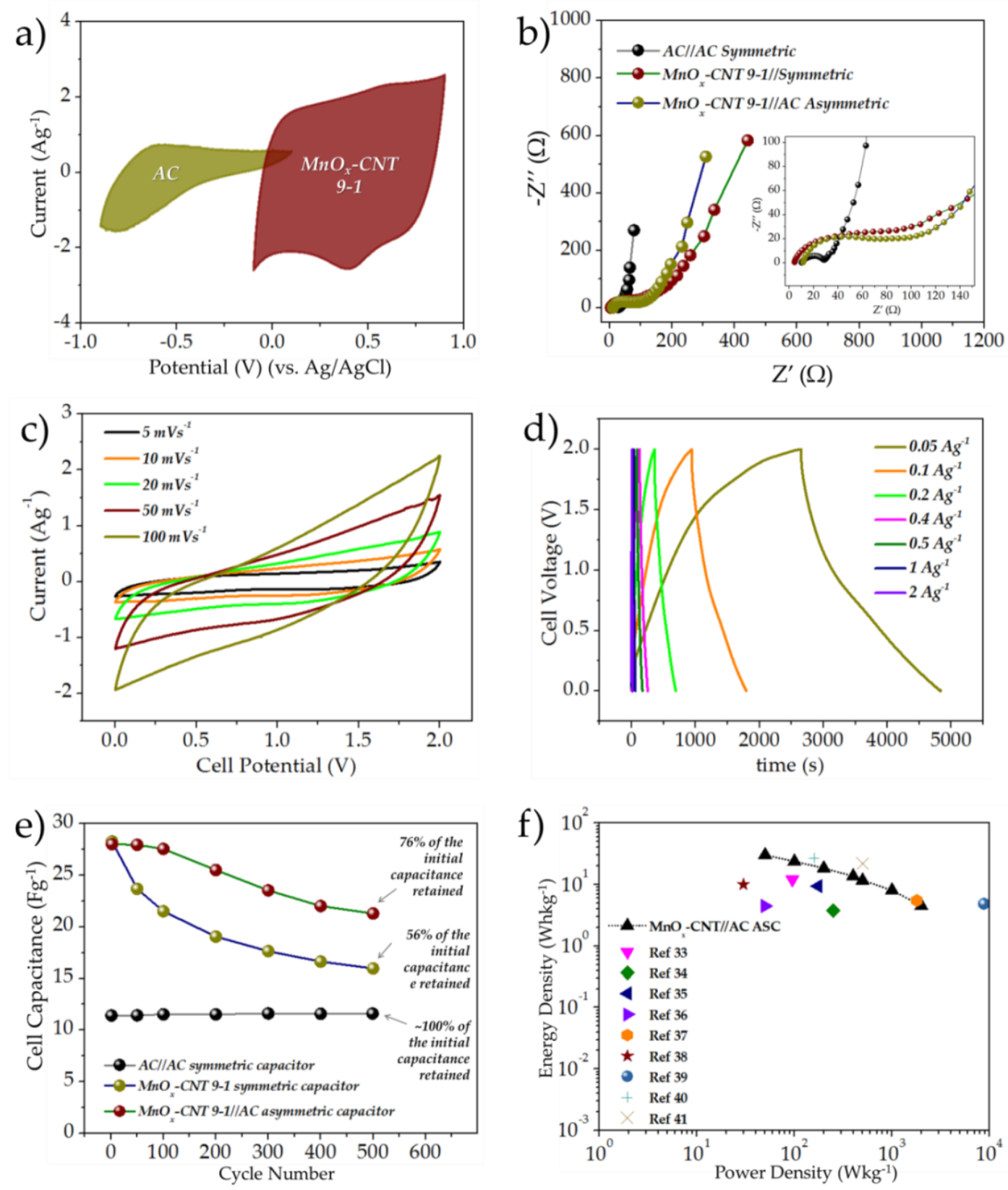

Figure 6.4: a) $\mathrm{CV}$ curves of the $\mathrm{AC}$ electrode and the $\mathrm{MnO}_{\mathrm{x}}-\mathrm{CNT}$ 9-1 electrode at a scan rate of $10 \mathrm{mVs}^{-1}$; b) typical Nyquist plots of the $\mathrm{AC} / / \mathrm{AC}$ and $\mathrm{MnO}_{\mathrm{x}}-\mathrm{CNT} 9-1 / / \mathrm{MnO}_{\mathrm{x}}-\mathrm{CNT}$ 9-1 symmetric systems as well as the asymmetric capacitor $\mathrm{MnO}_{\mathrm{x}}-\mathrm{CNT}$ 9-1//AC (mass 
ratio of 1:2.6); c) $\mathrm{CV}$ and d) GCD curves of the asymmetric $\mathrm{MnO}_{\mathrm{x}}-\mathrm{CNT}$ 9-1//AC system (MR 1:2.6); e) cyclability of the symmetric AC//AC, symmetric $\mathrm{MnO}_{\mathrm{x}}-\mathrm{CNT} 9-1 / / \mathrm{MnO}_{\mathrm{x}^{-}}$ CNT 9-1 and $\mathrm{MnO}_{\mathrm{x}}-\mathrm{CNT}$ 9-1//AC system (MR 1:2.6); f) Ragone chart depicting the energy-power characteristics of the $\mathrm{MnO}_{\mathrm{x}}-\mathrm{CNT}$ 9-1//AC system (MR 1:2.6) with works reported in the literature.

The gravimetric energy and power densities of the system were computed using equations (6.2) and (6.3), respectively:

$$
\begin{gathered}
E D=\frac{1}{2} C_{s} V^{2} \\
P D=\frac{E D}{t_{\text {discharge }}}
\end{gathered}
$$

where ED and PD symbolize the energy and power densities, respectively; $\mathrm{C}_{\mathrm{s}}$ stands for specific capacitance corresponding to a respective current rate and $\mathrm{V}$ is the cell voltage. From comparative studies, based on the optimal energy-power characteristics, it is evident that the asymmetric capacitors tested for mass ratios between 2-3 times AC as that of $\mathrm{MnO}_{\mathrm{x}}-\mathrm{CNT}$ 9-1 had superior energy and power densities as compared to both the symmetric capacitors based on $\mathrm{AC} / / \mathrm{AC}$ and $\mathrm{MnO}_{\mathrm{x}}-\mathrm{CNT}$ 9-1// $\mathrm{MnO}_{\mathrm{x}}-\mathrm{CNT}$ 9-1 configurations. From the rate capability and the Ragone chart (Figure 6S5), it can be seen despite the higher capacitance of the symmetric $\mathrm{MnO}_{\mathrm{x}}-\mathrm{CNT}$ 9-1 capacitor, the actual energy density is still lower than the symmetric AC capacitor. The lower energy density can be ascribed to the lower cell potential achievable by the $\mathrm{MnO}_{\mathrm{x}}-\mathrm{CNT}$ 9-1 symmetric capacitor $(0.8 \mathrm{~V}$ as opposed to $1.2 \mathrm{~V}$ of that of $\mathrm{AC} / / \mathrm{AC})$. The lower cell potential of the symmetric MnOx-CNT system can be ascribed to the oxygen evolution at the positive end and the irreversible reduction of $\mathrm{Mn}^{4+}$ to $\mathrm{Mn}^{3+}$ and the eventual disproportionation to soluble $\mathrm{Mn}^{2+}$ at the negative end $[1,31,32]$. Given the quadratic dependence of cell 
potential on energy density (equation (6.2)), the enhancement from the high capacitance of the $\mathrm{MnO}_{\mathrm{x}}-\mathrm{CNT}$ 9-1 electrode is offset in a practical two-electrode system. From capacitive as well as energy-power characteristics, the asymmetric capacitor with MR 1:2.6 exhibited superior electrochemical behavior than any other composition. The asymmetric capacitor with an MR of 1:4, on the other hand, exhibited poor energy-power trade-off in general, which could be attributed to the predominant AC component in the capacitor construction. With the massive AC component, the asymmetric capacitor starts mimicking the limiting electrode characteristics, resulting in low capacitance and relatively low rate handling. The relatively inferior characteristics of the asymmetric capacitor with MR 1:4 can be explained as an "unbalanced" system. While mass ratio is one measure to balance the charges stored by the individual electrodes, it does not necessitate that the accessibility of the actual charge storage capacities; other factors include electrode thickness, system kinetics, etc. From the comparative cell analyses at different mass ratios and cell configuration, the asymmetric capacitor with MR 1:2.6 was deemed as the optimal balanced system.

The Nyquist plots of the freshly assembled symmetric $\mathrm{AC}$, symmetric $\mathrm{MnO}_{\mathrm{x}^{-}}$ CNT 9-1 and the optimized $\mathrm{MnO}_{\mathrm{x}}-\mathrm{CNT}$ 9-1//AC systems are shown in Figure 6.4b. As evident, the Nyquist curves comprised a depressed semicircular region in the high frequency region followed by a linear response in the low frequency region. Given the steep linear component of the curves and the relatively small diameters of the semicircular region, all the systems exhibited capacitive behavior. The CV curves of the optimized $\mathrm{MnO}_{\mathrm{x}}-\mathrm{CNT}$ 9-1//AC capacitor at different scan rates are shown in Figure 6.4c; the curves are largely rectangular with no evident electrolyte decomposition for a 
potential window of $2 \mathrm{~V}$. The curves maintain the rectangular shape even at a high scan rate of $100 \mathrm{mVs}^{-1}$, indicating predominantly capacitive charge storage. The GCD curves of the optimized capacitor are shown in Figure 6.4d; the curves are primarily triangular with some curvature, which is expected given the coexistence of pseudocapacitive and double layer charge storage within one system. The cycling performance of the symmetric $\mathrm{AC} / / \mathrm{AC}$ system, the symmetric $\mathrm{MnO}_{\mathrm{x}}-\mathrm{CNT} 9-1 / / \mathrm{MnO}_{\mathrm{x}}-\mathrm{CNT}$ 9-1 system, as well as the optimized $\mathrm{MnO}_{\mathrm{x}}-\mathrm{CNT}$ 9-1//AC capacitor at a current rate of $0.5 \mathrm{Ag}^{-1}$ is shown in Figure 6.4e; the symmetric AC//AC capacitor maintains $\sim 100 \%$ of the initial cell capacitance after 500 cycles, whereas the symmetric $\mathrm{MnO}_{\mathrm{x}}$-CNT capacitor only maintains $56.4 \%$ of the initial cell capacitance after 500 cycles. The decrease in capacitance can be attributed to the largely pseudocapacitive behavior of the $\mathrm{MnO}_{\mathrm{x}}-\mathrm{CNT}$ 9-1 electrodes. However, it is worth noting that the $\mathrm{MnO}_{\mathrm{x}}-\mathrm{CNT}$ 9-1 symmetric capacitor maintained larger usable cell capacitance than the symmetric AC system. The optimized $\mathrm{MnO}_{\mathrm{x}}-\mathrm{CNT}$ 9-1 system on the other hand maintained $76 \%$ of the cell initial capacitance after 500 cycles; the intermediate capacitance retention can be ascribed to the composite charge storage characteristics of the hybrid capacitor. Figure $6.4 \mathrm{f}$ illustrates the energypower characteristics of the optimized hybrid capacitor compared to different capacitive systems reported in the literature. The optimized asymmetric capacitor is able to deliver a maximal energy density of $30.3 \mathrm{Whkg}^{-1}$, which is almost an order higher than both the symmetric capacitors. Detailed symmetric and asymmetric capacitor comparison is tabulated in Table $6 \mathrm{~S} 1$. Furthermore, it is noteworthy that the decay in the energy density of the hybrid capacitor is not as pronounced as the power density of the system progresses; the latter is ascribed to the good rate handling of the optimized hybrid 
capacitor. The excellent energy-power characteristics are attributed to the much wider potential window exhibited by the hybrid capacitor.

Figure 6.5 depicts a radar chart comparing different characteristics of the two symmetric systems as well the optimized $\mathrm{MnO}_{\mathrm{x}}-\mathrm{CNT}$ 9-1//AC capacitor, where all the factors have been normalized with the actual characteristic value exhibited by the hybrid capacitor. The maximal power density was calculated using equation (6.4):

$$
P D_{\max }=\frac{V^{2}}{4 E S R * M}
$$

where $\mathrm{PD}_{\max }$ symbolizes the maximum power density, $\mathrm{V}$ is the cell voltage, ESR is the equivalent series resistance computed from the linear iR drop in the GCD curves, and M is the total mass of the active material of the anode and the cathode. The values for all the capacitors are tabulated in Table 6S1. The hybrid capacitor was superior to both the AC and $\mathrm{MnO}_{\mathrm{x}}-\mathrm{CNT}$ 9-1 based symmetric capacitors in terms of capacitance, voltage window, and energy and power densities. However, in terms of capacitive retention, the hybrid capacitor was still inferior to the AC symmetric system $(\sim 100 \%)$, which can be ascribed to the combination of redox reactions and double layer charge storage in the asymmetric system. It should be noted that the capacitors reported in this work have been normalized with the total anode and cathode masses and for actual deliverables, a packaging factor should be considered. For a factor of $1 / 3$, the optimal asymmetric capacitor can deliver a maximal energy density of $10 \mathrm{Whkg}^{-1}$, which is still higher than commercial EDLCs. 


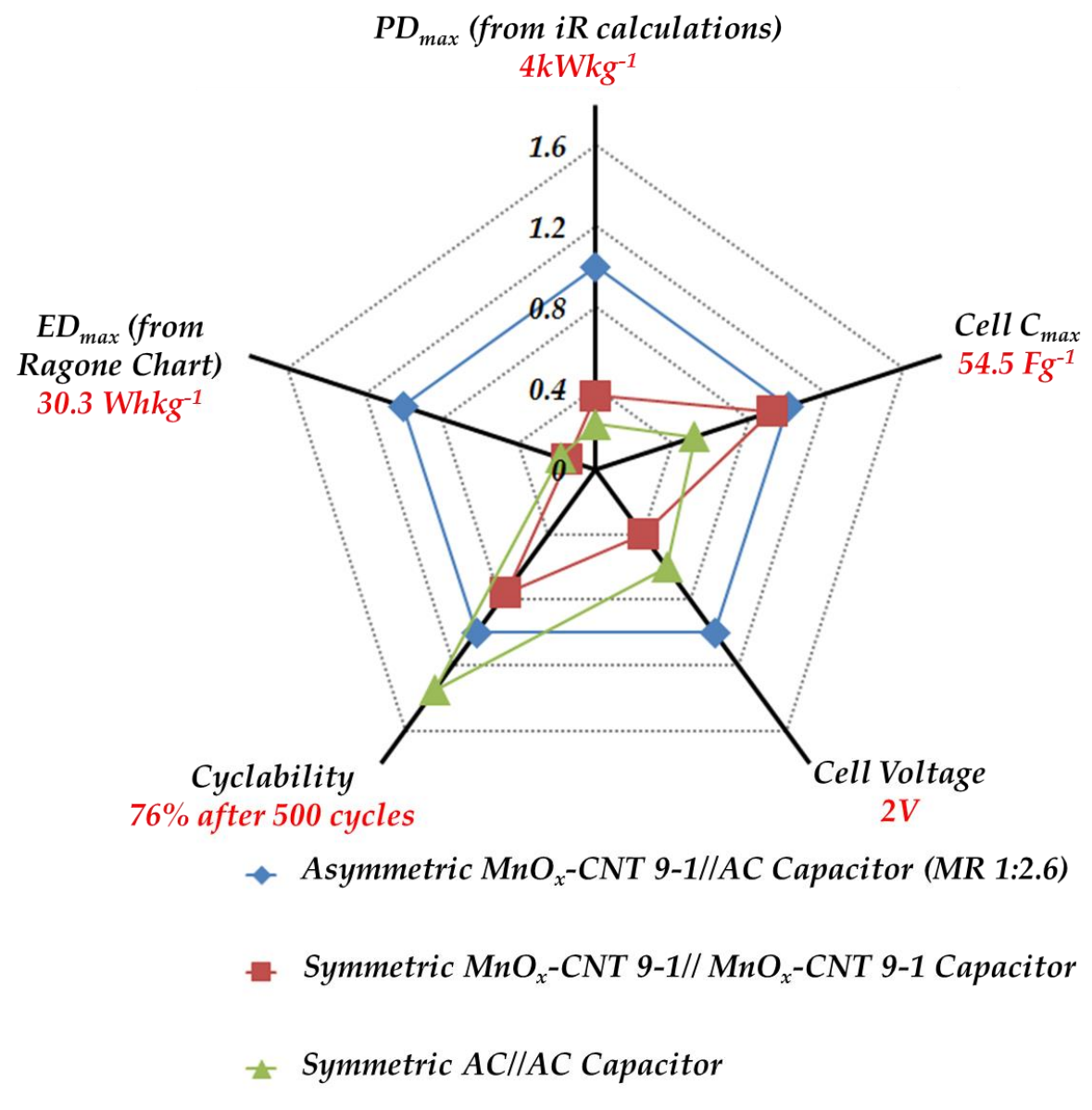

Figure 6.5: A radar chart depicting the electrochemical performance of the symmetric $\mathrm{MnO}_{\mathrm{x}}-\mathrm{CNT}$ 9-1// $\mathrm{MnO}_{\mathrm{x}}-\mathrm{CNT}$ 9-1 capacitor, the symmetric AC//AC capacitor and the asymmetric $\mathrm{MnO}_{\mathrm{x}}-\mathrm{CNT}$ 9-1//AC capacitor evaluated for mass ratio (MR) 1:2.6; the characteristics have been normalized by the values exhibited by the asymmetric capacitor and the red numbers next to axes labels depict the true values corresponding to the asymmetric capacitor.

\subsection{Conclusions}

In this work, three different manganese oxide compositions: i) pristine $\left(\mathrm{MnO}_{\mathrm{x}}\right)$, ii) with $10 \%$ carbon nanotube additive $\left(\mathrm{MnO}_{\mathrm{x}}-\mathrm{CNT}\right.$ 9-1), and iii) $20 \% \mathrm{CNT}$ additive $\left(\mathrm{MnO}_{\mathrm{x}}-\mathrm{CNT}\right.$ 8-2) were synthesized using electrostatic spray deposition (ESD) and investigated as electrochemical capacitor electrodes in neutral aqueous media. The $\mathrm{MnO}_{\mathrm{x}}-\mathrm{CNT}$ 9-1 composition exhibited superior electrochemical performance as 
compared to both the pristine $\mathrm{MnO}_{\mathrm{x}}$ and the $\mathrm{MnO}_{\mathrm{x}}-\mathrm{CNT}$ 8-2 composite films. The $\mathrm{MnO}_{\mathrm{x}^{-}}$ CNT 9-1 electrodes exhibited a high specific capacitance of $281 \mathrm{Fg}^{-1}$ for a current density of $0.2 \mathrm{Ag}^{-1}$ and were able to retain $87.4 \%$ of the maximal capacitance after 1000 cycles. Upon verifying the viability of the ESD derived $\mathrm{MnO}_{\mathrm{x}}-\mathrm{CNT}$ 9-1 films, the latter were used in asymmetric configuration comprising activated carbon (AC) counter electrodes. For the different mass ratios investigated, the ratio with 1:2.4, with the latter corresponding to the mass of $\mathrm{AC}$, exhibited the best electrochemical characteristics reaching a voltage of $2 \mathrm{~V}$ even in aqueous media. The asymmetric capacitor exhibited superior energy-power trade-off when compared to both the control groups consisting of symmetric $\mathrm{AC} / / \mathrm{AC}$ capacitor as well as the $\mathrm{MnO}_{\mathrm{x}}-\mathrm{CNT}$ 9-1// $\mathrm{MnO}_{\mathrm{x}}-\mathrm{CNT}$ 9-1 capacitor. The enhancement in the electrochemical characteristics is attributed to the combination of the wider electrochemical potential window as well as the high capacitance of the ESD based $\mathrm{MnO}_{\mathrm{x}}-\mathrm{CNT}$ 9-1 electrode.

\subsection{References}

1. Long, J.W., Bélanger, D., Brousse, T., Sugimoto, W., Sassin, M.B. and Crosnier, O., 2011. Asymmetric electrochemical capacitors-Stretching the limits of aqueous electrolytes. Mrs Bulletin, 36(7), pp.513-522.

2. Khomenko, V., Raymundo-Pinero, E. and Béguin, F., 2006. Optimisation of an asymmetric manganese oxide/activated carbon capacitor working at $2 \mathrm{~V}$ in aqueous medium. Journal of Power Sources, 153(1), pp.183-190.

3. Wang, J. G.; Kang, F.; Wei, B. Engineering of $\mathrm{MnO}_{2}$-based nanocomposites for high-performance supercapacitors. Prog. Mater Sci. 2015, 74, 51-124. 10.1016/j.pmatsci.2015.04.003

4. Wang, G.; Zhang, L.; Zhang, J. A review of electrode materials for electrochemical supercapacitors. Chem Soc. Rev., 2012, 41, 797-828. DOI: 10.1039/C1CS15060J. 
5. Gonzalez, A.; Goikolea, E.; Barrena, J. A.; Mysyk, R. Review on supercapacitors: Technologies and materials. Renew. Sustainable Energy Rev., 2016, 58,11891206. DOI: 10.1016/j.rser.2015.12.249

6. Wei, W.; Cui, X.; Chen, W.; Ivey, D. G. Manganese oxide-based materials as electrochemical supercapacitor electrodes. Chem. Soc. Rev., 2011,40, 1697-1721. DOI: 10.1039/C0CS00127A

7. Agrawal, R.; Chen, C.; Hao, Y.; Song, Y.; Wang, C. Graphene for Supercapacitors. In Graphene Based Energy Devices; Rashid bin Mohd Yusoff, A., Ed.; Wiley-VCH Verlag GmbH \& Co. KGaA: Weinheim, Germany, 2015; pp. 171-214; doi:10.1002/9783527690312.ch6.

8. Raymundo-Pinero, E., Khomenko, V., Frackowiak, E. and Beguin, F., 2005. Performance of manganese oxide/CNTs composites as electrode materials for electrochemical capacitors. Journal of the Electrochemical Society, 152(1), pp.A229-A235.

9. Agrawal, R., Nieto, A., Chen, H., Mora, M. and Agarwal, A., 2013. Nanoscale damping characteristics of boron nitride nanotubes and carbon nanotubes reinforced polymer composites. ACS applied materials \& interfaces, 5(22), pp.12052-12057.

10. Jaworek, A.; Sobczyk, A.T.; Krupa, A.; Lackowski, M.; Czech, T. Electrostatic deposition of nanothin films on metal substrate. Bull. Pol. Acad. Sci. Tech. Sci. 2009, 57, 63-70, doi:10.2478/v10175-010-0106-3.

11. Jaworek, A.; Sobczyk, A.T. Electrospraying route to nanotechnology: An overview. J. Electrostat. 2008, 66, 197-219, doi:10.1016/j.elstat.2007.10.001.

12. Chen, C.; Agrawal, R.; Kim, T.K.; Li, X.; Chen, W.; Yu, Y.; Beidaghi, M.; Penmatsa, V.; Wang, C. Nanostructured Electrodes via Electrostatic Spray Deposition for Energy Storage System. ECS Trans. 2014, 61, 155-163, doi:10.1149/06127.0155ecst.

13. Li, X.; Wang, C. Engineering nanostructured anodes via electrostatic spray deposition for high performance lithium ion battery application. J. Mater. Chem. A 2013, 1, 165, doi:10.1039/C2TA00437B.

14. Dhanabalan, A.; Li, X.; Agrawal, R.; Chen, C.; Wang, C. Fabrication and Characterization of $\mathrm{SnO}_{2}$ /Graphene Composites as High Capacity Anodes for LiIon Batteries. Nanomaterials 2013, 3, 606-614, doi:10.3390/nano3040606.

15. Agrawal, R., Adelowo, E., Baboukani, A.R., Villegas, M.F., Henriques, A. and Wang, C., 2017. Electrostatic Spray Deposition-Based Manganese Oxide FilmsFrom Pseudocapacitive Charge Storage Materials to Three-Dimensional Microelectrode Integrands. Nanomaterials, 7(8), p.198. 
16. Nam, K.W.; Kim, K.B. Manganese oxide film electrodes prepared by electrostatic spray deposition for electrochemical capacitors. J. Electrochem. Soc. 2006, 153, A81-A88, doi:10.1149/1.2131821.

17. Yuan, J., Chen, C., Hao, Y., Zhang, X., Agrawal, R., Zhao, W., Wang, C., Yu, H., Zhu, X., Yu, Y. and Xiong, Z., 2017. Fabrication of three-dimensional porous $\mathrm{ZnMn} 2 \mathrm{O} 4$ thin films on Ni foams through electrostatic spray deposition for high-performance lithium-ion battery anodes. Journal of Alloys and Compounds, 696, pp.1174-1179.

18. Yuan, J., Zhang, X., Chen, C., Hao, Y., Agrawal, R., Wang, C., Li, W., Yu, H., Yu, Y., Zhu, X. and Xiong, Z., 2017. Facile fabrication of three-dimensional porous $\mathrm{ZnO}$ thin films on $\mathrm{Ni}$ foams for lithium ion battery anodes. Materials Letters, 190, pp.37-39.

19. Yuan, J., Chen, C., Hao, Y., Zhang, X., Agrawal, R., Wang, C., Li, X., Hao, Y., Liu, B., Li, Q. and Xie, Y., 2017. Three-dimensionally porous CoMn2O4 thin films grown on $\mathrm{Ni}$ foams for high-performance lithium-ion battery anodes. Journal of Materials Science, 52(10), pp.5751-5758.

20. Agrawal, R.; Chen, C.; Dages, S.; Wang, C. A High Energy 3V Lithium-Ion Capacitor Synthesized via Electrostatic Spray Deposition. Adv. Mater. Lett. 2017, 8, 783-790, doi:10.5185/amlett.2017.7098.

21. Amer, A.A., Reda, S.M., Mousa, M.A. and Mohamed, M.M., 2017. $\mathrm{Mn3O4/graphene} \mathrm{nanocomposites:} \mathrm{outstanding} \mathrm{performances} \mathrm{as} \mathrm{highly} \mathrm{efficient}$ photocatalysts and microwave absorbers. RSC Advances, 7(2), pp.826-839.

22. Sun, Z., Liu, Z., Han, B., Miao, S., Miao, Z. and An, G., 2006. Decoration carbon nanotubes with $\mathrm{Pd}$ and $\mathrm{Ru}$ nanocrystals via an inorganic reaction route in supercritical carbon dioxide-methanol solution. Journal of colloid and interface science, 304(2), pp.323-328.

23. Ţucureanu, V., Matei, A. and Avram, A.M., 2016. FTIR spectroscopy for carbon family study. Critical Reviews in Analytical Chemistry, 46(6), pp.502-520.

24. Dubal, D.P.; Dhawale, D.S.; Salunkhe, R.R.; Lokhande, C.D. Conversion of chemically prepared interlocked cubelike $\mathrm{Mn}_{3} \mathrm{O}_{4}$ to birnessite $\mathrm{MnO}_{2}$ using electrochemical cycling. J. Electrochem. Soc., 2010, 157(7), A812-A817. doi: $10.1149 / 1.3428675$

25. Chu, H.Y.; Lai, Q.Y.; Wang, L.; Lu, J.F.; Zhao, Y. Preparation of $\mathrm{MnO}_{2} / \mathrm{WMNT}$ composite and $\mathrm{MnO}_{2} / \mathrm{AB}$ composite by redox deposition method and its comparative study as supercapacitive materials. Ionics, 2010, 16(3), 233-238. DOI: 10.1007/s11581-009-0378-5 
26. Julien, C.M.; Massot, M.; Poinsignon, C. Lattice vibrations of manganese oxides: Part I. Periodic structures. Spectrochim. Acta Mol. Biomol. Spectrosc, 2004, 60(3), 689-700. DOI: 1016/S1386-1425(03)00279-8

27. Ocana, M. Uniform particles of manganese compounds obtained by forced hydrolysis of manganese (II) acetate. Colloid Polym. Sci, 2000, 278(5), 443-449. DOI: $10.1007 / \mathrm{s} 003960050537$

28. Dong, R.; Ye, Q.; Kuang, L.; Lu, X.; Zhang, Y.; Zhang, X.; Tan, G.; Wen, Y.; Wang, F. Enhanced supercapacitor performance of $\mathrm{Mn}_{3} \mathrm{O}_{4}$ nanocrystals by doping transition-metal ions. ACS Appl. Mater. Interfaces, 2013, 5(19), 9508-9516. DOI: $10.1021 / \mathrm{am} 402257 \mathrm{y}$

29. Dubal, D.P.; Dhawale, D.S.; Salunkhe, R.R.; Lokhande, C.D. A novel chemical synthesis of $\mathrm{Mn}_{3} \mathrm{O}_{4}$ thin film and its stepwise conversion into birnessite $\mathrm{MnO}_{2}$ during super capacitive studies. J. Electroanal. Chem. 2010, 647, 60-65, doi:10.1016/j.jelechem.2010.05.010.

30. Wan, C.; Yuan, L.; and Shen, H. Effects of electrode mass-loading on the electrochemical properties of porous $\mathrm{MnO}_{2}$ for electrochemical supercapacitor. Int J Electrochem Sci, 2014, 9, 4024-4038.

31. Hsieh, Y.C., Lee, K.T., Lin, Y.P., Wu, N.L. and Donne, S.W., 2008. Investigation on capacity fading of aqueous $\mathrm{MnO} 2 \cdot \mathrm{nH} 2 \mathrm{O}$ electrochemical capacitor. Journal of Power Sources, 177(2), pp.660-664.

32. Ataherian, F., Lee, K.T. and Wu, N.L., 2010. Long-term electrochemical behaviors of manganese oxide aqueous electrochemical capacitor under reducing potentials. Electrochimica Acta, 55(25), pp.7429-7435

33. Tang, C., Tang, Z. and Gong, H., 2012. Hierarchically porous Ni-Co oxide for high reversibility ymmetric full-cell supercapacitors. Journal of The Electrochemical Society, 159(5), pp.A651-A656.

34. Zhang, Y.X., Huang, M., Li, F., Wang, X.L. and Wen, Z.Q., 2014. One-pot synthesis of hierarchical $\mathrm{MnO} 2$-modified diatomites for electrochemical capacitor electrodes. Journal of Power Sources, 246, pp.449-456.

35. Kuang, M., Wen, Z.Q., Guo, X.L., Zhang, S.M. and Zhang, Y.X., 2014. Engineering firecracker-like beta-manganese dioxides@ spinel nickel cobaltates nanostructures for high-performance supercapacitors. Journal of Power Sources, 270, pp.426-433.

36. Sun, X., Xie, M., Travis, J.J., Wang, G., Sun, H., Lian, J. and George, S.M., 2013. Pseudocapacitance of amorphous $\mathrm{TiO} 2$ thin films anchored to graphene and carbon nanotubes using atomic layer deposition. The Journal of Physical Chemistry C, 117(44), pp.22497-22508. 
37. Lin, Y.P. and Wu, N.L., 2011. Characterization of MnFe 2 O 4/LiMn 2 O 4 aqueous asymmetric supercapacitor. Journal of Power Sources, 196(2), pp.851854.

38. Wang, D.W., Li, F. and Cheng, H.M., 2008. Hierarchical porous nickel oxide and carbon as electrode materials for asymmetric supercapacitor. Journal of Power Sources, 185(2), pp.1563-1568.

39. Hung, P.J., Chang, K.H., Lee, Y.F., Hu, C.C. and Lin, K.M., 2010. Ideal asymmetric supercapacitors consisting of polyaniline nanofibers and graphene nanosheets with proper complementary potential windows. Electrochimica Acta, 55(20), pp.6015-6021.

40. Mandal, M., Ghosh, D., Chattopadhyay, K. and Das, C.K., 2016. A Novel Asymmetric Supercapacitor Designed with Mn3O4@ Multi-wall Carbon Nanotube Nanocomposite and Reduced Graphene Oxide Electrodes. Journal of Electronic Materials, 45(7), pp.3491-3500.

41. Chao-Fei, W., Shuang, L., Hui-Long, C., Fei-Long, G., Yu-Yin, G. and Feng, L., 2016. One-pot Synthesis and Application in Asymmetric Supercapacitors of Mn3O4@ RGO Nanocomposites. JOURNAL OF INORGANIC MATERIALS, 31(6), pp.581-587 


\section{ON-CHIP ASYMMETRIC MICROSUPERCAPACITORS COMBINING REDUCED GRAPHENE OXIDE AND MANGANESE OXIDE FOR HIGH ENERGY-POWER TRADEOFF}

\subsection{Introduction}

With the technological impetus of going "micro", it is imperative to create small-scale energy devices that can effectively power such miniaturized devices. Given the existing myriad of minuscule systems such as implantable medical devices (IMDs), wireless sensors, smart cards, personal electronics, etc. that typically require power in the range of several $\mu \mathrm{W}$ to several hundred $\mathrm{mW}$, it is essential to shrink the sizes of the energy storage components further. Currently, the majority of the micro-devices rely on batteries to provide the required energy and power. However the relatively poor power-handling ability and limited lifetime of batteries hinder their applicability to systems that require high current spikes [1]. As an alternative to batteries, energy harvesters hold significant promise for sustainable environments; however, the currently existing energy harvester systems require an energy storage device in tandem [1]. Electrochemical capacitors, also known as supercapacitors (SCs), on the other hand, can provide high powers along with long cycle lives. Based on the charge storage mechanisms, SCs can be divided into two major categories - electrochemical double layer capacitors (EDLCs) and redox or "pseudocapacitors". The former rely on the adsorption of ions at the electrode/electrolyte interface and typically comprise different forms of carbons, whereas the latter store charges in a faradaic/redox manner with fast and reversible redox reactions and encompass different transition metal oxides (TMOs) and conducting polymers [2]. Typically, pseudocapacitive materials exhibit larger specific capacitances, whereas double 
layer type materials exhibit better rate handling capability and superior cycle longevity [2].

Quite akin to their larger variants, miniaturized electrochemical energy storage (EES) systems can be connected externally for peak power and energy delivery; nevertheless, it is desirable for the next generation micro-power devices to be single standalone systems that can provide with simultaneous supply of high energy and high power. One of the strategies for achieving the latter is the asymmetric or hybrid supercapacitor design. Such systems typically combine a redox-type electrode along with a counter double layer capacitive electrode in one cohesive system and benefit from the larger capacity of the redox material and the superior kinetics and cycle life of the double layer material. Several asymmetric systems have been reported in the literature including pseudocapacitive metal oxides such as ruthenium oxide $\left(\mathrm{RuO}_{2}\right)$ [3], manganese oxide $\left(\mathrm{MnO}_{\mathrm{x}}\right)$ [4-8], nickel oxide $\left(\mathrm{NiO}_{\mathrm{x}}\right)[9,10]$, as well as lithium insertion materials (lithiumion capacitors) including pre-lithiated carbons [11-13], lithium titanate $\left(\mathrm{Li}_{4} \mathrm{Ti}_{5} \mathrm{O}_{12}\right)$ [1417], and lithium iron phosphate $\left(\mathrm{LiFePO}_{4}\right)[18,19]$ coupled with different carbons. While the asymmetric design offers significant promise from materials perspective, the "inplane interdigital design" offers a multitude of advantages from an architectural standpoint. For instance, having alternating digits of anode and cathode materials in close proximity can shorten the ion-transport pathways and can effectively enhance the rate capability of the on-chip systems. As opposed to the conventional two-dimensional (2D) thin-film design, the interdigital architecture allows for larger accessibility of the electrodes as the sides of the microelectrodes are exposed to the electrolyte [1]. The enhanced accessibility of the electrodes is especially well-suited for layered 2D materials, 
where the electrolyte ions can have facile access between the layers of the material by having the electrodes side-by-side [1].

One of the widely investigated 2D layered materials is graphene, which is essentially a one-atom thick $\mathrm{sp}^{2}$ hybridized carbon sheet [2]. Owing to its high theoretical specific surface area $\left(\sim 2600 \mathrm{~m}^{2} \mathrm{~g}^{-1}\right)$, exceptional electronic conductivity, and superior mechanical strength, graphene has been extensively explored as an EDLC material [2, 20-22].Despite the phenomenal properties of graphene, it is however challenging to fully realize the theoretical values, given the high degree of graphene sheet restacking [2, 12]. Furthermore, the hydrophobic nature of graphene makes it challenging to effectively disperse it in solvents. One of the derivatives of graphene is graphene oxide (GO), which in essence is graphene decorated with oxygen-containing groups on both the basal planes and the edges $[23,24]$. The oxygen functionality makes GO hydrophilic, which can assist in its effective dispersion in organic solvents as well as enhance the interaction with the electrolyte [25]. However, the oxygenated groups make GO insulating and for SC applications, effective reduction of GO is desired in order to utilize the electronic properties of graphene. Typically, GO is reduced to reduced graphene oxide (rGO) using strong reducing agents like hydrazine, which could be both cost-prohibitive and damaging to the environment [25]. As an alternative to chemical reduction, electrophoretic deposition (EPD) offers the possibility to effectively reduce GO without the need for any additional reducing agents [26]; An et al [27] noted that the rGO films synthesized via EPD exhibited much superior electrical conductivity over the parent GO papers $\left(1.43 \times 10^{4} \mathrm{Sm}^{-1}\right.$ as opposed to $\left.0.53 \times 10^{-3} \mathrm{Sm}^{-1}\right)$. EPD is a thin-film synthesis method, which essentially involves the movement of charged particles in a colloidal 
suspension under the influence of an electric field [26, 28]. Given the feasibility to simultaneously integrate and reduce GO using EPD, the latter method was utilized to fabricate the rGO microelectrodes for the microsupercapacitors (MSCs) for this work.

As pseudocapacitive or redox materials, manganese oxides $\left(\mathrm{MnO}_{\mathrm{x}}\right)$, in all polymorphs, have been widely studied owing to their high theoretical specific capacitance, environmental benignity, large abundance and low cost [29-32]. Different asymmetric configurations utilizing $\mathrm{MnO}_{\mathrm{x}}$ have been investigated for MSC applications including activated carbons (AC) [33], carbon nanotubes (CNT) [34], laser scribed graphene (LSG) [35], as well as graphene quantum dot (GQD) [36] counter electrodes. In this work, $\mathrm{MnO}_{\mathrm{x}}$ was electrochemically deposited onto gold micro-current collectors as the cathode component of the asymmetric MSCs against the electrophoretically prepared $\mathrm{rGO}$ counter microelectrode. The optimized asymmetric $\mathrm{rGO} / / \mathrm{MnO}_{\mathrm{x}} \mathrm{MSC}$ was able to deliver areal capacitances as high as $1.63 \mathrm{mFcm}^{-2}$, equivalent to a stack/volumetric capacitance of $3.6 \mathrm{Fcm}^{-3}$ as well as volumetric energy and power densities of 1.02 mWhcm ${ }^{-3}$ and $3441 \mathrm{mWcm}^{-3}$, much superior to those of both the symmetric $\mathrm{MnO}_{\mathrm{x}} / / \mathrm{MnO}_{\mathrm{x}}$ and $\mathrm{rGO} / / \mathrm{rGO}$ systems. The excellent energy-power tradeoff and high specific capacitance of the asymmetric capacitor is attributed to the synergy between the pseudocapacitive $\mathrm{MnO}_{\mathrm{x}}$ component and the double layer rGO component in addition to the in-plane interdigital microelectrode design.

\subsection{Materials and Methods}

\subsubsection{Fabrication of the interdigital gold micro-current collectors}

In order to construct the interdigital gold micro-current collectors, conventional photolithography and lift-off methods were used. A schematic illustration has been 
shown in Figure 7.1 (Step I-Step IV). First, AZ 5214 was spun-coated on a 4" $\mathrm{Si} / \mathrm{SiO}_{2}$ (100) wafer at a speed of $5000 \mathrm{rpm}$ for 30 seconds. After the spin coating process, a soft bake was carried out for 1 minute at a temperature of $110^{\circ} \mathrm{C}$ on a leveled hot plate. After the bake process, ultraviolet exposure was carried out using an OAI mask aligner with a UV dose of $230 \mathrm{mJcm}^{-2}$. Following the expose step, a develop step was carried out using AZ 300 MIF for $\sim 45$ seconds. After the develop step, a de-scum step was carried out using an $\mathrm{O}_{2}$ plasma at a flow rate of $60 \mathrm{sccm}$ and a pressure of $400 \mathrm{mT}$ Torr for 30 seconds using reactive ion etching (RIE). Following the patterning of the photoresist, metallization process $(\mathrm{Ti} / \mathrm{Au}(20 / 300 \mathrm{~nm}))$ was carried out using e-beam evaporation with a CHA evaporator. After the metallization process, lift-off was carried out in order to get rid of sacrificial photoresist using acetone and mechanical agitation, followed with isopropyl alcohol rinsing and $\mathrm{N}_{2}$ drying. Finally, a 30s $\mathrm{O}_{2}$ plasma treatment at 400 mTorr was carried out in order to get rid of any organic residues. The typical width of the gold fingers was $100 \mu \mathrm{m}$ with an interdigital gap of $100 \mu \mathrm{m}$ and a length of $8800 \mu \mathrm{m}$. Each electrode comprised 18 fingers, resulting in a total of 36 fingers for a single device and a total finger area of $0.3168 \mathrm{~cm}^{2}\left(\sim 0.32 \mathrm{~cm}^{2}\right)$, whereas the effective footprint area of the device (including finger gaps) was $\sim 0.66 \mathrm{~cm}^{2}$. Unless otherwise mentioned, the electrochemical parameters were normalized with the finger area in this work. 


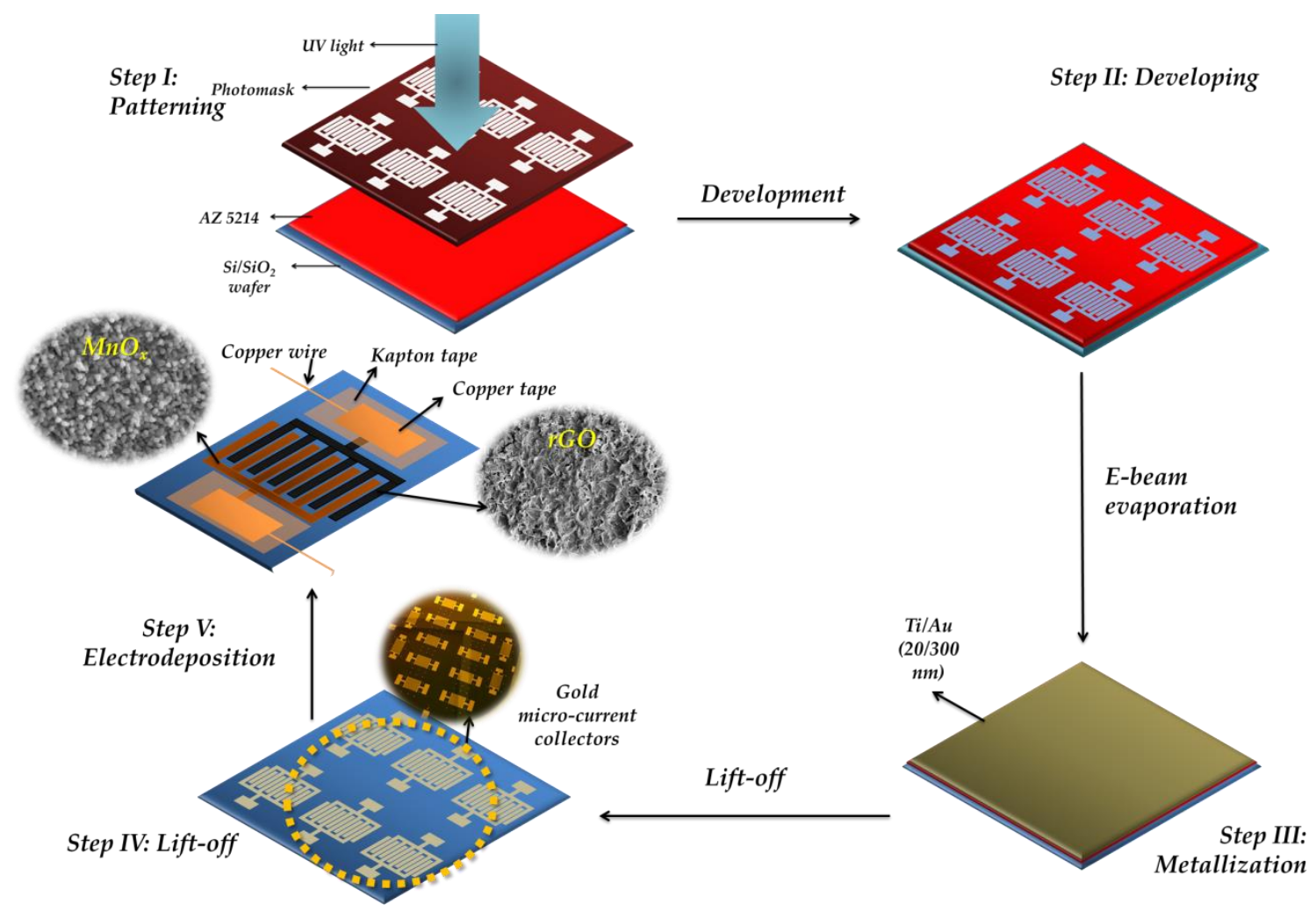

Figure 7.1: Schematic illustration of the asymmetric $\mathrm{rGO} / / \mathrm{MnO}_{\mathrm{x}}$ microsupercapacitor construction

\subsubsection{Active Material Integration}

After constructing the gold micro-current collectors, the active materials (rGO and $\mathrm{MnO}_{\mathrm{x}}$ ) were integrated onto the current collectors using electrodeposition (electrochemical and electrophoretic deposition methods). For the symmetric $\mathrm{MnOx} / / \mathrm{MnOx}$ microsupercapacitor, a three-electrode setup was used where the interdigitated gold current collectors functioned as the working electrode, and an $\mathrm{Ag} / \mathrm{AgCl}$ and a platinum coil functioned as the reference and counter electrode, respectively. An anodic current of $0.5 \mathrm{mAcm}^{-2}$ was applied for 20 minutes (equivalent to an applied charge of $0.6 \mathrm{Ccm}^{-2}$ ) in an electrolyte solution containing $0.2 \mathrm{M}$ manganese acetate (Sigma Aldrich) and $0.2 \mathrm{M} \mathrm{Na}_{2} \mathrm{SO}_{4}$ (Sigma Aldrich). After the deposition process, 
the electrodes were washed with DI water and dried overnight before being used for further characterization. For the $\mathrm{rGO}$ deposition for the symmetric $\mathrm{rGO} / / \mathrm{rGO}$ microsupercapacitor, a suspension containing single layer graphene oxide (SLGO, Cheap Tubes Inc., USA) and $\mathrm{C}_{2} \mathrm{H}_{5} \mathrm{OH}$ : DI water (90:10, v:v) in a concentration of $1 \mathrm{mgml}^{-1}$ was used for the EPD process after $1 \mathrm{~h}$ ultrasonication. An electric field of $\sim 40 \mathrm{Vcm}^{-1}$ was applied between the gold current collectors (working electrode) and a platinum coil (counter electrode); small amounts of $\mathrm{MgCl}_{2}\left(0.1 \mathrm{mgml}^{-1}\right)$ were added to the GO solution in order to enhance the conductivity and facilitate the EPD process. For the asymmetric microsupercapacitors (schematic illustration shown in Figure 7.1 Step V), three different depositions of manganese oxide comprising anodic charges of $0.6,0.9$ and $1.2 \mathrm{Ccm}^{-2}$ were evaluated against a 5 min deposition of rGO.

\subsubsection{Material Characterization}

$\mathrm{X}$-ray diffraction (XRD) studies on the electrochemically deposited $\mathrm{MnO}_{\mathrm{x}}$ were carried out using a Siemens D5000 Diffractometer with $\mathrm{Cu}-\mathrm{K} \alpha$ radiation. For spectroscopic characterization on the electrochemically deposited $\mathrm{MnO}_{\mathrm{x}}$ and the electrophoretically rGO films, Fourier Transform Infrared (FTIR) studies were carried out using a JASCO FTIR-4100 equipped with an attenuated total reflectance (ATR) accessory. The top and the cross sectional views of the symmetric and asymmetric microsupercapacitors were investigated using scanning electron microscopy (SEM) with a JEOL SEM 6330 in the secondary electron imaging (SEI) mode. 


\subsubsection{Electrochemical Characterization}

The electrochemical characterization on the symmetric $\mathrm{rGO} / / \mathrm{rGO}, \mathrm{MnO}_{\mathrm{x}} / / \mathrm{MnO}_{\mathrm{x}}$, as well as the asymmetric $\mathrm{rGO} / / \mathrm{MnO}_{\mathrm{x}}$ microsupercapacitors was carried out in a aqueous electrolyte containing $1 \mathrm{M} \mathrm{Na}_{2} \mathrm{SO}_{4}$ using a VMP3 Potentiostat (Princeton, Bio-Logic). Two-electrode studies were carried out for both the symmetric and asymmetric configurations and all the experiments were carried out room temperature. All the electrochemical parameters were normalized with the total finger/active material area $\left(\sim 0.32 \mathrm{~cm}^{2}\right)$ and the systems were evaluated using cyclic voltammetry (CV), galvanostatic charging and discharging (GCD), as well as electrochemical impedance spectroscopy (EIS) measurements.

\subsection{Results and Discussion}

\subsubsection{Spectroscopic, crystallographic and microstructural characterization performed on the manganese oxide and rGO microelectrodes}

The FTIR spectra of the starting GO powders and the EPD reduced GO (rGO) is shown in Figure 7.2. The broad absorption peak centered around $3378 \mathrm{~cm}^{-1}$ in the GO powder is the characteristic IR band position from the $\mathrm{OH}$ stretching vibrations [37, 38] , whereas the peaks at $1727 \mathrm{~cm}^{-1}, 1624 \mathrm{~cm}^{-1}, 1377 \mathrm{~cm}^{-1}, 1234 \mathrm{~cm}^{-1}$, and $1083 \mathrm{~cm}^{-1}$ are attributed to $\mathrm{C}=\mathrm{O}$ stretching [38], aromatic $\mathrm{C}=\mathrm{C}$ stretching [39], carboxyl [40], epoxide C-O-C or phenolic C-O-H stretching vibrations [40], C-O stretching in epoxy or alkoxy groups [40], respectively. It is worth noting that the intensity from the hydroxyl groups is substantially mitigated in the EPD based rGO film, indicating effective reduction of GO during electrophoresis. Furthermore, the intensity of the other functional groups signaling the presence of oxygen was reduced; the peak at $1615 \mathrm{~cm}^{-1}$ was however quite prevalent 
in the rGO spectrum, signaling the presence of aromatic $\mathrm{C}=\mathrm{C}$ stretching [39], which is from the parental graphitic skeleton.

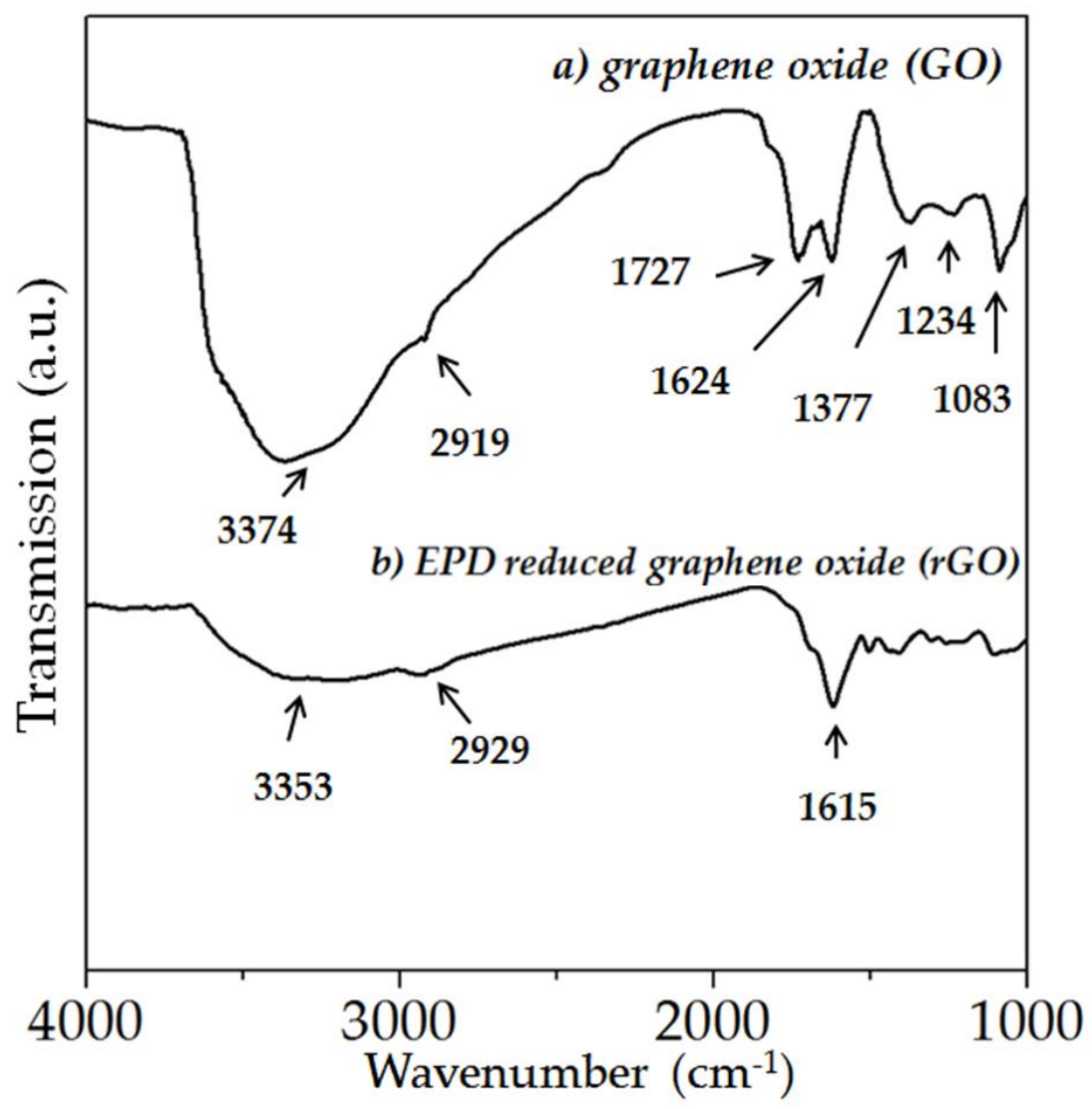

Figure 7.2: The FTIR spectra of the starting graphene oxide powders and the EPD reduced graphene oxide films

The Fourier transform infrared (FTIR) spectrum of the electrodeposited $\mathrm{MnO}_{\mathrm{x}}$ is shown in Figure 7.3a; the peaks located around 510, 526, and $581 \mathrm{~cm}^{-1}$ as ascribed to the $\mathrm{Mn}-\mathrm{O}$ vibrations from the $\mathrm{Mn}-\mathrm{O}$ octahedra and are consistent with previous reports [41, 42]. The XRD pattern of the electrochemically deposited manganese oxide films is shown in Figure 7.3b. The material is of low degree of crystallinity; however the faint peaks present in the diffraction pattern are ascribed to $\alpha-\mathrm{MnO}_{2}(\mathrm{JCPDS}$ Card Number: 
$00-044-0141)$. The peaks at $18.1^{\circ}, 28.8^{\circ}, 37.5^{\circ}, 46.1^{\circ}, 56.9^{\circ}$, and $65.2^{\circ}$ are indexed as (hkl) plane orientations of (200), (310), (211), (321), (431), and (002), respectively of $\alpha$ $\mathrm{MnO}_{2}$ phase. However, owing to the poor degree of crystallinity the manganese oxide is referred to as $\mathrm{MnO}_{\mathrm{x}}$.
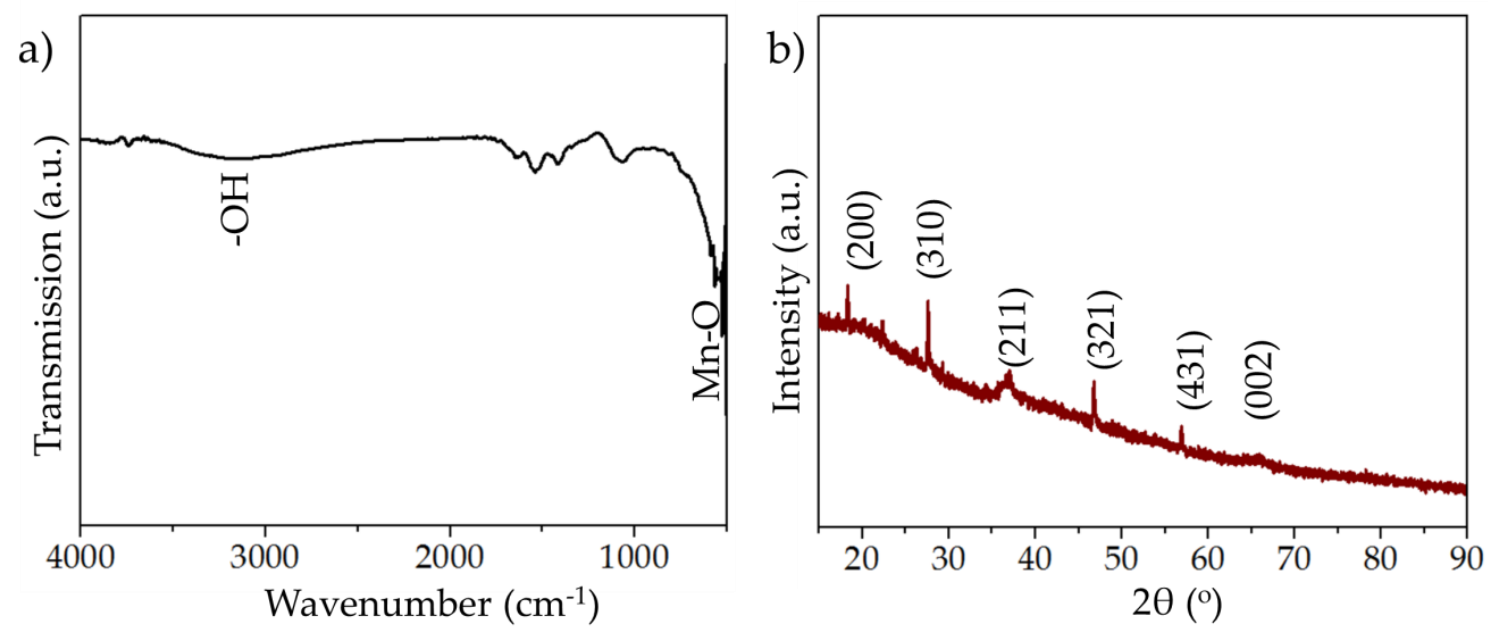

Figure 7.3: a) FTIR spectrum and b) the X-ray diffraction (XRD) pattern of the electrochemically deposited $\mathrm{MnO}_{\mathrm{x}}$ films.

The microstructure of the $\mathrm{MnO}_{\mathrm{x}}-\mathrm{rGO}$ coated asymmetric capacitors is shown in Figure 7.4a; as evident the system comprised alternating fingers of $\mathrm{MnO}_{\mathrm{x}}$ and $\mathrm{rGO}$ electrodes. Figure $7.4 \mathrm{~b}$ displays the cross-sectional view of the $\mathrm{rGO}$ electrode - the structure consisted of graphene layers as expected from the parent graphene oxide powders (SEM micrograph shown in Supplementary file Figure 7S1) and the rGO film had an average thickness of $\sim 4.5 \mu \mathrm{m}$. The top view of the rGO microelectrode is illustrated in Figure 7.4c; as evident the graphene sheets were well dispersed, thereby confirming effective sheet assembly during the EPD process. Figures $7.4 \mathrm{~d}$ through $7.4 \mathrm{f}$ show the cross sectional images of the $\mathrm{MnO}_{\mathrm{x}}$ films deposited at anodic charges of $0.6,0.9$ 
and $1.2 \mathrm{Ccm}^{-2}$ and the corresponding morphologies of the films are exhibited as Figures 7.4g through 7.4i. As expected, the $\mathrm{MnO}_{\mathrm{x}}$ film deposited for an anodic charge of 0.6 $\mathrm{Ccm}^{-2}$ was the thinnest amongst the films deposited for different charges. The average film thicknesses for the $\mathrm{MnO}_{\mathrm{x}}$ microelectrodes were $\sim 0.38, \sim 0.81$, and $\sim 0.95 \mu \mathrm{m}$ for deposition rates of $0.6,0.9$ and $1.2 \mathrm{Ccm}^{-2}$, respectively. The microstructure of the different $\mathrm{MnO}_{\mathrm{x}}$ films was similar and comprised homogeneously dispersed $\mathrm{MnO}_{\mathrm{x}}$ nanoparticles.
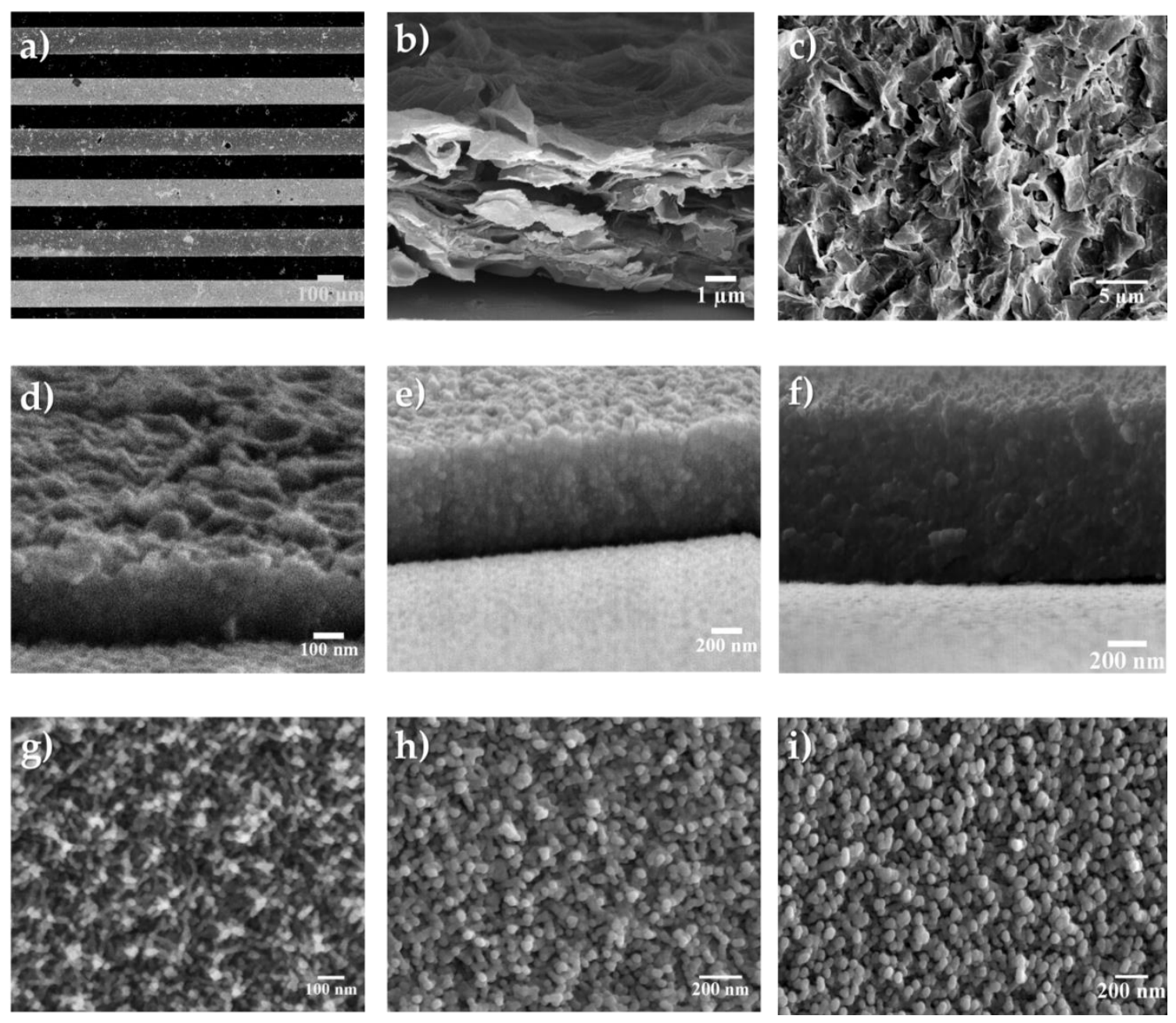

Figure 7.4: a) SEM micrograph of the interdigitated $\mathrm{rGO}$ and $\mathrm{MnO}_{\mathrm{x}}$ microelectrodes; b) cross sectional view and c) top view of the rGO coated microelectrodes; d-f) cross sectional view of the $\mathrm{MnO}_{\mathrm{x}}$ microelectrodes deposited at $0.6,0.9$ and $1.2 \mathrm{Ccm}^{-2}$, 
respectively; g-i) top-view of the $\mathrm{MnO}_{\mathrm{x}}$ microelectrodes deposited at 0.6, 0.9 and $1.2 \mathrm{Ccm}^{-2}$, respectively.

\subsubsection{Electrochemical Characterization of the symmetric rGO//rGO, $\mathrm{MnO}_{\mathrm{x}} / / \mathrm{MnO}_{\mathrm{x}}$, and asymmetric $\mathrm{rGO}-\mathrm{MnO}_{\mathrm{x}}$ microsupercapacitors}

\subsubsection{Electrochemical evaluation of the symmetric rGO//rGO MSCs}

The electrochemical characteristics of the $\mathrm{rGO} / / \mathrm{rGO}$ symmetric MSC are shown in Figure 7.5. The typical CV curves of the symmetric $\mathrm{rGO} / / \mathrm{rGO}$ MSCs at scan rates of 1,2 , 5, 10, and $20 \mathrm{Vs}^{-1}$ are shown in Figure 7.5a. As evident, even at a high scan rate of $20 \mathrm{Vs}^{-}$ 1 , the curves maintain predominantly rectangular shape, which is indicative of predominantly capacitive charge storage. The typical GCD curves of the $\mathrm{rGO} / \mathrm{rGO}$ MSCs at different current rates are shown in Figure 7.5b; the discharge areal capacitances were estimated as $\sim 252,223$, and $172 \mu \mathrm{Fcm}^{-2}$ at current densities of $0.32,0.64$, and 1.28 $\mathrm{mAcm}^{-2}$, respectively. Figure $7.5 \mathrm{c}$ shows the typical Nyquist plots of the $\mathrm{rGO} / / \mathrm{rGO}$ MSCs scanned for a frequency range of $100000-0.01 \mathrm{~Hz}$; as evident the curves comprised a depressed semicircular region in the high frequency regime followed by a linear slope in the low-frequency region, indicating typical capacitive behavior; the diameter of the semicircular region was $\sim 0.0035 \mathrm{k} \Omega \mathrm{cm}^{2}(\sim 11 \Omega)$, indicating very low charge transfer resistance; the $\mathrm{x}$-axis intercept was $\sim 8 \Omega$ mainly due to solution resistance. The typical cycling behavior of the $\mathrm{rGO} / / \mathrm{rGO}$ microsupercapacitor is illustrated in Figure $7.5 \mathrm{~d}$; the capacitor exhibited very stable cycling with a capacitive retention of $\sim 97 \%$ after 100 cycles. 
a)

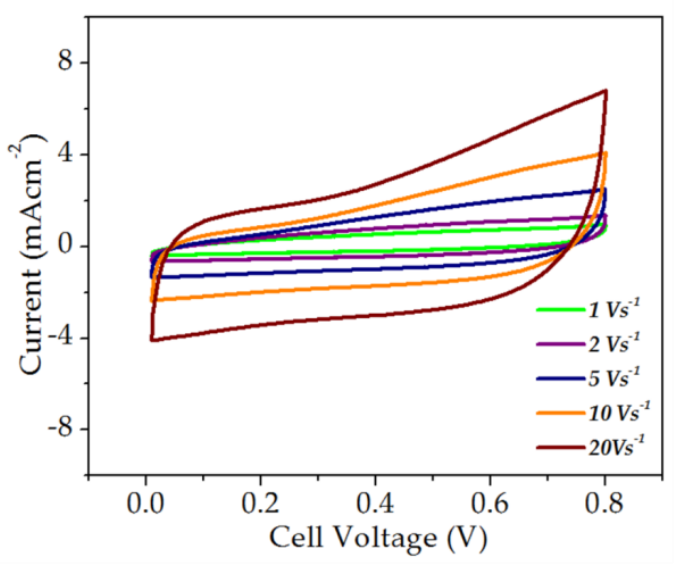

c)

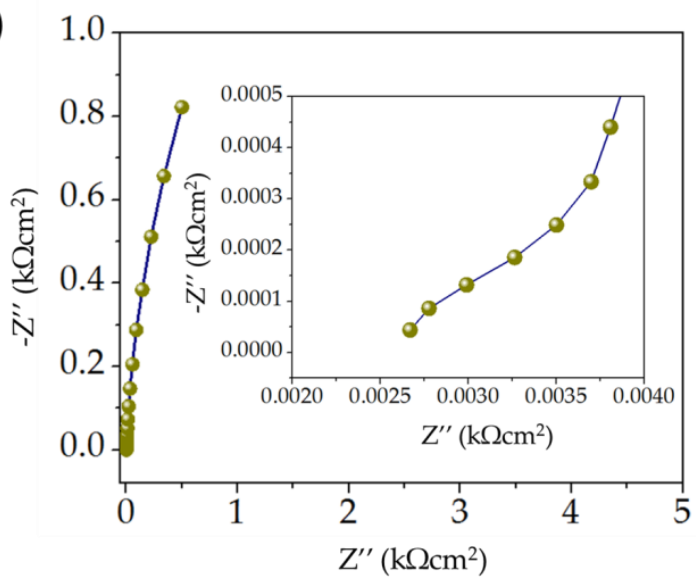

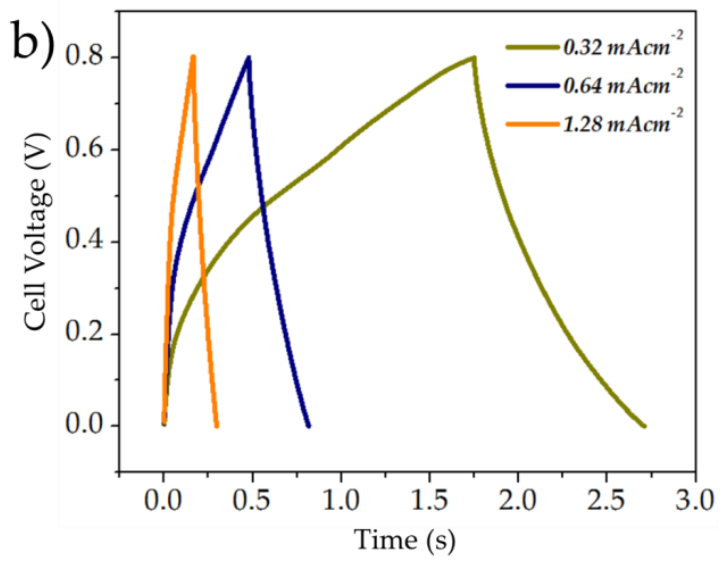

d)

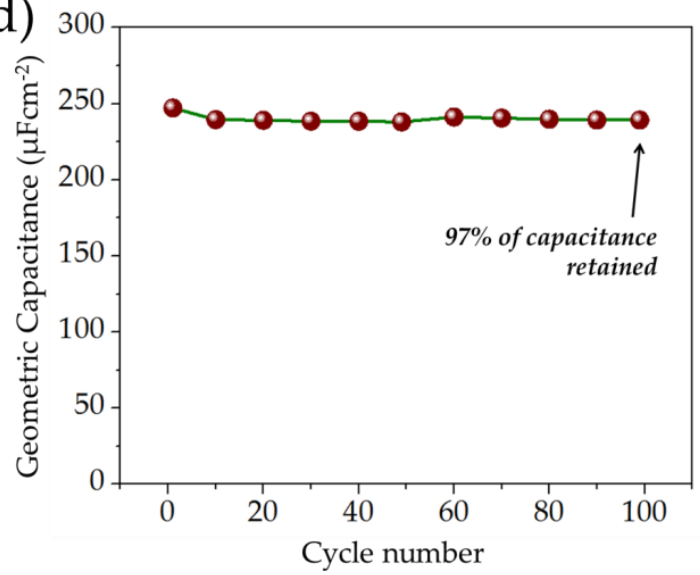

Figure 7.5: Typical CV curves (scanned at $1-20 \mathrm{Vs}^{-1}$ ); b) GCD curves at different current densities; c) EIS spectra (between $100000-0.01 \mathrm{~Hz}$ ) and d) cycle life of the symmetric rGO- rGO microsupercapacitor

\subsubsection{Electrochemical characterization of the $\mathrm{MnO}_{x} / / \mathrm{MnO}_{x}$ symmetric MSCs}

The electrochemical characteristics of the $\mathrm{MnO}_{\mathrm{x}} / / \mathrm{MnO}_{\mathrm{x}}$ symmetric MSCs are shown in Figure 7.6. The typical cyclic voltammograms (CV) of the symmetric $\mathrm{MnO}_{\mathrm{x}} / /_{\mathrm{MnOx}}$ MSCs at scan rates of $1,2,5,10$, and $20 \mathrm{Vs}^{-1}$ are shown in Figure 7.6a. As evident, even at a high scan rate of $20 \mathrm{Vs}^{-1}$, the curves exhibit predominantly capacitive shape with some depressed redox peaks around $0.5-0.6 \mathrm{~V}$, which can be attributed to the pseudocapacitive charge storage characteristics of the manganese oxide active material. The typical GCD curves at different current densities are shown in Figure 7.6b; the GCD 
curves display triangular sloping-desloping behavior for a voltage range of $0-0.8 \mathrm{~V}$ with some curvature. The discharge areal capacitances were estimated as $147,96,64 \mu \mathrm{Fcm}^{-2}$ at current densities of $0.16,0.32,0.64 \mathrm{mAcm}^{-2}$, respectively. Figure $7.6 \mathrm{c}$ shows the typical Nyquist plots of the freshly prepared $\mathrm{MnO}_{\mathrm{x}} / / \mathrm{MnO}_{\mathrm{x}}$ MSCs scanned for a frequency range of $100000-0.01 \mathrm{~Hz}$. As evident the curves comprised a depressed semicircular region in the high frequency regime followed by a linear slope in the low-frequency region, indicating typical redox behavior. The diameter of the semicircular region was $\sim 0.02 \mathrm{k} \Omega \mathrm{cm}^{-2}(\sim 60 \Omega)$ indicating low charge-transfer resistance. The typical cyclability and the capacitance retention of the $\mathrm{MnO}_{\mathrm{x}} / / \mathrm{MnO}_{\mathrm{x}} \mathrm{MSC}$ are shown in Figure 7.6d; 58\% of the initial capacitance was retained after 1000 cycles. The drop in capacitance has been observed in previous reports documenting the use of $\mathrm{MnO}_{\mathrm{x}}$ for symmetric MSCs [43]. 

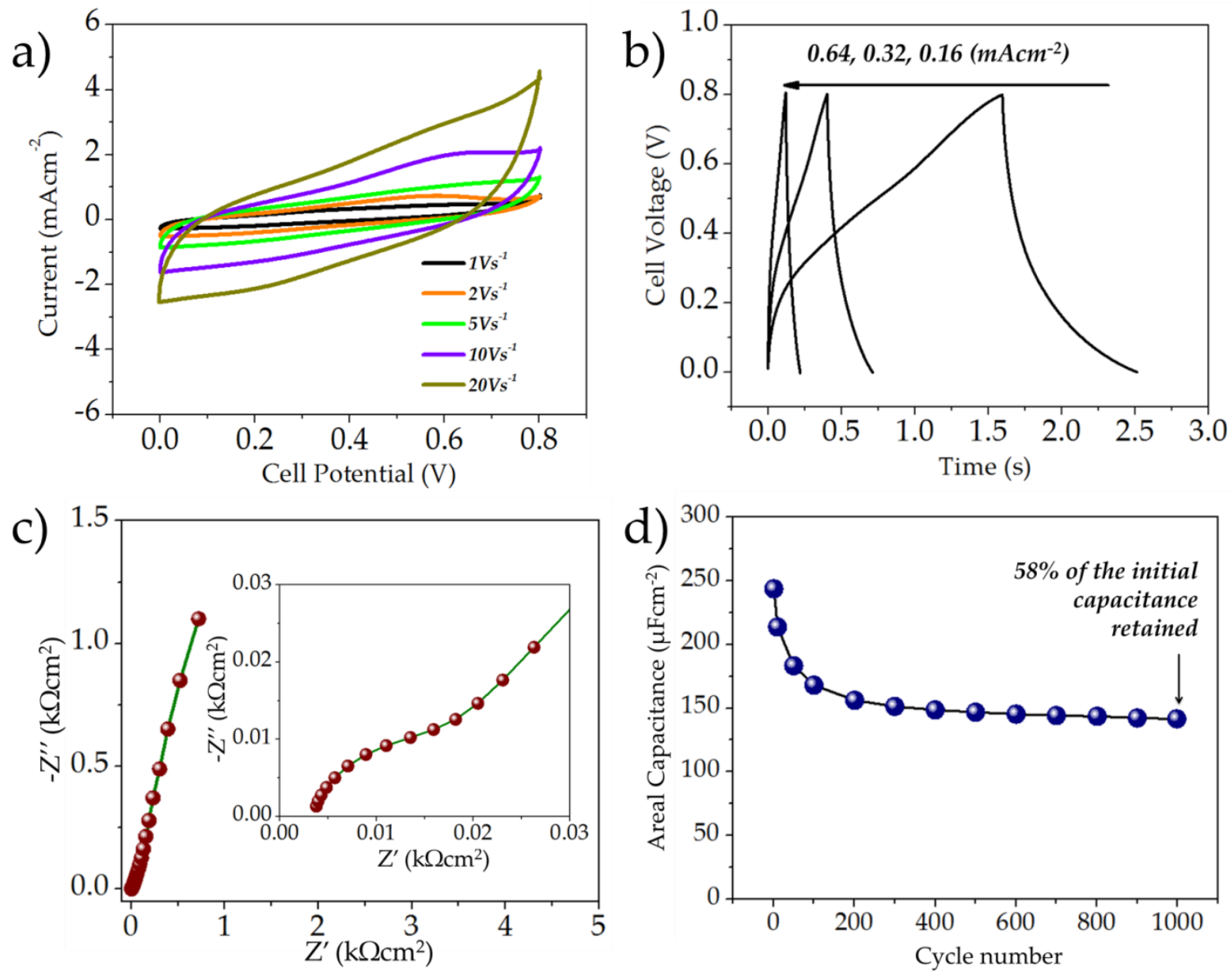

Figure 7.6: a) Typical CV curves (scanned at 1-20Vs ${ }^{-1}$ ); b) GCD curves at different current densities; c) EIS spectra (between 100000-0.01Hz) and d) cycle life of the symmetric $\mathrm{MnO}_{\mathrm{x}} / / \mathrm{MnO}_{\mathrm{x}}$ microsupercapacitor

\subsubsection{Electrochemical evaluation of the asymmetric $\mathrm{MnO}_{x} / / \mathrm{rGO}$ MSCs}

As seen in the previous sections, the areal capacitance of $\mathrm{rGO} / / \mathrm{rGO} \mathrm{MSC}$ was higher than that of the $\mathrm{MnO}_{\mathrm{x}} / / \mathrm{MnO}_{\mathrm{x}} \mathrm{MSC}\left(\sim 252 \mu \mathrm{Fcm}^{-2}\right.$ as opposed to $96 \mu \mathrm{Fcm}^{-2}$ at a current density of $0.32 \mathrm{mAcm}^{-2}$ ), as a result of which, three different $\mathrm{MnO}_{\mathrm{x}}$ thicknesses $\left(\mathrm{MnO}_{\mathrm{x}}\right.$ deposited at $0.6,0.9$, and $\left.1.2 \mathrm{Ccm}^{-2}\right)$ were evaluated for asymmetric systems in order to investigate the optimal energy-power tradeoff. The asymmetric MSCs were designated as $\mathrm{rGO} / / \mathrm{MnO}_{\mathrm{x}}-0.6 \mathrm{C}, \mathrm{rGO} / / \mathrm{MnO}_{\mathrm{x}}-0.9 \mathrm{C}$ and $\mathrm{rGO} / / \mathrm{MnO}_{\mathrm{x}}-1.2 \mathrm{C}$, where the 
suffix symbolizes the charge used for $\mathrm{MnO}_{\mathrm{x}}$ deposition. The detailed electrochemical characteristics of the asymmetric $\mathrm{rGO} / / \mathrm{MnO}_{\mathrm{x}}-0.9 \mathrm{C}$ MSC are shown in Figure 7.7, whereas the electrochemical characteristics of the $\mathrm{rGO} / / \mathrm{MnO}_{\mathrm{x}}-0.6 \mathrm{C}$ and $\mathrm{rGO} / / \mathrm{MnO}_{\mathrm{x}^{-}}$ 1.2C MSCs can be found in the supplementary file (Figure 7S2). The typical CV curves of asymmetric $\mathrm{rGO} / / \mathrm{MnO}_{\mathrm{x}}-0.9 \mathrm{C}$ MSC at different scan rates are shown in Figure 7.7a. As evident the current response from the asymmetric $\mathrm{rGO} / / \mathrm{MnO}_{\mathrm{x}}-0.9 \mathrm{C}$ MSC was much superior to that of both the symmetric $\mathrm{rGO} / / \mathrm{rGO}$ and $\mathrm{MnO}_{\mathrm{x}} / / \mathrm{MnO}_{\mathrm{x}}$ capacitors evaluated previously. Furthermore, composite charge storage characteristics are evident from the shape of the $\mathrm{CV}$ curves. GCD curves of the asymmetric $\mathrm{rGO} / / \mathrm{MnO}_{\mathrm{x}}-0.9 \mathrm{C}$ MSC at different current densities are shown in Figure 7.7b; the discharge areal capacitances were estimated as $1.63,1.59,1.29$, and $1.2 \mathrm{mFcm}^{-2}$ at current densities of $0.32,0.64$, and 1.28 , and $2.56 \mathrm{mAcm}^{-2}$, respectively. The Nyquist plot of the asymmetric $\mathrm{rGO} / / \mathrm{MnO}_{\mathrm{x}^{-}}$ 0.9C MSC scanned for a frequency range of $100000-0.01 \mathrm{~Hz}$ is shown in Figure $7.7 \mathrm{c}$ and the inset depicts the zoomed-in high-frequency response of the MSC. The diameter of semicircular region was $\sim 0.07 \mathrm{k} \Omega \mathrm{cm}^{-2}(\sim 218 \Omega)$, higher than both the symmetric $\mathrm{rGO} / / \mathrm{rGO}$ and $\mathrm{MnO}_{\mathrm{x}} / / \mathrm{MnO}_{\mathrm{x}}$ MSCs. The relatively higher charge-transfer resistivity can be attributed to the larger thickness of the manganese oxide component on the asymmetric MSC. The typical cycling performance of the asymmetric $\mathrm{rGO} / / \mathrm{MnO}_{\mathrm{x}}-0.9 \mathrm{C}$ MSC is shown in Figure 7.7d; the capacitor retained a capacitance of $\sim 85 \%$ after 1000 cycles, which is much superior to that of the $\mathrm{MnO}_{\mathrm{x}} / / \mathrm{MnO}_{\mathrm{x}} \mathrm{MSC}$. 


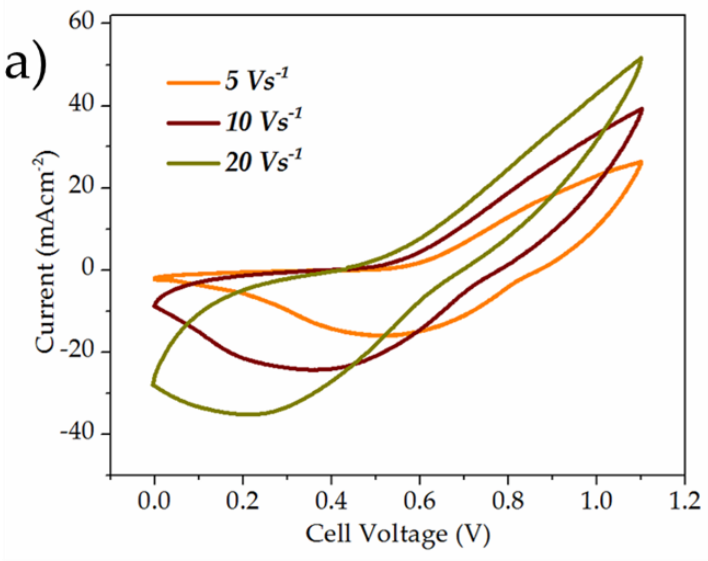

b)
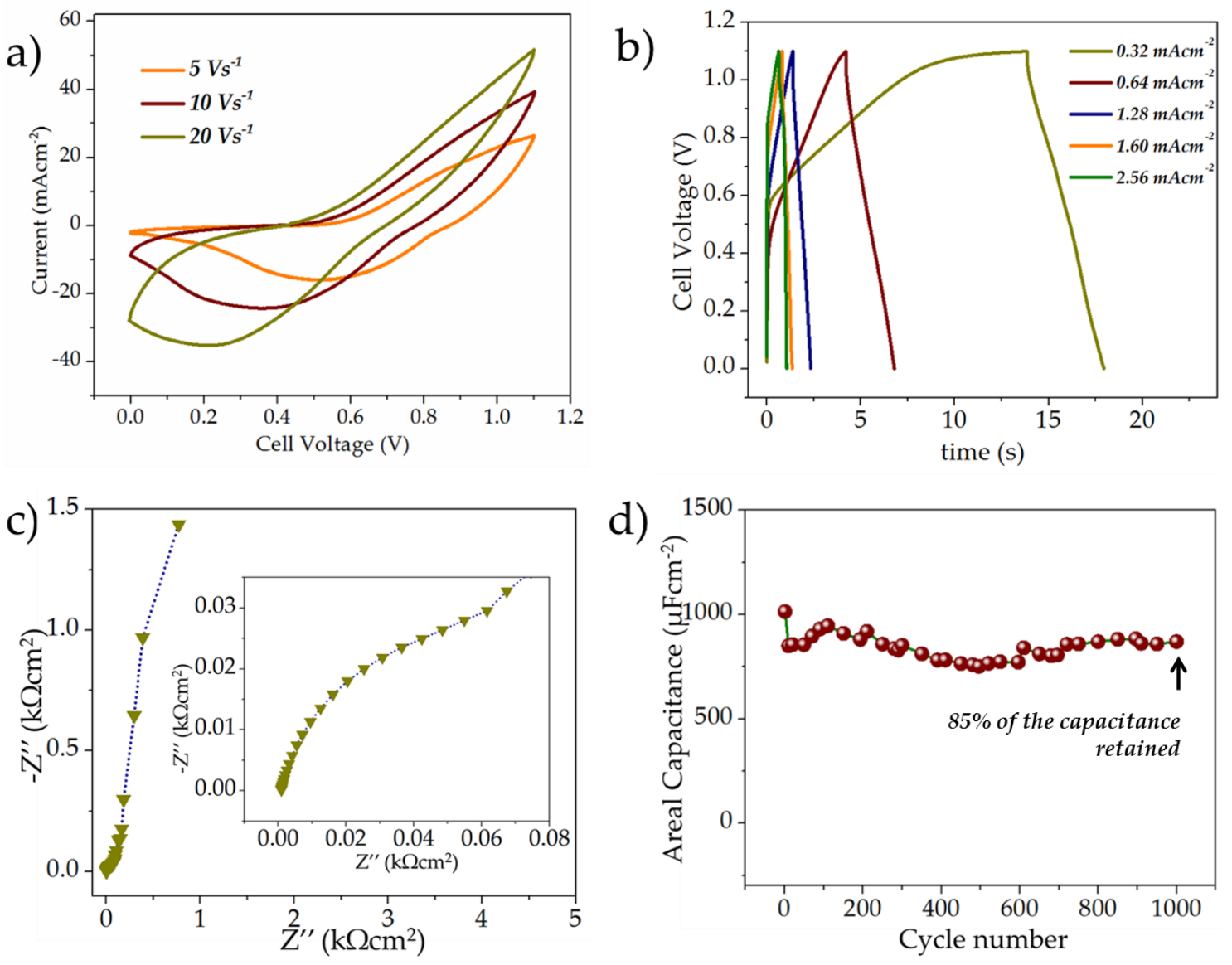

Figure 7.7: a) Typical CV curves (scanned at 5-20Vs ${ }^{-1}$ ); b) GCD curves at different current densities; c) EIS spectra (between 100000-0.01Hz) and d) cycle life of the asymmetric $\mathrm{rGO} / / \mathrm{MnO}_{\mathrm{x}}-0.9 \mathrm{C}$ microsupercapacitor

The comparitive rate capability of the different MSCs evaluated in this work is shown in Figures 7.8a and 7.8b. While areal normalization is essential in terms of practicality of miniaturized devices, stack calculations can provide with more insight into the intrinsic properties of the materials utilized for the MSC construction. The stack capacitances of all the asymmetric MSCs as well as the $\mathrm{rGO} / / \mathrm{rGO} \mathrm{MSC}$ were normalized with the thickness of the rGO film, whereas the stack parameters for the $\mathrm{MnO}_{\mathrm{x}} / / \mathrm{MnO}_{\mathrm{x}}$ symmetric capacitor were normalized with the thickness of the $\mathrm{MnO}_{\mathrm{x}}$ film. Figures 7.8a 
and $7.8 \mathrm{~b}$, it is clear that the asymmetric $\mathrm{rGO} / / \mathrm{MnO}_{\mathrm{x}}-0.6 \mathrm{C}, \mathrm{rGO} / / \mathrm{MnO}_{\mathrm{x}}-0.9 \mathrm{C}$, and $\mathrm{rGO} / / \mathrm{MnO}_{\mathrm{x}}-1.2 \mathrm{C} \mathrm{MSC}$ as well as the symmetric $\mathrm{rGO} / / \mathrm{rGO}$ MSC followed the same trend for both the areal and stack capacitances with the highest values for $\mathrm{rGO} / / \mathrm{MnO}_{\mathrm{x}^{-}}$ 0.9C followed by the $\mathrm{rGO} / / \mathrm{MnO}_{\mathrm{x}}-1.2 \mathrm{C}, \mathrm{rGO} / / \mathrm{MnO}_{\mathrm{x}}-0.6 \mathrm{C}$ and the $\mathrm{rGO} / / \mathrm{rGO} \mathrm{MSC}$ (in that order). The only discrepancy in stack and areal capacitance was exhibited by the symmetric $\mathrm{MnO}_{\mathrm{x}} / / \mathrm{MnO}_{\mathrm{x}}$ system, which can be explained by the relatively lower thickness of the $\mathrm{MnO}_{\mathrm{x}}$ as compared to the rGO film. The stack capacitance of the $\mathrm{MnO}_{\mathrm{x}} / / \mathrm{MnO}_{\mathrm{x}}$ system fades quickly with increasing current, which can be attributed to the use of pristine $\mathrm{MnO}_{\mathrm{x}}$ as electro-active material without the addition of any conducting additives.
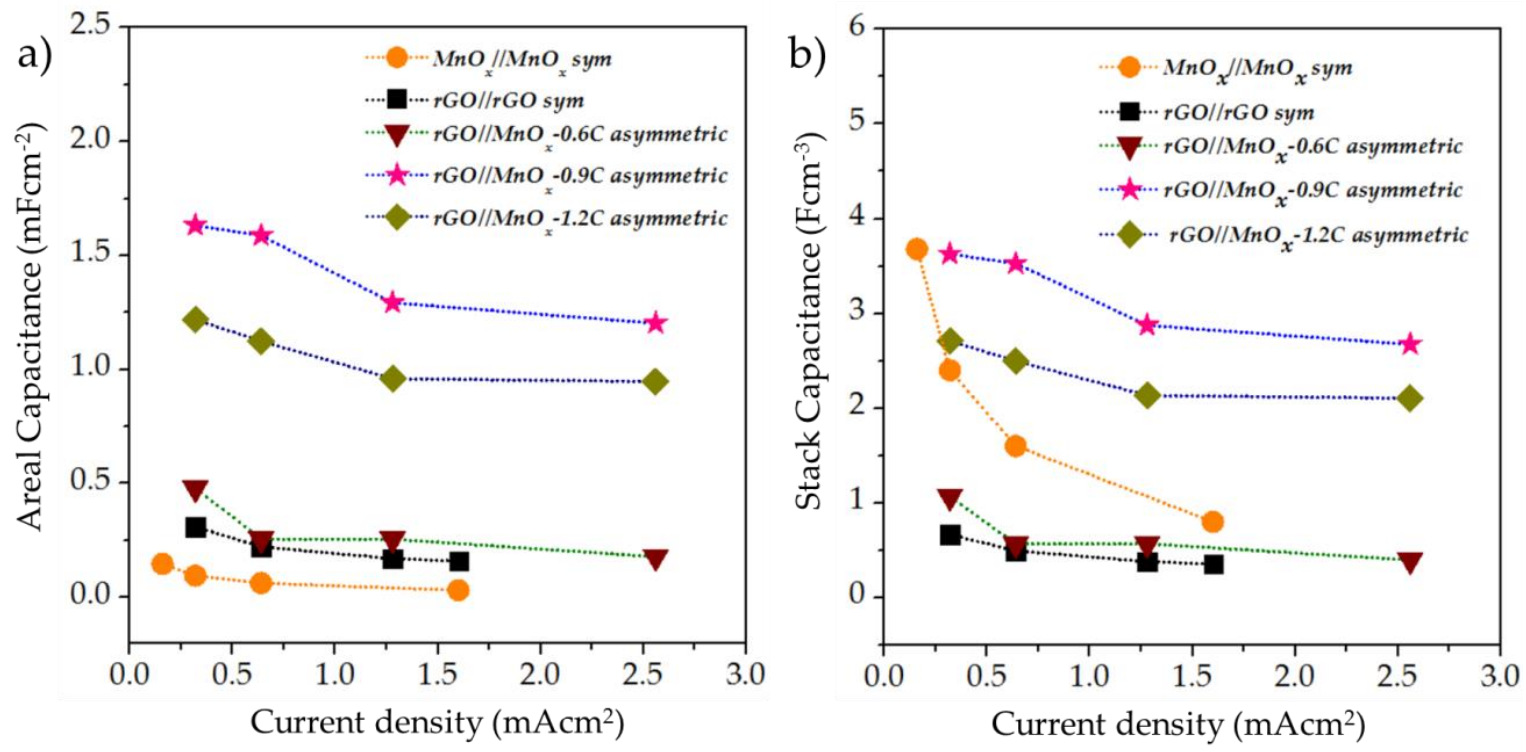

Figure 7.8: Rate capability of the $\mathrm{MnO}_{\mathrm{x}} / / \mathrm{MnO}_{\mathrm{x}}, \mathrm{rGO} / / \mathrm{rGO}, \mathrm{rGO} / / \mathrm{MnO}_{\mathrm{x}}-0.6 \mathrm{C}$, $\mathrm{rGO} / / \mathrm{MnO}_{\mathrm{x}}-0.9 \mathrm{C}$, and $\mathrm{rGO} / / \mathrm{MnO}_{\mathrm{x}}-1.2 \mathrm{C} \mathrm{MSCs}$ in terms of a) areal and b) stack capacitances. 
The areal energy and power densities of the MSCs were computed using equations (7.1) and (7.2):

$E D_{\text {areal }}=\frac{1}{2 * 3600} C_{\text {areal }} * V^{2}$

$P D_{\text {areal }}=\frac{E D_{\text {areal }}}{t / 3600}$

where $E D_{\text {areal }}\left(\mathrm{Whcm}^{-2}\right)$ and $P D_{\text {areal }}\left(\mathrm{Wcm}^{-2}\right)$ refer to areal energy and power density, respectively, $\mathrm{C}_{\text {areal }}$ refers to the areal capacitance $\left(\mathrm{Fcm}^{-2}\right), \mathrm{V}$ is the voltage window $(\mathrm{V})$, and $\mathrm{t}$ is the discharge time (s). The stack energy and power densities were calculated by normalizing the $E D_{\text {areal }}$ and $P D_{\text {areal }}$ with the $\mathrm{rGO}$ or $\mathrm{MnO}_{\mathrm{x}}$ thickness, depending upon the higher thickness. The areal energy-power trade-off between all the MSC devices constructed in this work has been depicted in a Ragone chart (Figure 7S3); the asymmetric $\mathrm{rGO} / / \mathrm{MnO}_{\mathrm{x}}-0.9 \mathrm{C} \mathrm{MSC}$ was able to deliver an energy density of 0.274 $\mu \mathrm{Whcm}^{-2}$ at a power density of $193.6 \mu \mathrm{Wcm}^{-2}$ (pertaining to a capacitance of $1.63 \mathrm{mFcm}^{-}$ ${ }^{2}$ ) which is higher than other reports documenting on-chip $\mathrm{MnO}_{\mathrm{x}}$ based systems [32, 35] but lower than reports on carbon onions and conducting polymers [44, 45]. A comparative Ragone chart depicting the stack energy and power densities of the asymmetric $\mathrm{rGO} / / \mathrm{MnO}_{\mathrm{x}}-0.9 \mathrm{C} \mathrm{MSC}$ along with other commercial EES [44] as well as other MSC systems reported in the literature is shown as Figure 7.9. The asymmetric MSC was able to deliver a maximal stack energy density of $1.02 \mathrm{mWhcm}^{-3}$ at a power density of $0.22 \mathrm{Wcm}^{-3}$, and a maximal power density of $3.44 \mathrm{Wcm}^{-3}$ at which an energy density of $0.45 \mathrm{mWhcm}^{-3}$ was maintained, resulting in a time constant of $0.47 \mathrm{~s}$. It can be seen that the hybrid MSC is well-placed in between the energy-power characteristics of thin film lithium-ion battery and commercial supercapacitors. It should be noted that the 
device characteristics have been reported in terms of volume of the interdigitated fingers and the values will diminish taking packaging into account. While the aqueous asymmetric MSC displays high energy and power tradeoff, further enhancement in electrochemical performance is expected with the use of high voltage electrolytes, advanced hierarchical materials, as well as more balanced hybrid designs, which are subjects of future works.

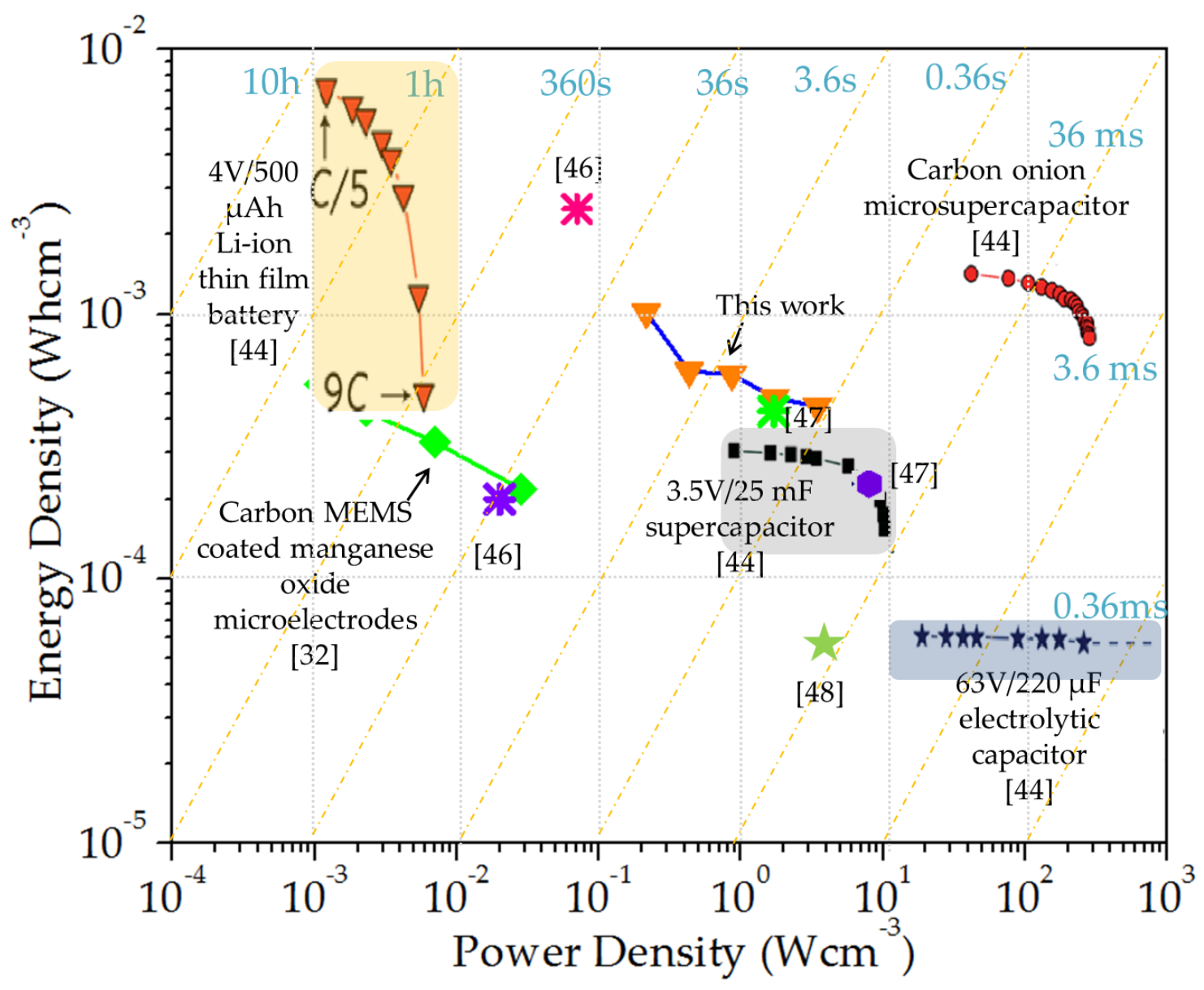

Figure 7.9: Ragone plot depicting the volumetric energy and power densities exhibited by the asymmetric $\mathrm{rGO} / / \mathrm{MnO}_{\mathrm{x}}-0.9 \mathrm{C}$ MSC in comparison with thin film lithium ion battery, commercial supercapacitors and electrolytic capacitors along with carbon onion based microsupercapacitors (Reproduced with permission from reference 44) and other data points taken from the literature [32, 46, 47, 48]. 


\subsection{Conclusions}

In summary, interdigitated microsupercapacitors were fabricated using photolithography, lift-off and electrodeposition methods. Symmetric $\mathrm{MnO}_{\mathrm{x}} / / \mathrm{MnO}_{\mathrm{x}}$, $\mathrm{rGO} / / \mathrm{rGO}$ as well as asymmetric $\mathrm{rGO} / / \mathrm{MnO}_{\mathrm{x}}$ microsupercapacitors with three different $\mathrm{MnO}_{\mathrm{x}}$ thicknesses were constructed and evaluated. The asymmetric microsupercapacitor with the $\mathrm{MnO}_{\mathrm{x}}$ film deposited at a charge of $0.9 \mathrm{Ccm}^{-2}$ displayed the optimal energypower trade-off much superior to that of both the symmetric and well as the other asymmetric configurations. The $\mathrm{rGO} / / \mathrm{MnO}_{\mathrm{x}} 0.9 \mathrm{C}$ microsupercapacitor exhibited a high stack energy density of $1.02 \mathrm{mWhcm}^{-3}$ and a maximal power density of $3.44 \mathrm{Wcm}^{-3}$ both of which are comparable with thin film batteries and commercial supercapacitors in terms of volumetric energy and power densities, respectively. The high energy-power trade-off of the device is attributed to the synergistic effects of utilizing double layer and pseudocapacitive charge storage mechanisms along with in-plane interdigital design within one optimized micro-device.

\subsection{References}

1. Beidaghi, M. and Gogotsi, Y., 2014. Capacitive energy storage in micro-scale devices: recent advances in design and fabrication of microsupercapacitors. Energy \& Environmental Science, 7(3), pp.867-884.

2. Agrawal, R.; Chen, C.; Hao, Y.; Song, Y.; Wang, C. Graphene for Supercapacitors. In Graphene Based Energy Devices; Rashid bin Mohd Yusoff, A., Ed.; Wiley-VCH Verlag GmbH \& Co. KGaA: Weinheim, Germany, 2015; pp. 171-214; doi:10.1002/9783527690312.ch6

3. Algharaibeh, Z., Liu, X. and Pickup, P.G., 2009. An asymmetric anthraquinonemodified carbon/ruthenium oxide supercapacitor.Journal of Power Sources, 187(2), pp.640-643. 
4. Khomenko, V., Raymundo-Pinero, E. and Béguin, F., 2006. Optimisation of an asymmetric manganese oxide/activated carbon capacitor working at $2 \mathrm{~V}$ in aqueous medium. Journal of Power Sources, 153(1), pp.183-190.

5. Long, J.W., Bélanger, D., Brousse, T., Sugimoto, W., Sassin, M.B. and Crosnier, O., 2011. Asymmetric electrochemical capacitors-Stretching the limits of aqueous electrolytes. Mrs Bulletin, 36(7), pp.513-522.

6. Hong, M.S., Lee, S.H. and Kim, S.W., 2002. Use of KCl aqueous electrolyte for 2 $\mathrm{V}$ manganese oxide/activated carbon hybrid capacitor. Electrochemical and SolidState Letters, 5(10), pp.A227-A230.

7. Liu, H. and Zhao, K., 2016. Asymmetric flow electrochemical capacitor with high energy densities based on birnessite-type manganese oxide nanosheets and activated carbon slurries. Journal of materials science, 51(20), pp.9306-9313.

8. Chen, L.F., Huang, Z.H., Liang, H.W., Guan, Q.F. and Yu, S.H., 2013. BacterialCellulose-Derived Carbon Nanofiber@ MnO2 and Nitrogen-Doped Carbon Nanofiber Electrode Materials: An Asymmetric Supercapacitor with High Energy and Power Density. Advanced materials, 25(34), pp.4746-4752.

9. Wang, D.W., Li, F. and Cheng, H.M., 2008. Hierarchical porous nickel oxide and carbon as electrode materials for asymmetric supercapacitor. Journal of Power Sources, 185(2), pp.1563-1568.

10. Xiao-Dan, Y., Jian-Guan, H., Qian, Y., Yi-Fan, Z. and Wan-Zhen, H., 2014. Preparation and properties of $\mathrm{NiO} / \mathrm{Ac}$ asymmetric capacitor. Journal of Inorganic Materials, 29(3), pp.250-256.

11. Sivakkumar, S.R. and Pandolfo, A.G., 2012. Evaluation of lithium-ion capacitors assembled with pre-lithiated graphite anode and activated carbon cathode. Electrochimica Acta, 65, pp.280-287.

12. Yu, X., Zhan, C., Lv, R., Bai, Y., Lin, Y., Huang, Z.H., Shen, W., Qiu, X. and Kang, F., 2015. Ultrahigh-rate and high-density lithium-ion capacitors through hybriding nitrogen-enriched hierarchical porous carbon cathode with prelithiated microcrystalline graphite anode. Nano Energy, 15, pp.43-53.

13. Ren, J.J., Su, L.W., Qin, X., Yang, M., Wei, J.P., Zhou, Z. and Shen, P.W., 2014. Pre-lithiated graphene nanosheets as negative electrode materials for Li-ion capacitors with high power and energy density. Journal of Power Sources, 264, pp.108-113.

14. Amatucci, G.G., Badway, F., Du Pasquier, A. and Zheng, T., 2001. An asymmetric hybrid nonaqueous energy storage cell. Journal of the Electrochemical Society, 148(8), pp.A930-A939. 
15. Agrawal, R., Chen, C., Dages, S. and Wang, C., 2017. A High Energy 3V Lithium-Ion Capacitor Synthesized via Electrostatic Spray Deposition. Adv. Mater. Lett, 8, pp.783-790.

16. Agrawal, R., Hao, Y., Song, Y., Chen, C. and Wang, C., 2015, May. Hybridization of lithium-ion batteries and electrochemical capacitors: fabrication and challenges. In Proc. SPIE (Vol. 9493, pp. 94930B1-94930B7).

17. Naoi, K., Ishimoto, S., Miyamoto, J.I. and Naoi, W., 2012. Second generation 'nanohybrid supercapacitor': evolution of capacitive energy storage devices. Energy \& Environmental Science, 5(11), pp.9363-9373.

18. Hu, X., Huai, Y., Lin, Z., Suo, J. and Deng, Z., 2007. A (LiFePO4-ACY Li4Ti5O12 Hybrid Battery Capacitor. Journal of the Electrochemical Society, 154(11), pp.A1026-A1030.

19. Hu, X.B., Lin, Z.J., Liu, L., Huai, J.Y. and Deng, H.Z., 2010. Effects of the $\mathrm{LiFePO} 4$ content and the preparation method on the properties of (LiFePO4+ AC)/Li4Ti5O12 hybrid batterycapacitors. Journal of the Serbian Chemical Society, 75(9), pp.1259-1269.

20. Zhai, Y., Dou, Y., Zhao, D., Fulvio, P.F., Mayes, R.T. and Dai, S., 2011. Carbon materials for chemical capacitive energy storage. Advanced materials, 23(42), pp.4828-4850.

21. Zhi, M., Xiang, C., Li, J., Li, M. and Wu, N., 2013. Nanostructured carbon-metal oxide composite electrodes for supercapacitors: a review. Nanoscale, 5(1), pp.7288.

22. Bonaccorso, F., Colombo, L., Yu, G., Stoller, M., Tozzini, V., Ferrari, A.C., Ruoff, R.S. and Pellegrini, V., 2015. Graphene, related two-dimensional crystals, and hybrid systems for energy conversion and storage. Science, 347(6217), p.1246501.

23. Dreyer, D.R., Park, S., Bielawski, C.W. and Ruoff, R.S., 2010. The chemistry of graphene oxide. Chemical Society Reviews, 39(1), pp.228-240.

24. Flyunt, R., Knolle, W., Kahnt, A., Prager, A., Lotnyk, A., Malig, J., Guldi, D. and Abel, B., 2014. Mechanistic aspects of the radiation-chemical reduction of graphene oxide to graphene-like materials. International journal of radiation biology, 90(6), pp.486-494.

25. Kuila, T., Mishra, A.K., Khanra, P., Kim, N.H. and Lee, J.H., 2013. Recent advances in the efficient reduction of graphene oxide and its application as energy storage electrode materials. Nanoscale, 5(1), pp.52-71. 
26. Diba, M., Fam, D.W., Boccaccini, A.R. and Shaffer, M.S., 2016. Electrophoretic deposition of graphene-related materials: A review of the fundamentals. Progress in Materials Science, 82, pp.83-117

27. An, S.J., Zhu, Y., Lee, S.H., Stoller, M.D., Emilsson, T., Park, S., Velamakanni, A., An, J. and Ruoff, R.S., 2010. Thin film fabrication and simultaneous anodic reduction of deposited graphene oxide platelets by electrophoretic deposition. The Journal of Physical Chemistry Letters, 1(8), pp.1259-1263.

28. Zhang, H., Zhang, X., Zhang, D., Sun, X., Lin, H., Wang, C. and Ma, Y., 2012. One-step electrophoretic deposition of reduced graphene oxide and $\mathrm{Ni}(\mathrm{OH}) 2$ composite films for controlled syntheses supercapacitor electrodes. The Journal of Physical Chemistry B, 117(6), pp.1616-1627.

29. Wang, J.G.; Kang, F.; Wei, B. Engineering of $\mathrm{MnO}_{2}$-based nanocomposites for high-performance supercapacitors. Prog. Mater Sci. 2015, 74, 51-124.

30. Wang, G.; Zhang, L.; Zhang, J. A review of electrode materials for electrochemical supercapacitors. Chem. Soc. Rev.2012, 41, 797-828.

31. Wei, W.; Cui, X.; Chen, W.; Ivey, D.G. Manganese oxide-based materials as electrochemical supercapacitor electrodes. Chem. Soc. Rev. 2011, 40, 16971721.

32. Agrawal, R., Adelowo, E., Baboukani, A.R., Villegas, M.F., Henriques, A. and Wang, C., 2017. Electrostatic Spray Deposition-Based Manganese Oxide FilmsFrom Pseudocapacitive Charge Storage Materials to Three-Dimensional Microelectrode Integrands. Nanomaterials, 7(8), p.198.

33. Shen, C., Wang, X., Li, S., Zhang, W. and Kang, F., 2013. A high-energy-density micro supercapacitor of asymmetric $\mathrm{MnO} 2$-carbon configuration by using microfabrication technologies. Journal of Power Sources, 234, pp.302-309.

34. Dinh, T.M., Mesnilgrente, F., Conédéra, V., Kyeremateng, N.A. and Pech, D., 2015. Realization of an Asymmetric Interdigitated Electrochemical MicroCapacitor Based on Carbon Nanotubes and Manganese Oxide. Journal of The Electrochemical Society, 162(10), pp.A2016-A2020.

35. El-Kady, M.F., Ihns, M., Li, M., Hwang, J.Y., Mousavi, M.F., Chaney, L., Lech, A.T. and Kaner, R.B., 2015. Engineering three-dimensional hybrid supercapacitors and microsupercapacitors for high-performance integrated energy storage. Proceedings of the National Academy of Sciences, 112(14), pp.42334238 . 
36. Liu, W.W., Feng, Y.Q., Yan, X.B., Chen, J.T. and Xue, Q.J., 2013. Superior Micro-Supercapacitors Based on Graphene Quantum Dots. Advanced Functional Materials, 23(33), pp.4111-4122.

37. Beidaghi, M. and Wang, C., 2012. Micro-supercapacitors based on interdigital electrodes of reduced graphene oxide and carbon nanotube composites with ultrahigh power handling performance. Advanced Functional Materials, 22(21), pp.4501-4510.

38. Chaiyakun, S., Witit-Anun, N., Nuntawong, N., Chindaudom, P., Oaew, S., Kedkeaw, C. and Limsuwan, P., 2012. Preparation and characterization of graphene oxide nanosheets. Procedia Engineering, 32, pp.759-764.

39. González, M.G., Cabanelas, J.C. and Baselga, J., 2012. Applications of FTIR on epoxy resins-identification, monitoring the curing process, phase separation and water uptake. In Infrared Spectroscopy-Materials Science, Engineering and Technology. InTech.

40. Sim, L.C., Leong, K.H., Ibrahim, S. and Saravanan, P., 2014. Graphene oxide and $\mathrm{Ag}$ engulfed $\mathrm{TiO} 2$ nanotube arrays for enhanced electron mobility and visiblelight-driven photocatalytic performance. Journal of Materials Chemistry A, 2(15), pp.5315-5322.

41. Wang, H., Lu, Z., Qian, D., Li, Y. and Zhang, W., 2007. Single-crystal $\alpha-\mathrm{MnO} 2$ nanorods: synthesis and electrochemical properties. Nanotechnology, 18(11), p.115616.

42. Yang, R., Wang, Z., Dai, L. and Chen, L., 2005. Synthesis and characterization of single-crystalline nanorods of $\alpha-\mathrm{MnO} 2$ and $\gamma-\mathrm{MnOOH}$. Materials chemistry and physics, 93(1), pp.149-153.

43. Wang, X., Myers, B.D., Yan, J., Shekhawat, G., Dravid, V. and Lee, P.S., 2013. Manganese oxide micro-supercapacitors with ultra-high areal capacitance. Nanoscale, 5(10), pp.4119-4122.

44. Pech, D., Brunet, M., Durou, H., Huang, P., Mochalin, V., Gogotsi, Y., Taberna, P.L. and Simon, P., 2010. Ultrahigh-power micrometre-sized supercapacitors based on onion-like carbon. Nature nanotechnology, 5(9), pp.651-654.

45. Wang, K., Zou, W., Quan, B., Yu, A., Wu, H., Jiang, P. and Wei, Z., 2011. An All-Solid-State Flexible Micro-supercapacitor on a Chip. Advanced Energy Materials, 1(6), pp.1068-1072.

46. Lin, J., Zhang, C., Yan, Z., Zhu, Y., Peng, Z., Hauge, R.H., Natelson, D. and Tour, J.M., 2012. 3-dimensional graphene carbon nanotube carpet-based 
microsupercapacitors with high electrochemical performance. Nano letters, 13(1), pp.72-78.

47. Gao, W., Singh, N., Song, L., Liu, Z., Reddy, A.L.M., Ci, L., Vajtai, R., Zhang, Q., Wei, B. and Ajayan, P.M., 2011. Direct laser writing of micro-supercapacitors on hydrated graphite oxide films. Nature Nanotechnology, 6(8), pp.496-500.

48. Zeng, Z., Long, X., Zhou, H., Guo, E., Wang, X. and Hu, Z., 2015. On-chip interdigitated supercapacitor based on nano-porous gold/manganese oxide nanowires hybrid electrode. Electrochimica Acta, 163, pp.107-115. 


\section{CONCLUSIONS AND OUTLOOK}

\subsection{Summary}

This dissertation presents design, construction, and evaluation of both "scale-up" and miniaturized asymmetric/hybrid supercapacitors. Utilizing redox and double-layer charge storage mechanisms within one system is an attractive solution to enhance the energy density of electrochemical capacitors. However, several research challenges are posed with the seemingly simple hybridization approach, which include relatively inferior kinetics and cycle life of the redox electrode, and lower specific capacitance of the double layer electrode. Several routes have been adopted in order to maximize the performance of the hybrid capacitors synthesized in this dissertation and the major findings are summarized as follows:

In the first part, hybrid capacitors comprising ESD based rGO-CNT composite cathode and an anatase $\mathrm{TiO}_{2}-\mathrm{Li}_{4} \mathrm{Ti}_{5} \mathrm{O}_{12}$ anode was constructed and analyzed. The cathode and anode were first analyzed as working electrodes against a lithium counter electrode and were able to deliver discharge capacities of ca. $63 \mathrm{mAhg}^{-1}$ and $95 \mathrm{mAhg}^{-1}$ with good reversibility and cycling. The full Li-HEC cells were able to deliver a maximum energy density of $33.35 \mathrm{Whkg}^{-1}$ and a maximum power density of $1207.4 \mathrm{Wkg}^{-1}$, with specific energy ranging between $33.35-15.09 \mathrm{Whkg}^{-1}$ at power densities of $83.55-1207.4 \mathrm{Wkg}^{-1}$, where all the cell parameters were normalized with the total anode and cathode masses. Furthermore, the Li-HEC cells were able to retain $\sim 77 \%$ of capacitance retention after 100 cycles. The superior energy-power cell characteristics were attributed to the porous electrode structure and the utilization of organic electrolyte which allows for a wider electrochemical potential window. 
In the second part of the dissertation, manganese oxide films were synthesized using electrostatic spray deposition (ESD) and characterized as pseudocapacitive materials for electrochemical capacitor applications in neutral aqueous media. The initial phase synthesized was the relatively insulating hausmannite- $\mathrm{Mn}_{3} \mathrm{O}_{4}$, which partially transformed into the conducting birnessite- $\mathrm{MnO}_{2}$ upon electrochemical cycling, resulting in an enhanced gravimetric capacitance from $72 \mathrm{~F} \cdot \mathrm{g}^{-1}$ to $225 \mathrm{~F} \cdot \mathrm{g}^{-1}$. Furthermore, $\mathrm{MnO}_{x^{-}}$ MEs were created by combining bottom-up ESD approach and top-down C-MEMS approach. In a two-electrode setup, the $\mathrm{MnO}_{x}$-MEs were able to deliver geometric specific capacitances as high as $0.055 \mathrm{~F} \cdot \mathrm{cm}^{-2}$, and maximal volumetric energy and power densities of $0.51 \mathrm{mWh} \cdot \mathrm{cm}^{-3}$ and $28.3 \mathrm{~mW} \cdot \mathrm{cm}^{-3}$, respectively. The excellent areal capacitance and the high stack energy density of the $\mathrm{MnO}_{x}$-MEs were attributed to the pseudocapacitive $\mathrm{MnO}_{x}$ as well as the three-dimensional architectural framework of the micro-pillars. The feasibility of using ESD for high gravimetric thin-film manganese oxide films and high areal capacitance 3D microelectrodes was therefore established.

To further examine the utility of manganese oxide films in an asymmetric configuration, three different manganese oxide compositions: i) pristine $\left(\mathrm{MnO}_{\mathrm{x}}\right)$, ii) with $10 \%$ carbon nanotube additive $\left(\mathrm{MnO}_{\mathrm{x}}-\mathrm{CNT} 9-1\right)$, and iii) $20 \% \mathrm{CNT}$ additive $\left(\mathrm{MnO}_{\mathrm{x}}-\mathrm{CNT}\right.$ 8-2) were synthesized using electrostatic spray deposition (ESD) and investigated as electrochemical capacitor electrodes in neutral aqueous media. The $\mathrm{MnO}_{\mathrm{x}}-\mathrm{CNT}$ 9-1 composition exhibited superior electrochemical performance as compared to both the pristine $\mathrm{MnO}_{\mathrm{x}}$ and the $\mathrm{MnO}_{\mathrm{x}}-\mathrm{CNT}$ 8-2 composite films. The $\mathrm{MnO}_{\mathrm{x}}-\mathrm{CNT}$ 9-1 electrodes exhibited a high specific capacitance of $281 \mathrm{Fg}^{-1}$ for a current density of $0.2 \mathrm{Ag}^{-1}$ and were able to retain $87.4 \%$ of the maximal capacitance after 1000 cycles. Upon verifying the 
viability of the ESD derived $\mathrm{MnO}_{\mathrm{x}}$-CNT 9-1 films, the latter were used in asymmetric configuration comprising activated carbon (AC) counter electrodes. For the different mass ratios investigated, the ratio with 1:2.6, with the latter corresponding to the mass of AC, exhibited the best electrochemical characteristics reaching a voltage of $2 \mathrm{~V}$ even in aqueous media. The asymmetric capacitor exhibited superior energy-power trade-off when compared to both the control groups consisting of symmetric AC//AC capacitor as well as the $\mathrm{MnO}_{\mathrm{x}}-\mathrm{CNT}$ 9-1//MnO${ }_{\mathrm{x}}-\mathrm{CNT}$ 9-1 capacitor. The enhancement in the electrochemical characteristics was attributed to the combination of the wider electrochemical potential window as well as the high capacitance of the ESD based $\mathrm{MnO}_{\mathrm{x}}-\mathrm{CNT}$ 9-1 electrode.

To extend the applicability of asymmetric systems to on-chip miniaturized devices, asymmetric microsupercapacitors were constructed using electrodeposited manganese oxide $\left(\mathrm{MnO}_{\mathrm{x}}\right)$ as the positive electrode and electrophoretically deposited reduced graphene oxide ( $\mathrm{rGO}$ ) as the negative electrode on patterned interdigitated gold microcurrent collectors. Symmetric $\mathrm{MnO}_{\mathrm{x}} / / \mathrm{MnO}_{\mathrm{x}}, \mathrm{rGO} / / \mathrm{rGO}$ as well as asymmetric $\mathrm{rGO} / / \mathrm{MnO}_{\mathrm{x}}$ microsupercapacitors with three different $\mathrm{MnO}_{\mathrm{x}}$ thicknesses were constructed and evaluated. The asymmetric microsupercapacitor with the $\mathrm{MnO}_{\mathrm{x}}$ film deposited at a charge of $0.9 \mathrm{Ccm}^{-2}$ displayed the optimal energy-power trade-off much superior to that of both the symmetric and well as the other asymmetric configurations. The $\mathrm{rGO} / / \mathrm{MnO}_{\mathrm{x}}$ 0.9C microsupercapacitor exhibited a high stack energy density of 1.02 $\mathrm{mWhcm}^{-3}$ and a maximal power density of $3.44 \mathrm{Wcm}^{-3}$ both of which are comparable with thin film batteries and commercial supercapacitors in terms of volumetric energy and power densities, respectively. The high energy-power trade-off of the device is 
attributed to the synergistic effects of utilizing double layer and pseudocapacitive charge storage mechanisms along with in-plane interdigital design within one optimized microdevice.

\subsection{Future Works}

Future works in the direction of this dissertation include:

1. Theoretical Optimization for hybridization of redox and double layer materials: The energy-power optimization for this dissertation is largely empirical and future works in the direction include theoretical simulations to optimize the electrochemical performance of the hybrid supercapacitors. As seen in this work, several parameters govern the final performance of the device, which include cell voltage, electrode thickness, electrode kinetics, the anode and cathode mass ratio, the distance between the anode and the cathode, etc. A more comprehensive and a systematic theoretical model can provide more insight into the dependence of each of the aforementioned parameters on the electrochemical performance of the final device.

2. Detailed investigation of performance degradation of the symmetric microsupercapacitors based on pseudocapacitive materials: As seen in Chapter 7, the symmetric microsupercapacitor based on manganese oxide degrades quickly. More detailed electron microscopy studies can be carried out to investigate the performance degradation mechanisms.

3. Use of emerging advanced materials for hybrid microsupercapacitors: This dissertation is based on popular materials (manganese oxides, nanostructured carbons, lithium insertion hosts) used for electrochemical applications. Future works along the 
direction of this work include using emerging electrode materials such as MXenes [13], chalcogenides [4-5], etc. for microsupercapacitor applications.

4. Packaged microsupercapacitor systems: The electrochemical characterization for the microsupercapacitors investigated in this work was carried out in a two-electrode beaker cell setup and the energy-power values are anticipated to diminish in a fully packaged system. Future works include using solid state electrolytes that can facilitate packaging as opposed to liquid electrolytes or optimizing the packaging of prototype cells. Packaged systems can thereafter be used for self-powered applications along with harvesters, computing units and sensing components.

\subsection{References}

1. Ling, Z., Ren, C.E., Zhao, M.Q., Yang, J., Giammarco, J.M., Qiu, J., Barsoum, M.W. and Gogotsi, Y., 2014. Flexible and conductive MXene films and nanocomposites with high capacitance. Proceedings of the National Academy of Sciences, 111(47), pp.16676-16681.

2. Zhao, M.Q., Ren, C.E., Ling, Z., Lukatskaya, M.R., Zhang, C., Van Aken, K.L., Barsoum, M.W. and Gogotsi, Y., 2015. Flexible MXene/carbon nanotube composite paper with high volumetric capacitance. Advanced Materials, 27(2), pp.339-345.

3. Rakhi, R.B., Ahmed, B., Hedhili, M.N., Anjum, D.H. and Alshareef, H.N., 2015. Effect of postetch annealing gas composition on the structural and electrochemical properties of Ti2CT x MXene electrodes for supercapacitor applications. Chemistry of Materials, 27(15), pp.5314-5323.

4. Lu, M., Yuan, X.P., Guan, X.H. and Wang, G.S., 2017. Synthesis of nickel chalcogenide hollow spheres using an L-cysteine-assisted hydrothermal process for efficient supercapacitor electrodes. Journal of Materials Chemistry A, 5(7), pp.36213627.

5. Ni, J., Bi, X., Jiang, Y., Li, L. and Lu, J., 2017. Bismuth Chalcogenide Compounds Bi2X3(X= O, S, Se): Applications in Electrochemical Energy Storage. Nano Energy. 


\section{APPENDIX 1: Supplemental Information for Chapter 6}
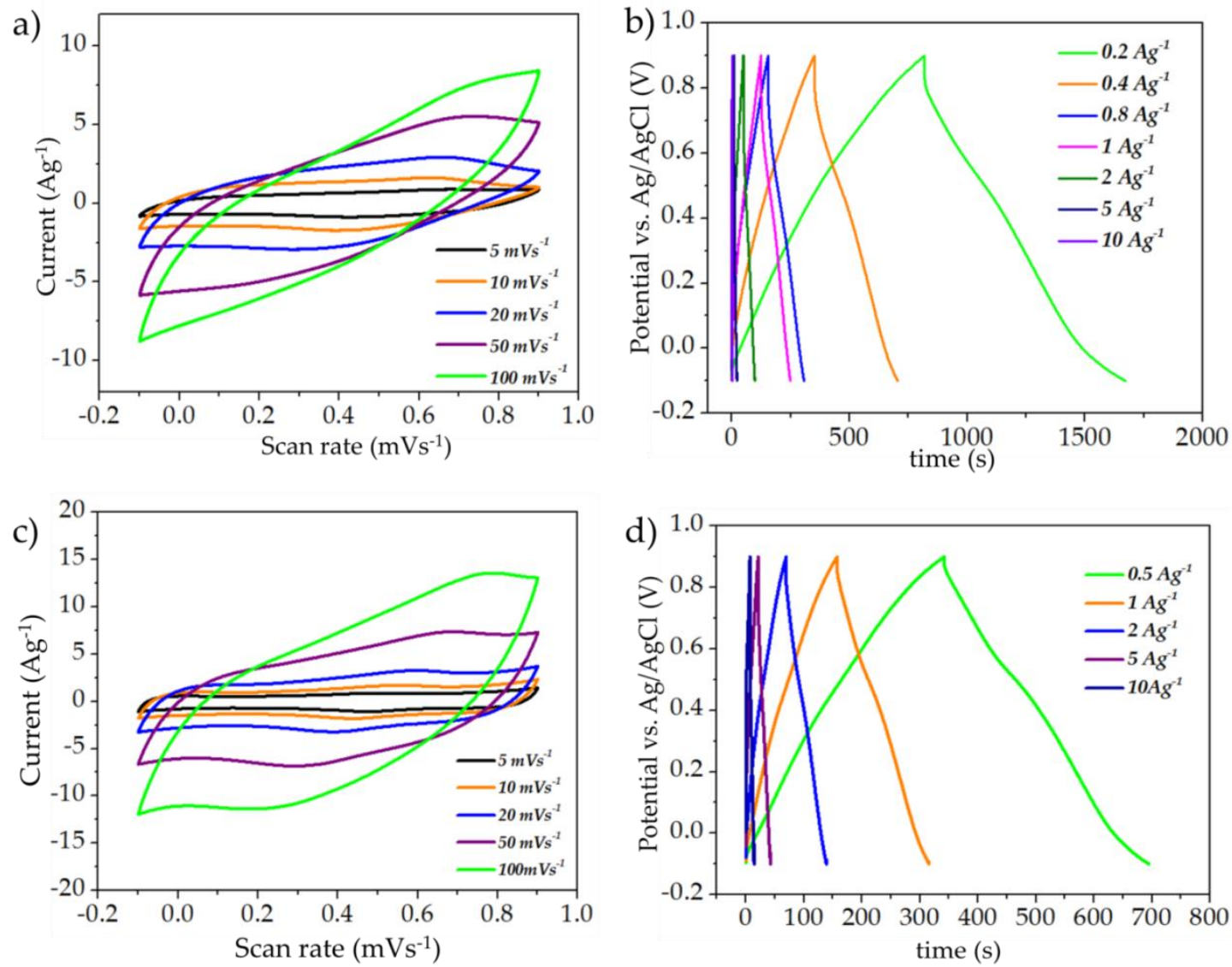

Figure 6S 1: a) cyclic voltammetry (CV) and the b) galvanostatic charge-discharge (GCD) curves of the $\mathrm{MnO}_{\mathrm{x}}$ electrode; a) CV and the d) GCD curves of the $\mathrm{MnO}_{\mathrm{x}}-\mathrm{CNT} 8$ 2 electrode. 

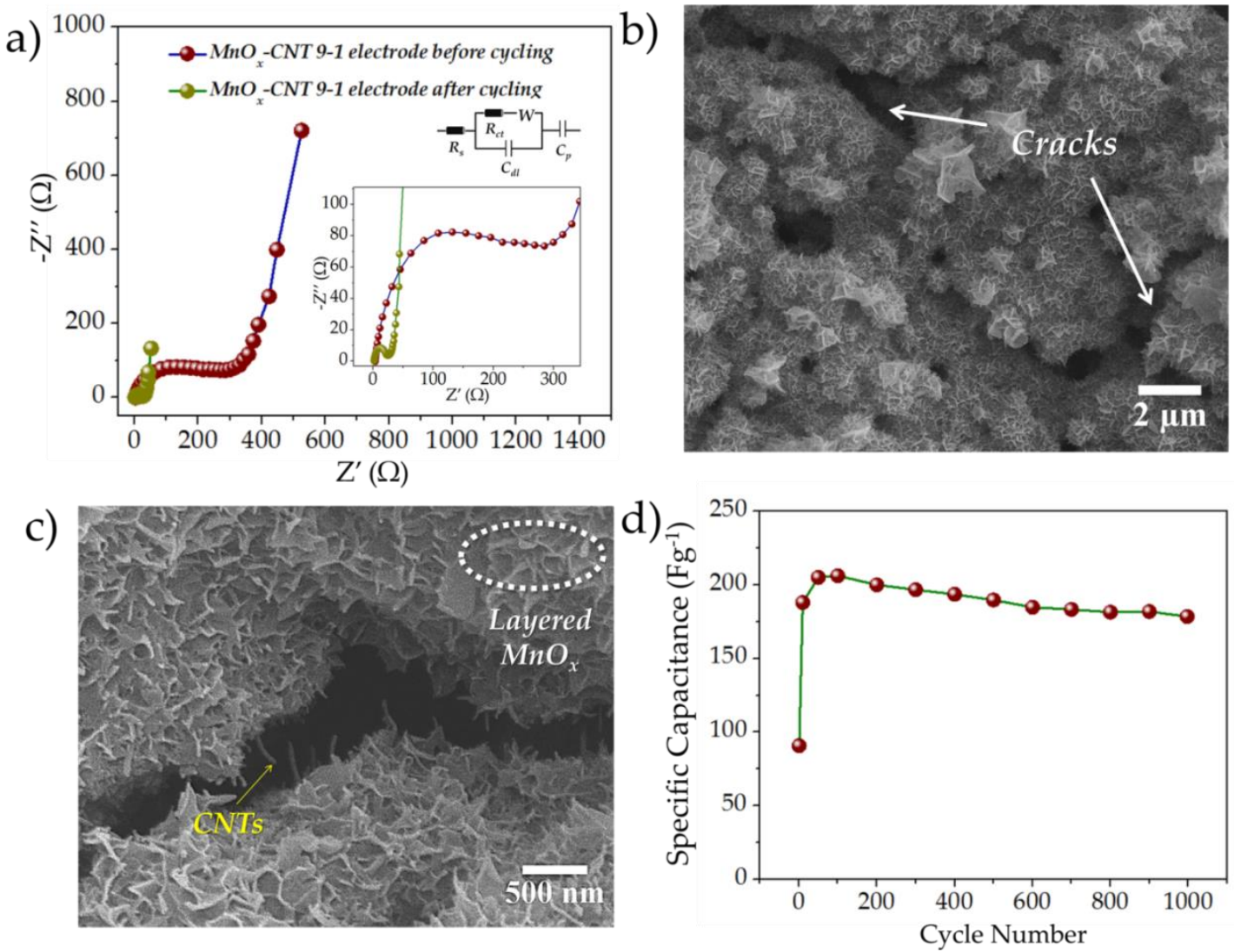

Figure 6S 2: a) Nyquist plots of the $\mathrm{MnO}_{\mathrm{x}}-\mathrm{CNT}$ 9-1 electrode before and after cycling; the inset depicts the equivalent circuit analyses; b) $\mathrm{MnO}_{\mathrm{x}}-\mathrm{CNT}$ microstructure after cycling; some cracks are visible after cycling; c) zoomed-in version of the microstructure; CNTs are conspicuous; d) long-term cycling of the $\mathrm{MnO}_{\mathrm{x}}-\mathrm{CNT}$ 9-1 electrode. 

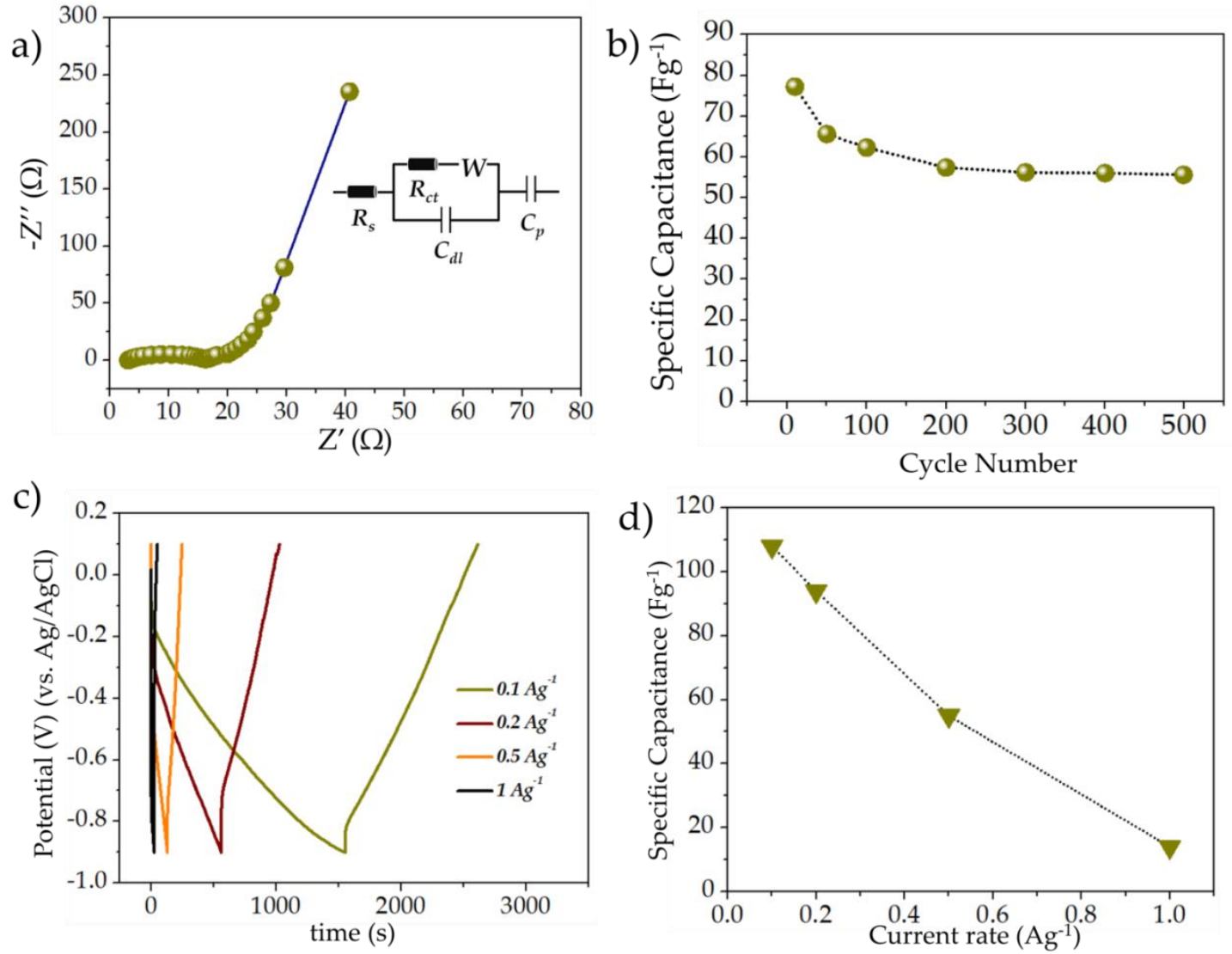

Figure 6S 3: a) Nyquist plot of the freshly prepared AC electrode; the inset depicts the equivalent circuit used for cell analyses; b) cycling of the AC anode; c) GCD plots of the $\mathrm{AC}$ anode at different current rates; d) rate capability of the $\mathrm{AC}$ anode. 

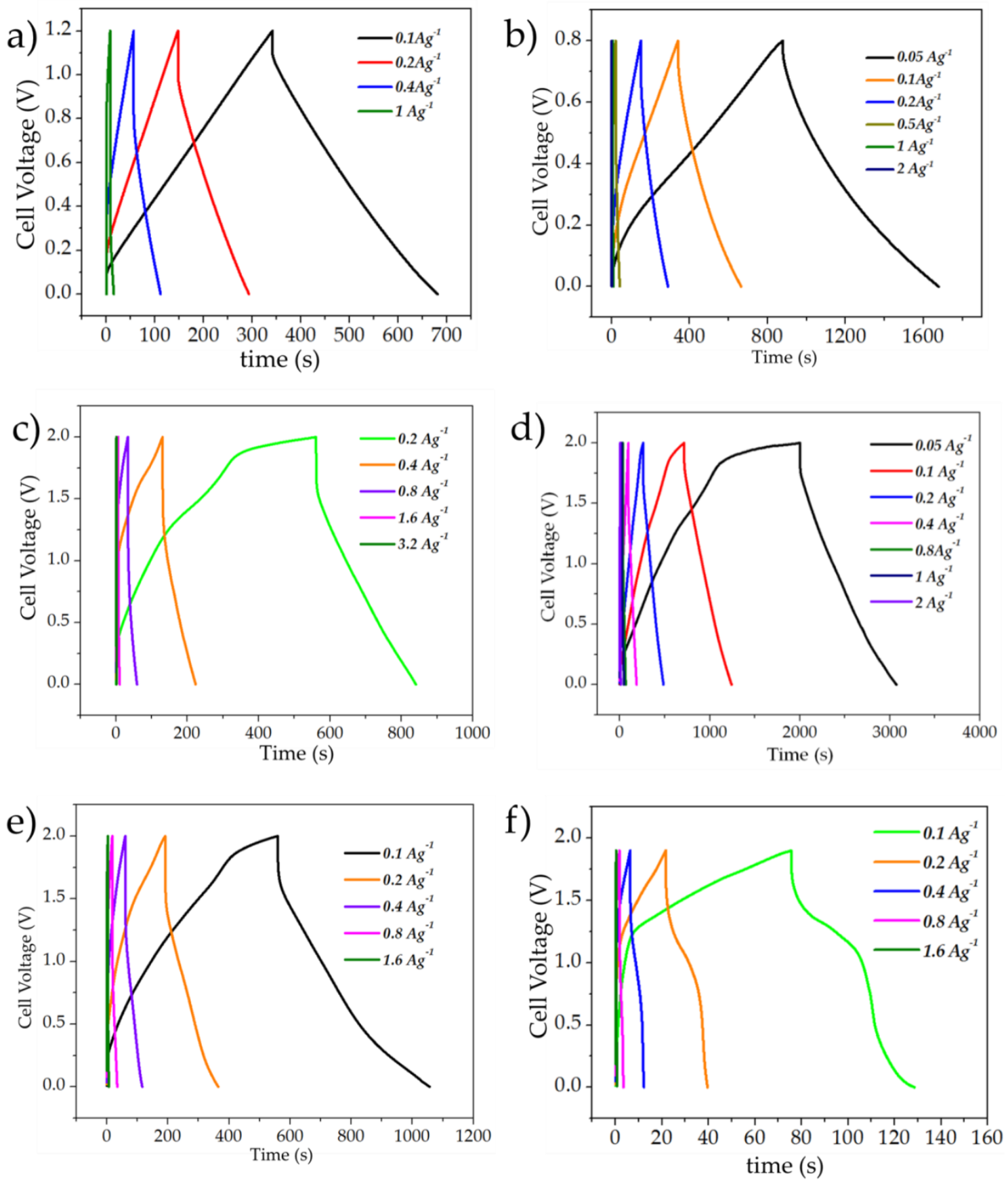

Figure 6S 4: GCD curves of the a) symmetric AC//AC capacitor; b) symmetric $\mathrm{MnO}_{\mathrm{x}^{-}}$ CNT 9-1// $\mathrm{MnO}_{\mathrm{x}}-\mathrm{CNT}$ 9-1 capacitor; c) asymmetric capacitor MR 1:2; d) asymmetric capacitor MR 1:2.4; e) asymmetric capacitor MR 1:3; f) asymmetric capacitor MR 1:4. 

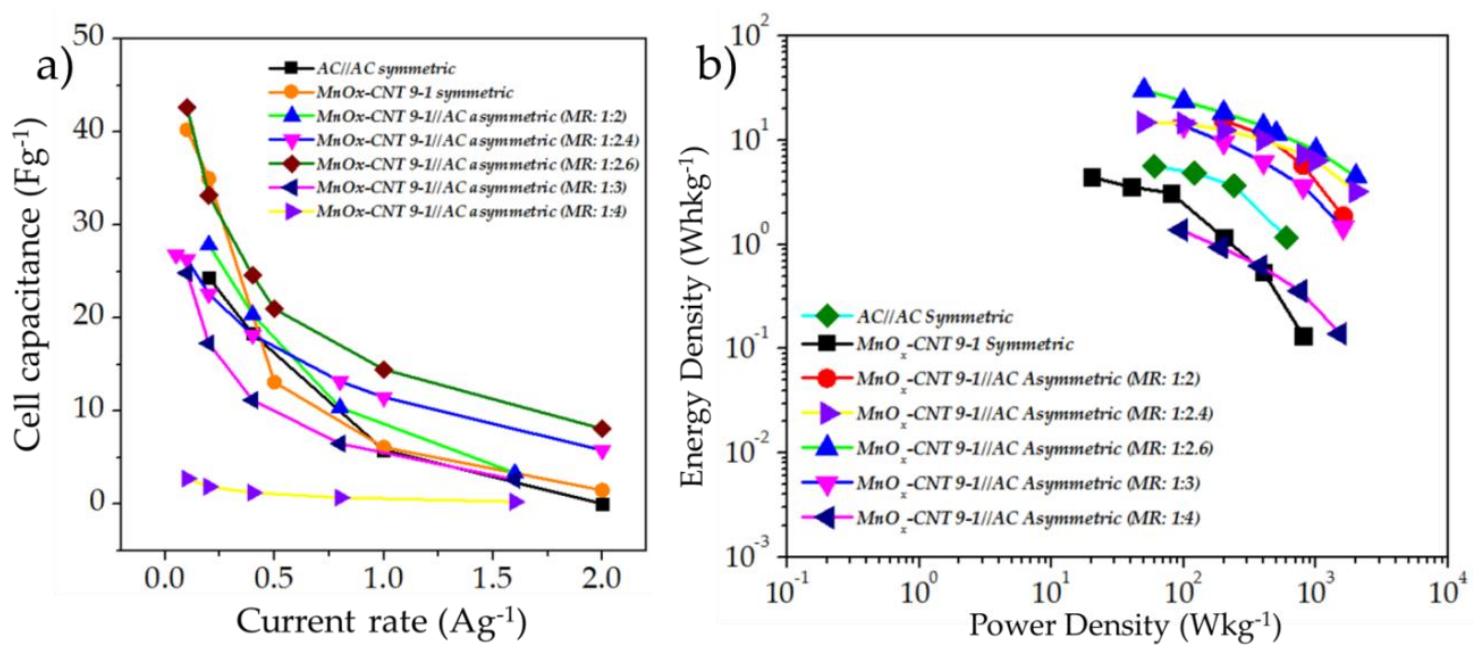

Figure 6S 5: a) Rate capability and b) Ragone chart of the different EC systems. 
Table 6S 1: Electrochemical characteristics of the symmetric AC//AC system, symmetric $\mathrm{MnO}_{\mathrm{x}}-\mathrm{CNT}$ 9-1//MnO $\mathrm{M}_{\mathrm{x}}-\mathrm{CNT}$ 9-1 system, and the optimized asymmetric $\mathrm{MnO}_{\mathrm{x}}-\mathrm{CNT}$ 9-1//AC system

\begin{tabular}{|c|c|c|c|c|c|c|}
\hline System & $\begin{array}{l}\text { Capacitive } \\
\text { retention }\end{array}$ & $\begin{array}{c}\text { Cell } \\
\text { Voltage }\end{array}$ & $\begin{array}{c}\text { Cell } \\
\text { Capacitance } \\
\left(\mathrm{Fg}^{-1}\right)\end{array}$ & $\begin{array}{c}\mathrm{ED} \\
\left(\mathrm{Whkg}^{-1}\right)\end{array}$ & $\begin{array}{c}\text { PD } \\
\left(\mathrm{Wkg}^{-1}\right) \\
\text { (from } \\
\text { Ragone } \\
\text { Chart) }\end{array}$ & $\begin{array}{c}\mathrm{PD}_{\max } \\
\left(\mathrm{Wkg}^{-1}\right) \\
\text { (from iR } \\
\text { calculations) }\end{array}$ \\
\hline $\begin{array}{l}\text { Symmetric } \\
\text { AC//AC }\end{array}$ & $\begin{array}{c}\sim 100 \% \text { after } \\
500 \text { cycles }\end{array}$ & $1.2 \mathrm{~V}$ & 28 & 5.6 & 600 & 888 \\
\hline $\begin{array}{c}\text { Symmetric } \\
\mathrm{MnO}_{\mathrm{x}}-\mathrm{CNT} \\
\text { 9-1//MnO } \mathrm{Mn}^{-} \\
\text {CNT 9-1 }\end{array}$ & $\begin{array}{c}56.4 \% \text { after } \\
500 \text { cycles }\end{array}$ & $0.8 \mathrm{~V}$ & 49.9 & 4.4 & 800 & 1454 \\
\hline $\begin{array}{c}\text { Asymmetric } \\
\mathrm{MnO}_{\mathrm{x}}-\mathrm{CNT} \\
9-1 / / \mathrm{AC} \\
(\mathrm{MR}: 1: 2.6)\end{array}$ & $\begin{array}{l}76 \% \text { after } \\
500 \text { cycles }\end{array}$ & $2 \mathrm{~V}$ & 54.5 & 30.3 & 2000 & 4000 \\
\hline
\end{tabular}


APPENDIX 2: Supplemental Information for Chapter 7

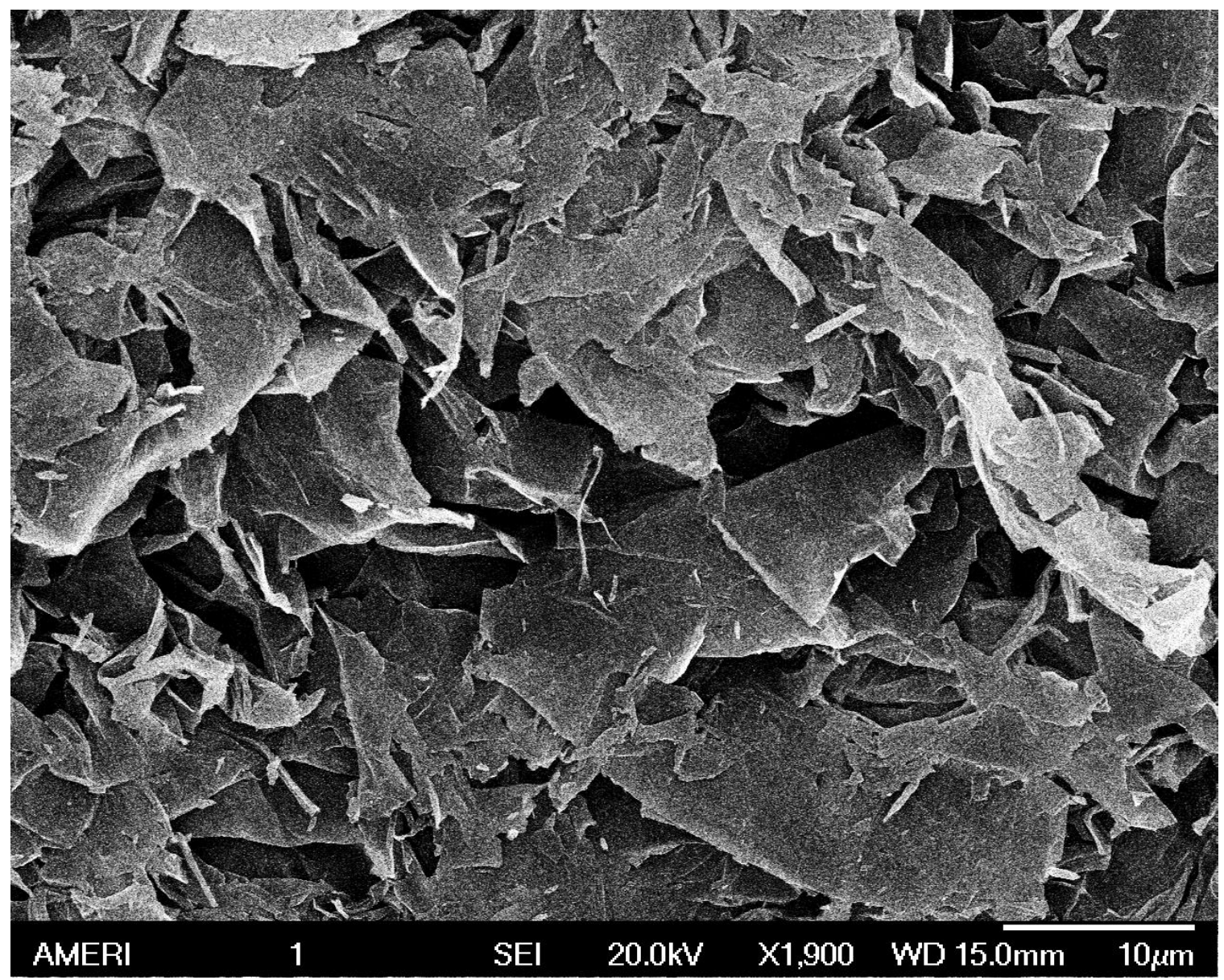

Figure 7S 1: Microstructure of the single layer graphene oxide (SLGO) 
a)

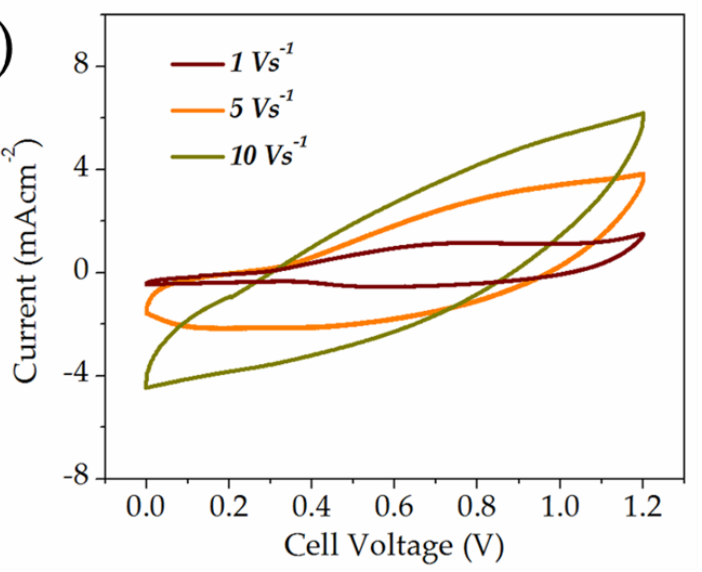

c)
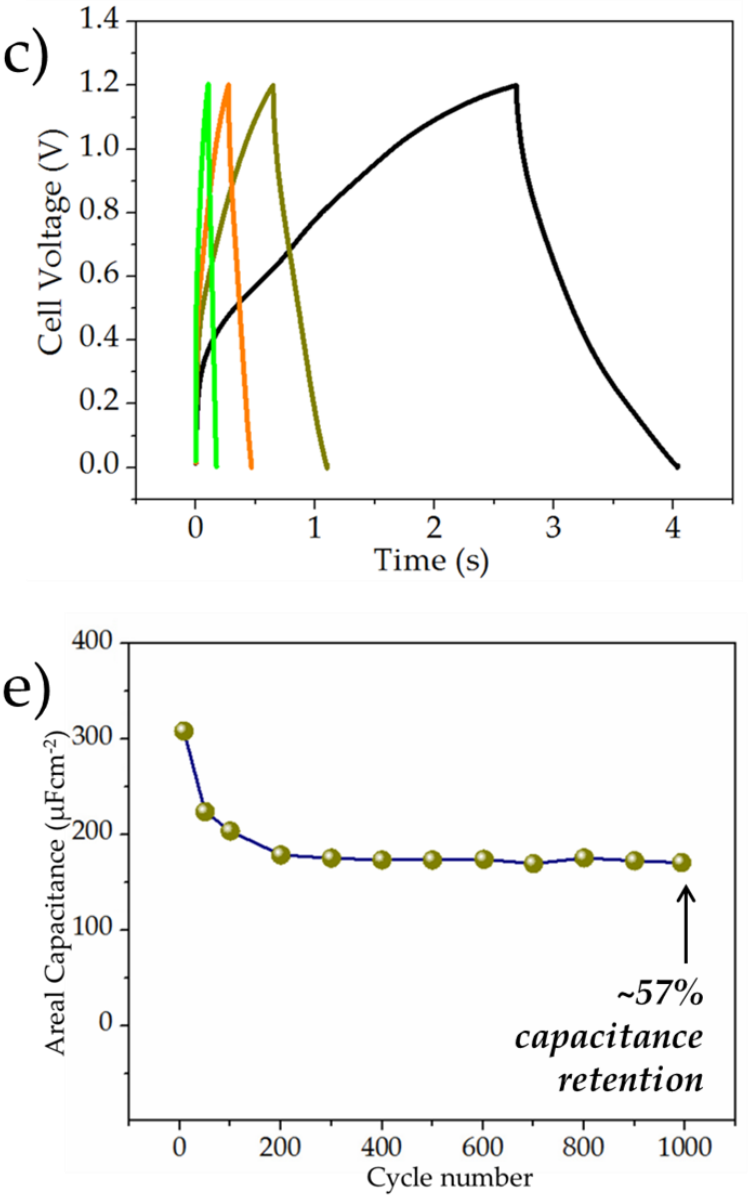
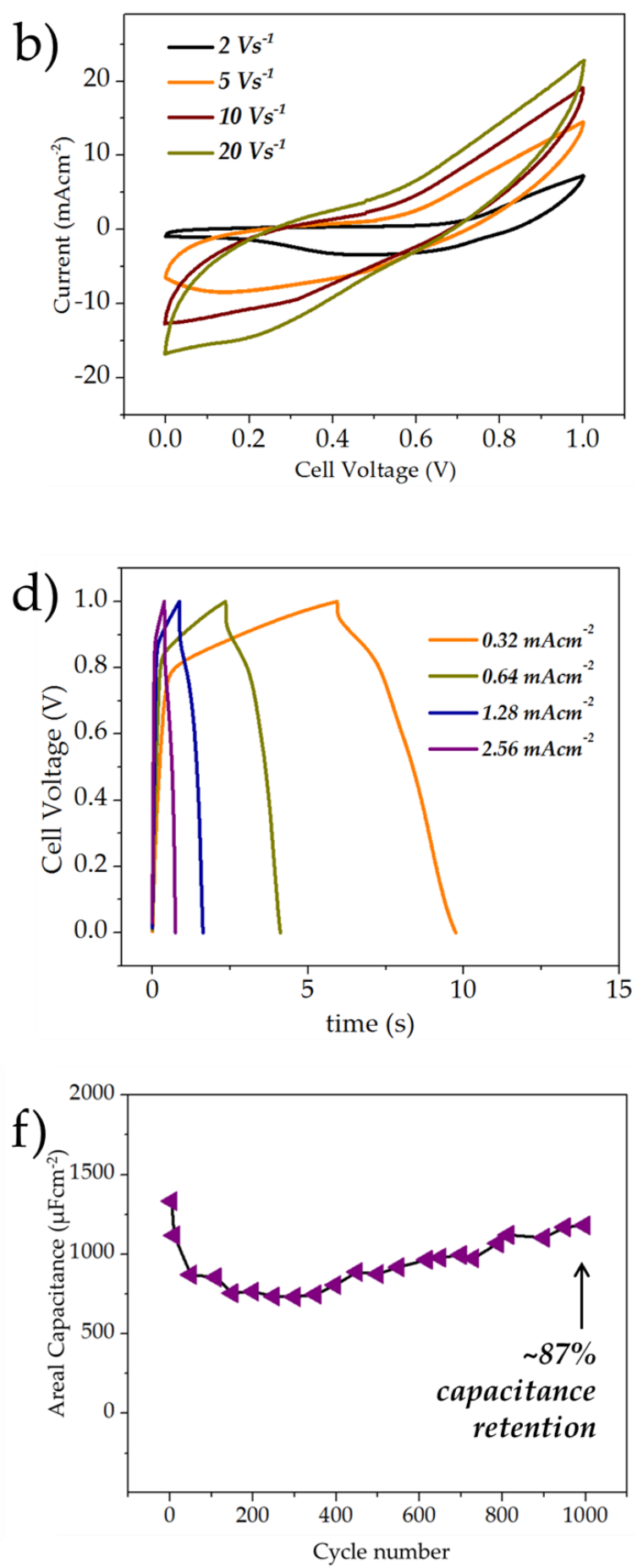

Figure 7S 2: Typical cyclic voltammograms at different scan rates of a) the asymmetric $\mathrm{rGO} / / \mathrm{MnO}_{\mathrm{x}}-0.6 \mathrm{C} \mathrm{MSC}$ and b) the asymmetric $\mathrm{rGO} / / \mathrm{MnO}_{\mathrm{x}}-1.2 \mathrm{C} \mathrm{MSC}$; typical GCD curves of c) the asymmetric $\mathrm{rGO} / / \mathrm{MnO}_{\mathrm{x}}-0.6 \mathrm{C} \mathrm{MSC}$ and d) the asymmetric $\mathrm{rGO} / / \mathrm{MnO}_{\mathrm{x}^{-}}$ $1.2 \mathrm{C}$ MSC; cycle life of e) the asymmetric $\mathrm{rGO} / / \mathrm{MnO}_{\mathrm{x}}-0.6 \mathrm{C} \mathrm{MSC}$ and $\mathrm{f}$ ) the asymmetric $\mathrm{rGO} / / \mathrm{MnO}_{\mathrm{x}}-1.2 \mathrm{C} \mathrm{MSC}$. 


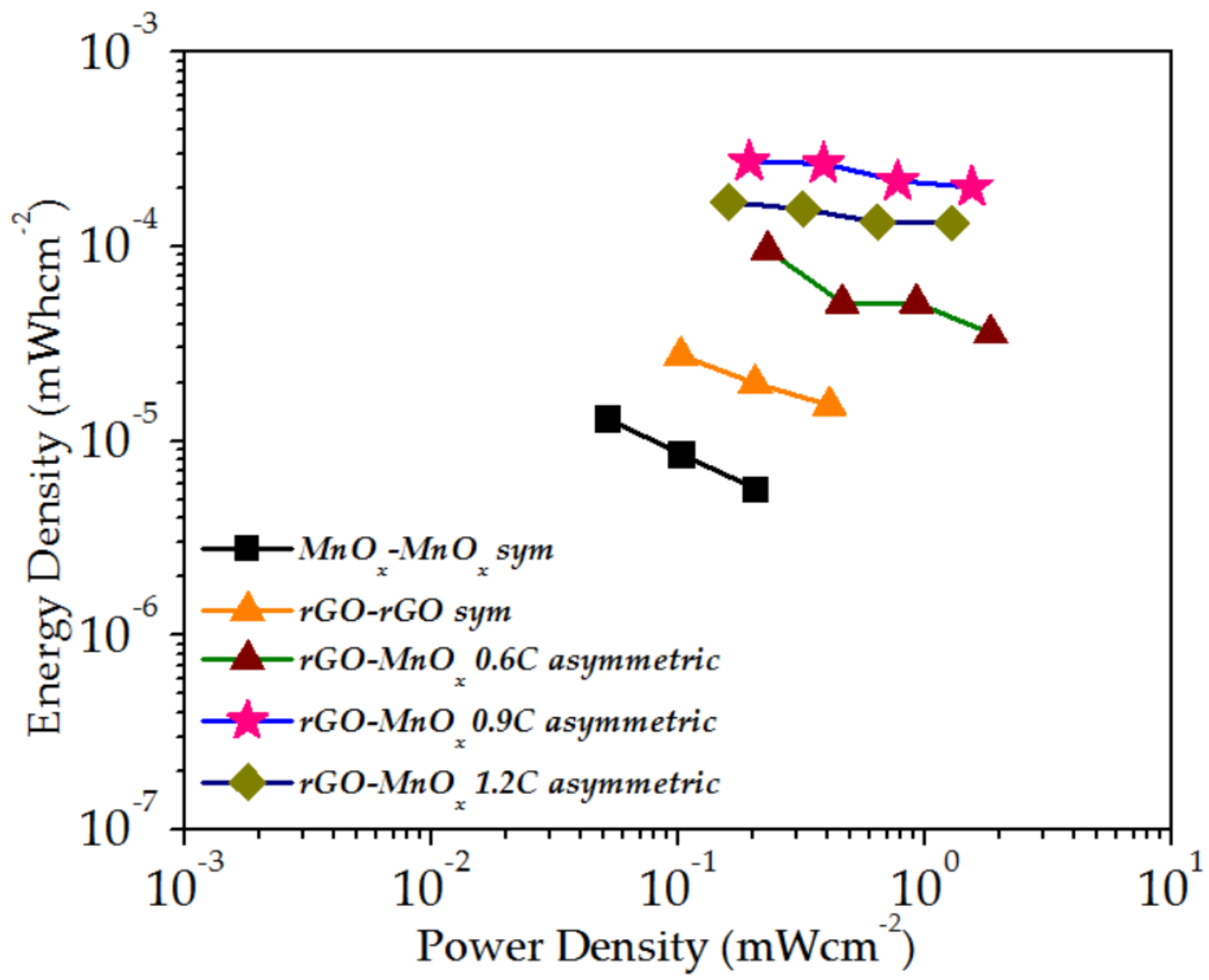

Figure 7S 3: Ragone chart of the different MSC systems. 
VITA

RICHA AGRAWAL

2009

B.Sc. (Honors), Physics

2012

Miranda House, University of Delhi, Delhi, India

2015

M.Sc., Physics

Miranda House, University of Delhi, Delhi, India

M.S., Materials Science and Engineering

Florida International University, Miami, FL, USA

2018

$\mathrm{Ph}$.D. Candidate, Materials Science and Engineering

Florida International University, Miami, FL, USA

\section{SELECTED PUBLICATIONS AND PRESENTATIONS:}

1. Agrawal, R. et al, On-Chip Hybrid Microsupercapacitors Combining Reduced Graphene Oxide and Manganese Oxide for High Energy-Power Tradeoff (In preparation)

2. Agrawal, R. et al, Expanding The Potential Window of Aqueous Asymmetric Electrochemical Capacitors with Electrostatically Sprayed Manganese Oxide Composite Films (Submitted to Electrochimica Acta)

3. Agrawal, R. et al, Electrostatic Spray Deposition Based Manganese Oxide Films From Pseudocapacitive Charge Storage Materials To Three-dimensional Microelectrode Integrands, Nanomaterials 2017, 7, 198 (Original Article)

4. Agrawal, R. et al, A High Energy 3V Lithium-Ion Capacitor Synthesized via Electrostatic Spray Deposition, Advanced Materials Letters, 2017, 8(7), 783-790 (Original Article)

5. Agrawal, R. and Wang, C., Laser beam Machining: In Encyclopedia of Nanotechnology (ed. Bharat Bhushan) pp 1-15, SpringerReference (2016); ISBN: 978-94-007-6178-0 (Book Chapter)

6. Agrawal, R. and Wang, C., C-MEMS based on-chip microsupercapacitors: In Carbon: The next silicon? Book 2--Applications (eds. Marc Madou, Victor H. PerezGonzalez, and Bidhan Pramanick), pp 123-137, Momentum Press (2016); Print ISBN: 9781606508831 (Book Chapter)

7. Agrawal, R. et al, Graphene for Supercapacitors: In Graphene-Based Energy Devices (ed A. R. bin Mohd Yusoff), pp 171-214, Wiley-VCH Verlag GmbH \& Co. KGaA, Weinheim, Germany (2015); ISBN: 978-3-527-33806-1 (Book Chapter) 
8. Agrawal, R. et al, Nano-scale damping characteristics of Boron Nitride Nanotubes and Carbon Nanotubes Reinforced Polymer Composites, ACS Applied Materials and Interfaces, 2013, 5 (22), 12052-12057 (Original Article)

9. Agrawal, R., Adelowo, E., Wang, C., Electrostatic Spray Deposition (ESD) Based $\mathrm{Li}_{4} \mathrm{Ti}_{5} \mathrm{O}_{12}$ for Nonaqueous $3 \mathrm{D}$ Hybrid Microsupercapacitor, $231^{\text {st }}$ ECS Meeting, New Orleans, LA, May 28-June1, 2017

10. Agrawal, R., Hao, Y., Adelowo, E., Henriques, A., Wang C. Materials and Architecture Perspectives for On-Chip Energy Storage and Power, SMEC 2017, April 1-9, 2017, Fort Lauderdale, Florida; Labadee, Haiti; San Juan, Puerto Rico; Philipsburg, St. Maarten; Basseterre, St Kitts \& Nevis; Fort Lauderdale

11. Agrawal, R*., Adelowo, E., Henriques, A., Wang C., 3D microsupercapacitors based on carbon micro-pillars encrusted with activated manganese oxide thin films, Graduate Student Appreciation Week (GSAW) 2017, March 28-31, 2017, Florida International University, Miami, FL, United States (*Presenter and Winner $1^{\text {st }}$ place in the Engineering and Computing Category)

12. Agrawal, R., Development of Miniaturized Hybrid Electrochemical Capacitors, NSF Nanosystems Engineering Research Center (NERC) for Advanced Self-Powered Systems of Integrated Sensors and Technologies (ASSIST) (Invited Pitch), January 2017, North Carolina State University, Raleigh, United States

13. Agrawal, R. and Wang, C., C-MEMS Based Micro-Power: From Symmetric to Battery-Type Hybrid Microsupercapacitors, June 21, 2016, 18th International Meeting on Lithium Batteries, June 19-24, 2016, in Chicago, Illinois, United States

14. Agrawal, R., Development of Miniaturized Hybrid Electrochemical Capacitors, NSF Nanosystems Engineering Research Center (NERC) for Advanced Self-Powered Systems of Integrated Sensors and Technologies (ASSIST), January 2016, Webinar (Invited)

15. Agrawal, R., Chen, C., Hao, Y., and Wang, C., Lithium-ion based Hybrid Supercapacitors - Materials Research Society (MRS) Spring 2015, San Francisco, United States, April 9, 2015 